

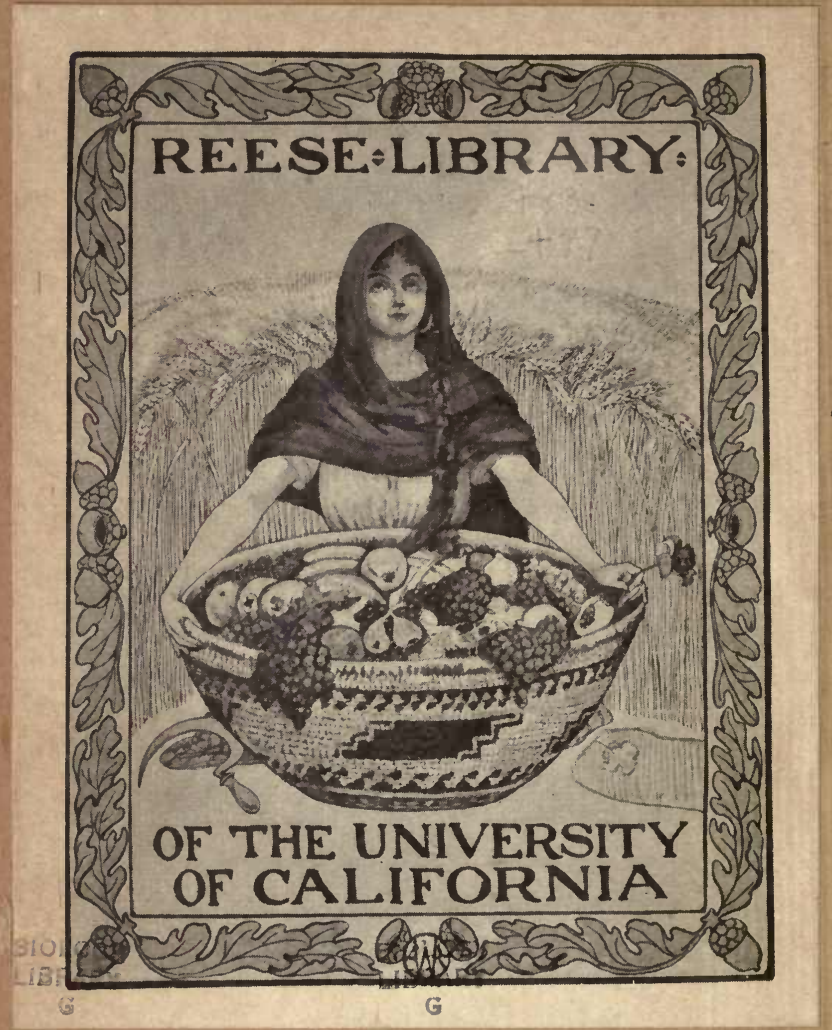





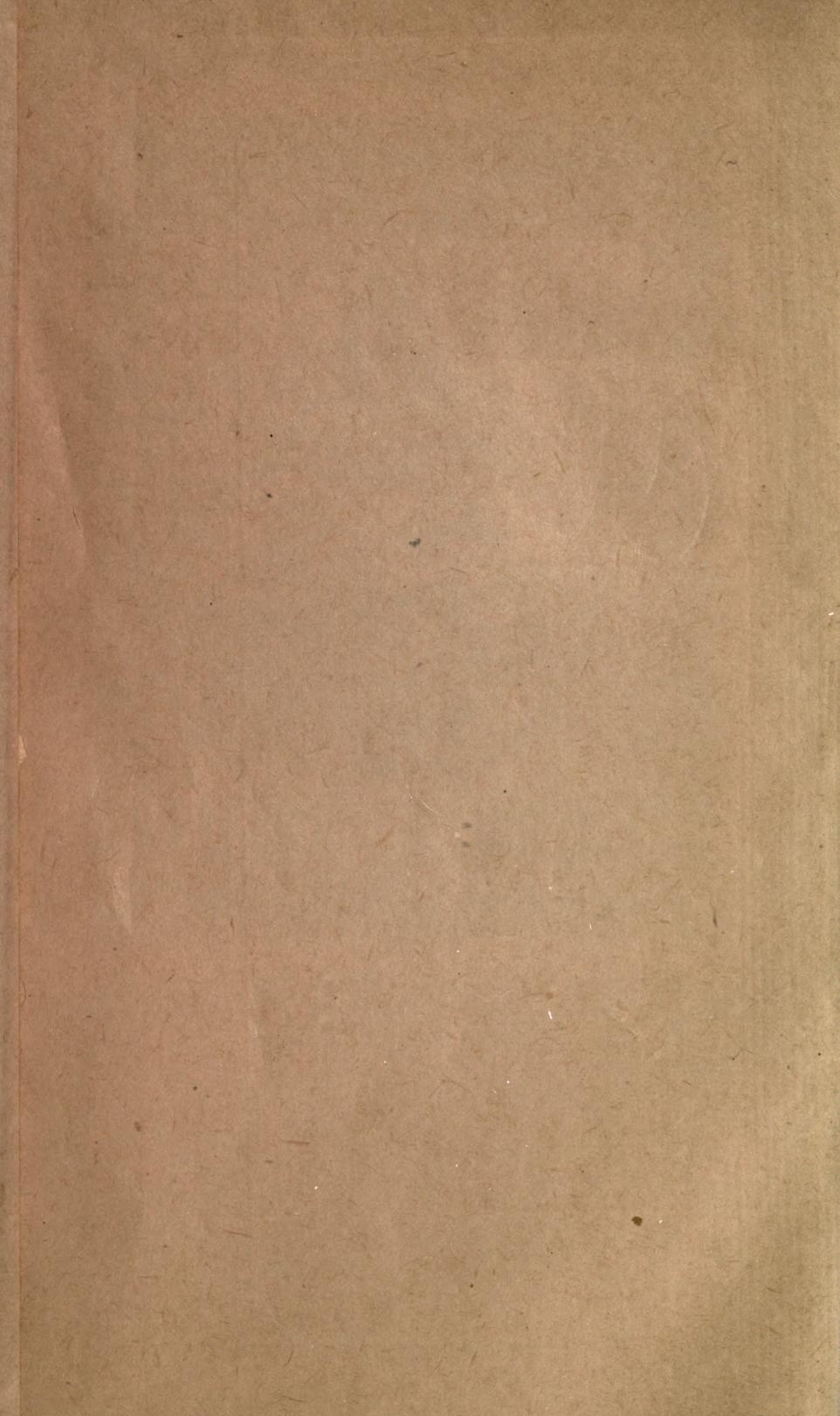





\title{
HUMAN PHYSIOLOGY,
}

\author{
FOR THE USE OF
}

\section{ELEMENTARY SCHOOLS.}

\section{BY CHARLES A. LEE M. D.,}

LATE PROFESSOR OF MATERIA MEDICA AND MEDICAL JURISPRUDENCE, IN THE UNIVERSITY OF THE CITY OF NEW YORK.

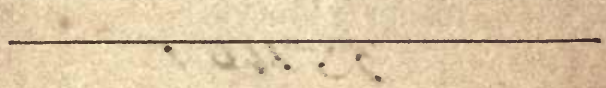

"The proper study of Markind is Man.

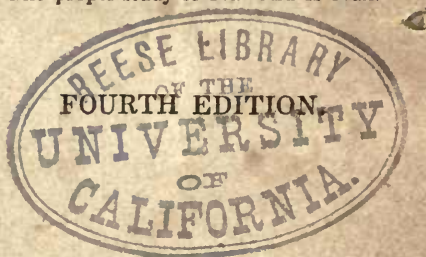

NEW YORK:

TURNER, HUGHES, \& HAYDEN, No. 10 JOHN ST.

RALEIGH, N. C.-TURNER \& HUGHES. 


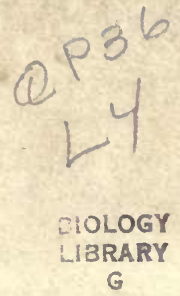

Entered, according to Act of Congress, in the year 1838, By J. Orville Taylor, In the Clerk's office of the District Court of the Southern District of New York.<smiles>C=[AsH2][AsH2]</smiles>

Piercy \& Reed, Printers, 9 Spruce St. N. York. 
CHARLES ANTHON, L. L. D.

JAY PROFESSOR OF LANGUAGES

in Columbia College,

THIS HUMBLE ESSAY,

IS BY PERMISSION,

GRATEFULLY INSCRIBED,

IN TESTIMONY OF PROFOUND RESPECT.

25401 

PREFACE TO THE SECOND EDITION.

In presenting to the public the present stereotype edition of this work, it is proper to state, that no labor or expense has been spared to render it still more worthy of the kind approbation with which it has been received. A large proportion of it has been entirely re-written, many corrections have been made, and numerous and highly valuable illustrations introduced; these improvements, together with the questions at the end of each chapter, cannot but render the work better adapted to the objects for which it was written.

The author flatters himself that this treatise will be found to contain the substance of what is yet known on the subject of Human Physiology, and most that is valuable, which is scattered through many learned and ponderous volumes. In preparing it, more than fifty different works have been consulted, from all of which the author has freely taken whatever he found adapted to his purpose. Originality has not been aimed at, as it was precluded by the very nature of the subject; indeed it would have been unsuited to the object in view. 
From the rapid sale of the first edition, and the numerous orders for the work from all parts of the United States, it may safely be concluded, that Physiology is henceforth to be one of the common branches of knowledge taught in our schools, academies, and other seminaries of learning. Indeed it is remarkable, that sciences, so closely connected with the health and happiness of our race, as those which teach us the structure and functions of the human body, should so long have been confined to those who intend to pursue the practice of medicine and surgery as a profession, especially when the practical application of such knowledge is daily and hourly of the utmost importance to every individual, connected as it is, with the preservation of health and of life. That such studies are not above the comprehension of children I can testify, not only from my own observation, but from the experience of numerous teachers, such as those whose names are appended to the testimonials, on the first pages of this work. If this is not sufficient, I have to commend to the attention of the reader, the following extract from a lecture of Mr. George Combe, the distinguished phrenologist of Edinburgh, which he was so kind as to communicate to me by letter :

"I take the liberty to urge very earnestly on your attention, not only the advantage, but the necessity of in-

- troducing instruction in anatomy and physiology into popular education. The great laws of health cannot be understood, nor can their importance be appreciated 
without this knowledge. I do not mean that you should teach your children all the minute details of these sciences, which would be necessary if you intended them for the practice of medicine and surgery: all I desire is, that the structure of the leading organs of the body should be explained so far as to render the functions of them intelligible, and that on this knowledge should be founded a clear and practical elucidation of the laws of health. I can certify, from observation, that this instruction may be communicated to children of ten years of age, and upwards, with great success. The structure addresses their observing faculties, and an explanation of the functions is as interesting to them as a romantic story."

In treating of physiological subjects, I have unavoidably employed some technical terms, but only in cases where there was an evident advantage attending their use; but in all such cases the exact meaning of the term has been assigned it. This explanation saves the necessity of a glossary, which was appended to the first edition, and it is, therefore, omitted in the present.

It will be perceived that the present edition contains more anatomy than the former. This has arisen from the full conviction, that in order to understand the functions of an organ, its structure must first be learned To aid in the accomplishment of this object, numercus well-executed wood cuts have been introduced, alıke creditable to the artist and useful to the learner. 
From the rapid sale of the first edition, and the numerous orders for the work from all parts of the United States, it may safely be concluded, that Physiology is henceforth to be one of the common branches of knowledge taught in our schools, academies, and other seminaries of learning. Indeed it is remarkable, that sciences, so closely connected with the health and happiness of our race, as those which teach us the structure and functions of the human body, should so long have been confined to those who intend to pursue the practice of medicine and surgery as a profession, especially when the practical application of such knowledge is daily and hourly of the utmost importance to every individual, connected as it is, with the preservation of health and of life. That such studies are not above the comprehension of children I can testify, not only from my own observation, but from the experience of numerous teachers, such as those whose names are appended to the testimonials, on the first pages of this work. If this is not sufficient, I have to commend to the attention of the reader, the following extract from a lecture of Mr. George Combe, the distinguished phrenologist of Edinburgh, which he was so kind as to communicate to me by letter :

"I take the liberty to urge very earnestly on your attention, not only the advantage, but the necessity of in-

- troducing instruction in anatomy and physiology into popular education. The great laws of health cannot be understood, nor can their importance be appreciated 
without this knowledge. I do not mean that you should teach your children all the minute details of these sciences, which would be necessary if you intended them for the practice of medicine and surgery: all I desire is, that the structure of the leading organs of the body should be explained so far as to render the functions of them intelligible, and that on this knowledge should be founded a clear and practical elucidation of the laws of health. I can certify, from observation, that this instruction may be communicated to children of ten years of age, and upwards, with great success. The structure addresses their observing faculties, and an explanation of the functions is as interesting to them as a romantic story."

In treating of physiological subjects, I have unavoidably employed some technical terms, but only in cases where there was an evident advantage attending their use; but in all such cases the exact meaning of the term has been assigned it. This explanation saves the necessity of a glossary, which was appended to the first edition, and it is, therefore, omitted in the present.

It will be perceived that the present edition contains more anatomy than the former. This has arisen from the full conviction, that in order to understand the functions of an organ, its structure must first be learned 'To aid in the accomplishment of this object, numerous well-executed wood cuts have been introduced, allke creditable to the artist and useful to the learner. 
The work is, therefore, presented to the public in its present shape, with the hope and belief, that it will subserve the cause of human knowledge and happiness.

New York, April, 1839. 


\section{CONTENTS.}

Chap. I.-Organic and Inorganic Bodies . . . . 13

Chap. II.-Division of the Animal Kingdom . . . 20

Chap. III.-Structure of the Human Body . . . - 24

Chap. IV.-Structure of the Human Body continued . $\quad 39$

Chap. V.-Chemistry of the Human Body - . . 56

Chis. VI.-The Human Skeleton _ . . . . 63

Chap. VII.-Properties of Animal Bodies . . . • 95

Char. VIII.-Relation of Animal Bodies to Heat, Light, and

Electricity . . . . . . . 105

Chap. IX.-The Nervous System . . . . . 110

CHap. X.-Intellectual and Moral Faculties . . . 123

Chap. XI.-The Spinal Marrow and its Functions . 135

Chap. XII.-The Nerves and their Functions . • . 144

Char. XIII.-The five Senses-Sense of Touch . . 156

Chap. XIV.-Sense of Taste _ . . . . . . 167

Chap. XV.-Sense of Smell . . . . . . . 177

Cirap. XVI.—Sense of Sight . . . . . . 190

Char. XVII.-Sense of Hearing . . . . . . 225

Chap. XVIII.-Respiration . . . . . . 237

Chap. XIX.-The Circulation of the Blood . . . . 256

Chap. XX.-Nutritive Functions-Digestion . . . 274

Chap. XXI.-Secretion . . . . . . . . . 286

Chap. XXII_Absorption . . . . . . . 292

Cirap. XXIII.-Nutrition . . . . . . . . 298

Chrs. XXIV.-Animal Heat . . . . . . 304

Chup. XXV.-The Voice . . . . . . . 312

Chap. XXVI.-Locomotion, and its Organs, . . . 319

Chap. XXVII.-The Teeth* . . . . . . 326

Cirap. XXXIII.-Sleep and Death . . . . . 331

* Written by Solomon Brown, A. M. Scientific and Practical Dentist of this city. 


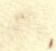

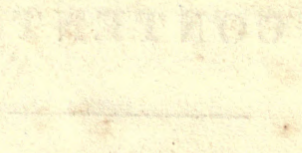

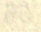

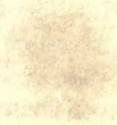




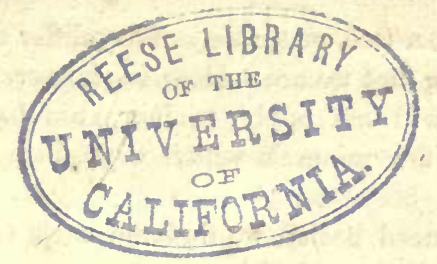

HUMAN PHYSIOLOGY.

\section{CHAPTER I.}

DEFINITION;-ORGANIC AND INORQANIC BODIES.

1. Physrology is "the science of life," or that branch of knowledge which explains the uses of the various.organs of living beings. Vegetable physiology treats of the func. tions of plants ; and Comparative physiology, of those of the inferior orders of animals ; while Human physiology treats exclusively of man.

2. The kingdom of nature embraces three great classes, animals, vegetables, and minerals. According to a more scientific arrangement, it is composed of organic and inor. ganic bodies. By' organic bodies, we mean those which possess organs or instruments for the performance of certain functions ; and by inorganic, those which do not. It is by a knowledge of these works of God, that we derive our ideas of his power, wisdom, and goodness.

3. Organized bodies are divided into two great classes, animals and vegetables; which differ from inorganic matter in several respects, the most important of which are the following :-

4. Organized bodies have a certain determinate form, peculiar to the species to which they belong. Every species of plant or animal may be known by its external shape ; as 
a horse, a cow, a tree, or a rose. They differ so much from all other kinds, that we are seldom in danger of mistaking them. This will not apply to inorganic bodies, except, perhaps, to a few minerals which crystallize in a certain shape.

5. In organized bodies, we find the parts of which they are composed, distinguished by round or oval forms; as the body and leaves of trees; the petals of flowers; the bodies and limbs of animals. We scarcely ever see straight lines, or sharp angles among them, as in mineral substances.

Every species of animal or vegetable has its own proper size, from which it varies but little. But minerals may be large or small ; the substance called granite, for example, may make a pebble or a mountain.

6. Inorganic bodies contain either a single element, as carbon, sulphur, \&c., or several of the elementary or simple substances, which are fifty-two in number, as lime, silex, and magnesia; while in organized bodies, we find at least three of these elements, as carbon, hydrogen, and oxygen in vegetables; and the same, with the addition of azote or nitrogen in animals. In organic bodies, there have been discovered in all eighteen simple substances, though they generally contain but three or four.

7. But these two classes of substances, not only differ as to the number of the elements which enter into their com. position, they also differ, as to the mode in which these elements are combined. Thus in minerals, two elementary substances unite and form a compound, and this again, combines either with another simple substance, or with a compound composed of two other simple substances. Thus, for example, carbonate of ammonia is composed of carbon, oxygen, hydrogen, and nitrogen, but combined as follows :-

The carbon and oxygen unite to form carbonic acid; the hydrogen and nitrogen, to form ammonia; these two com. pounds thus uniting, form carbonate of ammonia. 
In animals, we find the same simple elements uniting, each with all the others, forming the peculiar principles of organic bodies, such as fibrin, gelatine, \&c.

8. Organized bodies contain small particles of matter of a round or oval shape, both among their solid and fluid parts. These are supposed, according to their different arrangement, to make up all the elementary forms of organized bodies; as when arranged in lines, they form nerves, tendons, and muscles; in sheets, the various membranes and coats of vessels ; and in masses, the solid substance of the glands, as the liver, kidneys, and pancreas.

9. There are but few changes in inorganic bodies. The elements of which they are composed remain at rest. Rocks and mountains are the same now, as they were five thousand years ago. But in organized bodies, compounds are continually forming to be again separated; animals feed on vegetables, and vegetables on animals ;

"See dying vegetables life sustain;

See life dissolving, vegetate again ;

All forms that perish, other forms supply-

By turns we catch the vital breath and die."

10. In organized bodies the parts are mutually dependen on each other for support. If we cut off the limb of a tree, it dies, because it can receive no sap; if we amputate a finger, it mortifies, because the circulation of the blood has ceased; but if we break off a piece of marble, it will remain unchanged as long as the original mass.

11. Inorganic substances exist either in solid, liquid, or gaseous forms. 'They are wholly solid, liquid, or gaseous. But organic matter always presents a combination of solid and fluid parts. We find fluids circulating in regular vessels, and the solids and fluids mutually dependent on each other for support. In vegetables, we discover various parts, 
such as wood, bark, leaves, roots, and flowers; and in animals, muscles, nerves, tendons, vessels - all of which are organs, or instruments for the accomplishment of certain purposes. Inorganic bodies are formed of homogeneous parts, or parts perfectly similar.

12. Organic bodies are composed of two kinds of elements, chemical, such as oxygen, carbon, and hydrogen, which exist in minerals; and organic, or proximate, such as albumen, gel. atine, fibrin, \&c., such as are never found in inorganic mat. ter. It is because these organic substances are produced by the peculiar forces of organic life, and not by chemical laws, that we cannot decompose and then re-form them, out of the same elements, as we can minerals. For example, we can dissolve alum, salt, or copperas, and then by evapora. tion, crystalize them in the same shape again.

13. The general properties of organic or inorganic bodies differ in many particulars. In the first place there is a constant warfare going on, between the chemical and physical laws, which govern inorganic matter, and the vital laws which maintain animal life. This conflict commences at the first period of our existence, and is kept up to the moment of our dissolution. Life is enabled, for wise purposes, to wrest portions of matter from the domain of the laws of matter, for a certain indefinite period; for a while, the vital powers maintain a successful contest, but at last they have to yield, and death gives over the body to the action of the chemical forces.

14. This power of resisting the mechanical and chemical laws of matter, is shown by the faculty which animal bodies possess of maintaining the same degree of temperature, amid the great changes from heat to cold to which they are exposed; in the power of changing to chyle and blood, the various forms of food on which they subsist; and also in their power of forming from these the various tissues and organs of which they are composed, and all in opposition to the general laws of matter. 
15. The growth of organized bodies proceeds from within, that of inorganic matter from without. If minerals increase in size, it is by attracting matter to their external surface, while animals and, vegetables grow by a process, called nutrition; that is, laying hold of nutritious substances and converting them to their own nature, by means of internal organs.

16. Organized bodies possess the power of being affected with disease and recovering from it. They also have a determinate duration, beyond which they do not often live. This period varies for each species of animal and vegetable. Some insects live but a single day; most plants live but a single year; but some trees, such as the oak and cedar, are supposed to live more than two thousand years. The average duration of human life in this country is not over thirty years.

17. But the great distinction between a living being and an inorganic body is, that the former carries on a number of processes, not performed by the latter. A plant, for example, absorbs food, converts it into its own proper substance, arranges it into bark, wood, leaves, and other organized structures, grows, arrives at maturity, generates and maintains a certain degree of heat, decays, and finally perishes. No such phenomena are exhibited by a stone, or other inorganic bodies. These processes, therefore, are called vital, because they are peculiar to a state of life, and afford characters by which a living being is distinguished from all others.

18. Organized beings are divided into two classes, animals and vegetables, differing from each other in several wellknown features.

19. Sensation and voluntary motion are possessed by animals, but not by vegetables. Had animals no sensibility or feeling, they could not know their wants ; and if they knew them but had not the power of motion, they would perish for want of food; hence the necessity of these two faculties being joined together.

20. An animal, like a plant, receives food, transforms it into 
its own proper substance, and builds it up into certain struc. tures; it also generates and maintains a certain degree of temperature, and after having arrived at maturity decays and dies; but in addition to these vital processes which are similar in both, the animal possesses the faculty of feeling and moving spontaneously, or according to the dictates of its will, a property peculiar to itself.

21. Vegetables are nourished by the substances immediately around them, such as air, water, and the saline properties of the soil. They draw their support from without, by absorption at their surface, or by means of roots. But animals draw their nutriment from a great variety of sources, and they are furnished with an internal cavity to receive and prepare it for the purposes of nourishment.

22. Vegetable matter is composed chiefly of three elements, viz. carbon, hydrogen, and oxygen; besides these, animal matter contains azote, which gives the peculiar smell that we perceive on burning flesh, hair, bones, or feathers. Eighteen simple substances, however, have been found in vegetables, in very small quantities; such as lime, sulphur, iodine, silex, potash, soda, \&c.

23. Animals and vegetables both consist of solid and fluid parts; the fluids, however, in animals, exist in much the largest proportion. This is the reason why decomposition occurs more rapidly in animals than in vegetables. Vegetables, abounding in fluids, decay sooner than those of a more solid or fibrous texture.

24. Though the differences between animals and vegetables, are in general sufficiently obvious and striking, yet in some few instances, their distinguishing characteristics are not so evident. This is apparent from the fact, that some animals have been mistaken for vegetables, and some vegetables for animals. Some animals we find to be as firmly attached to the soil, as most vegetables are, as is the case in many of the zoophytes, or lowest order of animals, as the sponge, coral, \&c.; while on the other hand, some 
vegetables float in the water, as many kinds of sea-weed, and are never attached to the soil.

Questions.-What is physiology? What does vegetable physiology treat of? What human? What classes does the kingdom of nature embrace? What other division? What is meant by organic bodies? What by inorganic? How are organic bodies divided? How do organic and inorganic bodies differ from each other? How do they differ as to form? -as to size ?-as to their number of elements ?-as to their mode of combination? - as to the shape of their particles?-as to the changes they undergo ? - as to the mutual dependence of parts? -as to the kinds of elements ? -as to their general properties? How as to their mode of growth? of disease? What is the grand distinction between the two classes of bodies? How are organized beings divided? How do animals and vegetables differ? How are vegetables nourished? What is vegetable matter composed of? Do animals or vegetables possess the greatest amount of fluids? What animals have been mistaken for vegetables? 


\section{CHAPTER II.}

DIVISION OF THE ANIMAI KINGDOM.

1. Cuvier has divided animals into four great groups. 1. The vertebral. 2. The molluscous. 3. The articulated. 4. The radiated. The three last are destitute of vertebrae, or a connected series of bones to form a spinal column. They are, therefore, called invertebrated, while the term vertebrated is applied to the former. The vertebral are again divided into four classes, viz. 1. Mammalia. 2. Birds. 3. Reptiles. 4. Fishes. These are also distinguished by the terms warm, and cold-blooded; the warm-blooded, including the two former, which possess a temperature considerably above that in which they live; while the two latter, or the cold-blooded animals, are but little warmer than that of the medium by which they are surrounded. The mammalia are divided into nine orders; Birds into six; while Reptiles include Tortoises, Lizards, Serpents, and Frogs. Fishes are divided into the Cartilaginous and Bony.

2. Molluscous animals, as the name signifies, are those which have no bones corresponding to those of the higher orders of animals. They include all those animals with soft bodies, which dwell in calcareous habitations, constructed by themselves; many of them are accordingly called shell-fish, such as the oyster, muscle, clam, \&c. This division also embraces the snail, slug, and the nautilus. The articulated class includes such animals as are furnished with joints, with a hard external crust, or skeleton, to which are attached the organs of motion. It embraces the annelides, or red. blooded worms, the Crustacea, (the lobster and crab,) Spiders, and Insects. The Radiated class includes the Zoophytes, or Plant animals, so called from their resemblance to the veget- 
able kingdom. Most of these are of a soft texture, as the Polypus, so well known from its being capable of existing when turned inside out, and of reproducing any part of its body when destroyed by accident. To this class belongs the Sponge, and the numerous families of the Coral.

3. The mammalia are placed at the head of the animal kingdom; not only because it is the class to which man himself belongs, but because it also enjoys the most numerous faculties, the most delicate sensations, the most varied powers of motion, and the highest degree of intelligence.

4. The peculiar characters of these different classes must be learned from works which treat especially of Comparative Anatomy. It will be proper, however, in this place, to point out some of the peculiarities which distinguish man.

5. In structure and external shape, man bears considerable resemblance to some varieties of the ape tribe, particularly the ourang outang. But we find his position to be upright; his foot is large, and the leg placed vertically upon it; while the toes are short and but slightly flexible, and the great toe is horizontal with the others, so that his feet is well adapted to support the body, but cannot be used for seizing or climbing. Apes have thumbs both upon their hands as well as feet, so that they can seize with both equally well. The head of man is also very large and heavy, owing to the magnitude of the brain, and the smallness of the cavities of the bones; yet the means of supporting it, except in a perpendicular position are very small, as the ligament of the neck, which in quadrupeds is very thick, in him is almost wanting.

6. Besides this, the spinal column is so constructed, that its flexure forwards is not prevented, so that should he attempt to walk on all-fours, his mouth and eyes would be directed towards the earth, and he could not see before him, while in an erect attitude he preserves the use of his hands, and at the same time his organs of sense are most favorably situated for observation. 
7. Though man surpasses all other animals in dexterity, yet there are many that exceed him in strength, swiftness, and the acuteness of many of the senses. The eagle excells him in acuteness of vision, the grey hound in delicacy of smell, and a vast number of animals in strength, yet reason makes up for all other deficiences. Though physically defenceless, yet the whole brute creation is subjected to his control.

8. It was formerly supposed that man, because gifted with the highest mental endowments possessed the largest of all brains. But as elephants and whales surpass him in this respect, and the sagacious monkey and dog have smaller brains than the comparatively stupid ass, hog, and ox, the opinion was-relinquished, and man was said only to have the largest brain in proportion to the size of his body. But more extensive observation proved that canary and other birds, and some varieties of the monkey tribe, have larger brains than man in proportion to the body, and several mammalia to equal him in this particular; and as rats and mice too, surpass the dog; horse, and elephant in the comparative bulk of their brains; this opinion gave way to the one now generally adopted by physiologists, viz. that man possesses the largest brain in comparison with the nerves arising from it.

9. In consequence of the great size of his brain, man has a larger facial angle, which is the space included by lines drawn from the centre of the ear to the root of the nose, and from thence to the forehead. In the best formed human heads, this angle is equal to 80 or 90 degrees. In man also, the chin is more prominent, and the lower front teeth more perpendicular ; his teeth also are of the same length, which is not the case in the inferior animals. Man only can adapt himself to the great varieties of climate, and of food, which exist on the surface of the earth.

10. Lastly, man is possessed of faculties that enable him to trace effects to their causes, to distinguish between virtue and vice, to reflect upon events that have passed, to anti- 
cipate the issues of the future; and, above ath, to raisen his mind to the Supreme Intelligence, the cause of causes to whom all nature owes her existence, and to whom, with more or less clearness of conviction, he feels conscious of responsibility.

Questions.-How is the animal kingdom divided ? What is meant by vertebrated, and what by invertebrated animals? How are the vertebral divided? What is understood by a warm-blooded animal? What by a cold-blooded? Into how many orders are the mammalia divided? Birds? Reptiles? What are molluscous animals? What does the articulated class include? What the radiated? What class is placed at the head of the animal kingdom? -and why? What species of animals does man most resemble? How does he differ from the ape tribe? Is man excelled in any respect by the inferior animals? Mention some of the peculiarities of man. 


\section{CHAPTER III.}

\section{STRUCTURE OF THE HUMAN BODY.}

1. Tire human body is composed of solids and fluids. These terms, however, are merely relative. There is no fluid which does not contain some solid matter in solution; and no solid however dense, which does not contain some fluid. The nature of both fluids and solids is essentially the same, for we see one readily passing into the other; indeed no fluid long remains a fluid, and no solid a solid; but the fluid is constantly passing into the solid, and the solid into the fluid.

2. The relative proportion of the fluids in the human body much exceeds that of the solids, the excess being about 8 to 1 . But the excess varies according to the age. The younger the age, the greater the preponderance of the fluids. As age increases, the fluids gradually diminish, till in old age, they become so much lessened, that the body assumes a dry, wrinkled, shriveled and stiff appearance. In this manner we explain the softness and roundness of the body in infancy and youth, and its hard, unequal and angular surface in advanced life.

3. The fluids, then, are very important, as they furnish not only the material out of which every part of the body is formed, but they also furnish the medium by which the noxious and useless matter is carried out of the system. Every part of the body is a laboratory in which complicated and transforming changes are constantly going on; the fluids are the materials on which these changes are wrought, and the vital forces are the agents by which they are effected. The fluids either contribute to form the blood, or they 
constitute the blood, or having performed some special office, is moistening the various surfaces, are returned to the blood; lence according to their nature, they are called aqueous, lbuminous, mucous, serous, \&cc.

4. The solids are composed of the same chemical priniples as the fluids, and by analysis are reduced to the same iltimate elements. In the formation of solids, the particles f matter are supposed to be arranged in one of two modes, iz., either in the form of minute threads or fibres, or of thin lates or laminae; hence every solid of the body is said to fibrous, or laminated. These fibres, or laminae are variusly interwoven, and interlaced, so as to form a net-work; nd the spaces included between them are called areolae, or ells. According to some microscopical observers, the ultinate animal solid is a minute sphere or globule of matter, ot exceeding an eighth thousandth part of an inch in diam. ter.

5. The fibrous or laminated matter is often so arranged $\mathrm{s}$ to form a structure, possessing distinct and peculiar roperties; and each of these modifications is considered a eparate form of organized matter, and is called a primary issue. These tissues have been variously classified by diferent anatomists and physiologists, some making them to onsist of five, viz., the membranous, the cartilaginous, the sseous, the muscular, and the nervous; while others make ut three, the cellular, the muscular, and the nervous. Anther arrangement is into filaments, fibres, tissues, organs, pparatuses, and systems.

6. A filament is made up of a series of minute or primiive molecules, arranged in a row. A fibre is composed of everal of these filaments united together, as the muscular nd nervous fibres. A tissue is supposed to be composed of bres disposed in planes, forming in this manner an expanion, or when crossing each other, forming spongy solids, ith cells interspersed throughout. In this way are the ellular, serous, and mucous membranes formed. When 
these tissues are so arranged as to form a piece of animal mechanism, designed for the performance of a certain office, they form what is called an organ, as the lungs, brain, liver, \&c. The action of this organ is called its function. The liver, for example, is an organ ; the conversion of the blood which passes through it into bile, is its function. When several organs are associated together for the accomplishment of a common object, such an assemblage is called an apparatus. The apparatus of digestion consists of the mouth, teeth, esophagus, stomach, intestinal canal, liver, pancreas, lacteals, \&c., as all these concur in the process of digestion. By system, is understood an assemblage of organs, possessing a similar structure, as the nervous system, the muscular system, \&c.

7. Membrane may be considered as the first or primary tissue. It is the simplest form of organized substance, and is extensively employed in the composition of the body. Indeed, it is the principal material used in forming covering, containing, protecting, and fixing every other component part of it. It is this which contains in its cells the earthy matter which goes to form the bones; the canals in which are deposited the substance which composes the muscular and nervous tissues; which forms a covering for the whole body; which lines all its internal surfaces; surrounds all its internal organs; which makes up the solid portion of every part of the system; forming the tubes and vessels, such as the arteries and veins; it comnects all parts of the body together, and fixes them in their several situations; in short, it is the substratum, or mould, in which all the other particles are deposited, thus giving form and outline to the whole body, so that if every other kind of animal matter were removed, this tissue alone would preserve the exact figure and present a perfect skeleton of the whole, and of every one of its parts.

8. There are several kinds of membrane ; the simplest form of which, and that from which all the others are supposed to 
be produced, is termed the cellular. It is this which I have already alluded to as entering into the compositions of every organ, and forming the basis of the solid structure of the body. Into its cells all other kinds of animal matter are deposited as phosphate of lime and gelatine, which form the bones. It forms sheaths for the muscles and nerves ; composes a greater part of the ligaments, tendons, and cartilages, and even the hair and nails, thus constituting not only the basis of all the solids, but serving as a bond of union by which the organs are connected together. By its softness and elasticity, and the oily fluid by which its cells are filled, it also promotes the mobility of the parts on one another. It possesses the property of contractility, and is composed chiefly of gelatine.

9. One remarkable circumstance connected with this tissue is, that as it exists throughout the body, it forms a connected whole, or an immense net-work, every where accessible to air. This is shown by forcing air into its cells, in any part of the body; which is found gradually to penetrate and pervade every part till the whole body is inflated. Butchers often avail themselves of a knowledge of this fact, by blowing their meat, or in other words, inflating animals by making a puncture in some part where the cellular tissue is loose, and from this one aperture forcing the air to the most distant parts of the body, in order to give the meat a fat appearance. If we raise up a portion of cellular membrane, in the form of a thin slice, it appears as a semi-transparent and colourless substance, composed of minute threads which are seen to cross each other in every possible direction, leaving spaces between them, and thus forming a mesh, similar to the spider's web. As to the precise form of these cells or cavities we have no accurate knowledge. They are generally supposed to be narrow spans with acute angles, the sides of which are flattened, and when not forcibly expanded, we may suppose to be in contact. Some physiologists indeed deny that any cavities at all exist, but the weight of ovidence is altogether in favour of their existence. 


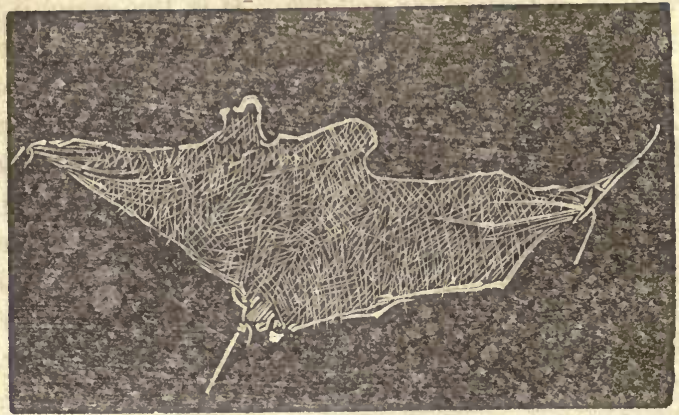

A single film of the cellular tissue lifted up, and slightly distended.

10. In health, the spaces between these lines are filled with a thin exhalation of a watery nature, which serves to keep the tissue always soft and moist. This is composed of the thinner part of the blood, which is poured out by a process called secretion, but is speedily taken up again by absorption. These two operations exactly balance each other in health, but when from any cause the equilibrium is disturbed, the fluid accumulates, constituting the disease called dropsy. This is often relieved by the operation of tapping, or draw. ing off the water. Cellular membrane is dense or loose, coarse or fine, according to its situation and office. Where it is subject to pressure, as in the palm of the hand and sole of the foot, it is dense and firm; around the internal organs it is more loose and delicate. Although cellular tissue enters into the composition of all the organs, it never loses its own character, nor participates in the functions of the organ, of which it forms a part. Though present in the nerves it does not share in their sensibility, and though it accompa. nies every muscle and every muscular fibre, it nowhere partakes of the irritability which belongs to these organs. The microscope shows that the minute particles of this tissue are of a globular figure, arranged like strings of pearls, as represented in the following cut. 


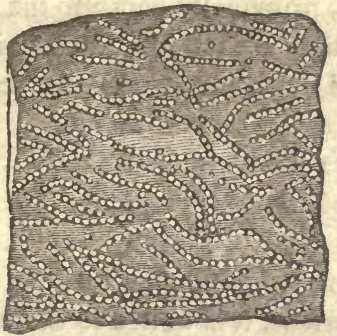

A portion of cellular tissue, very highly magnified, showing the strings of globules of which its ultimate fibres are supposed to consist.

11. The principal varieties of membrane, which are formed by the cellular tissue, are the(adipose, the serous, the mucous, the dermoid, the fibrous, the cartilaginous, and the osseous. The adipose is that tissue which contains the fat which is so disposed as to form distinct bags in which the fat is contained. Now it should be recollected, that while the cells of the cellular tissue are continuous over the whole body, each adipose vesicle is a distinct bag, having no communication whatever with any other. While also, the cellular tissue is universally disposed, the adipose is placed only in particular

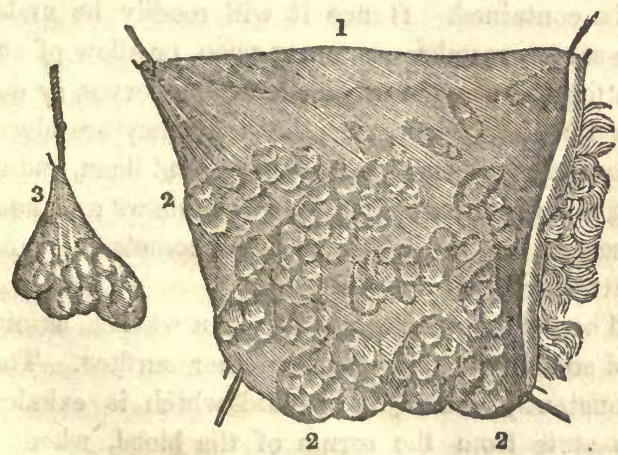

1. A portion of adipose tissue : 2. minute bags containing the fat: 3. a cluster of the bags, separated and suspended. 
parts of the body, principally beneath the skin and the abdominal muscles, and around the heart, kidneys, \&c. while none is ever found in the cranium, the brain, the eye, the ear, the nose, and several other organs.

12. The Serous Membranes. fThese line all the closed cavities, or sacs of the body, and are reflected over the organs contained in them? Thus the cavities of the brain and chest, the abdomen and joints, are lined by serous membrane. By its external surface, it is united to the walls of the cavity, or the substance of the organ it invests ; by its internal surface it is free and unattached; whence this surface is in contact only with itself, forming a close cavity, having no communication with the external air.

13. If it were possible therefore to dissect serous membranes from off the parts which they invest, they would have the form of a sac, without an opening, the organ invested by one of these folds being altogether external to the cavity of that sac; just as happens when a double night-cap is worn, of which the part immediately covering the head is analagous to that portion of the serous membrane which adheres to and invests the organ, whilst the external portion of the cap represents the lining of the cavity in which that organ is said to be contained. Hence it will readily be understood that the serous membranes never open, or allow of any perforation for the passage of blood-vessels, nerves, or ducts, to or from the enclosed organs ; but that they are always reflected over them, forming a sheath around them, and accompanying them in their course. It also follows as a necessary consequence, that their free surfaces completely isolate the parts between which they intervene.

14. The serous membranes are of a whitish, shining colour, and smooth on their free or inner surface They are kept constantly moist by a fluid which is exhaled in a gaseous state from the serum of the blood, whence they derive their name. They are also elastic and extensible, and are said to be destitute of blood-vessels and nerves; 
being composed of condensed cellular membrane. According to Rudolphi, serous membranes line not only the closed cavities of the body, but the interior of the vessels also, and the canals which open outwardly, as the alimentary canal and the air passages, forming a cuticle over the mucous membranes, which line these passages. The uses of the serous membranes are to separate different organs, to diminish friction, and to facilitate the motion or gliding of these parts upon one another, by means of thin smooth, moist, and polished surfaces.)

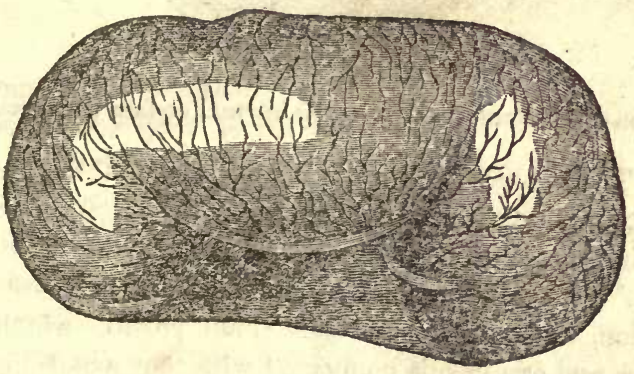

15. Mucous Membranes. -These membranes are also another form of the cellular structure, and derive their name from the nature of the fluid, which it is their office to secrete by means of numerous minute glands imbedded in their sub. stance. Ás serous membranes form a shut sac, completely excluding the air, nucous membranes on the contrary, line the various cavities, which are exposed to the air, such as the mouth, the nostrils, the windpipe, the gullet, the stomach, the intestines, and the urinary organs. Their internal surface, or that by which they are attached to the passages they line, is smooth and dense, while their external surface, or that which is exposed to the contact of the air, is soft and pulpy, like the pile of velvet, or the rind of a ripe peach. 


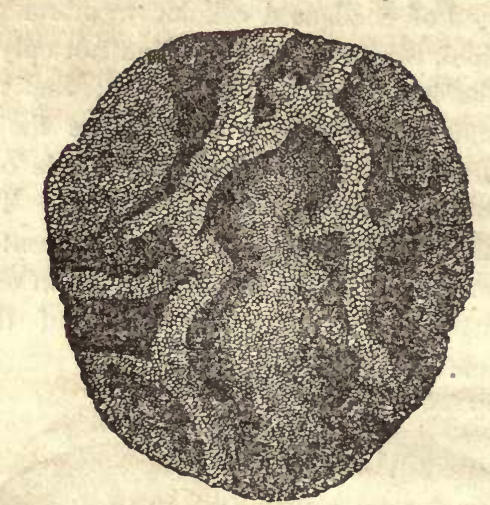

A portion of the stomach, showing its internal surface or mucous coat.

16. The mucous coat is the seat of some of the most im. portant functions of the economy ; in the lungs, of respiration; in the stomach, of digestion; and in the mouth and nose, of taste and smell, \&c., and forms, with scarcely an exception, a continuous whole. That portion which lines the eyes and eye-lids, is connected with that which lines the nostrils, by means of the nasal canal ; while that which lines the mouth, meets in the throat with that which comes down from the nose. In the fauces it divides, and while one portion goes down the windpipe into the lungs, the other passes down the esophagus into the stomach, forming a lining for the whole tract of the intestinal canal.

17. Mucous membranes are of a loose, spongy texture, of a reddish colour, and are largely supplied with blood-vessels and nerves. They are also numerously supplied with small glandular bodies called mucous glands or folicles. The chief use of these membranes is, to sheath and protect the inner surfaces of the body, as the skin does the outer, and by means of the mucus, with which they are always covered in a state of health, to guard them against the contact of irritating substances. 
18. We find a remarkable sympathy existing between all the mucous membranes; accordingly their diseases, particularly the catarrhal affections, to which they are often subject, are very apt to spread in them. By reason of this sym. pathy, the state of one part of these membranes may be ascertained by examining another part ; the state of the tongue for example, indicates the condition of that of the stomach and intestinal canal. There is also an extraordinary sym. pathy between the mucous membranes and the respiratory organs.

19. Dermoid Membrarte.-This membrane, called also cutis or skin, is not only directly (continuous with the mucous membranes that line the internal passages, but is also analagous in its structure. We see them passing into each other at the orifices of the internal canals, as in the lips, nos. trils, eye-lids, external ear, \&c. We find it varying in thickness according to its situation; in the face and body being thin and delicate, and on the palms of the hands and soles of the feet, considerably firmer and thicker. The skin is abundantly supplied with blood-vessels and nerves; so numerous indeed, that the finest needle cannot enter the skin without piercing many of both, which is proved by the bleed. ing, as well as the pain which follow.

20. The skin, in man, is made up of four parts, or layers, the cuticle, rete-mucosum, corpus papillare, and corium. It is covered externally by the (cuticle) or epidermis, which is destitute of nerves and blood-vessels, insensible, and probably inorganic. It is the cuticle which is raised by the application of a blister, or by a burn or scald. It is supposed to be a secretion from the true skin which concretes on the surface, becomes dry, and thus offers protection to the parts beneath, and also serves to prevent excessive absorption or the escape of the fluids by evaporation.) It is pierced by little pores, for the passage of hairs, sweat, and the fluids, taken up by absorption, although Humboldt asserts that he could not discover them with a miscroscope which magnified 312,000 times. 
21. The next layer of the skin is the rete mucosum, or mucous web.) It has been supposed to consist chiefly of mucus, as it is of a soft pulpy texture. It is the/seat of the coloring matter in the different races. In the European, it is white, in the African black, and in the Mulatto and Malay, copper-coloured. In the Ethiopian race, it is much thicker than in the light-coloured varieties of the human species, and may easily be separated both from the cutis and cuticle, and made to appear as a distinct membrane.

22. The dark color of the skin in the inbabitants of the torrid zone, is ascribed by most physiologists, to the influence of the sun upon the surface of the body; but the tinge pro. duced on the skin by exposure to a bright light, appears to have no connection with the permanent colour of the negro. Dr. Bostock states, that the blackest complexions are not found in the hottest regions, and that there are some tribes nearly under the equator, whose skin is whiter than that of many Europeans. Besides, the tinge produced by the sun is not transmitted from parents to their offspring, whereas the children of negroes are equally black in whatever climate they are born, and their complexion is not altered by any number of generations. When a person is tanned, as it is called, by the influence of the sun, it is the cuticle only which is affected; if this be removed by a blister, in a few days new cuticle will be formed, and the skin in that place will appear as white as it ever did.

23. Albinos.-In the Caucasian race, from which Europeans and Americans have descended, there is usually a mixture of red or brown, with white in the complexion; but where the skin is of a uniform, clear, pearly whiteness, the individuals are called Albinos, from albus, white. In these persons, the hair is generally white, corresponding with the colour of the skin, while the eye is without that substance which gives the various colours to the iris. The iris, in such 
cases, is generally of a bright rose-colour, and the eyes are so sensible to light, that they cannot be kept open in the sun-shine, although in the shade, or dusk of the evening, the vision is perfect. It is now well ascertained that the red. ness of the eye and the whiteness of the skin in albinos depends on the same physical defect in their organization, and that it is owing to the absence of the colouring matter in the rete mucosum. In the eye, this matter, spread over the retina, is called Pigmentum nigrum, or the black paint.

24. What is called the (Corpus papillare) is merely a col. lection of small papillae, formed by the extremities of nerves and blood-vessels, and lying immediately under the mucous web, \&c. It is in this layer that the sense of touch resides the papillae can easily be seen when the cuticle has been removed by a blister.

25. The Cutis vera, or true skin, is the innermost of the four layers above mentioned. (It is a firm stratum of dense fibres intersecting each other in every direction, and having holes for the passage of vessels and nerves,

26. The true skin is composed chiefly of gelatine, and hence is used for the manufacture of glue Gelatine combined with tannin, which is a proximate vegetable principle obtained from oak and other barks, forms a compound that is insoluble in water; and it is to this circumstance that leather owes the properties it possesses. Leather, then, may be considered as the product of the union of tannin and gelatine.

27. Though the skin consists of four distinct strata, yet it is only/from one-sixth to one-fourth of an inch in diameter. The true skin is united to the structure below by cellular membrane, and this, with the layers above described, constitute the common integument. The following sketch represents the several layers entering into the composition of the skin. 


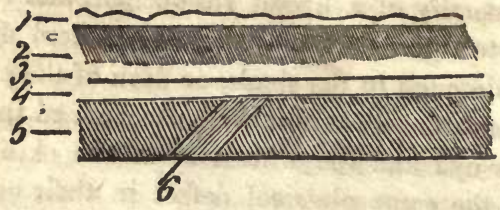

1. Cuticle.

2. Rete mucosum.

3. Corpus papillare.

4. Cutis vera.

5. Cellular membrane.

6. Paniculus carnosus.

(There are in certain parts of the body, and especially in animals, muscular fibres passing up through the cellular membrane, and inserted obliquely into the cutis veras) as at 6 in the plate. These form the muscular web, or paniculus carnosus. It is this which raises the feathers in birds and which in the hedgehog and porcupine rolls up the body, and erects the spines; and by means of this, animals shake off flies from their skin.

28. The skin is defended from the action of moisture, and is also (kept soft and pliant by an oily fluid, which is separated from the blood by numerous sebaceous follicles.) We find these the most numerous where there are folds of the skin, or hairs, or where the surface is exposed to friction. We sometimes see the oily matter secreted by these glands assume a dark appearance, in the form of black specks, scattered over the face, which are called by many worms, because when pressed out they assume that aspect.

29. The hair is usually treated of by physiologists as an appendage to the skin. The hair takes its origin from the cellular membrane in the form of bulbs, each bulb consisting of two parts; an outer, which is vascular, and from which the hair obtains its nourishment; an inner, which is mem. braneous, and which forms a sheath or tube to the hair during its passage through the skin. The external covering of each hair is of a horny structure, while the central part is 
soft and pulpy, and is called medulla, or pith. The colour of the hair varies in different individuals, and is (generally supposed to depend on the fluids contained in the pith! The hair, it is said, has been known in several instances to have changed from black to grey in the course of a single night, from the effects of grief, fear, or some other great mental agitation. Vauquelin supposes that as the colouring matter of the hair is destroyed by acids, this phenomenon is owing to the production of some acid in the system. Others sup. pose that the effect depends upon the sudden stagnation of the vessels which secrete the colouring matter, while the absorbents continue to act and remove that which already exists. There are probably two causes which act in changing the hair to grey; (the first is a defective secretion of a colouring fluid, and the second, the canals which convey the fluid into the hair become obliteratedy In the first case, the hair will remain; in the last, it inevitably dies and drops out.

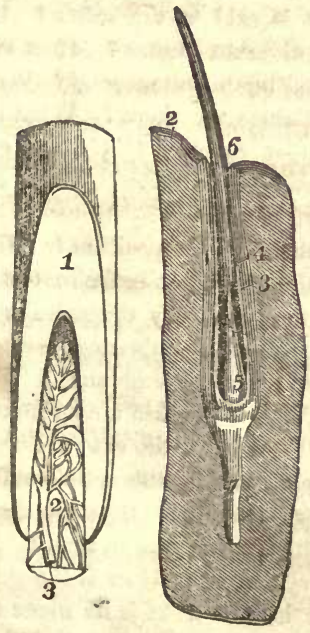


30. The figure on the last page represents the pulp of a liair injected; 1 , cut surface of hair ; 2, the pulp; 3 , injected vessel ramifying in it. The figure on the right shows the hair in its fallicle, though the drawing was made from the whisker of a Walrus ; 2 , the cutis ; 3 , external sheath of the fallicle; 4, internal sheath continuous with the cuticle; 5 , pulp; 6 , shaft of hair ; 7 , large nerve going to it.

31. The nails are also an appendage to the skin. Therr chief use seems to be to support the pulp of the finger while it is exercising touch. Animals are provided with struc. tures analogous in their physical and vital properties, such as horns, beaks, hoofs, nails, spurs, scales, \&c. Some physiologists consider the teeth as belonging to the same class. The various and peculiar functions of the skin, so important to be understood in order to the preservation of the health, will be fully described hereafter.

Questions.-Of what is the human body composed? What is said of the identity of solids and fluids ? What proportion do the fluids bear to the solids? How modified by age? What purposes do the fluids serve? What is said of the solids? How are their particles arranged to form the different organs? How are the areolae formed? Of what shape is the ultimate animal solid? What is a primary tissue? How many primary tissues are there? What is a filament?-a fibre -a tissue-an organ-a function? Give an example? What is an apparatus?-a system?-membrane? What are its uses? What is the simplest form of membrane?-its use? What property does it possess ? What its chemical composition? What remarkable circum. stance connected with it ? What is the seat of dropsy? What varieties of membrane are formed by the cellular tissue? Describe the adipose? What are serous mombranes?-where found ?-their use? structure? What are mucous membranes? Describe their structure, situation, use, \&c. What is the skin a continuation of? Of how many parts is it composed? What is the external layer called ? - what is its use? What is the layer next to the cuticle called ? Of what is it the seat? - the next layer ?-its use? Describe the cutis vera? What is it used for? How thick is the skin in man? By what contrivance is the skin susceptible of motion? How is the skin kept soft and pliant? What is said of the hair?-what is its structure?-what is its colour owing to? What causes it to turn grey? What is said of the nails? 


\section{CHAPTER IV.}

\section{STRUCTURE OF THE HUMAN BODY CONTINUED.}

1. Another form of cellular structure is called fibrous, from the arrangement of its component parts, which consist of longitudinal fibres, plainly visible to the naked eye, placed parallel to each other and closely united. These fibres are sometimes so combined as to form a thin, smooth, dense, and strong membrane, like that which covers the external surface of bones, termed periosteum, or the internal surface of the skull, (dura mater.) At other times it forms a firm sheath, which dips down between the muscles, separating them from each other, or it may be spread over them, binding them firmly down in their places.

2. In the loins and along the back bone there is a strong binder of this kind, which greatly facilitates the motions of -the body and powerfully contributes to the action of the muscles.) Where this is weak, a belt round the waist is of considerable service, but in a well-formed person it is a clumsy substitute of art for nature, and ultimately tends to weaken the back, for exercise strengthens and invigorates all parts of the frame, while artificial substitutes invariably weaken the parts they are supposed to strengthen.

3. It also constitutes the strong, tough, and flexible band, used for tying parts firmly together, termed ligaments, such as are found about the joints, connecting the bones and it also forms those white cords in which muscles terminate, called tendons, which serve to attach the muscles to the bones, thus acting as mechanical instruments of motion. This tissue forms a firm covering or envelope to the bones, muscles, tendons, cartilages, the eye, kidneys, spleen, and most of the organs of the body. 
4. Every joint is enclosed by a firm fibrous bag, called the capsular ligament, the internal surface of which secretes a fluid, termed synovia, which lubricates the joints, and serves the same purpose that oil does in a piece of machinery (At the wrist and ankle, and along the fingers and toes, the ligaments form strong bandages to bind down the muscles and tendons, and enables them to act with greater precision and steadiness; otherwise when the muscle contracted, the tendons would start out like the string of a bow, and thus not only destroy the symmetry of the parts, but entirely prevent motion, (When sprained by over exertion or accident, an artificial bandage becomes necessary); we then find how su. perior the natural ligaments are to any artificial bandage that can be contrived.

5. Tendon or Sinew.-This well.known structure is plainly perceptible at the wrist, on the back of the hand, at the heel, \&c. (They have a white, pearly lustre, possess great strength, but little elasticity? (They are composed of bundles of parallel threads, bound together by transverse threads, and they vary both in figure and extent; some being cylindrical and tapering to the point of insertion, and in others forming broad expansions. (So insensible are tendons, that when ruptured, as the tendon of Achilles at the heel, not the slightest pain is felt, but the person feels that he has received a smart blow, or that a part of the floor has given way under him.

6. Where force is to be exerted upon some distinct point, it is transmitted along a tendon, as forces in machinery are by ropes.) When a tendon passes over a joint, a bone is formed sometimes where it crosses, as the knee-pan in front of the knee joint ; which is a bone placed directly in the centre of the tendon, and (serves, to throw the force farther -from the centre of motion, thereby increasing the lever, and consequently the effect.) Similar bones are often found in the tendons of the feet. 
7. Another primary tissue, or modification of cellular. structure, is termed the cartilaginous. This seems to be a substance intermediate between membrane and boned It is firm, smooth, highly elastic, of a pearly white colour, and except bone, the hardest part of the animal frame. It is destitute of red vessels, and neither nerves nor lymphaties have been discerned in it; though as it becomes highly sensible, like the fibrous tissue, by disease, it no doubt is supplied with nerves $)$ It is placed at the ends of the bones, particularly about the joints, where by its smooth surface, it facilitates motion, and by its yielding nature, prevents the shock or jar which would be produced were the same kind and degree of motion effected by a rigid and inflexible substance. Where strength and flexibility are required to be united, we there find cartilage, as in the spinal column, between the ribs and breast bone, in the larynx, the ear, nose \& \&c.

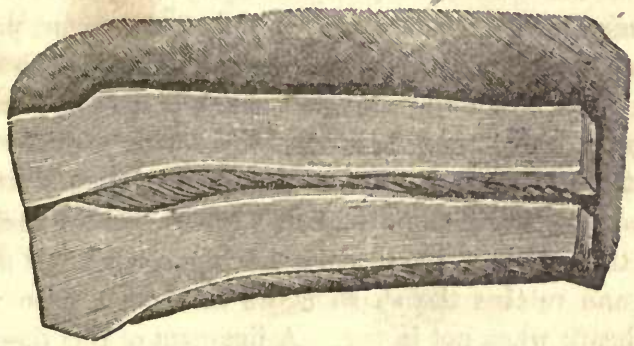

Portions of cartilage seen in section.

8. By immersing cartilage in nitric aeid and then in wa. ter for some little time, we find its intimate structure so un. folded, that we can perceive it to be composed of an infinite number of minute fibres, arranged perpendicularly like the pile of velvet. Thus we see that in the construction of the joints, millions and millions of springs of the most curious and excellent contrivance stand perpendicular to the direction of the force applied, bend to pressure, and on its removal, regain 
their form by their elasticity. When we stand in the erect posture, the number of minute but efficient springs on which the weight of the body rests, in the several joints of the back, in the hip, knee, and ankle joints, infinitely surpasses the powers of the human mind to calculate or even to imagine.

9. There is a peculiar tissue, allied to ligament in its texture, distinguished by a high degree of elasticity, fibrous structure, and tawny colour, and is hence often called elastic tissue This structure is very conspicuous in the neck of those animals, which have to support a heavy load horizontally at the the extremity of a long neck, as in the elephant, the deer, and our domestic cattle. Had their heads been supported merely by muscular action, as that is liable to fatigue and requires intervals of rest, as well as the exercise of volition, the postures could not have been sustained for any length of time without pain and exhaustion. This tissue, which is liable to none of these objections, is accordingly (substituted for muscular power, in fixing the forms, preserv. ing the attitudes, and contributing to motion. The strong fibrous band, stretching along the back part of the neck to the head of these animals, enables them with perfect ease to support the head. It is the elasticity of this membrane which causes the head of these animals to be bent back after death, the action of the muscles having ceased. It also retracts and retains the sharp claws of the cat tribe within their sheath when not in use. A ligament of this tissue also retains the wings of birds in a bent position when they are in a state of rest.

10. - The osseous fabric. 1-The osseous or bony tissue is another form of cellular matter. The bones constitute the hardest and the most solid parts of the whole system, and are the principal parts that give it form and stability, forming as it were, the frame work of the animal machines The num. ber of bones in the human adult, including the teeth, is 245 , When we examine the broken surface of a bone, with a microscope wive find it abundantly supplied with minute blood. 
vesselsy without any appearance of fibres or plates. The different densities of bones (depends on the different mechanical arrangements of the parts composing them.

11. The bones not only constitute the frame work of the human fabric, but they also protect the vital organs, as the heart and lungs, the brain and spinal marrow, and also constitute a series of levers, by means of which, through the agency of muscles, locomotion is performed. The bones in man also furnish cavities for the secure lodgment of the delicate organs of the senses, as the orbits of the eye, ear, mouth, and nostrils. In man, and the higher order of animals, the bones are for the most part in the interior of the body) and when near the surface, as in the skull, they are covered by muscles or membranes; but in the crustacea, insects, \&c., the bones compose an external case within which all the soft parts are contained

12. If we divide any of the long bones longitudinally, we find two kinds of structure, the hard or compact, and the alveolar or spongy) Indeed there is no bone that does not exhibit to some extent both of these structures; the compact forming its external, and the spongy its internal part. These two formations are clearly seen in the bones which compose the skull, (as in the following cut,) with the spongy or cancel.

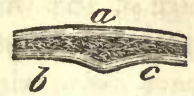

a. External plate. b.c. Internal plates.

lated structure between them. This will serve to illustrate the structure of all the flat bones.

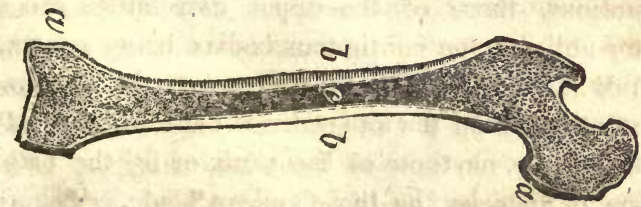

13. The above cut represents a section of the thigh bone. 
a. $a$. the extremities having a shell or thin plate of compact texture, crowded with small cells, diminishing in size, but increasing in number as they approach the articulation; $c$, the cavity for containing the marrow; $b . b$. the walls of the shaft very firm and solid. The compact part is thickest near the middle of the bone where the greatest strength is required. This structure admirably combines the greatest degree of strength, with the least degree of weight aud expense of material. It an be mathematically demonstrated that the resistance of a cylindrical body, such as a pillar or mast, to a force applied transversely is increased in proportion to its diameter. The same quantity of matter, therefore, placed in the circumference of a circle produces a stronger bone than if united in the centre with proportionally diminished diame. ter.

14. How admirably adapted is the arrangement of the parts of the long bones to the purposes for which they are destined. Their extremities are the fixed points from which the muscles re-act, and where greater space was required for the insertion of the tendons ; their diameter is on this account considerably increased, and their osseous matter is disposed in nearly an equal degree through their whole substance; while in the middle of the bone, which is more exposed to external violence, and where nothing was wanting but mere strength, the bony plates are all consolidated together into a compact dense ring, leaving the centre nearly hollow.

15. While the long bones of the lower extremities are adapted for the support of the body, and its various progressive motions, those of the upper extremities are equally fitted for acting upon contiguous bodies, being so attached to the trunk as to be casily applied to them in all directions.

(The flat bones on the other hand offer an extensive surface of defence, as those of the skull, or for the origin and insertion of muscles, as the shoulder blade. The rounded bones composing the spinal column and the angular bones of 
the wrist and ankle, have the bony matterestonded pver a considerable space, in order in the most emerent nramer to combine the properties of lightness and strength. The whole assemblage constitutes an apparatus which is capable of executing all the various movements that are necessary for the purposes of life, with a degree of precision and velocity that is truly wonderful.

16. (The bones are covered with a fibrous sheathing of dense membrane, called periosteum, which seems to nourish the bone, for where it is abraded the bone perishes. (It contains an abundance of blood-vessels which run from it into the bone; besides these, a large blood-vessel enters the shafts of the long bones near the centre, and branches out in each direction, while numerous others enter at their extremities? These blood-vessels, though generally too minute to convey the red particles of the blood, yet they readily transmit the colouring matter of madder. Numerous experiments have proved that when animals are supplied with food mixed with that substance, in a few days the bones are coloured red, or of a pinkish colour, and on the discontinuance of it, in a short time their natural colour is restored, showing the rapidity with which deposition and absorption are carried on in the healthy state. This is shown in cases of fracture, where the broken ends of a bone become speedily united. I have lately had a case of fractured thigh bone in a child, where it became united with considerable firmness in one week.

17. Marrow is a species of fat deposited in the central canals of the cylindrical bones, and in the lattice work of the spongy bones.) (It is contained in the cells of a delicate membranous web) and (has been supposed by some to serve as a reservoir of nourishment, and by others, to keep the bones from becoming dry and brittle.) It is found in greater quantity in the adult and aged than in the youngt; in the latter, indeed, its place is occupied by a gelatinous fluid.

18. Chemical examination shows that/bone is composed 
of earthy and animal matter, the former constituting about two-thirds, the remaining one-third being animal matter As we find portions of both these substances in the minutest particles of bones, both are therefore considered essential to its composition, and existing in a state of chemical union, and not as a mere mechanical mixture. These two substances can be readily separated from each other. (If we immerse bones for some time in diluted nitric acid, or muriatic acid, though they retain their size and form, their weight is considerably diminished, and they are rendered soft, pliable, and elastic. The earthy portion, phosphate of lime, has been dissolved, and is held in solution in the fluid, and the animal portion, gelatine, remains uninjured,

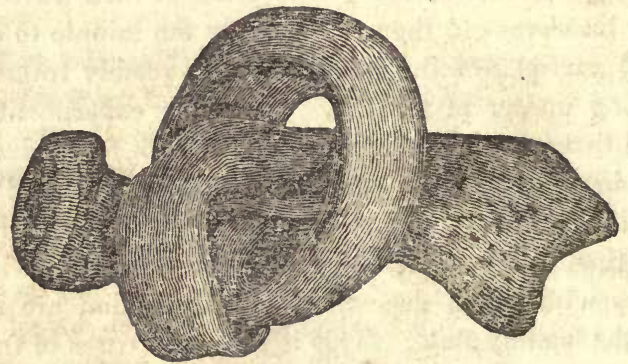

Membranous, or gelatinous portion of bone; the earthy portion being so completely removed, that it is capable of being tied in a knot.

19. If bones are subjected to a strong heat, as in a char. coal fire, on cooling they appear to have undergone no alteration in figure or bulk; but they are rendered white as chalk; their weight is lessened, and they become very brittle. In this case, the animal matter has been wholly consumed by the fire, while the earthy part remains un. changed; in the former case, the very reverse happened; the animal matter remaining, and the earthy being removed. 


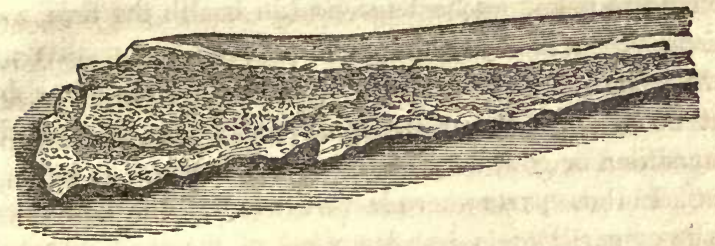

Earthy portion of bone.

20. The proportion between the animal and earthy sub. stances varies in different individuals, and in the same individual at different periods of life, and under various condi. tions of health. In youth, the former, in old age, the latter predominates. The earthy matter is sometimes so deficient that the bones have not the necessary degree of firmness and rigidity? The consequence is, that those parts of the skeleton which have to support any considerable weight bend under it, as the spine, the bones of the pelvis, and the lower limbsy. This is one cause of spinal distortions, though they are generally caused by debility of the muscles from want of proper exercise. In many cases of the former kind, by the subsequent deposition of earthy matter, the bones become sufficiently dense and compact; but the distortion remains fixed and permanent, and mechanical means, such as pulleys, screws, inclined planes, \&c., only serve to torture the patient, without affording the slightest prospect of a cure. No one who understands physiology will attempt to correct such distortions by mechanical means. Where there is a deficiency of animal matter, the bones want a poper degree of tenacity, and are therefore easily fractured by slight blows or falls.

21. The ends of the bones which are used for motion, as already mentioned, are tipped with cartilage or gristle, which is very smooth and hard; and it is constantly wet, in a state of health, by a fluid which answers the same purpose as oil in machinery, or tar upon wagon wheels. The joints are 
enclosed in membranous bags, and in health the fluid which moistens them is of just the right quantity and quality ; but if we do not take proper exercise, or if we take food or drink that is too heating or irritating, the joints grow stiff, or rheumatism or gout may be the consequence.

22. In those parts where bones are to be formed, a mould of gristle or cartilage is first deposited, of the exact shape that the future bone is to take; and as bony particles are secret. ed by the blood, the cartilage is taken up by the absorbent vessels. In the long round bones, this process begins in the middle, and in the flat bones, like the shoulder blade, or those of the skull, it begins in the centre and extends gradually towards the circumference? But in the skull, all the bones are not completely formed, till several months after birth.

23. The bones are variously connected by joints or articulations, which admit of different degrees of motion, both in extent and variety. Some of these connections allow free, easy, and conspicuous motion, as the shoulder and hip joints, which are called ball and socket joints; in others, there is motion in only two directions, as the knee, elbow, wrist, and ankle. These are called hinge-joints, from their resemblance to a hinge. Some bones, like those of the skull, though connected by a kind of articulation, are nevertheless immoveable.

24. Another form of animal matter, differing essentially from those we have been considering is, muscular tissue. This is familiar to all under the name of flesh. It is a substance of a peculiar nature, arranged in fibres of extreme delicacy, It is distinguished from every other texture in the body, by an innate power of contraction ; on examining it with microscopes of great magnifying power, it is found to be composed of filaments so fine as the one forty thousandth part of an inch in diameter. These filaments collected together, form fibres, which are plainly perceptible in boiled flesh. (A collection of these fibres form a bundle, and these bundles. collectively constitute a muscle; and 
muscles appear coarse or fine according to the size of these bundles.

25. These fibres appear to be very uniform as to shape, size, and general appearance, being delicate, soft, flattened, and though consisting only of a tender pulp, still solid (The fibrous and fascicular arrangement appears to be chiefly con. fined to muscles of voluntary action, as they are scarcely perceptible in the heart, and not at all in the alimentary canal, or urinary bladder. In the stomachs of birds, however, the fibrous structure is very distinct, especially in hawks and owls.

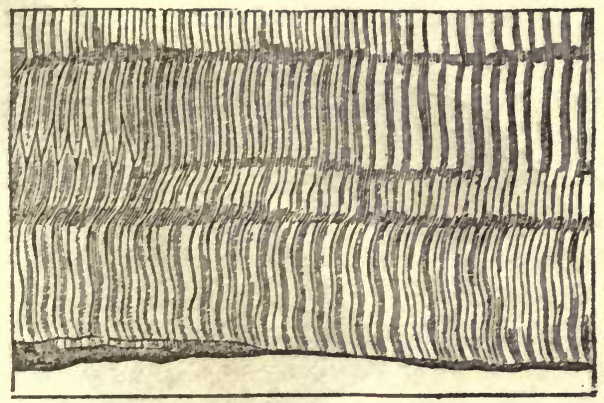

The appearance of the uitimate fibres and of their transverse lines, as seen under the microscope of Mr. Lister, when the object is magnified 500 diameters.

26. The muscular fibres are every where penetrated by cellular tissue and numerous blood-vessels and nerves. The colour of the muscle of course varies, according to the quan. tity and quality of the blood.) In adult animals it is of various shades of red; in young animals, of a cream colour, as in veal; in birds, it varies in different muscles; in fowls, for example, it is white. on the breast, and a deep brown on the legs ; while in fishes, it is bluish, or white, \&c.

27. No part of the body except, perhaps, the organs of sense, is so abundantly supplied with blood-vessels and 
nerves, as the muscular tissue. There is reason to believe that every filament, however fine, is provided with the ulti. mate branch of an artery, vein, and nerve. The direction of the fibres of muscles varies; in some, being parallel; in others, radiating in different directions. In some instances, they form nearly or quite a circle, as the muscle which closes the eye, and those of the intestinal canal ; in others, they are penniform, or having their fibres disposed like those forming the feathery part of a quill,

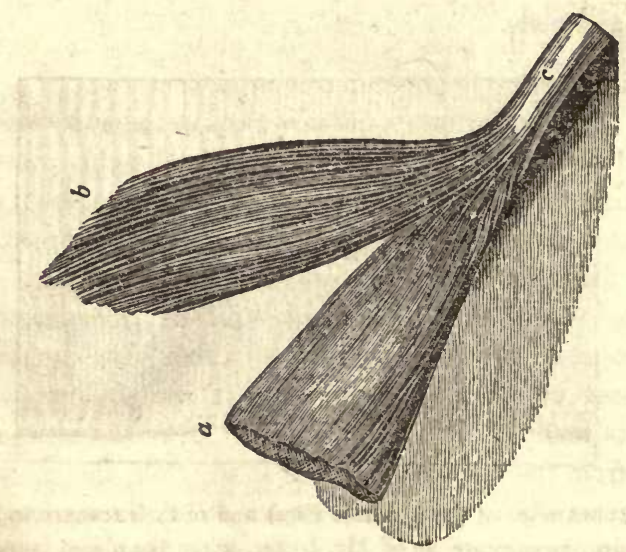

Two portions of muscle; one of which, $a$, is covered with mem. brane; the other, $b$, is uncovered; $c$, the muscular fibres terminating in tendon.

27. (Muscular tissue is supposed to consist chiefly of fibrin, though some chemists state that it contains albumen, gelatine, and osmazome These latter substances however, are probably obtained from the cellular tissue which encloses and dips down between the fibres of muscles. Fibrin contains a larger proportion of azote, the element peculiar to the animal body, than any other animal substance. The flesh of young animals affords a large proportion of gelatine, while 
it is deficient in fibrin-in adult animals, the fibrin pre. dominates, and the gelatine is deficient.

28. The peculiar property of muscular tissue is vital, and consists in the power of diminishing its length, or shortening on the application of stimulus) All the motions of the body are performed by means of it, and without its incessant action, respiration, digestion, nor circulation could be carried on for a moment. Tendons, ligaments, cartilages, and bones seem to be mechanical contrivances to aid the muscles in accomplishing their varied purposes, so that the only source of motion in the body is muscular tissue, and the only mode in which motion is generated is by contractility.

29. The last primary tissue which we have to describe, is termed nervous. (It consists of a soft and pulpy matter, of a brownish white colour, and appears to be composed of solid, elongated threads, differing in thickness from that of a hair to the finest fibre of silk) (Like the muscles, the nerves are enclosed in a sheath of condensed cellular membrane, called neurilema, or nerve coat ; and like them also, each nerve is composed of many bundles; these of many fibres; and the fibres of many filaments. In one respect the nervous fibres differ from the muscular, and that is, while the muscular fibres generally run parallel to each other, those of the nerves cross and penetrate each other, so as to form an intimate in. terlacement, as represented on the following page. When we come to describe the vascular system, it will be seen that either all the vessels proceed from one large trunk, which goes on progressively to divide and subdivide, until its branches become so minute as to be invisible; or that they arise by numerous and invisible branches, which unite to form larger and larger vessels, until they ultimately constitute only a few trunks. But the muscular and nervous fila. ments never divide and subdivide in this manner. It is the opinion of the best anatomists, that there is a diameter beyond which they no longer diminish. That diameter they maintain is quite uniform in each. 


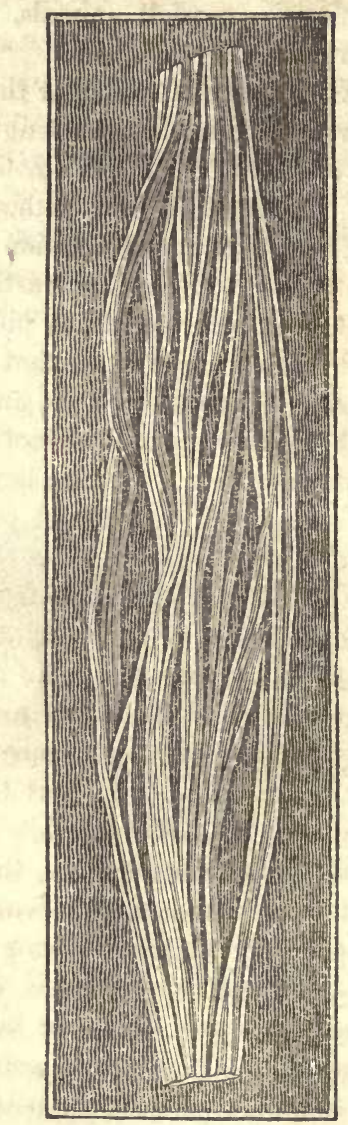

Nervous fibres, deprived of their neurilema and unravelled, showing the smaller threads, or filaments, of which the fibres consist.

30. The nervous tissue is also abundantly supplied with blood-vessels, like the muscular; so that there is not a fibre or filament, however minute, which is not supplied by a distinct blood-vessel. The nervous structure forms the brain, 
spinal marrow, nerves and their ganglions? The nervous tissue appears to consist of two substances, which as far as the eye can distinguish, appear to be entirely distinct from each other. The one is called cineritious, or gray, from its colour ; from its position, cortical, and from its consistence pulpy) This last appears to be composed chiefly of blood-vessels. The other is termed white, or medullary. It is of firmer consistence than the pulpy. This is decidedly fibrous in its nature. In every part of the nervous system which constitutes a distinct nervous apparatus, both substances are conjoined. Neither the pulpy, nor the fibrous alone, forms a distinct organ ; the union of both is necessary to constitute an instrument capable of performing a specific function.

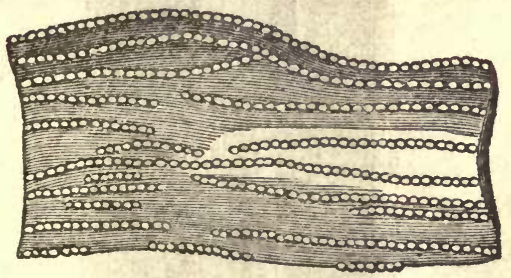

Ultimate fibres of nerve highly magnified; showing the strings of globules of which they consist.

31. Much controversy exists in relation to the shape of the ultimate particles of nervous matter; but while micro. scopical observations differ as much as they have done hith. erto, the question may fairly be considered as unsettled. (The common opinion is, that the ultimate filaments of which they are composed, are formed of globules of extreme minuteness. But then, when we consider the peculiar difficulties attending investigations of this nature, that they require unwearied perseverance, extreme accuracy, great patience, and a dexterity with the hand, united with a delicate discrimina. tion of the eye, that belong to few ; and when we consider moreover, that these very endowments can only be acquired 
by long practice, we shall be led to pause, before we adopt the opinions of every microscopical enthusiast who enters on this very extensive, and deeply fascinating field of discovery.

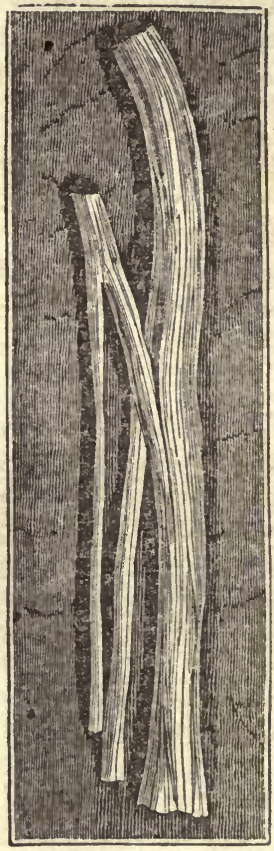

Portion of the trunk of a nerve dividing into two branches.

Questions.-Describe the fibrous structure. What are its uses? What are ligaments? What is a capsular ligament? What use do ligaments serve? When sprained, what is a good remedy? What is a tendon or sinew? Where are they found? What their use? Of what composed? Have they much sensibility? Why are bones sometimes placed in a tendon? What use does the knee-pan serve? Describe the cartilaginous tissue. What are its uses? How may its structure be shown? What is the elastic tissue? Where is it found? What are its uses? What constitutes the most solid portion of the sys. 
tem? What are the uses of the bones? How many are there in the human skeleton? Is bone supplied with blood-vessels? What is the different density of bones owing to? What situation do the bones occupy in man? In the crustacea and insects ? Describe the structure of the long bones? -of the flat bones? What is the chief use of the flat bones? What covering have the bones? What is the structure of the periosteum? What its use? How are the bones nourished? What effect has madder upon bones when taken internally? What is marrow? Where is it deposited? What its use? At what period of life is it most abundant? What is the composition of bone. What pro. portion is animal matter? What earthy? How are these different substances shown? Are their proportions affected by age or health? What is the consequence when the earthy matter is deficient? What when the animal? How are spinal distortions best remedied? How is bone formed? Are all the bones formed at the time of birth? What is muscular tissue? By what property is it distinguished?-Of what composed? What are fibres? What bundles? How do the fibres appcar? Do all muscles possess the fibrous arrangement? To what is the colour of muscle owing? Of what colour is the muscle of fishes? Of what shape are muscles? What is the chemical composition of muscular tissue? Does age affect the quantity of fibrin in animals ? What peculiar property does muscular fibre posscss? What its use? Describe the nervous tissuc. What is the neurilema? Does nervous tissue abound with blood-vessels? What does it form? How many kinds of substance is contained in it 1 What is the cineritious? What their cortical portion? Does either alone form any organ? What is said of the shape of the ultimate particles of matter? 


\section{CHAPTER V.}

\section{CHEMISTRY OF THE HUMAN BODY.}

\section{Ulimate and Organic Elements.}

1. By the chemical composition of the body, is meant those ultimate elements of which it is made; such as bxygen, carbon, hydrogen, and azote. By the organic composition, we mean the proximate elements, which are formed out of these by the power of the living principle; such a albumen, fibrin, gelatine \& \&c.

2. The ultimate elements of animal matter have been divided into non-metallic, and metallic substances; the former consisting of oxygen, hydrogen, carbon, azote, phosphorus, sulphur, chlorine, and fuorine; the latter, 1, the bases of the alkalies, viz., potassium, sodium, and calcium; 2 , the bases of the earths, magnesium, silicium, and aluminum; 3 , the ponderous metals, iron, manganese, and copper.

Of the first class, or the non-metallic substances, oxygen, hydrogen, carbon and azote exist in much the largest pro. portion, and are in fact the only essential elements of animal matter.

3. All the solids and fluids of the body contain oxygen.) It is essential to all the proximate elements. United with hydrogen, it forms water, which is calculated to constitute nine-tenths of the whole weight of the body. In union with carbon, it forms carbonic acid, which exists in the blood, and is thrown out by the lungs and skin.

3. Oxygen forms with phosphorus, phosphoric acid, which with lime constitutes the earthy portion of the bones; it also exists in some of the secretions. In union with their metalic bases, it forms potash, soda, and lime. It also is a consti. 
tuent part of albumen, fibrin, gelatine, and mucus. Oxygen is derived partly from the air we breathe, and partly from our food and drinks. It is given off in all the secretions and excretions. The air contained in the swimming bladder of fishes, is pure oxygen.

4. (Hydrogen exists in all the fluids and most of the solids, constituting as it does one element of water. In venous blood, it exists in a larger proportion than in arterial blood, which contains more oxygen. In the bile, it is very abundant, and in fat and oil, is one of the essential elements. It is this gas which often causes so much distress in a weak state of the stomach. Hydrogen is introduced into the system by means of food and drinks, and is discharged in the same manner as oxygen

5. (Carbon abounds in the vegetable as well as animal kingdom. In oil, fat, albumen, gelatine, fibrin, and mucus, it always forms a part. In bile, and in venous blood, it exists largely. If we burn a piece of animal substance, what is left is found to be chiefly carbon. We obtain it from our food, and give it off by breathing and the secretions. It is carbon that makes venous blood darker than arterial, and the change from purple to bright crimson which takes place in the lungs, is supposed to be owing chiefly to the fact, that the excess of carbon contained in venous blood is discharged by respiration

6. (Azote exists in large quantities in all animal matter. It also exists to some extent in a few vegetables, but it is an essential element in animal substances. It is more abund. ant in fibrin, of which the muscular flesh is chiefly formed, than in any other portions of the body, though it is found in the brain and nerves. The peculiar smell of burning animal matter is owing to azote. When animal substances putrefy, it combines with hydrogen, and forms anmonia or hartshorn

7. Azote is chiefly taken into the system by means of animal food. It is also taken into the blood by respiration, 
as it forms a constituent part of the atmosphere. This, however, is denied by some chemists. It is discharged from the system in the same manner as oxygen, hydrogen, and carbon; though chiefly through the kidneys.

8. Phosphorus exists both in animal and vegetable substances. Nearly every part of animal bodies contain it, though it is found more abundantly in the bones. It generally exists in combination with oxygen, forming phosphoric acid. It is discharged mostly through the kidneys. The spontaneous combustion of human bodies, of which we have some well-attested cases of drunkards, is supposed to be owing to an accumulation of phosphorus in the system, from some unknown cause.

9. (Sulphur is always united, in animal substances, with other elements, as soda and potash. It is found in albumen, in the hair and nails, and in muscular flesh. It is given off by the intestines and by the skin.

10. Chlorine is found in most of the animal fluids combined with hydrogen. This forms hydrochloric acid. In the blood it is combined with soda and potash. It is found also in the gastric juice, in sweat, milk, saliva, \&c.

11. Potash exists more abundantly in plants than in animals. It is, however, contained in the blood, bile, urine, sweat, milk, \&c.

12. Soda is more abundant in animals than plants. It exists in the same fluids in which potash is found; also in bones and muscular flesh. It is always combined with some acid.

13. Lime forms a large part of the bones, in union with phosphoric or carbonic acid. Silex exists in human hair, and in some of the secretions. Magnesia is contained in bones, and in some animal fluids, as milk. It is also found in the brain. Iron forms the colouring principle of the red globules of the blood, and is therefore pretty extensively found in animal bodies. 
14. (The organic or proximate elements of the body are formed from the ultimate elements already described We cannot explain their formation on any chemical or mechanical laws, but refer them solely to the influence of the vital forces.

15. These proximate elements are mostly formed from a combination of oxygen, carbon, hydrogen, and azote, and are (divided into two classes, acids and oxyds)

16. The acids found in the human system are the acetic, . oxalic, the benzoic, and the urich The three first are also found in the vegetable kingdom, and are composed of oxygen, hydrogen, and carbon. When these organic elements are made of three simple elements, they are called ternary oxyds; such are sugar, resin, and the fixed and volatile oils.

17. Milk contains a considerable quantity of sugar. It can be obtained from whey by evaporating it slowly to the consistence of a syrup, and then allowing it to cool. It may then be purified by, the white of an egg, or albumen, and crystalized again. It has a different taste from the sugar of the cane.

18. The bile contains a peculiar resin. Fat and the mar. row of the bones contain fixed oils. But the most important compounds of the body are albumen, fibrin, gelatine, mucus, and osmazomed

19. Albumen exists in the body, both in a solid and fluid form Combined with water it forms the white of eggs; hence its name. (It exists most abundantly in the serum, but is found in all the fluids of the body. It is transparent, without colour, taste, or smell, and coagulates by heat, acids, and alcohol

20. Solid albumen is also a white and tasteless substance. It forms the basis of the nerves and brain, and is contained in the skin, hair, nails, glands, and vessels. Tumours and wens are mostly composed of albumen. It is composed of 
Carbon 52 parts; Oxygen 23 parts; Hydrogen 7 parts; Azote 15 parts.

21. Fibrin is the basis of muscular flesh and enters largely into the formation of the blood, chyle, and lymph. It is owing to the presence of fibrin that blood coagulates when removed from the body. Fibrin is a solid, white substance, of a fibrous structure, destitute of smell and taste, and in. soluble in water.

22. Fibrin may be obtained by washing the thick part of the blood with cold water, and thus separating the colouring matter, or the red globules It differs from albumen by possessing the property of coagulating at all temperatures. Fibrin is composed of Carbon 43 parts; Oxygen 19 parts; Hydrogen 7 parts; Azote 19 parts. It contains more azote and less oxygen than albumen.

23. Gelatine is found in none of the fluids of the human rody: (It is, however, found in nearly all the solids) It is known from all the other animal principles (by its readily dissolving in warm water, forming a kind of jelly) (When dry, it forms a hard, shining, brittle substance, called glue. This is mostly prepared from the skins and hoofs of animals, by boiling them in water, and then evaporating the solution. Isinglass is obtained from the sounds of the sturgeon, and is a very pure gelatine.

24. Gelatine exists largely in the skin, cartilages, ligaments, tendons, and bones, and it forms the basis of the cellular tissue As it does not exist in the blood, it is probably a modification of albumen. It is composed of $C$ arbon 47 parts ; Oxygen 27 parts ; Hydrogen 7 parts ; Azote 16 parts.

25. It appears that gelatine contains less carbon than albumen, by 5 or 6 per cent., and a larger proportion of oxygen in the same ratio. Now, if we suppose, that near the skin, and in the various tissues of the body, the albumen of the blood gives off a portion of its carbon, a part of which 
is taken up by the veins, and a part thrown off by the skin, lungs, and various secretions, we shall see how gelatine may be formed out of albumen.)

26. Osmazome is an element which exists in all the animal fluids, and in some of the solids, as the brain and muscular fibre. It is of a reddish brown colour, of an aromatic smell and agreeable taste fit is this which gives the strong flavour of roasted meat, and the peculiar taste of the various kinds of animal food. It is supposed to be tonic and stimu. lating, but to possess no nutritive properties.

27. Mucus is that bland fluid which moistens the surface of all the mucous membranes (In some of the hard parts of the body, which are destitute of sensibility, it is found to exist in considerable quantities, as in the nails, hair, and cuticle of man, and in the scales, feathers, and wool of different animals. That part of the skin called rete mucoscum, is supposed to be compacted mucus. Mucus is transparent, has no colour or taste, and has a ropy and viscid consist. ence. When dry, it is insoluble in water. It contains much azote.)

28. There are some other substances found in the human body, such as caseine, or that principle of the milk which forms the basis of cheese, curd, \&c. ; but they are not of sufficient importance to need a particular description.)

Questions.-What is meant by the chemical composition of the body? What are some of the ultimate elements? What are some of the proximate elements? How have the ultimate elements been divided? Is oxygen essential to all the proximate elements? What is said of hydrogen?-Of carbon?-Of Azote? How do oxygen, hydrogen, and azote get into the system? Is phosphorus found in animal bodies? What other elements are met with in animals? How are the organic elements of the body formed? How divided? What acids are found in animal bodies 24 What are the most important compounds in the body? What is said of albumen? In what is it found? What is fibrin the basis of? How may it be obtained from 
blood? Of what is it composed? Where is gelatine found in the animal body? How known from the other animal principles? What does it form when dried? Of what is glue prepared? In what does gelatine exist? How may we account for the productions of gela. tine? What is osmazome? What peculiar properties has it? What is mucus? Where found, what is its use? Are any other substances found in the human body? 


\section{CHAPTER VI.}

\section{THE HUMAN SKELETON.}

1. OF all the wonderful works of the great Architect, none bears such convincing proofs of divine wisdom and goodness as the mechanism of the human body. Every part, down to the minutest fibre or blood-vessel, bears the impress of the Creator's hand, and the marks of design and contrivance are so obvious throughout, as to lead the mind irresistibly to an all-wise, Omnipotent designer !

2. The human skeleton consists of about ( 252 bones, including the sesamoid, the teeth, and the small bones of the ear; though they are generally reckoned at 211 . They are divided into those of the head, trunk, and extremities, some of them being single, others in pairs. (When the bones composing the skeleton are connected together by natural ligaments, they form what is called a natural skeleton; when by wires, it is termed an artificial skeleton. The latter is the common and most useful mode of articulation to the anato. mist, as the joints can be easily moved and examined. (The skeleton has been called the bony frame work of the body, because by its form and solidity, it not only retains every part of the fabric in its proper shape, but also affords a hard surface for the attachment of muscles, and the protection of many important organs.) If we suppose a plane to pass down from the top of the head through the middle of the skeleton, the latter will be divided into two equal portions, called the right and left side of the body, which are perfectly alike in shape and size. Those bones which are situated in the centre, such as the spine and breast bone, and are intersected by it, are said to be symmetrical, because they are divided equally; the others, such as the bones of the arm and leg, are in pairs. 


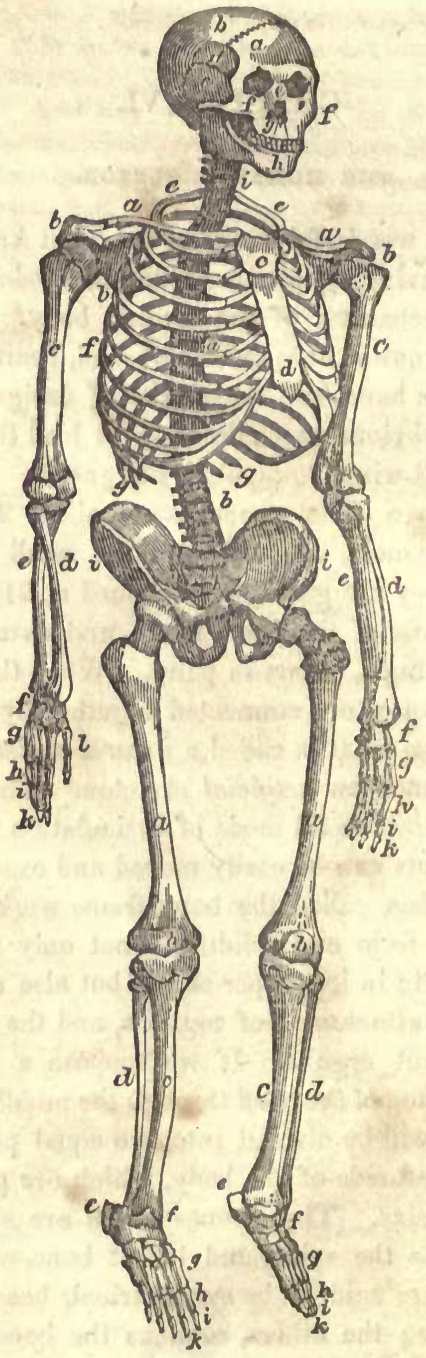




\section{THE HUMAN SKELETON.}

3. The bones of the head are 55 in number, as follows :

\begin{tabular}{|c|c|c|c|}
\hline \multirow{2}{*}{\multicolumn{4}{|c|}{$\begin{array}{l}\text { Frontal, (Os Frontis, } a, \text { ) } \\
\text { Parietals, (Ossa Parietalia, } b, \text { ) }\end{array}$}} \\
\hline & & & . \\
\hline Temporal . & . & . & . \\
\hline Occipital, (Os Occipitis) & . & . & . \\
\hline Sphenoidal, (Os Spherroides, & d,) & . & . \\
\hline Ethmoid, (Os Ethmoides) & - & . & . \\
\hline Nasal, (Ossa Nasi, $e$, ) & - & . & \\
\hline Mular, (Ossa malarum $f$ ) & $\cdot$ & . & - \\
\hline Lachrymal, (Ossa Lachryma & alia, ) & . & . \\
\hline Upper Jaw bones, (Ossa max & xillaria & super & ora) \\
\hline Palate bones, (Ossa palatina) & & & . \\
\hline Inferior turbinated bones, $(\mathrm{O}$ & Ssa tur & binata & \\
\hline Vomer, . & . & . & . \\
\hline Lower Jaw, (Os maxillare in & nferi & $h)$, & \\
\hline Teeth, (Dentes) & . & . & . \\
\hline Tongue bone (Os hyoides & & & \\
\hline
\end{tabular}

To these are sometimes added the proper bones of the ear, contained in the temporal bones.

\begin{tabular}{lr} 
Mallei, (hammer) & 2 \\
Incudes, (anvil) & 2 \\
Stapedes, (stirrup) & 2 \\
Orbicularia, (round bones) & $\mathbf{2}$ \\
\hline
\end{tabular}

4. The trunk contains 57 bones, viz:

\begin{tabular}{lr} 
Vertebræ, $(a)$, & 24 \\
Ribs, Costa, $e, f, g,)^{-}$ & 24 \\
Breast bone, (Sternum, $c, d$ ) & 2 \\
Hip bones, (Ossa innominata, $i$, ) & 2 \\
Rump bones, (Os sacrum, $k)$, & 1 \\
Coceygeal bones, (Ossa coceygis) & 4 \\
\hline
\end{tabular}

5. The upper extremities contain 68 bones, viz:

Collar bones, (Claviculæ, $a$, ) . . 2

Shoulder blades, (Scapule, $b$, ) ( . . 2

Arm bones, (Ossa humeri, $c$, ) . . 2

Fore arm bones, Radii et ulnæ, $d, e$,$) . . 4$

Wrist bones, (Ossa carpi, $f$, ) - 16

Hand bones, (Ossa metacarpi, g, . . 8

Finger bones, (Phatanges digitorum manus, $h, i, k$, ) 24

Thumb bones, (Ossa policis, $l$, ) . 6

Sessamoid bones,(Ossa sessamoidea). 4

6 The inferior extremities contain 64 bones, viz:

Thigh bones, (Ossa femoris, $a$, ) . . 2

Knee-pans, (Patelæ, $b$, ) . . . 2

Shin bones, $($ Tibiæ, $c$, ) . . . $\quad$. 2

Small bone of the legs, (Fibulæ) _ . 2

Tarsal, (Ossa tarsi, $e$, ) . $\quad$. . . 14

Metatarsal, (Ossa metatarsi, $f$, ) $\quad$. 10

Toe bones, (Phalanges digitorum peđis, $h, i, k$ ) 28

Sessamoid, (Ossa sessamoidea) 


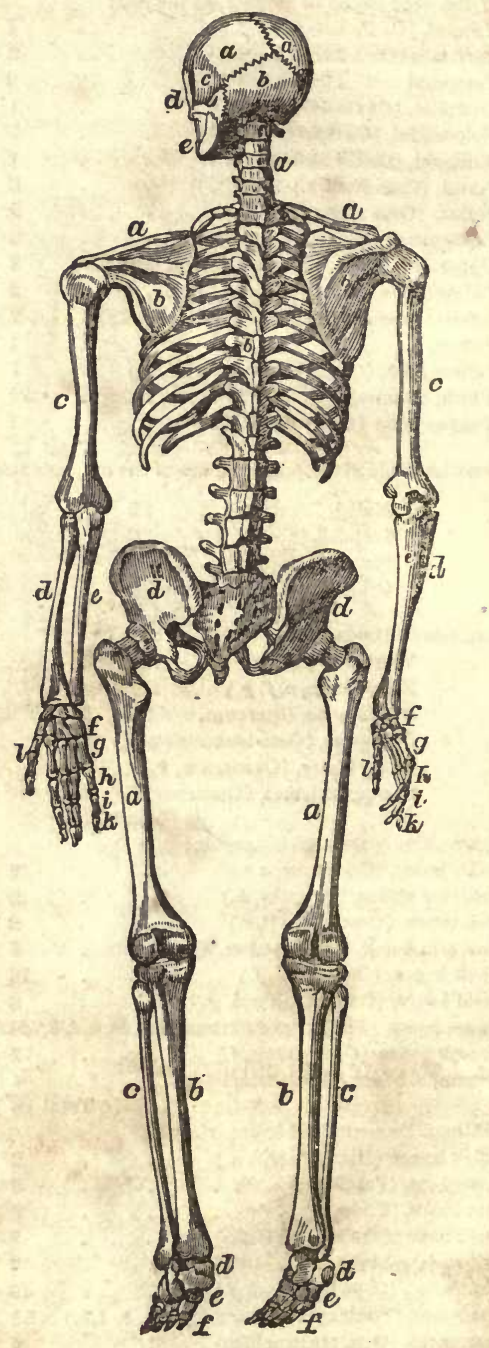


7. The second plate represents a back view of the male skeleton, while the first is a front view.
a. The parietal bone.
b. The occipital bone.
c. The temporal bone.
$d$. The cheek bone.
e. The lower jaw bone.
'Neck and Trunk.
a. The bones of the neck.
$b$. The bones of the back.
c. The bones of the loins.
d. The hip bones.
c. The sacrum.

\section{Upper Extremity.}

a. The collar bones.

$b$. The blade bone.

c. The upper bone of the arm.

d. The radius.

e. The ulna.

$f$. The bones of the wrist.

g. The bones of the hands.

$h$. The first row of finger bones.

$i$. The second row of finger bones.

$k$. The bones of the thumb.

\section{Lower Extremity.}

a. The thigh bone.

b. The large bone of the leg.

c. The small bone of the leg.

$d$. The heel bone.

e. The bones of the instep.

$f$. The bones of the toes.

8. It does not fall within the plan of the present work to give a description of the individual bones which go to make up the skeleton; this must be sought in treatises on anatomy. Still there are many points connected with the subject of extreme interest to every reflecting mind, to which the attention of the young may be profitably directed, particularly as connected with the marks of wisdom and design in the Al. mighty architect. If our curiosity is excited to see a piece of ingenious machinery, or a new engine, shall we neglect to raise the covering which displays in the body the most striking proofs of design, surpassing all art in simplicity and effectiveness, and without any thing useless or superfluous. 
9. If we compare the human body, as a work of art, with any forms of human architecture, how vastly superior does it appear. A watch, or a musical automaton are highly in. genious specimens of inventive skill; but where is the watch or the automaton that can, without repair, for the space of 80 or 100 years, continue to perform its movernents with regularity and precision. And yet how much less complicated is their machinery, how vastly more solid, and durable the materials out of which they are formed!

10. If we examine a ship, we find it built for passive motion, and for resisting force externally applied ; a house or a bridge is constructed for solidity and firmness, on the prin. ciple of gravitation; a railroad car is built for rapid motion, and its wheels so adjusted, that they may not run off the track; but in the human body, we find not only securities against the gravitation of the parts, provisions to withstand shocks and injuries from without, but at the same time, the frame work is calculated to sustain an internal impulse from the muscular force which moves the bones as levers, or like a hydraulic engine, propels the fluids through the body.

11. The human fabric is admirably adapted to resist the influences to which it is subjected; in other words, there is a nice balance between the power of exertion and the capability of resistance. A deer or a giraffe is never injured by any leap which their muscular powers enable them to make, because the inert power of resisting the shock, bears a rela. tion to the muscular power with which they spring; and so it is in man. The elasticity of his limbs is proportioned very accurately to his activity; he readily resists shocks and im. pulses upon the lower extremities, because they are adapted to this end; but if the same are applied to the upper, the bones are broken or displaced, because they are adapted rather for extensive and rapid motion, than for resisting violent shocks.

12. It has been truly remarked that the foundation of the Eddystone light-house, the perfection of human architecture 
and ingenuity, is not formed on principles so correct, as those which have directed the arrangement of the bones of the feet; that the most perfect pillar is not adjusted with the accuracy of the hollow bones which/support our weight; that the in sertion of a ship's mast into the hull is a clumsy contrivance compared with the connexions of the human spine and pelvis; and that the tendons are composed in a manner supe rior to the improved chain cables of Bloxham.

13. As the head is the noblest part, and the brain the most essential organ of the animal system, let us first direct our attention to it. The brain is liable to injuries, not only by sharp bodies touching and entering it, but by a blow upon the head, which shall vibrate through it, without the instru. ment piercing the skull; and such a blow would more effectually destroy a man's senses, than even if a sword penetrated into its substance. It is obvious, that if the bony case were soft it would be easily pierced; if of a brittle nature, it would be easily cracked, and if very firm and solid, like metal, it would ring and vibrate, and thus communicate the concussion to the brain.

14. To obviate these dangers, (we find the skull composed of two plates of bone, one external, which is fibrous and tough, and one internal, so dense and hard, that it is called by anatomists the glassy table Now, as the brain is liable to be hurt both by sharp and blunt instruments, the inner table is hard and brittle, calculated to resist any thing penetrating; while the outer table is tough to give consistence, and stifle the vibration which would take place, if the whole texture were uniform. This may be illustrated by an ex. ample. If a soldier's head be covered with a steel helmet or cap, the blow of a sword, which does not penetrate, will yet bring him to the ground; but if it be lined with leather and covered with hair, the vibration is not transmitted to the brain, and the wearer escapes without injury. 


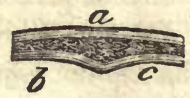

$a$, the external, $b, c$, the internal table; the intermediate cellular texture, being soft and spongy, and conveying vessels and nerves from one part to another.

15. It is worthy of particular remark, how the changes in the structure of the bones of the skull are adapted to the changes in the mind at different periods of life. (At birth, the skull is soft and yielding, there being considerable inter. vals between the adjacent bones of which it is composed; during childhood, it is highly elastic, so that the heedlessness of that period may not endanger concussion, to which it is so often exposed from falls; and during youth and up to manhood, the parts which are exposed to the contact of ex. ternal bodies, are thicker, and the bones are still not firmly consolidated at their sutures or seams, by which they are united. As old age approaches, man grows more timid, and is little disposed to feats of agility or activity; something teaches him that falls or blows, which could once be borne with impunity, can no longer be encountered with safety; and if we examine the skull, we find the two layers of bone consolidated into one. The result of which is, that con. cussion at this period would be far more dangerous than in early life, or at the age of manhood.

16. The sutures, or joinings of the bones of the skull, in. terrupts, in a measure, the shock of the vibration produced by external violence, and also prevent fractures from extend. ing as far as they otherwise would do, in one continued bony substance No one can examine the joinings of two of the bones of the cranium, without admiring the minute dovetailing by which one portion of the bone is inserted into, and surrounded by the other, whilst that other pushes its processes out between those of the first in the same manner; 
and the fibres of the two bones are thus interlaced, as you might interlace your fingers. But this dove-tailing exists only in the external plate on the internal surface the bones are simply laid in contact.

17. Sir Charles Bell compares the human skull/to the dome of a building which is acknowledged to be one of the most difficult pieces of architecture. The dome of St. Sophia, in Constantinople, built in the time of the Emperor Justinian, fell three times during its erection; and the dome . of the Cathedral of Florence, stood unfinished 120 years for want of an architect. "Yet," says this writer, "we may, in one sense say, that every builder who tried it, as well as every labourer employed, had the most perfect model in his own head." The difficulty in constructing a dome, is the tendency of the weight of its upper part, to disengage the stones from each other which form the lower circle, and crowd out the circular wall on which it rests. This is guarded against, either by soldering the stones into each other, or by hooping them together by strong iron hoops. The dome of St. Paul's, in London, is secured by several strong double iron chains, linked together at the bottom and along the sides of the cone. Now, in the bones which compose the dome of the cranium, we find the edge of a bone at the suture lying over the adjoining bone at one part and under it at another; which, with the dove-tailing abovementioned, holds each bone securely in its place. But while a dome is calculated to resist one kind of force, viz. that acting perpendicularly, or in the direction of gravity, the skull is equally calculated to resist forces operating in all directions. Thus it can be shown, that no other form of equal strength could be devised. When we reflect on the strength displayed by the arched film of an egg-shell, we need not wonder at the severity of blows which the cranum can withstand. 


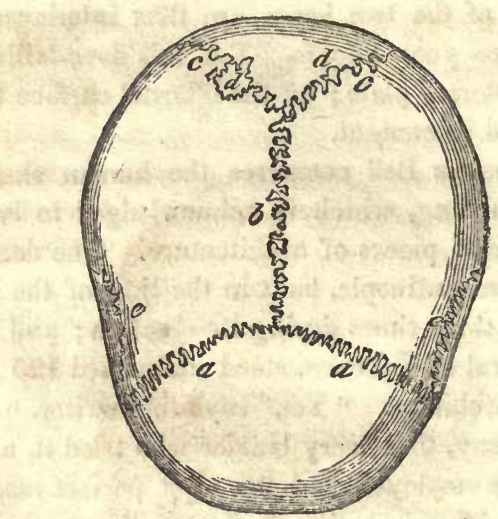

$a, a$, the coronal, suture, from the Latin corona, crown, so called from its situation on that part of the head, upon whieh the ancients placed the laurel, or olive crown, given to the victors in their games. It connects the frontal to the parietal bones; $b$, the sagittal suture, from a Latin word, signifying arrow, from its straight course. It runs from the middle of the frontal to the angle of the occipital bone, connecting the two parietals; $c$, the lambdoidal suture, extending from the sagittal suture down to the base of the brain on each side; $e, e$, the scaly overlapping of the temporal upon the parietal bones; hence called squamous suture.

18. The frontal bone is one of the most important in the skull. It has been compared to a clam-shell from its shape, and it forms the fore-head, part of the temples, and the roof of the orbits of the eyes. Like the other bones, it is composed of two plates, which often recede from each other, immediately over the nose to a considerable distance, leaving a space between them called the frontal sinuses. These cavities communicate with the nose, and are supposed to increase the intensity of the sound of the voice, and also to render it more melodious. The change of voice, observable in a person affected with a cold, is owing to a closure of the passage between the nose and cavity, preventing the access 
of the sound to this reverberating sinus. Snuff-taking, it has been supposed, injures the voice by obstructing this canal.

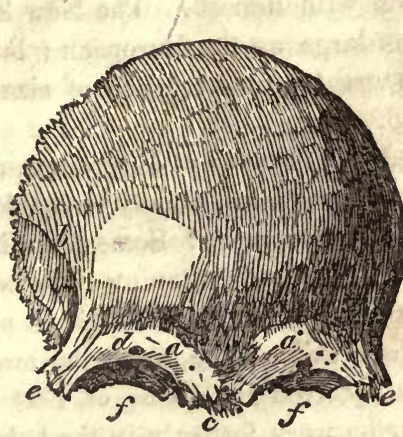

A front view of the frontal bone; $a, a$, frontal sinuses; $b$, the temporal arch, beneath which lies the temporal muscle, which closes the lower jaw ; $d$, the supra-orbitary hole for a psssage of a branch of the fifth pair of nerves.

19. The shape of the head, as well as its size, varies greatly in different individuals. There are also national peculiarities in the form of the head, constituting a well-marked national feature. Thus the Caucasian race, to whom we belong, is distinguished by the beautiful oval form of the head. To this race the most civilized nations belong, and those which have ruled over the others. The Mongolian race, which inhabits China and Japan, is known by its prominent cheek bones, flat face, narrow and oblique eyes, straight and black hair, thin beard, and olive complexion.

20 . The negro race has a compressed skull, and a flattened nose, a prominent mouth, and thick lips; thus bearing some resemblance in features to the monkey tribe. The North American Indian has a very singular shaped head; it being high from the ear upward, and short from the front to the back. The fore-head is not as largely developed as 
in the Caucasian. The head of the Hindoo is much smaller than that of the European, while that of the New-Hollander is but little superior to that of the ourang outang, who roams the same forests with himself. The New Zealanders have heads nearly as large as the European; but the fore-head is low, and the great preponderance of size is in the back part of the head,

21. The heads of the ancient Egyptians, as appears from an examination of mummies, closely resembled in shape and size those of modern Europeans, Some of our North American Indians are in the habit of flattening their heads by binding a piece of board on the fore as well as back part of the head, in infancy. From this custom, one tribe among the Rocky Mountains, has received the name of Flat Head Indians. The Choctaw tribe were formerly in the habit of flattening their heads in the same way ; but for some years past, they have discontinued the practice. The heads of the different European nations differ somewhat from each other; but a common type characterizes them all.

22. Not only the size, but the tcxture of skulls among different nations varies. The grain of the New Holland skulls is extremely rough and coarse; that of the Hindoos, fine, smooth, and compact, more closely resembling ivory. The Swiss skulls are open and soft in the grain, while the Greek are closer, and finer. It has been suggested that there may possibly be a corresponding quality of brain in the individuals, which may influence the mental, and consequently the national character. This difference is generally attributed to the effects of temperament.

23. The bones of the cranium increase in extent, thickness, and weight, from the commencement till the termina. tion of their development in adult age ; but after this time, and till old age, they always diminish in these three rela. tions.) In advanced life, we often find them reduced to a mere shell, and perhaps perforated in some places. They thus become much lighter than in middle life. Meckel found 
the skull of a female, seventy years of age, weigh but fourteen ounces, while that of a girl, twenty years of age, weighed twenty-four ounces. In the early periods of life, the whole form of the head is much rounder than at an advanced age ; owing, perhaps, to the small development of the face, which the skull envelopes in every direction.

24. The size of the cavity formed by the bones of the skull, is always proportional to the size of the organs it lodges and protects. The shape and size of the cranium depend on the brain, and not of the brain on the cranium. The soft parts model and adapt to themselves the hard, and not the hard, the soft. The brain is formed before the case which contains it and it is not till after several years that the bones of the cranium become perfectly consolidated. In a child of ten years of age, afflicted with dropsy in the head from infancy, and which was exhibited a year or two since in this city as a great curiosity, although the head measured thirty.two inches in circumference above the ears, yet nearly the whole surface was protected by a bony covering.

25. The Spine.-However admirably the skull may appear to be adapted to the objects for which it was obviously designed, the spine exhibits no less evidence of wisdom and skill in the divine Architect. In addition to the firmness which was required in the joinings of the bones of the cranium, a new principle is now introducedd, viz. the attainment of mobility or pliancy. The spinal column indeed serves three important purposes; it is the great bond of union be. tween all the parts of the skeleton; it forms a tube for the safe lodgment of the spinal marrow; and lastly, it is a pillar to sustain the head.

26. In order to accomplish these various purposes, the back bone, so called, is composed of /twenty-four distinct bones, or vertebra, from vertere, to turn, as the hody turns on them, which are/arranged into three classes, the cervical, dorsal, and lumbar, The first seven are the cervical, because they belong to the neck; the next twelve are the dorsal, be- 
cause they belong to the back; and the last five are the lumbar, because they are situated in the loins. The bones comprising these classes, differ somewhat from each other in shape; a description of the dorsal pieces will prove sufficient for our purpose.

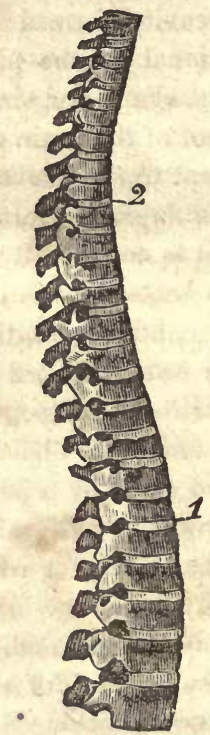

A lateral view of the spine divided into its cervical, dorsal, and lum bar portions.

27. Each of these twelve bones consists of a body, four articulating processes, two transverse processes, and one spinous process. The body is formed of soft and spongy bone, which is circular before, flat towards the sides, hollowed out behind into a crescent shape for containing the spinal marrow, and concave above and below for the accommodation of the intervertebral substance. On the side of the bone are 
situated the four articulating processes, each bone being connected with the two immediately adjoining it. Two of these processes are situated near its upper surface to articulate with corresponding processes belonging to the bone above, and two are placed near its under surface to join with those of the bone below. The two superior articulating processes of one vertebræ are thus connected with the two inferior articulating processes of another, and these points of union not only co-operate with the intervertebral cartilages in keeping these two vertebræ together, but permit a slight rotatory motion of the one upon the other. The spinous process projects directly backwards from the body of the vertebræ, and may be felt externally by passing the hand along the spine; the two transverse stand out on either side, and have the ends of the ribs attached to them.

?

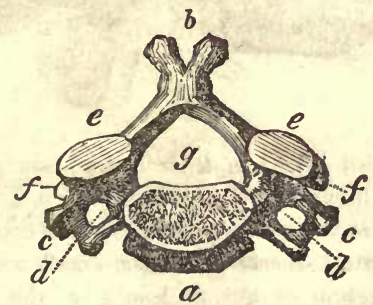

A vertebra of the neck; $a$, body of the bone; $b$, the spinal process; $c, d$, the transverse processes double, showing circular holes for the passage of the vertebral artery; $e, e$. the superior; $f, f$, the articular, or oblique processes; $g$, the spinal hole for the spinal marrow. The roots of the articular processes are hollowed out above and below into notches; and these, when the bones are fitted together, form apertures on each side of the spine, through which the nerves pass out from the spinal canal. 


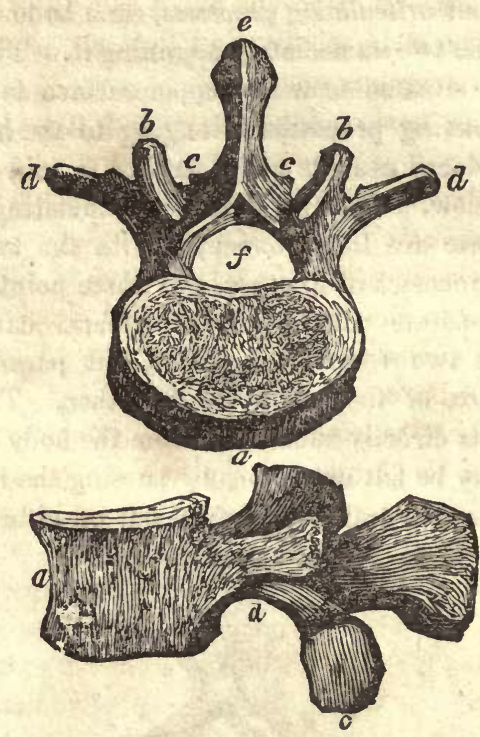

A vertebra of the loins; $a, a$, their bodies, larger and more spongy than those of the others; $b, b, b$, the superior; $c, c, c$, the inferior articular processes, strong and deep, the superior concave; the inferior convex; $d, d, d$, the transverse processes, small and long, serving as levers for the attachment of muscles; $e, e$, the spinous processes, strong, horizontal, and flattened at the sides; $f$, the spinal foramen.

28. The vertebræ, as I have stated, are not in contact, but separated by a considerable interval, which is filled by a peculiar gristly substance of a highly elastic nature, which is pressed out from betwixt the bones, and therefore permits them to approach, and play a little in the motions of the body. This compressible cushion of cartilage and ligament serves indeed the triple purpose of uniting the bones to each other, of diminishing and diffusing the shock in walking or leaping, and of admitting a greater extent of motion than if the bones were in more immediate contact. These separate vertebræ are firmly bound to each other in such a way as to 
admit of flexion and extension, and a certain degree of rota. tion, while by their solidity and firm attachment to each other, great strength is secured.

29 . We can now readily perceive how great the influence of these twenty-four joinings must be in giving elasticity to the whole column, and how much this must tend to the pro. tection of the brain. Indeed, were it not for the interposition of this elastic material, every motion of the body would produce a jar to the delicate texture of the brain, and we should suffer almost as much in alighting on our feet, as in falling on our head.

30. But there is another very curious provision for the protection of the brain, and that is the curved form of the spine. By looking at the cut, you see that it is shaped like an italic $\int$. Now, suppose it were straight, and stood perpendicularly, it is evident that when we alighted on our feet it would recoil with a sudden jerk, like a straight steel spring pressed between the hands, from its extremities. In such a case, the weight bearing equally, the spine would nelther yield to one side or the other, and consequently, there would be a resistance, from the pressure on all sides being balanced. But shaped as it is, we find it constantly yielding in the direction of its curves; the pressure is of necessity more on one side of the column than on the other, and its elasticity is immediately in operation without a jerk. It yields, recoils, and so forms the most perfect spring, admirably calculated to carry the head without jar or injury of any kind,

31. When we reflect that the spinal column is composed of so many separate parts, so nicely adapted to each other, and kept in place by such a complicated array of ligaments, tendons, and muscles, we might expect that injuries and diseases of the structure would be very frequent. But fortu. nately this is not the case, except where undue restraint and confinement are imposed; and it is only within a few years 
since a change has been introduced into the system of edu. cation for young ladies, that the spine disease, so called, has become a common affection.

32. Every one who has paid the least attention to physiology, is aware that a certain degree of exercise is as necessary to the growth and strength of the body, and of every part of it, as nourishment itself; and that if such exercise be withheld during the period of growth, the body never acquires its due form and proportions, and often is permanently crippled. How cruel it is, then, to repress that overflow of life and energy, which nature has given to young creatures, to prompt them to that exertion which is necessary to the full development of their physical powers ; and instead of allowing the young of both sexes to jump, and skip, and dance, and play, as nature dictates, to curb all propensity to such vulgar activity, for fear that they may not receive the praise of being well-bred. How preposterous, unnatural, and ruinous is the practice of confining delicate females for hours together every day to sedentary employment, the sure consequence of which will be, weakness of the body generally, and of the back in particular, especially if the seat be a stool which has no back, or even a narrow chair with a perpen. dicular back.

33. The effect of such a practice is, that in consequence of the fatigue induced by such a posture, the spine gives way in some part and bends, and in a little time the curvature becomes permanent. And often when a bend has taken place in one direction, there immediately follows an opposite bend above or below, to keep the centre of gravity of the body always directly over the base; the eurve accordingly thus becomes double, like an italic $\int$, and the distortion is rendered complete.

34. The means employed to remedy this affection almost invariably make it worse. In the first place, strong, stiff stays are put on, to support the back, as it is said; and sa they do, perhaps, while they are on; but as they supersedo 
the action of the muscles, placed there by nature as the sup. ports, they cause these to lose their strength, and when the stays are withdrawn, the muscles are found too weak to sup port the body. Other mechanical expedients may now be employed, the back may be forcibly stretched by pullies, or the patient may be kept all day and night lying on an inclin. ed plane. The victim of fashion may next, perhaps, be placed under the charge of a regular spine doctor, who, by means of pulleys, screws, paddings, stays, and close confinement, destroys what little chance there still remains of a cure. A decline now sets in, and the sufferer sinks into an early grave.

35. Dr. Arnott justly remarks, - " it would be accounted madness to attempt to improve the strength and shape of a young race horse or grey hound, by binding tight splints or stays round its beautiful young body, and then tying it up in a stall; but this is the kind of absurdity and cruelty which has been so commonly practised in this country towards what may well be called the most faultless of created beings." This disease may always be prevented by suitable exercise, and the same remedy so applied, as directly to strengthen the affected part, will hold out the best prospect of a cure, Boys never suffer from the spine disease, because steel and whalebone in them are never made to perform the office which God designed for the bones and muscles.).

36. The Chest. - The thorax, or chest extends above from the first bone of the neck, by which it is connected with the head, to the diaphragm below, by which it is divided from the abdomen. It is composed of bones, muscles, and cartilages, so disposed as to sustain and protect the most vital parts, the heart and lungs, and to turn and twist with perfect facility in every motion of the body, and to be constantly in motion in the act of respiration, without the least cessation during a whole life. In front, the chest is bounded by the sternum, or breast-bone; behind by the spinal column, or back.bone, and at the sides by the ribs. Below, the 
diaphragm forms a membranous partition between it and the cavity of the abdomen. It is conical in shape, with its apex above, where, indeed, it is so contracted, that there is barely room in the aperture to contain the tubes which go to the lungs and stomach, and for the larger blood-vessels that go and come from the heart?

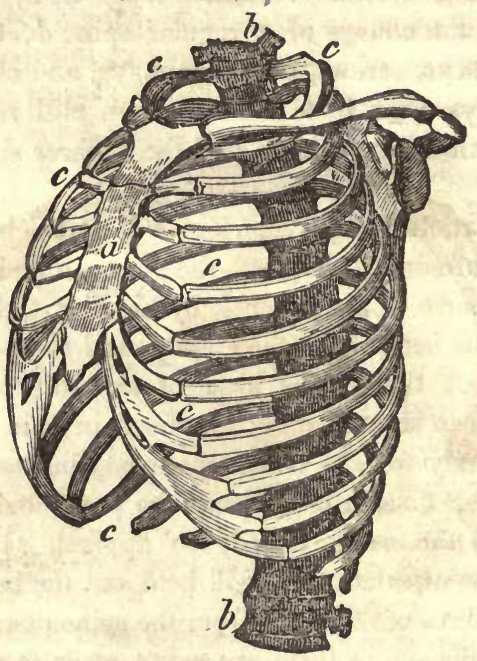

Thorax or chest ; $a$, the sternum; $b, b$, the spine; $c, c$, the ribs, the cartilages being in front.

37. The ribs are 24 in number, twelve on each side, of which the seven upper are united to the sternum by cartilage, and are called true ribs; ( the cartilages of the other five are united with each other, and are not attached to the sternum; these are called false ribs); all of them are connected behind to the spinal column. The ribs increase in length as far as the seventh, by which the cavity of the chest is enlarged ; from the seventh, they successively diminish in length, thus diminishing the cavity. The direction 
of the ribs from above downwards is oblique, forming, as it were, a bundle of hoops playing on each other.

38. The curve of the ribs diminishes considerably from the first to the twelfth; the second, however, is usually moro curved than the first. The inferior ribs are very flat; the twelfth is sometimes straight. The external surface of each rib is convex, the internal concave. Each rib on its outer surface near the spine presents an oblique ridge, occasioned by the insertion of a muscle; and at this point there is a curvature somewhat abrupt, called the angle of the rib.

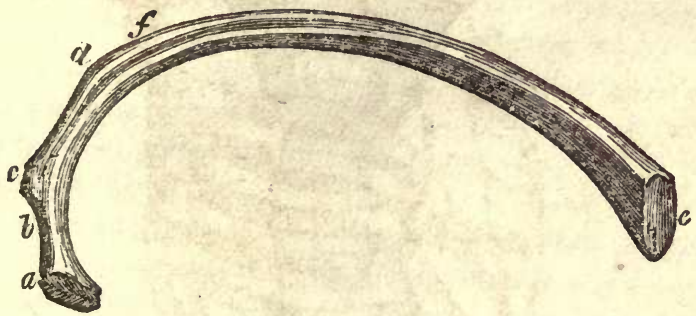

Fourth rib; $a$, vertebral extremity, called the head, which is connect. ed with the bodics of the two contiguous dorsal vertebrae. At $b$, the bone is contracted, forming the neck; $c$, is the tubercle at the back of the rib, which is articulated with the transverse process of the vertebrae; $d$, the angle ; $e$, the stornal extremity; $f$, a groove for the inter. costal vessels. This will serve for a general description of the ribs.

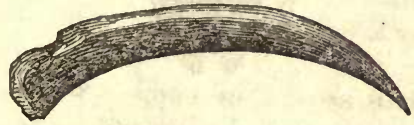

Twelfh rib, nearly straight.

39. Sternum. - Between the forward ends of the ribs, directly in front of the chest, lies the sternum, or breastbone.) It is light and spongy, depending chiefly for its strength on the numerous ligaments which cover it. In the child, it is divided into eight pieces by cartilaginous portions, 
which as life advances, are reduced to three; and, in old age, are united into one. It terminates below in a sharppointed cartilage, which lies over the stomach, and may be felt externally. It is somewhat hollowed beneath at its upper end for the passage of the treachea or wind-pipe, which lies directly under it; and on each side there are seven oval depressions for admitting the cartilaginous ex. tremities of the first seven ribs.

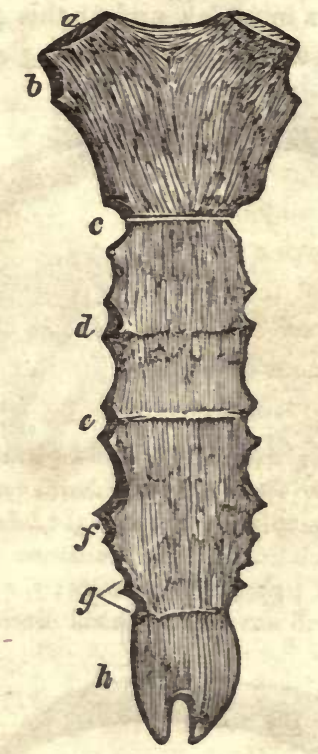

40. The sternum in this cut consists of two bones. The first is broad and thick above, and contracts as it descends. It is convex before and concave behind. At the upper angle $a$, the collar-bone is articulated; $b$, the articular surface for the cartilage of the first rib; $b$, for second rib; $c, d, e, f, g$, mark the articular surfaces of the $3 \mathrm{~d}, 4 \mathrm{th}, 5$ th, 6 th, and 7 th ribs; $h$, the ensiform cartilage, terminates the lower extrem. 
ity of the sternum. In old pcople, this cartilage is often changed into bone.

41. The manner in which the ribs are attached to the sternum by means of slips of elastic cartilage, is worthy of particular notice. (It is to this circumstance that it is owing, that the ribs are so seldom injured by blows and falls; for if they were wholly bone from one extremity to the other, life would be endangered by any accidental fracture, and even the rubs and jolts to which we are continually exposed, would be too much for their delicate and brittle texture. When we lean forward or to one side, the ribs accommodate themselves not by a change of form in the bones, but by the bending of the cartilages. It is owing to this elasticity that the blows of boxers so seldom succeed in fracturing the ribs; as they yield in proportion to the violence of the force in. flicted. But this is not the case in old age. Then the car. tilages of the ribs become bony, and the whole arch unyielding and inelastic; so that blows which formerly would have caused little or no injury, are now attended with fracture of the rib. The influence of the elastic structure of the ribs, in the action of breathing, is highly interesting and important, and will be fully explained when we come to treat of Respiration.)

42. (The next division of the trunk is called the pelvis or basin, which (consists of a circle of large firm bones, situated between the lower portion of the trunk and the inferior extremities. They are the sacrum, the coccyx, the ilium, the ischium, and the pubis. The ilium forms the upper, the ischium the lower, while the pubis is situated at the fore part of the pelvis; and each one of these bones contributes to form the large and deep socket, for the head of the thigh bone. (The pelvis not only affords lodgment for the organs contained within its cavity, but it also sustains the entire weight of the body, and furnishes sockets for the heads of the thigh bones to roll in, and a broad surface for numerous mus. oles to spring from, 


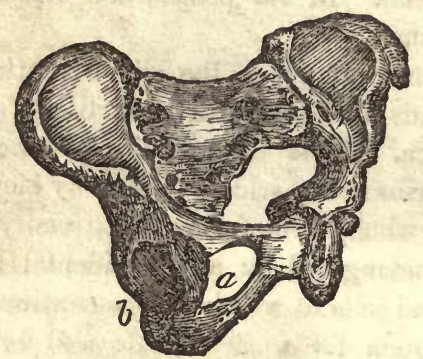

The pelvis.

43. The last division of the body comprehends the upper and lower extremities, The upper consist of the sheulder, arm, fore-arm, and hand. The bones composing the shoulder are two, the clavicle, or collar bone, and the scapula, or the blade bone (The clavicle, named from its resemblance to a $k e y$, resembles the italic $s$, and extends across the upper part of the chest, from the shoulder to the breast bone, and it serves not only to sustain the upper extremity and connect it with the chest, but also to prevent its falling forward upon the thorax, and to afford a fixed point for steadying the arm in the performance of its various actions.

44. (The scapula, or shoulder blade, is a large, flat, triangular bone placed upon the upper and back part of the chest, and extends from the second to the seventh ribs. It lies embedded in muscles, and has no connection with any other bone except the clavicle at a single point. It is separated from the thorax by a double layer of muscles, on which it is placed as on a cushion. (It serves for the attachment of sixteen muscles which go to the ribs, the bone of the tongue, the arm, the head, and the spine. It thus serves not only as a support, but a fulcrum for every action of the superior extremity, 


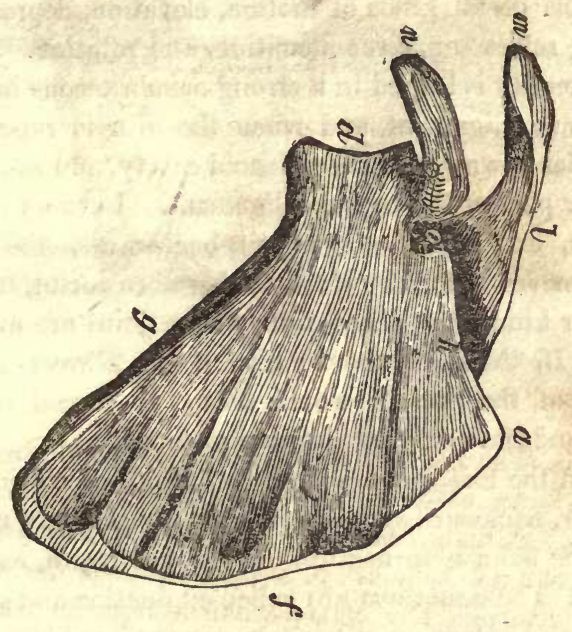

Scapula. $a$, superior angle; $d$, the glenoid cavity, or socket for the round head of the arm bone; $m$, the aeromion process : $n$, the coracoid process, which serve to protect the joint; $f$, the base; $g$, the costa, or inferior border, and $h$, the superior border of the triangle; $l$, the spine; $o$, the semi-lunar notch, for the passage of an artery, vein, and nerve.

45. As a general rule, in the joints, strength and security are sacrificed, in some degree, to obtain great freedom and latitude of motion. Accordingly, we find that the shoulder joint, which allows of more extensive motion than any other, is also more frequently dislocated. In the hinge joints, such as the knee and ankle, such an accident is comparatively rare. Where a bone is dislocated, a regularly educated surgeon should, if possible, always be employed to reduce it, as there is great danger in trusting to a natural bone-setter, so called, who is entirely ignorant of the anatomy of the parts. 46. The os humeri, or arm bone, is of a cylindrical shape, and forms at the elbow a perfect hinge-joint with the two 
bones of the fore-arm, called radius and ulna.)(This bone is susceptible of all kinds of motion, elevation, depression, advancing, retreating, circumlocution, and rotation. Its scapular extremity is lodged in a strong membraneous bag, called the capsular ligament, and when the arm is raised up, the bone slides downward in the glenoid cavity, and thus distends the lower part of the capsular ligament. In every motion of the arm, except in carrying it backwards, the scapular readily moves or follows it; it is therefore during motions of the latter kind, that dislocations of the joint are most apt to occur. If, therefore, the scapula could always follow the motions of the arm, it would rarely be forced out of its socket, and then only by extreme violence.

47. In the fore-arm we find two kinds of motion, one at the elbow, backward and forward, and also a rotary motion, by which the palm is turned upward or downward, as occasion requires. These motions are called supination and pronation. Flexion and extension of the arm are performed by means of the ulna, which being articulated, with the os humeri, by a hinge joint, carries the radius along with it in all its move. ments. Now while the larger part of the ulna is above, the larger part of the radius is below, so that while the former presents a large surface for articulation at the elbow, the latter does the same at the wrist, and this inverse arrangement also contributes to the uniform diameter of the fore-arm. While the fore-arm is thus attached to the os humeri, the radius is attached to the wrist; so that when we turn the palm of the hand, the radius rolls on the ulna carrying the hand with it. Indeed so admirable is this contrivance, that both motions may be performed at the same time, for while we are bending the arm, we may also be rotating or turning it upon its axis. To facilitate these motions, it will be observed that near the elbow, a tubercle of the radius plays into a socket of the ulna, whilst near the wrist, the radius finds the socket, and the ulna the tubercle. 

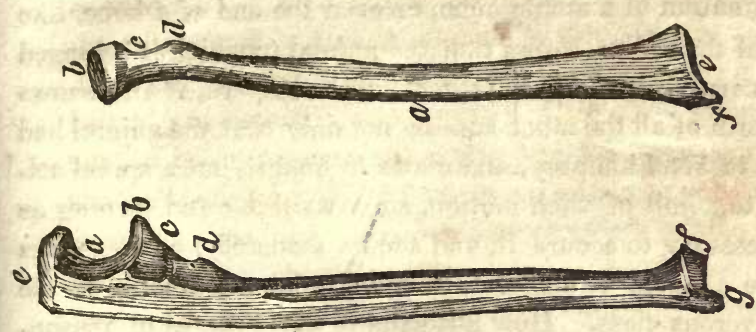

$g$, the ulna; $a$, the radius.

48. It has been remarked that the ulna has a hooked pro. cess, the olecranon, $e$, which catches round the lower end of the humerus, forming with it a hinge joint. The radius also, has a neat, small, round head, $b$, bound to the ulna by ligaments, which, as it turns, carries the hand, which is attached to its lower extremity along with it. Now in animals that have solid hoofs, such a motion would be useless and a source of weakness, accordingly we find these bones united together and consolidated in such animals. (By an examination of these bones alone, the anatomist is able to determine whether the animal to which they belonged, perhaps thousands of years ago, was carniverous or graminiverous, that is, whether he was an animal or a vegetable feeder; whether he had claws or hoofs. If he finds merely the end of the radius, and notices in it a smooth depression where it bears against the humerus, and the smooth surface that turns on the cavity of the ulna, he concludes at once, that the animal had a paw, and a motion of the wrist which implies claws. It was in this way that Cuvier and Buckland made those singular and interesting discoveries in relation to antediluvian fossil bones, which have given such importance to geological researches.

49. But let us examine this point a little further. If the $8 *$ 
examination of a single bone, or even the end of a bone, like that of the radius, shows that the animal to which it belonged was carniverous, like the tiger, lion or leopard, it also shows the form of all the other bones; not only that the animal had teeth to rend his prey, and claws to hold it, but a spinal col. umn to admit of such motion, such writhing and turning as is necessary to secure it, and such a stomach and intestines as are adapted to digest it, in short, such as belong to the carniverous class. How beautiful is that process of reasoning, and how interesting that science which enables us from a small portion of a skeleton, to determine the existence of a carniverous animal, of a fowl, or a bat, a lizard, or a fish; which teach us the wisdom and the extent of that plan, which adapts the members of every creature to its proper office; which exhibits a system extending through the whole range of animated beings, whose motions are conducted by the operation of muscles and bones.

50. Twenty-nine bones enter into the composition of the human hand, of which eight constitute the wrist. The metacarpal bones support the fingers, and are four in number, the thumb being directly articulated with the wrist. From this arrangement there results great strength, mobility, and elasticity. Indeed, it may be said, that on the length, strength, free lateral motion, and perfect mobility of the thumb, depends the power of the human hand. In strength it is said to be equal to that of all the fingers, hence it is called pollex, from "pollere," to have much strength. If we examine the thumb of the monkey, we find that it extends no farther than to the root of the fingers. (The fingers would be comparatively of little use, were it not for the fleshy bed of the thumb. ? 


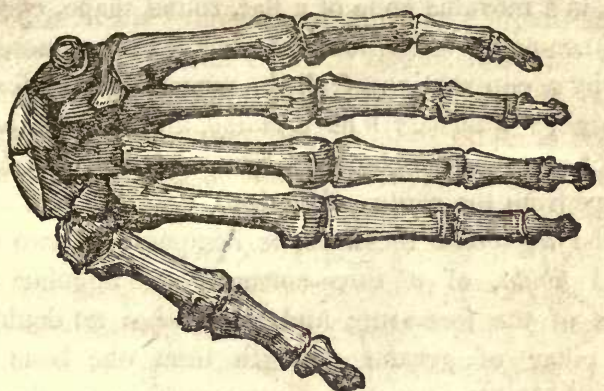

Bones of the hand.

51. (The bones of the lower extremity consist of the thigh, leg and foot.) The thigh bone (os femoris, is the longest bone of the human skeleton, and is remarkable for its great strength, supporting, as it does, the whole body, and often several hundred pounds in addition. (The hip joint is a perfect specimen of the ball and socket joint. This is for the purpose of giving great extent and variety of motion to the legs, as in walking. The end of the hip bone is perfectly round like a ball, and covered with a smooth, shining cartilage; and this is received into a deep cup, also lined with cartilage and moistened with the synovial fluid. Besides all this, there are strong ligaments all around, binding the bone firmly in its place, so that it is a very rare thing for it to be dislocated.

52. The knee is a hinge joint of singular construction. The rubbing parts are flat and shallow, and therefore would easily get out of place, were it not for the very strong liga. ments which surround it. When the ligaments on the inside of the joint are too weak, a person is said to be knock-kneed, because the knees knock together. In weakly children, this deformity may frequently be cured by exercise. It can also be shown that, owing to the air being completely shut out of the joint, forming what is called a vacuum, the bones of the knee are held together by a constant pressure of the atmos. phere equal to sixty or seventy pounds. On the fore-part of 
the knee, is a movable bone of a flat, round shape, called $p a$ tella, or knee-pan, over which a cord or tendon passes, which is made by a contraction of all the muscles on the fore part of the thigh. This serves as a pulley, and enables the mus. cles to act to greater advantage, by increasing the distance of the rope from the centre of motion.

53. (The leg below the knee, is composed of two bones, tibia and fibula, of a three-cornered or angular shape, like those of the fore-arm; and the design no doubt is, to form a pillar of greater strength than one bone would make; and also to furnish a greater surface for the origin and attachment of the numerous muscles required for the feet.) (The ankle, like the wrist, the clbow, and the knee, is a perfect hinge of great strength. In front of it there is a narrow strap, or ligament, which binds down the cords which go to move the toes. There is a small groove just within the inner ankle, for the passage of a tendon, exactly like a little pulley? The heel is a lever for those strong mus. cles to act by, which form the calf of the leg. It is the action of these muscles, pulling on the heel, that lifts the body, in walking, dancing, standing on the toes, \&c. In the negro, the heel is longer than in any other race of mankind.

54. The bones of the foot are divided into the tarsus, which is composed of seven bones, reaching from the heel to the middle of the foot.) The metatarsus consists of five long bones, parallel to each other, which extend from the tarsus to the roots of the toes. The bones of the toes are called phalanges, from being in the form of a phalanx. There are in all thirty-six bones in the foot, and as each bone forms a joint, and as each joint (not only permits motion, but bestows elasticity, the obvious design of this number is to render the foot elastic, and thus save the body from shocks. It should be recollected that each bone is tipped with cartilage, that the fibres composing cartilage are disposed longitudinally or perpendicularly to the surface of the bone and the pressure made upon it ; thus acting like 
an infinite number of springs of the most delicate structure. Besides this, the foot is a double arch; (it is arched from the toes to the heel, and from side to side, and the bones are so wedged together, and bound to each other by ligaments, that solidity is combined with elasticity and lightness.)

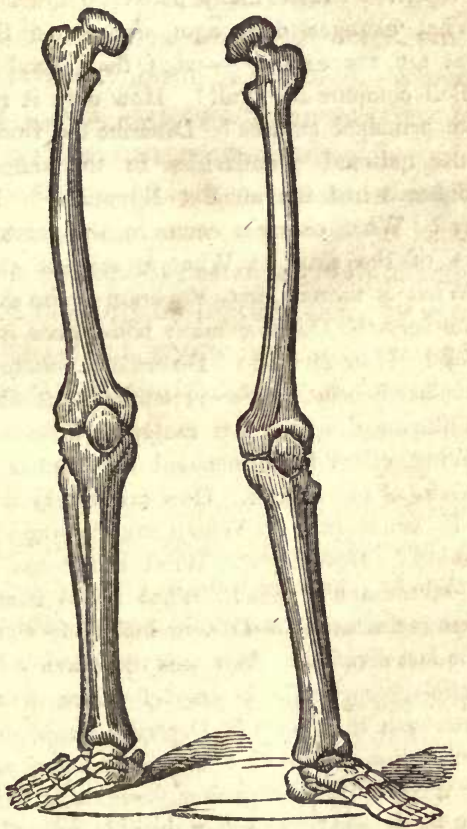

55. In reviewing the human skeleton, we cannot but remark the nice adaptation of all the parts to each other, and to the shares which they have respectively to bear; how the objects of strength and lightness are combined, and how the nature and strength of material in different parts are so admirably adapted to the purposes which the parts are designed to serve. No one can contemplate the marks of wisdom and design displayed in the osseous fabric, without being led insensibly to acknowledge the hand of an all-wise and benevolent Master Builder. 
Questions.-Of how many bones does the human skeleton consist ? How are they divided? What is a natural skeleton? What an artificial ? What uses does the skeleton serve? What bones are said to be symmetrical? How many bones are there in the head? -in the trunk -in the upper extremities? in the lower? How does the skeleton compare with works of human art? How is the brain protected from injuries? How many plates do the bones of the skull contain? What changes does age produce in the bones of the skull? What are the sutures? - what their use? To what does Sir Charles Bell compare the skull? How does it resemble a dome? What are the principal sutures? Describe the frontal bone. What is said of the national peculiarities in the shape of the head? What shaped heads had the ancient Egyptians? Does the texture of skulls vary? What changes occur in the thickness and weight of the bones of the skull ? What is said of the cavity of the cranium? What is formed first, the brain or the skull? What uses does the spine serve? Of how many bones does it consist ? What are they called? How divided? Describe a vertebra. What sort of substance is placed between the vertebrae?-its use? Why is the spine curved like an $f$ ? What is the spine disease?-its causes ? its cure? What effect have mechanical remedies? Do boys ever have it? Describe the thorax. How many ribs are there? What are true ribs? What false? Which are the largest? Where is the sternum situated? Deseribe it. What is the use of the cartilages between the sternum and ribs? What is the next division of the trunk? What is the pelvis?-Of how many bones composed? What its use? The last division? Where is the clavicle?-its use? Describe the scapula,-its use? Is great freedom of motion compatible with great strength in a joint? Describe the os humeri. Of how many kinds of motion susceptible? Describe the fore arm?-the radius? -the ulna. What is the contrivance for rotating the arm? What is the olecranon?-its use? In graminiverous animals, how are these bones constructed? How can the anatomist tell to what kind of animal any bone belongs? How many bones are there in the hand ? -how many in the wrist? What is said of the thumb?-Of the fingers? What are the bones of the lower extremity? Describe the hip joint? - the knee. Does the pressure of the atmosphere affect the joints If Describe the leg below the knee? - the ankle. How are the bones of the foot divided? How many bones in the tarsus? - the metatarsus ?-the phalanges f-the foot? What is the use of so many bones? What is the use of the arched form of the foot? 


\section{CHAPTER VII.}

\section{PROPERTIES OF ANIMAL BODIES.}

1. There are various properties which distinguish living from dead animal matter. Both, in common, possess certain physical properties, such as weight, extensibility, flexibility, \&c. ; but living matter has certain physiological or vital properties peculiar to it.) It is these which bring it under the influence of external agents.

2. (All the phenomena of life are the effect of impressions made upon the various organs of the body, by external or internal agents: and each organ has its own proper stimulus. Thus the eye is stimulated by light; the ear by sound, the nose by odours, the organs of taste by condiments, \&c.

3. The chick in its shell is developed by the influence of heat the seed germinates under the combined effect of warmth and moisture; and so the growth of the human body requires the application of the appropriate stimulants, such as food, drink, air, exercise, \&c.

4. Every tissue and organ has its own mode of activity. For example, the lungs react under the influence of the air ; the heart under that of the blood ; the muscles under that of the will; the stomach under that of food, \&c. Every gland, though supplied by the same blood, is excited to secrete or form that particular fluid for which it was so designed; and why the liver does not secrete urine and the kidneys bile, it were useless to inquire.

5. This property of living matter has three principal modifications in the solids and fluids, which have been called (sensitive, motive, and alterative.) By the sensitive powers, are meant sensibility and its modifications the motive are contractility and expansibility; the alterative are those which 
preside over the formation and nutrition of the different organs and tissues of the body?

6. (Sensibility belongs exclusively to animals provided with a nervous system) It enables us to receive impressions from external objects, or from changes going on in our own bodies; and to the accuracy of this power, we owe our ability to guard ourselves against the influence of noxious agents.

7. Sensibility may be divided into two kinds, general and special.) (By general sensibility is meant, that universal sense, of which we are conscious over the whole body, in the mouth, \&c. The same also exists in the interior of the body, and conveys to the mind a knowledge of the wants of the system; and when disease attacks any part, it immedi. ately apprizes us of the danger, in order that we may take early measures to remove it) (By special sensibility, we mean that property which renders the eye sensible to light, the ear to sound, \&c. Every organ has its own special sensibility

8. (The brain is the common centre of sensibility, both general and special) No impression can be felt on any part or organ, unless it has a connection with the brain. If the nerves going from that organ are divided, or if their function is lost from palsy or any cause whatever, there can be no sensation perceived, as none is excited.

9. By perception is meant, the faculty which the brain has of perceiving or taking notice of these impressions? Perception and thought then, are owing to the property of matter, called sensibility. Without it, we would be like stocks or stones, alike unconscious of pleasure or of pain.

10. According to some physiologists, there is another kind of sensibility, which is termed organic. This resides in the several internal organs, where it is called into exercise, and does not require the action of the brain.) It depends for nervous influence upon the great sympathetic nerve. That such a kind of sensibility exists is very probable, but 
we have no proof of its existence in our own feelings and consciousness, as we have of the other kinds of sensibility.

11. By organic sensibility, we mean that the stomach is sensible to food, the heart to the blood, \&c. ; and that this feeling is confined to the organ and not transmitted to the brain. It presides over the process of digestion, circulation, secretion, absorption, and nutrition.

12. Although the internal organs of the body are not sensible to the presence of the fluids or solids with which they are usually in contact, yet if foreign bodies are brought in contact with them, or substances calculated to injure them, we are immediately made sensible of it. Thus let a person drink a quantity of brandy, or spirits, to which he is not accustomed, and he will at once feel a sensation of heat in the region of the stomach, altogether unnatural to that organ. This proves that ardent spirits are not designed for the drink of man, and are therefore hurtful.

13. Certain parts of the body, which, in a healthy state, are nearly insensible; yet, by disease, (become the seats of acute pain. This is particularly the case with the bones, cartilages, and ligaments-parts usually wholly destitute of feeling.

14. Contractility, or the property of contracting, is the chief motive power of the system.) It exists in various degrees, in different kinds of animal matter. (That element which pos. sesses it in the greatest degree is fibrin and those tissues which have the most fibrin, have the greatest degree of con. tractility. The same is true of muscles, for the heart, which is in constant motion, is almost pure fibrin.

15. It is supposed that the coagulation of the blood is owing to this contractile power of fibrin. In the living vessels, the blood is kept fluid by the vital influence of the walls of the vessels themselves; but as soon as it is withdrawn from this influence, the particles of fibrin immediately rush together and form a solid mass.

16. Those tissues which contain but little fibrin and are 
made up mostly of gelatine, as the membranes, cartilages, skin, vessels, \&c., have but a slight degree of contractility; that they possess it, in some measure, is evident from the contraction of blood-vessels by the application of stimulants.

17. (There are two modifications of contractility); one of which depends for its exercise on the brain, and the other does not. For example, if we wish to bend the arm, we have but to transmit to the muscles of the arm, through the nerves with which it is supplied from the brain, a volition, or act of the will, to that effect, and the arm bends. Here we perceive that the influence of the brain is necessary to contractility or motion.

18. When certain muscles are deprived of this power of contracting, they are said to be paralyzed, or the limb is called paralytic. When they have it in excess, they are in a state of spasm, or convulsion We see such a state often brought on by excessive drinking. There is no cure for this but by entirely breaking off the habit.

19. The other kind of contractility belongs to every part of the body. It does not depend for its existence on the brain, nor is it at all under the influence of the will, or accompanied with consciousness. Thus the heart and the stomach contract constantly under the application of their proper stimuli, but the brain is not conscious of it; their action is entirely beyond its jurisdiction. This form of contractility has been called insensible.

20. It is owing to the inscnsible, organic contractility, that the blood circulates in the capilary vessels; the lymph and the chyle in the absorbents and lacteals, and all the secreted fluids through the vessels that prepare them. In all animals destitute of a heart, the fluids can only be moved by this insensible contractile power. A similar force is supposed to exist in the vessels of plants.

21. These two kinds of contractility, viz., the sensible and insensible, have been compared to the hour and minute hands on the dial of a clock, which are both moved by the 
same power; yet the motion of one is insensible to the eye, while that of the other is distinctly visible.

22. By means of the alterative powers, all the changes which take place in the composition of the solids and fluids of the body are effected. By these, the food is changed into chyme, and then into chyle; chyle into blood, and blood into bone, muscle, cartilage, \&c. By these, animal heat is preserved uniform ; and the solids preserve their cohesion, and the fluids their fluidity) In short, it is these powers that for a time successfully resist the agency of chemical laws.

23. Some physiologists attempt to account for every thing that takes place in the body, on chemical or mechanical principles. But the vital laws, or organic forces, form compounds which could never be produced by chemical affinity. In fact, they are antagonistic forces, fighting against each other. 'The chemist can decompose blood, bile, saliva, albumen, gelatine, and fibrin, but he can not re.form one of them. He can no more make a piece of bone, than he can make a diamond.

24. The physical properties of the animal tissues are usually reckoned as five in number, viz. (elasticity, extensibil. ity, flexibility, imbibition, and evaporation. $)$

25. (Elasticity is one of the physical properties of animal matter. It is that power which tends to restore parts that have been stretched of extended to their former state. It is possessed in the greatest degree by the cellular tissue, which enters largely into the composition of all the structures in the body. All the organs and membranes of the body are in a constant state of extension. All the hollow organs, as the stomach, gall-bladder, and blood-vessels are kept distended by the volume of their contents. The extensor and flexor muscles, when in a state of inaction, are in a state of extension. If such were not the case, all the organs would contract and shrink to a comparatively small size)

26. When the stomach is empty, its sides contract till they almost touch each other. When a muscle is cut, the 
wound gapes open, owing to the two parts receding. The cartilages of the ribs are highly elastic, and this facilitates much the function of respiration. The same is true of the substance of the lungs themselves. The cartilages between the bones and the spine are highly elastic. The loss of this elasticity makes a difference of an inch or more between the height of a man in the morning and at evening. It is not unusual for a very tall person to lose an inch in height by dancing all the evening. "During sleep, the force of elasticity restores these cartilages to their usual dimensions.

27. The elasticity of the arteries contributes much to the circulation of the blood. The blood as.it is forced into these vessels, is constantly reacted upon, by their elastic coats, and in this way driven along towards their termination in the capillary vessels. The same power assists in circulating the lymph and chyle in the vessels which contain them. It is the last function that ceases to act, and it is not wholly destroyed even at death.

28. Flexibility and extensibility are properties existing in various degrees in different parts of the body. The ligaments, or little bands, which tie together the bones, are more flexible than any other part. By observing the astonishing feats of the rope-dancer, we see how flexible these parts are. The tendons which connect muscles with the bones they move, are capable of little, if any extension. If they stretch. ed, when the muscles to which they belong contract, the limbs would not move, and the moving force would thus be lost.]

29. Imbibition, is another power possessed by living animal bodies. (It means the act of drinking in, or taking up fluids, which may be in contact with any part. $?$ For example, if a certain fluid be placed in contact with an animal tissue, it will penetrate into the latter, as water would into a sponge, and this property is possessed by all the soft tissues to a greater or less extent. All the serous membranes absorb 
with great facility. The epidermis or cuticle of the skin permits fluids to pass with difficulty. That water is taken up in considerable quantity, however, is proved by the fact, which has often been proved by experiment, that a man increases in weight by remaining for a considerable time in a warm bath.

30. The following experiments prove the nature of this process. (If we fill the intestine of a chicken with milk, and place it in water, we shall see the milk pass through its coats into the water, and the water will pass through in an opposite direction to supply its place. In the same manner, if a bladder be filled with hydrogen gas, and suspended in the air, in a short time it will be found to be mixed with atmospheric air, which has passed through its coats. The result of all the experiments on this subject seems to show, that when any cavity containing a fluid is immersed in another fluid less dense than the former, there is a tendency in the membrane to expel the denser, and absorb the thinner fluid.

31. Many of the animal tissues are indebted for their physical properties to the water they imbibe. If they are deprived of this water, they are unable to perform their proper office and function, until they are again supplied with it. Hence one important reason why the system craves water, and why the want of it produces such distressing effects.

32. (By the functions of man, we understand the operation of the various organs) in other words, his vital actions. Life is made up of a constant series of these actions, from the period of birth to the moment of dissolution. Physiologists have attempted to define life; but the best definition we can give is, that it is an assemblage of actions. Indeed, the essential nature of life is an impenetrable mystery, and not a proper subject for philosophical inquiry. As the fluids are as much endowed with life as the solids, it cannot be said that life is the "effect of 'organization ;" besides, a 
dead man has the same organization as when alive. It is, therefore, far better to confess our ignorance, and say with John Hunter, - "life is a property we do not understand."

33. All the actions or functions of the body are mutually dependent on each other. They constitute a circle, without beginning or end. The motion of the blood depends on the action of the heart and arteries; the action of the heart and arteries depends on the presence of blood. The heart cannot act without the action of the lungs; the lungs can. not act without the action of the heart. Neither lungs nor heart can act without the influence of the brain ; the brain would have no influence, were it not for the action of the lungs and heart.

34. Thus the steam of a steam-engine works a bellows which blows a fire that produces the steam.) It would be as difficult in this case, as in that of the animal functions to say, which of these might be easiest dispensed with. If we spare the bellows, the fire will not burn; if we spare the fire, the steam will not be raised; if we spare the steam, the bellows will not be worked; so that if we spare either fire, bellows, or steam, the machinery must stop. So it is in the human body.

35. The functions which fall within the scope of this work to notice, may be divided into three classes; 1/vital; 2 , nutritive; and 3 , sensorial. (The vital functions are those which are every moment essential to preserve life They also may be considered as three in number, viz: innervation, circulation, and respiration; or the functions of the nervous system, those of the heart, and those of the lungs.

36. The nutritive functions preside over the growth and nutrition of the body, By their influence, the food is as. similated, and becomes a part of our structures; while all the waste materials and worn-out elements are expelled from the system. It thus embraces four functions; digestion, absorption, nutrition, and secretion. 
37. The sensorial functions are sometimes called the functions of relation, because it is through them that we hold communication with the external world. They comprise the sensations, intellectual operations, and voluntary motions.) (It is the sensorial functions that raise man above all other animals In proportion as they are more or less perfect, organized beings ascend or descend in the scale of existence. In the lower animals, they are limited to the circle of physical wants ; but in man, they confer moral and intellectual faculties, which are his noblest attributes.

38. These functions have the brain as their common centre. They can be improved to an almost indefinite degree by education and habit. We see this in the perfection which some of the senses acquire when others are lost; in the gigantic intellect of a Newton or a Locke, whose mental efforts at first were probably as weak as those of other men. In all such cases, individuals acquire superiority chiefly by education and constant practice.

Questions.-How is living animal matter distinguished from dead? What properties are possessed in common? What are the phenomena of life owing to? What developes the chick? What properties does living matter possess? What is understood by the sensitive powers? -the motive?-the alterative? What characterizes animals provided with a nervous system ? How many kinds of sensibility are there? What is meant by general sensibility?-by special? What is the common centre of sensibility? What is perception? What is organic sensibility? Are the internal organs sensible to the presence of their contents How are such parts affected by disease? What is contractility? What element possesses it in a great degree? How many kinds of contractility are there $?$ - When is a limb said to be paralytic? When in spasm? What are the alterative powers? What their use? Is the body under the influence of chemical laws $?^{\text {ma }}$ What are the physical properties of the animal tissues? What office does elasticity perform? Describe its operation in cartilages, arteries, \&c. What are the uses of flexibility and extensibility in the animal body ? What is imbibition? Do the serous mernbranes absorb ? What experiments 
prove imbibition? What are understood by the functions of man? What is life? Are the fluids alive as well as the solids $y$ Are the functions of the body dependent on each other ?M-Mllustrate this dependence? How are the functions divided? What are vital func. tions?-nutritive? - sensorial? What raises man above all other ani. mals ? 


\section{CHAPTER VIII.}

RELATION OF ANIMAL BODIES TO HEAT, LIGHT, AND

ELECTRICITY.

1. The relations which animal bodies have to heat, light, and electricity, are highly interesting, and worthy of particular notice. To a certain extent, all animal bodies have the power of regulating their own temperature, Many of them develope electricity; and some of them, like the lightningbug, and other insects, can produce light. These are singular properties of living animal matter.

2. The heat of animal bodies is produced within them. selves. It is not received from without, nor can it be; as the natural temperature of the body is near 100 degrees; even when the temperature of the surrounding air is below zero. How this is produced we shall inquire when we come to treat especially of animal heat.

3. Plants have a lower temperature than animals, and the higher animals are in the scale of organized beings, so much the more animal heat do they produce. Thus the temperature of what are called the cold-blooded animals, such as fishes, is not much above that of the water in which they live; and although they do not often freeze to death in the winter, yet they become so torpid as to be incapable of mo. tion.)

4. It is a favourite sport in New England in the winter season, to hunt, on skates, for the pickerel, and other fish, which abound in the lakes and ponds; and when found to take them, by cutting through the ice with a hatchet; and to spear them by torchlight at night. Now had they the faculty of producing animal heat, like quadrupeds, or birds, or man, they would not be rendered torpid and incapable of motion by cold. 
5. Living animal bodies have not only the fuculty of pro. ducing heat, but they can also resist heat of a much higher temperature than their own bodies. The heat of the body is kept at its usual standard of 98 degrees, (by the exhalent vessels of the skin, which absorb by means of the perspira. tion the excess of caloric, and fly off with it in a state of vapour

6. In very hot weather, those functions of the body, such as digestion, nutrition, and secretion, on which the produc. tion of animal heat depends, are weakened by the excessive heat, so that in fact less caloric is produced in the system than in cold weather. This is a wise provision of Providence, that when much internal heat is wanted to guard against the cold, it is produced; when less is needed, on account of the warmth, the system generates less.

7. Animal bodies are also capable of developing electricity; as most of the bodies which surround us are conductors of the electric fluid, it generally passes off as fast as it is formed. Sparks of fire, however, are often seen in winter, on taking off in the dark, silk dresses or stockings, or flannel drawers. Some physiologists maintain that the nervous power is nothing but the electric fluid; but though this may not be admitted, there is a very close analngy between them.

8. It has also been found that needles plunged into the middle of a nerve, become magnetic, and are capable of attracting light substances, such as pieces of paper; and a physiologist by the name of Weinhold says, that he has seen sparks obtained by bringing the divided ends of a nerve together. Muller mentions in his late work on Physiology, that efti. cient galvanic piles can be constructed from organic sub. stances, without any concurrence of metals. Concentrated solutions of organic substances were spread upon thin paper, and with disks of this, paper piles constructed, the two layers of different substances being separated by two thicknesses of paper; electricity was developed by these piles, and tested by an electrometer. It would seem from these experiments, 
that the nervous system is capable of developing electricity, under the influence of vitality.

9. Certain fishes, such as the torpedo, the electrical eel, and five or six other species, are provided with special organs for the production of electricity. In the torpedo they consist of a large number of prisms, of from three to six sides, stund. ing close together, near the gills of the fish, and perpendicu. lar to the surface. They are composed of membranous tubes, divided into numerous transverse cells, abundantly supplied with blood vessels and nerves. These vessels are filled with a fluid of an albuminous nature. These organs are connected with the brain by three large nerves on each side)

10. In the gymnotus the electrical apparatus may be compared to a battery of galvanic troughs. Two of these are found on each side of the spine, separated from each other by a long ligument, and extending the whole length of the fish. They are composed of horizontal membranous plates, separated from one another by a small interval, and crossed in a perpendicular direction by membranous partitions, so as to form a great number of cells, which aro filled with a gelatinous fluid. These organs receive numerous branches and nerves from the spinal marrow.

11. The resemblance of these organs to the galvanic pile is very striking. 'The latter çonsists of alternate plates of copper and zinc with a fluid between them. Thus we have in these fishes alternnte layers of membranous partitions and albuminous fluid. But is is worthy of particular notice that these organs lose their electric powers if the nerres which supply them are divided. There can bo no doubt then, that the electric shock which they give is a vital act, depending on a nervous influence, and under the control of the animal's will.

12. The sensation produced by the shock of an electrical fish, is also similar to that of common electricity. It is pow. erful enough to kill small fishes, and is the animal's weapon 
of defence. Sparks also have been seen to attend the discharges; and the shock has been communicated through a chain consisting of several persons with their hands joined.

13. Common electricity, and that produced by the organs of electric animals, are generally believed to be different, but it has lately been discovered by Dr. Davy, that the electric organs of the torpedo affect the galvanometer, render needles magnetic, and decompose water

14. Many animals as well as plants are endowed with phosphorescent properties. Every person almost, has seen rotten wood, or dead fish, shine in the dark; such are phosphorescent. This phenomenon is probably owing to the fact, that during the decomposition of animal or vegetable matter there is formed a highly inflammable compound of carbon, hydrogen, and oxygen, which like phosphorous, burns at the ordinary temperature of the air, with an evolution of light?

15. But several living animals exhibit luminous appearances. Many of the lower order of animals that inhabit the sea, and some fishes, are phosphorescent.) It is this that causes the luminous appearance of the ocean in warm climates. If a ressel be filled with sea-water containing these animalcula they immediately become phosphorescent, on shaking the vessel.

16. It is not uncommon to find insects which have the faculty of phosphorescence in a high degree. It is supposed to reside in a peculiar albuminous principle, secreted by the animal, and that it requires for its manifestation atmospheric air and a certain degree of heat. It is evidently under the control of the animal's will, and probably depends on the nervous action. Some say, however, that it is a peculiar animal matter secreted at will, which, combining with the oxygen of the air gives rise to the disengagement of light.

Questions.-Have bodies the faculty of regulating their own temper- 
ature ? What is said of animal heat? What is the temperature of cold blooded animals? What preserves the heat of the body uniform? Is as much heat produced in the body in hot as in cold weather? Do animal bodies develope electricity. Can galvanic piles be made of animal substances alone 5 What kind of fish are electrical? Describe the electrical apparatus of the torpedo. What is a galvanic pile? What effects have the electrical discharges of the torpedo, \&c.? In what respects like common electricity? What is said of the phosphorescent properties of animals? What animals have this property? What does it depend on? 


\section{CHAPTER IX.}

THE NERVOUS SYSTEM.

The Brain, Spinal Marrow, and Nerves.

1. There is no subject, which falls within the range of physiological enquiry, more interesting or more important, than that of the nervous system. It is this which furnishes the material instrument of thought, the means by which we become acquainted with the external world around us, and also the channels by which the will sends forth its commands to the instruments it employs in their execution.) Besides this, it presides over and regulates the functions of the animal economy, and binds the various organs into one sympathizing, harmonious whole.

2. The nervous system may be considered as embracing, 1st. the brain; $2 \mathrm{~d}$. the medulla oblongata; $3 \mathrm{~d}$. the spinal marrow; 4th. the nerves; 5 th. the ganglia (These are all embraced under two general departments, the first consisting of the brain and its dependencies; and the second, of the ganglia and their nervous connections / / the first appertain. ing particularly to animal life, conveying impressions calculated to produce sensations, and sending out volitions to its servants; the organs destined to receive them; while the second supply those organs not under the influence of the will, viz. of digestion, circulation, respiration, and the secretions.

3. (These two grand divisions of the nervous system, may be still further distinguished by the circumstance, that the first, or cerebral department, is exactly symmetrical, The nerves all go out in pairs from each side of the brain and spinal cord, while the ganglionic system of nerves is distributed irregularly to all the internal organs. The nerves 
of the first kind, are either nerves of sensation or of motion. These nerves, as discovered by Sir Charles Bell, are entirely distinct, the one rarely, if ever, performing the function of the other. Although these nerves are endowed with different properties, the common function of both is, to give us correct intelligence of the relative condition of our existence. When these functions are interrupted, as in apoplexy, or concussion of the brain, , the individual is deprived of all feeling and sensibility, hence they are called the nervous department of external or animal life.) The nervous filaments which furnish the power of motion, (arise from the anterior column of the spinal marrow / while those in which sensation resides, are connected with the posterior column.)

4. The brain fills the cavity of the cranium or skull, and in an adult weighs between three and four pounds. Its greatest length is about six inches, and its breadth five inches, though its dimensions vary greatly in different persons. In infancy its texture is soft, but it grows harder in proportion to the age. (Ihe brain is chiefly composed of two distinct parts, the cerebrum, or brain proper; and the cerebellum, or the little brain. These again are divided, each into two distinet lobest The medulla oblongata is the commencement of the spinal marrow.

5. The brain is surrounded by three membranes; the two inner ones thin and delicate; the outer one thick and firm, and called dura mater) It is a perpendicular fold of the dura mater, and divides the brain into two hemispheres. It adheres loosely to the bones of the skull; the internal perios. teum of which it forms.

6. The other two thin membranes are called arachnoid and pia mater. (The first is a serous membrane, as the dura mater is a fibrous membrane; and forms a completely closed sac or bag. This membrane, which derives its name from its resemblance to a spider's web, spreads over the whole surface of the brain, without dipping into any of its furrows or con- 
volutions, and also forms a sheath for all nerves or blood. vessels that pass out of, or into the brain.)

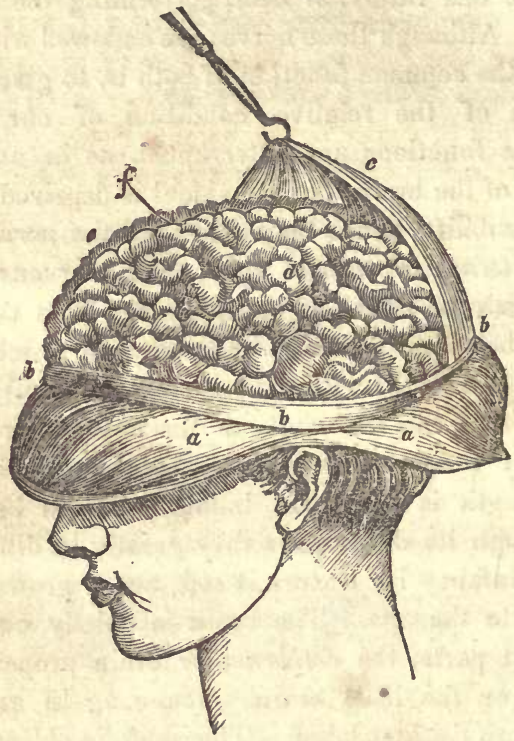

a. The scalp, turned down.

b. The cut cdge of the bones of the skull.

c. The external strong membrane of the brain, (dura mater) sus pended by a hook.

d. The left hemisphcre of the brain, showing its convolutions.

e. The superior edge of the right hemisphere.

$f$. The fissure between the two hemispheres.

7. The pia mater is a loose cellular membrane, composed chiefly of blood vessels, which dips into all the fissures, and wraps round all the convolutions of the brain. The chief use of these membranes seems to be to support the different parts of the brain in their respective places, so that they may not be injured by sudden shocks and jars, or by compression; 
to moisten the brain ; and furnish a medium of transmitting blood vessels and absorbents.)

8. The outside surface of the brain is cut up, or intersected by deep winding fissures, forming numerous irregular eminences called convolutions. These fissures are generally about an inch deep.) The brain on the outer surface, is to a considerable depth of a grey or ash colour; thence it is called the cineritious or ashy portion, and sometimes cortical, from its position, like the bark surrounding a tree. The internal portion is white, and is therefore called the medullary part of the brain

9. The cortical part of the brain which is found on the exterior surface, is on an average about one-sixth of an inch in depth, and dips down every where between the convolutions. Besides its being of a greyish colour, it is of a firmer consistence than the medullary matter. It is full of vessels, and from this circumstance has been supposed to nourish the medullary part.

10. There are four cavities in the substance of the brain, sermed ventricles. Of these the two lateral ventricles are the largest. During life a serous exhalation is constantly going on into their interior, and in health this fluid is absorbed or taken up, as fast as it is secreted. In dropsy of the brain, the water sometimes accumulates in these cavities in im. mense quantities. Not long since, a child, about ten years of age, was exhibited in this city, whose head measured two feet and seven inches in circumference, just above the ears. The head was so heavy he could not raise it from the pillow. This was owing to water in the ventricles. The medullary or white matter of the brain occupies the interior part of that organ. It makes up by far the largest portion, and is fibrous in its structure.

11. The cerebellum or little brain, is situated at the base and back part of the skull, and in weight it is only about one. eighth or ninth part of that of the cerebrum. Like the large brain, it is divided into two lateral halves. It is made up of 
several little lobes, and if the two hemispheres be divided by a knife, a beautiful appearance is presented, resembling the trunk and branches of a tree; composed of the white and grey matter of the brain. From its shape it has been called arbor vita, or tree of life.

12. The Spinal marrow is a round cord of nervous matter which passes down through the spine to the loins. It is di: vided into two equal lateral parts, by a deep fissure or groove, which runs through its whole length both on its front and back surface. Some say that it consists of four distinct columns; others that it is made up of six white strands, two before, two behind, and two on the sides; proceeding from the cerebrum, the restiform bodies, and the cerebellum.

13. There are forty-three pair of nerves, making 86 in all, proceeding from the brain and spinal marrowy These nerves run to every part of the system, conveying, as already stated, all sensations and impressions to the brain, and also volition from the brain, to all the voluntary muscles of the body. Of these, two pair go from the cerebrum, viz., those for smell and sight, or the olfactory and optic ; five pair go from the pons varolii, which is that round mass of nerve, which lies between, and seems to connect the cerebrum and cerebellum. Of these, the third, fourth, and sixth pair go to the muscles of the eye; while the fifth and seventh are dis. tributed over the face.

14. The remaining thirty-six pairs go out from the spinal marrow, viz., five from the medulla oblongata; eight from the cervical ; twelve from the dorsal ; five from the lumbar; and six from the sacral portion of the spinal cord. These nerves supply filaments to every muscular fibre in the system; or pass directly to the organs of sense without sending off twigs; some of them are chiefly employed to form plexuses, or a network of nervous threads, woven closely together, so that it cannot be unravelled. 


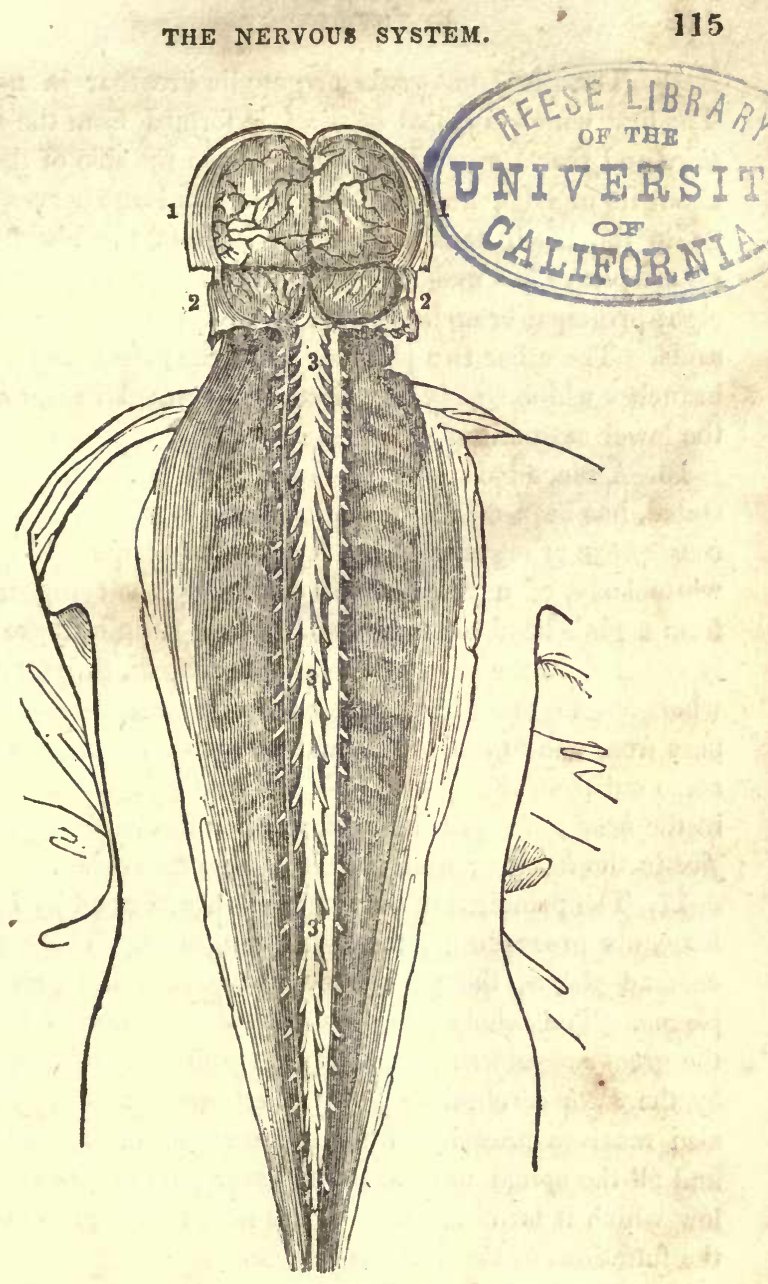

1. Hemispheres of the brain proper, or cerebrum.

2. Hemispheres of the smaller brain, or cerebellum.

3. Spinal cord continuous with the brain, and the spinal nerves pro. ceeding from it on each side. 
15. The chief net-uorks or ganglia are four in number. The first which is called cervical, is formed from the second, third and fourth cervical nerves; lies on the side of the neck about its middle; and it gives rise to four large nerves which go to the head, neck and upper part of the chest. The second plexus lies under the pit of the arm, and gives rise to eight principal branches which go to the chest, shoulder and arms. The other two plexuses lie in the pelvis, and give off branches which supply the viscera contained in it, and also the lower extremities?

16. A second division of the nervous system, as $I$ have stated, has been called by anatomists ganglionic, or the ner. vous system of organic life. (A ganglion is a small grayish white body, of a roundish or oval shape, varying in size, from a pin's head to an almond? These ganglions are chiefly situated on the sides of the spinal column, throughout its whole length, and are connected by nervous threads, which pass from one to the other, and also with the nerves which come out from the spine. (Six of these ganglions are found in the head; three in the neck; twelve in the dorsal region; five in the lumbar; and three in the sacral region?

17. The principal of the plexuses are formed by nervous filaments proceeding from these ganglions. These are the cardiac plexus, the pulmonary plexus, and the great solar plexus. TThe whole ganglionic system of nerves is called the great sympathetic nerve./This is connected with the brain by the sixth cerebral nerve and a branch of the fifth. It also receives branches from the seventh, eighth, and ninth, and all the spinal nerves, to the lower part of the spine, below which it terminates We are now prepared to consider the functions of the nervous system.

18. The brain being the centre of the nervous system, is the most important organ of the human body? (In the lowest order of animals, we find but imperfect rudiments of a nervous system but as we ascend in the scale of animal exist. ence, we find it more and more developed as we advance, till 
at length we arrive at man, who possesses it in its highest form of development. The functions over which the brain presides, are (the sensations, the voluntary motions, and the intellectual and moral faculties.)

19. (The mind itself is immaterial ta principle superadded to matter ; but the brain is the instrument which it employs in all its operations. Though it is not matter, yet it works by means of matter. In like manner, the eye is not sight, but the instrument of sight; the ear is not hearing, but the organ of hearing; so the brain is not mind, but the organ of mind. Revelation teaches us all we know, with respect to the powers and capacities of mind, when separate from the body.

20. The spinal marrow and the nerves are of subordinate importance; as organs of the nervous system, their use seems to be, to transmit impressions from the organs of sense to the brain; or the influence of the brain in a contrary direction to the muscles which are employed for motion.

21. The first class of functions which pertain to the brain are the sensorial. Though the brain is the actual seat of all impressions, yet the organs of sense and the nerves seem to be the immediate seats of sensation. Indeed, no sensation can be excited in any part or organ, unless its nervous connection with the brain be entire. For example, the sense of touch seems to reside in the ends of the fingers, and that of sight in the eye, yet if the nerve which connects these parts with the brain be divided, no impression is felt, no sensation whatever is excited; showing conclusively that it is the brain that perceives all impressions made on the organs of sense.

22. It is a curious fact connected with this subject, that though the brain is the real seat of the sensation, yet it is always referred to the part or organ, on which the impression is made, so that there seems to be a double action, viz., from the organ to the brain, and from the brain back again to the 
organ. Thus it is not unusual to see persons who have lost a limb complaining of pain, or some other sensation in the part which has been cut off, and thus they often imagine that the limb is entire. Here the sensation existed only in the mind ; in the same manner ghosts, hobgoblins, and other strange sights are seen; but the sensation is only in the brain.

23. That the brain is the real seat of all our sensations may be proved from other facts. If a person receives a blow upon the head so as to stun him, or deprive him of consciousness, though the organs of sensation and the senses are wholly uninjured, he takes no notice of any thing; he receives no sensations from any of his senses ; in fact, he is said to be insensible. The same thing happens if he become stupid by the use of alcohol, opium, or any narcotic. If the quantity is not enough to produce entire torpor of the brain, his senses are impaired, his reason is gone; he is in short a voluntary mad-man.

24. During sleep, the senses are said to be locked up. But though the eye is closed, the ear is open; the nerves in which the sense of touch resides, are still spread out upon the skin, but yet no impressions are felt; no sensations are excited; no notice is taken. The reason is, the brain is in a state of repose; the ship does not obey the rudder, because the man at the helm is asleep; the steamboat is not in motion, for although she has furnace, boilors, condensers, paddle-wheels, and all, yet the steam is not up ; so in sleep, the organs of sense are all sound, yet the brain, the rudder of the mind, the moving agent of the animal machine, is dormant; the messages of its servants, the organs of sense, are neither received, noticed, nor acted upon.

25. There is another curious circumstance connected with the brain; (it may be so much employed in thought, or deep meditation, as not to notice the impressions made on the senses, In this case, a person is said to be absent. minded. Though the eyes and ears are open, the brain is 
too busy about other matters, to take notice of the impressions made on them; accordingly, there are instances known, where persons have walked off a precipice, or into the water, without noticing the danger till it was too late.

26. Sensations, then, are the more vivid ; and the impressions which they make, more durable, in proportion to the degree of attention with which the mind is directed towards them; or the degree of activity of the brain. To obtain ideas, which are/the pictures of sensible objects painted on the brain) we must therefore endeavour to concentrate the whole attention upon the subject before us, or the impressions we receive will be weak and speedily fade away. We see a great difference in this respect in different persons. Two individuals will travel together through the same coun. try, and apparently take the same degree of interest in the objects which come under their notice. Yet, while one of these persons will be able to describe minutely every thing he has seen, the other can give only a confused and indistinct account of what he has observed. It is, therefore, not only necessary in the acquisition of knowledge that objects should make an impression on the sensual organs; but the brain must act upon them, and that not in a slight and careless manner, but vividly and energetically.

27. It is possible even that sensations may be excited by the action of the brain itself, without the intervention of any sensible objects. We see this often in diseases of the brain, and especially in that form of insanity, called delirium tremens, or drunken delirium.) Here, the wretched victim of depraved habit sees serpents, and lizards, and bats, and all creeping things, and devils, flying about ; and he hears singing and various sounds, to which he listens, and calls the attention of others, and nothing can break the spell by which he is bound, or dispel the illusory conviction, that what he sees and hears is real and not imaginary.

28. Such illusory and false impressions, are no doubt sometimes excited in the minds of those, who cannot be said 
to labour under actual disease; but their imaginations have been excited by the influence of fear and superstition, and the brain is accordingly excited to act in the same manner as it would by the actual sight of some frightful object. Thus a post will appear in the night, to be a robber; a black stump of a tree, a bear, or a tomb-stone, a ghost; according to the idea or apprehension at the time uppermost in the mind.

29. But though the brain is the seat of sensation, yet it is very remarkable that it is not itself sensible. Wounds in its substance do not seem to excite pain. The whole of the cerebrum as well as the cerebellum has been pared away, and yet the animal appeared to suffer no pain; but as soon as that portion of the base of the brain which seems to be the commencement of the spinal marrow, is touched, con. vulsions immediately follow. The posterior surface of the spinal marrow is also highly sensible. This is the substance of what is yet known on the subject of sensation.

30. Voluntary motion, líke sensation, has also its seat in the brain. Though the muscles are the instruments of motion, yet all their voluntary motions are performed through the influence of the brain, by an act of the will If the brain is in a state of repose the body is at rest; if the brain by an act of violition sends a portion of nervous influence to a voluntary muscle, it immediately contracts, and the limb or organ to which it is attached, moves. All we are conscious of in this process, is, the act of the will and the motion, which that act causes. The volition and the motion seem to be at the same instant; at least there is no perceptible interval between them.

31. But though the voluntary muscles are excited to action through the agency of the brain, yet they are not always under the control of the will. In many diseases of the brain : in lock jaw, hydrophobia, and other disorders where the whole nervous system is in a state of irritation, the muscles are excited to violent spasmodic contraction, alto. 
gether beyond the control of the will. Where convulsions arise from sympathy, as in teething, or irritation of the bowels, the painful impression is transmitted to the brain, and hence reflected back upon the muscles. Thus pricking the finger with a needle has thrown a nervous woman into spasms, by exciting the brain to action.

32. If a nerve which supplies any voluntary muscle be divided, that muscle will no longer contract. This proves that the influence of the brain is necessary. (In palsy, there is generally some disease of the brain, as the rupture of a small blood-vessel, or tumour growing in its substance.) Here the power of the will, or the faculty of volition is not destroyed; but the brain is unable to carry into execution the command of the will, as when a person is very willing to take a load upon his back, but he happens not to have suffi cient strength to carry it.

33. During sleep, all voluntary motion is suspended, be. cause the brain ceases to act. In those cases where persons walk and talk in their sleep, the brain is not entirely dormant. Some of the senses seem to be awake at times, while the others are asleep. That is, those portions of the brain which are excited to action by certain nerves of sense, are awake and active, while other portions are dormant and at rest. The brain needs repose and relaxation, as much as the muscles. Periodical cessation of effort is necessary to both, in order to a vigorous performance of their respective functions.)

Questions.-What functions belong to the nervous system? What does it embrace? How many departments ? What offices does each perform? What marks characterize each? When their functions are interrupted, what happens? From what portion of the spinal mar. row do the nerves of motion arise?-the nerves of sensation? Des. cribe the brain;-its divisions;-its membranes;-dura mater;-pice mater; What are the convolutions of the brain? How do the cine. ritious and medullary portions differ from each other? Which is ex terior? How many cavities in the brain $\%$, What are they called? 
Describe the cerebellum,-the spinal marrow. How many pairs of nerves are there? How many nerves arise from the eerebrum ?from the pons varolii 8 \& from the spinal marrow $\$$ - from the medulla oblon. gata? How many principal ganglia or net-works of nerves 1 t-their situation? What is a ganglion? What are the principal ganglions of the nervous system of organie life? What is the sympathetic nerve? -where situated ? What is the most important organ of the body? What is said of the brain in the lower animals? Over what functions does the brain preșide? Is it immaterial What is the first class of functions over which it presides? What is understood by sensorial functions? What becomes of the senses during sleep ?-during absent. mindedness? What are ideas? Is atter tion neeessary in order to im. press sensations durably on the mind ? without the intervention of sensible objects? In what disease does this happen? Is the brain itself sensible? Where is the seat of voluntary motion? How is it performed? What is volition? Are motions always under the control of the will? In what diseases is this not the case? What effect has the division of a nerve? What happens in palsy? Why is voluntary motion suspended during sleep? 


\section{CHAPTER X.}

\section{INTELLECTUAL AND MORAL FACULTIES.}

1. The great superiority of the intellectual faculties of man over those of other animals, has led to a diligent examination, whether there be any thing in his anatomical struc. ture which would seem to account for this superiority. Aristotle noticed the great size of the human brain compared with that of other animals, andflaid it down as a general principle, that the faculties referred to this organ were in proportion to its size, compared with that of the whole body: Though this rule will hold true in relation to some of the do. mestic animals, yet it does not in relation to many others, for accurate researches have shown that while in man the ratio of the weight of the brain to that of the whole body is as 1 to 28 in the dog, it is as 1 to 160 (in the horse, as 1 to 400) in the elephant, 1 to 500 , a n the canary bird, 1 to 14 , (and in one species of ape, 1 to 11 .)

2. It is now generally admitted by physiologists, that the perfection of the sensitive functions does not depend on the absolute size of the brain, nor on its proportion to the body at large, butfupon the proportion between the size of the brain, and the aggregate bulk of the nerves that proceed from it ; in other words, betwcen the sensorial and nervous organs. For example, the absolute size of the brain of the horse is only about half the size of the human brain, while the mass of the nerves of the horse at their origin is no less than ten times larger than that of man. Extensive observa. tions prove that though most of the inferior animals have larger nerves, and possess some of the nervous functions in a much more acute state than inan, yet man decidedly exceeds them all in the comparative size of the brain, and in the perfection of his intellectual faculties. 
3. The brain then, is the organ of the intellectual and moral faculties, the material instrument of the mind. (This is proved not only by comparative anatomy, and experiments on animals, but by the history of injuries of the brain, com. pared with those of other organs. We know that if the nerves supplying any limb are severed, the will has no longer any influence over it ; it is to all useful purposes a dead portion of matter. The same is true of the spinal marrow. If this be compressed by fracture or dislocation of the spine, the whole body below that point, is deprived both of sensa. tion and motion, but the mind loses none of its powers any more than if a limb had been amputated.

4. If the brain is not the seat of the intellectual faculties, neither are any of the other organs of the body. The lungs, the liver, the spleen, the intestines, or the kidneys, may be affected with gangrene, and still the mind remains clear; though from sympathy, inflammation of any organ may cause delirium, or other mental affections. Neither is the heart the seat of the mind; for cronic disease of that organ, does not impair the mental faculties. Besides the functions of all these organs are known and cannot be mis. taken. If the brain is not the seat of the intellectual faculties, they cannot be said to have any seat in the body.

5. But the effects of injuries of the brain are very different, for every cause which disturbs its action suddenly or slowly, affects at the same time the mind. Inflammation of the brain is always attended with delirium, or stupor); pres. sure on it, whether produced by depressed bone, foreign bodies, a tumour, serum, blood or pus, always gives rise to similar symptoms, and often destroy both sensation and motion. In cases of apoplexy, where a person falls in a fit, and becomes insensible, we find pressure on the brain from effusion of blood or serum. In cases of lunatics, we find in nearly all cronic cases, structural changes in the brain; but if the case be recent, these changes though they probably exist, yet may escape our imperfect means of investigation. Alcohol, opium, and other narcotics affect the mind and the 
nerves through their influence upon the brain. Whenever in fact, we see a person become stupid and insensible, we may be certain that the brain has suffered some physical change; and where in cases of sickness, we see the mental faculties unimpaired to the last, we may be equally sure, that the brain is not affected.

6. The following facts also show that the brain is the organ of the mind. A man received a blow on his head, and immediately lost his mental faculties, and his bodily power. His appetite and digestion were good ; the blood circulated freely; and his breathing and pulse were natural. He con. tinued in this state more than a year, when a surgeon raised up a piece of bone which had been driven in upon the brain. His reason was immediately restored; the next day he spoke, and in a short time he recovered entirely; but he could recollect nothing of what had happened since the accident. Not long since a beggar exhibited himself in Paris, who had lost a portion of his skull ; his brain was only cov. ered by the skin and membranes. For a trifling sum he would allow any one to press on this exposed part. As soon as any pressure was made he became wholly unconscious; but his intellect was immediately restored when the pressure was taken off.

7. (It has been objected to the brain's being considered the seat of the mind, that in some cases, considerable disease has been found affecting an entire hemisphere without the mental faculties having suffered; but experiments on animals show that a sudden lesion of one hemisphere only, does not immediately produce complete stupor, and that this effect does not follow until both are removed; so that it appears that one hemisphere aids the other, and compensates for its inaction in the operations of the mind.

8. But though it is almost universally admitted, that the brain is the seat of the higher intellectual faculties, yet some physiologists, like Bichat, contend that the passions are seated in the thoracic and abdominal viscera. It is, however, 
to be remarked, that the passions, by means of the change which takes place in the brain, affect the whole nervous sys. tem. We find, for example in nervous females, that the exciting passions give rise to spasmodic action of certain muscles, especially those supplied by nerves belonging to the respiratory system; hence the crying, sobbing, sighing, and the spasmodic distortion of the features. In the depressing passions, such as fear and terror, the muscles of the body lose their tone, because the supply of nervous influence from the brain is cut off; the limbs are not able to support the body; the features lose their expression ; and the loss of power may be so great as to cause complete paralysis of the whole body.

9. In like manner is the heart affected by the exciting and depressing passions. IIt throbs irregularly under the influ. ence of far and terror; it beats high and strong under the influence of joy; while its action is weakened under the operation of grief and care; in short, it is affected in a greater or less degree by every emotion which agitates the human breast. But this no more proves that the passions are seated in the heart, than that they are seated in the eye, because grief brings tears into that organ.) Neither has the liver, as the ancients believed, any relation to the passions of rage and vexation, although a fit of jaundice, may, in some persons labouring under a disease of this organ, follow a paroxysm of these passions. In other individuals, a fit of dyspepsia may follow as a consequence of the same emotions; or any other organ, may suffer, according as it is predisposed by debility, disease, or other causes. Such phenome. na only prove that the whole body is bound up in one indissoluble bond of sympathy, or as St. Paul expresses it, "God hath tempered the body together, that there should be no schism in the body, but that the members should have the same care one for another ; so that, whether one member suffer, all the members suffer with it, or one member be honored, all the members rejoice with it."

10. The brain, like all the other organs of the body, in - 
creases in volume, by the exercise of its functions. When the mind is properly cultivated, the brain attains its full growth and development; and where suitable opportunities of education have been enjoyed, the intellectual powers are generally proportioned to the size of this organ. Majendi says, "The volume of the brain is generally in direct proportion to the capacity of the mind." This was also believed by the ancient Greeks ; for their statuaries, or workers in marble, made the heads of their Apollo, and other intellectual gods and heroes, much larger than the heads of their Hercules, and other heroes, who were remarkable only for their great physical strength.) The heads of idiots are known to be extremely small ; some, indeed, are not more than onefifth the average size.

11. That the brain is constructed with evident design, and is composed of a number of curiously wrought parts, all physiologists admit; yet they have not been able thoroughly to penetrate the intention with which they are formed, or to agree with respect to the particular functions which each part performs. (It is, however, pretty well ascertained, that the hemispheres of the large brain, or cerebral lobes, are the instruments by which the intellectual operations are carried on ; in other words, are the seats of the faculties of thinking, memory, and the will; while the central parts, such as the optic lobes, and the medulla oblongata, are principally con. cerned in sensation; and that the cerebellum, or little brain, is the chief sensorial agent in voluntary motion, and the seat of the animal, or lower propensities.

12. Many cruel experiments have been made on living animals, to determine the exact functions of particular parts of the brain ; but so much violence is done in these experi. ments, that but little dependence can be placed on them. Many attempts have been made to determine the exact place in the brain where perception resides, but all such attempts have been fruitless. That it is placed in the base of the brain $n$ r 
the norves of sense terminate in that part; but it is difficult to prove this by actual experiment.

13. (The brain, like all the organs of the senses, is double; the one side, as in the eyes, ears, and limbs, being exactly similar to the other; so that it may be said, that we have two brains as well as two optic nerves, and two eyes. As the structure of the brain is fibrous, in order that the two sets of fibres may co-operate, and constitute a single organ, they pass obliquely across from one side of the brain to the other, and these bridges constitute what are called the commissures of the brain, It follows from this, that if the right side of the brain receives an injury, it will be felt on the opposite side of the body. The following case proves this.

14. (A piece of wire pierced the brain of a boy just over the right eye; he immediately lost all motion in the left arm and leg, although his sense of feeling was as perfect as ever. There are many such cases on record, which conclusively show that the right side of the brain furnishes nerves of sense and motion to the left side of the body ; and the left side of the brain to the right side of the body. If, then, a portion of brain is lost by a wound, on one side of the head only, as has often happened, and the intellect does not suffer; as the brain is a double organ, it does not prove, that it is not the seat of the mental faculties.

15. The office of the cerebellum is supposed by many to be, \{to regulate and combine different motions For example, if the cerebellum be wounded, the animal cannot walk with. out staggering, and there will be a particular weakness on that side which is wounded. When a person is intoxicated, his inability of walking in a straight course, is supposed to be owing to the influence of the alcohol on the cerebellum. In experiments, where the cerebellum has been wounded or divided, the animal has rolled over and over, or whirled round and round; the eyes squinted; and all power of regulating its motions seems to have been lost.

16. Though man is infinitely exalted above the brute 
creation, by the endowments of reason and a moral sense, yet many of the inferior animals excel him in the perfection of subordinate powers. In strength and swiftness, he is sur. passed by many of the quadrupeds; in powers of vision, the eagle and other birds excel him; in acuteness of hearing, taste, and smell, a large number of animals are superior to him. Man is indeed a stranger to those delicate perceptions, which teach the lower animals to seek the food which is salutary, and avoid that which is injurious, and has to depend upon a painful and hazardous experience for that lknowledge which the brutes possess by instinct.

17. "But he has gifts of infinitely higher value. / In the fidelity and tenacity with which impressions are retained in his memory; in the facility and strength with which they are associated ; in grasp of comprehension, in strength of reasoning, in capacity of progressive improvement he leaves all other animals at an immeasurable distance behind. He alone enjoys in perfection the gift of utterance; he alone is able to clothe his thoughts in words; in him alone do we find implanted the desire of examining every department of nature, and the power of extending his views beyond the confines of this globe."

18. "On him alone have the high privileges been bestow. ed of recognising and adoring the Power, the Wisdom, and the Goodness of the Author of the universe, from whom his being has emanated, to whom he owes all the blessings which attend it, and to whom he has been taught to look forward to brighter skies, and to purer and more exalted conditions of existence."

19. Phrenology.-The actual meaning of the term Phren. ology, is "a discourse about the mind," or, " the doctrine of the mind.) It professes indeed to be a system of Mental Philosophy, and as it is pretends to be founded in nature and supported by facts, it certainly is not beneath the attention of the candid inquirer after truth. 
20. The chief ductrines which Phrenology claims to have established are the following :-

1. That the moral and the intellectual faculties are innate.

2. That their exercise, or manifestation, depends on organization.

3. That the brain is the organ of all the propensities, sentiments, and faculties.

4. That the brain is composed of as many particular organs as there are propensities, sentiments, and faculties, which differ essentially from each other. These four pro. positions may be said to constitute the phrenological doctrine, and they are sustained by such numerous experiments, observations, and facts, that a large proportion of enlightened physiologists of the present day acquiesce in their correctness:?

21. Another and a different proposition, however, and one which, by many, is erroneously supposed, alone, to constitute Phrenology, is, that we are able to recognise on the exterior of the skull, the seats of the particular organs, or intellectual and moral faculties, and thus determine the character of individuals. This proposition has not received that general concurrence of Physiologists, in its support, which has attended the former; but there are so many zealous and able inquirers now in the field, and such is the ardour in pursuit of knowledge, connected with this subject, that a few years at farthest, probably, will suffice to overthrow or establish it.

22. I have already mentioned some facts, to prove that the brain is the organ of the mind, and that the condition of that organ influences the mind ; let us now inquire whether the mind, in every act, employs the whole brain as one organ, or whether separate faculties of the mind are connected with distinct portions of the brain as their respective organs ?

23. It is a well established fact in Physiology, that different functions are never performed by the same organ, but that each function has an organ for itself. (Thus the eyes 
see, the ears hear, the tongue tastes, the nose smells, the stomach digests food, the heart circulates the blood, the liver secretes bile, \&c. Even where the function is compound, as in the tongue, where a feeling, taste, and motion are all combined, we find a separate nerve for each function, and the same occurs in every part of the body. Now, as no nerve performs two functions, we may, reasoning from analogy, conclude, that it is so in the brain; different sentiments, different faculties, and different propensities, require for their manifestation different organs or portions of cerebral matter.

24. Again, the external senses have for their exercise, not only separate and external organs, but also as many separate internal organs. Hearing, seeing, smelling, \&c., require different portions of cerebral substance for their exercise ; may we not then from analogy, be justified in the conclusion, that there are as many cerebral, or nervous systems, or organs, as there are special internal senses, and particular intellectual and moral faculties?) (The legitimate inference then is, that each faculty does possess in the brain a nervous organ appropriated to its production, the same as each of the senses has its particular nervous organ.)

25. The structure of the brain is not homogeneous, but differs greatly in different parts, both in composition, form, colour, consistence, and arrangement. But what object could there be in all this variety, if the brain acted as a whole, and there was but a single intellectual principle or faculty? A difference of structure shows that there must be a difference of function, and as the brain has been proved to be the organ of the mind, it follows that different portions or organs of the brain must be employed by the intellectual and moral faculties.

26. The faculties do not all appear at once, nor do they fail at once, but they appear in succession, and as a general rule, the reflecting or reasoning faculties are the latest in arriving at perfection. So also the organization of the brain is un. 
folded in a slow and gradual manner, and the intellectual faculties appear in succession only as the structure is perfected. For example, in infancy, the cerebellum forms one fifteenth of the encephalic mass; in adult age about one sixth. In childhood the middle parts of the forehead preponderate; in later life, the upper lateral regions are more prominent, which facts are also in accordance with the periods of unfold. ing the knowing and reasoning faculties.

27. Genius is almost always partial; that is, men generally have a taste or faculty, for one particular pursuit, or study, in which alone they have the power of excelling. One has a talent for poetry, another for mechanics, another for drawing, music, or mathematics, and that is often developed at a very early age, and without the advantages of educa. tion, or particular instruction, and these persons may, in all other pursuits, be below mediocrity. Indeed, nothing is more common than to see in the same individuals some fac. ulties acute and powerful, while others are feeble and defective; having an extraordinary memory for dates, words, places, \&c., while as to other things it is deficient. Such facts are not easily explained on the scheme of a single in. tellectual faculty, and a single organ devoted to its exercise.

28. It is an observation of common notoriety, that when the mind is fatigued with one kind of occupation or study, it can engage, with vigour, in one of a different kind, requiring the exercise of different faculties; and thus, instead of fatiguing, actually acts as a restorative. Could this happen, unless there were a plurality of faculties and organs of the intellect?

29. The phenomena of partial idiocy and partial insanity are at variance with the doctrine of a single organ of mind. We often see persons in a state of monomania, that is, (they are rational enough on all subjects but one; but in relation to that, they are entirely mad.) Now, if the brain be suffi. ciently sound to manifest all the other faculties in their perfect state, why is it not also able to manifest this? 
30. Numerous cases are contained in medical works where a wound of the brain was succeeded by the loss of a single faculty, and sometimes by exciting inflammation, bestowed unwonted energy on a single faculty. Larrey, in his surgical memoirs, mentions several cases of wounds made by bayonets and swords penetrating the brain through the orbit of the eye, which entailed the loss of memory for names, but not of things, \&c.

31. Such are a few of the arguments adduced by writers on this subject, to prove that the brain is not only the organ of the mind, but an apparatus, a congeries of organs, each of which is the seat of a particular faculty, the organ of a par. ticular function. The evidence to most minds will appear satisfactory and conclusive on this point, though other facts and /more extended investigations are needed to place the science on a permanent foundation.

Questions.-What was Aristotle's theory in relation to the size of the brain? How does its size compare with that of the body in man? in the dog, the horse? the elephant? the canary bird ? the ape? What is now the received doctrine in relation to the size of the brain? How is it proved that the brain is the organ of the intellectual and moral powers? How do you prove that no other organ than the brain can be the seat of the mind? How does inflammation or injuries of the brain affect the mind? What cases prove this connection? What objections have been raised to the brain being the organ of the mind ? What is said of the passions being situated in the viscera of the cliest or abdo. men? Does the affection of the heart by passion prove that it is the seat of the mind Why not? Does the brain increase in size by exercise ? What was the opinion of the ancient Greeks on this subject ? What is said of the functions of particular portions of the brain? Is much dependance to be placed on the experiments made on animals ? Where is it supposed perception resides? What are the commisseurs of the brain? When the brain is injured on the right side, which side of the body is affected What accident proves that the opposite side is affected? What is the office of the cerebellum? What effect do we see in animals when they have been wounded? Is man excelled by animals in the perfection of the senses ? In what respect does he excel all ani. 
mals? What is Phrenology? What are its chief doctrines? What is said of locating the organs on the exterior of the skull ? What facts show that the brain does not act as as a whole in the intellectual opera. tions? Have the external senses separate internal organs? WWhat may we infer from this? Is the structure of the brain homogeneous? Do the faculties all appear at the same time ? Is genius generally partialy When the mind is fatigued, what effect is experienced by turning the attention to a different subject? What is monomania? What do we infer from its existence? What is the general conclusion in relation to the clief doctrines of Phrenology? 


\section{CHAPTER XI.}

THE SPINAL MARROW AND ITS FUNCTIONS.

1. WE have seen, that of all animals, the brain of man has the greatest development, in proportion to the spinal marrow and nerves; if we descend to the lower animals, such as reptiles and fishes, we shall find that the brain presents merely a delicate, anterior termination of the spinal cord, not much larger in diameter than the cord itself.) In these animals, we find the instincts very limited, and the displays of sagacity extremely obscure ; while they possess great tenacity of life. Frogs, for example, continue to jump about for many hours after their heart has been torn out; and the heart of the shark will palpitate as long after it has been removed from the body. Turtles have been known to live for months after the whole brain has been scooped out. These facts prove, that such an imperfect development of the cerebral mass, leaves the different systems of organs less intimately connected and more independent of each other.

2. If we descend still lower in the scale of invertebrate animals, we shall find the different parts still more independ. ent of each other ; for if we divide their bodies, so that each part will possess a nervous ganglion, it will become a separate individual, and exercise all the functions performed by the entire animal ; and if we descend to zoophytes, we find that in cutting them into threads, however minute, each piece will retain life and continue to grow.

3. Medulla oblongata. - There is no distinct line of demarcation between the medulla oblongata and the spinal cord. For this reason, they are considered and described as one organ. (The medulla oblongata, however, consisting of six columns, gives rise to several nerves of distinct function, and 
is supposed to be the point at which excitement to motion commences and sensation terminates, and to possess the power of originating motion in itself. Mr. Mayo infers this, from the fact that the brain proper, the optic tubercles, and even the cerebellum may be removed by successive por. tions, and still the animal live, and exhibit feeling and in. stinct; but if the medulla oblongata be removed, all consciousness is immediately destroyed. Other physiologists say, that it is the hemispheres of the cerebrum that take cognizance of sensation, and the source from whence volition proceeds; and that though they may be removed, layer after layer, without pain, yet by so doing, the senses are destroyed, memory and intelligence abolished, and the animal reduced to an automaton, destitute of design, apprehension, and judgment. As all the nerves which supply the larynx, lungs, heart, stomach, and external muscles of respiration originate from it, its removal must instantly destroy life.

4. The spinal cord passess down through the foramen magnum, or great hole of the skull, and the canal of the ver. tebra, till it reaches the second vertebra of the loins, where it generally terminates in a tapering point//Besides the bony case in which it is lodged, the cord is enclosed by a prolongation of the dura mater, which, however, does not adhere immediately to the bone, as it does in the skull. It also is supplied with extensions of the arachnoid and pia mater ; between which, there is usually a quantity of serous fluid, varying from two to six ounces, which seems to impart a certain degree of support by its pressure and obviates the effects of concussion,

5. The general form of the spinal cord is cylindrical, though somewhat flattened, from its transverse diameter being the greatest. Its thickness, however, is not uniform, as it bulges out at the lower part of the neck, where the nerves go off to the arms, and also at the lower part of the back, from whence spring the nerves of the legs It is composed of grey and white, or cineritious and medullarv mat. 
ter, like the brain ; the situation of the two is, however, reversed; the medullary matter being disposed in a thin layer upon the surface, while the grey portions occupies the centre. We, however, find the same arrangement in the medulla oblongata, and the central parts of the cerebrum and cerebellum. The chord, as I have already mention. ed, is divided into two lateral halves by a groove in front and a similar groove behind. Besides this, there are on each side two lateral grooves faintly marked, from which the anterior and posterior nerves have their origin, so that in fact, the cord consists of four columns, from the two anterior of which, the nerves of motion spring, and from the two posterior those of sensation.

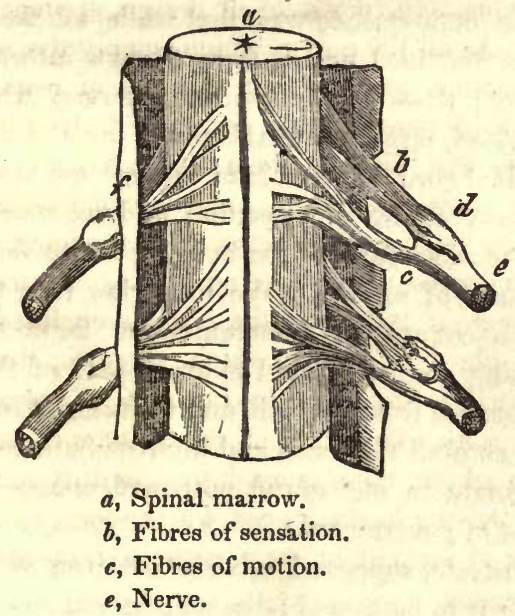

6. There are thirty pairs of nerves that spring from the spinal marrow, viz., eight from the region of the neck, twelve from that of the back, and five from the pelvis. By examin. ing the above cut, it will be seen that they arise by two roots, one from the anterior, and one from the posterior column. The fibres of the posterior swell out into a gang. lion before they unite with the anterior. 
7. A few years ago, Sir Charles Bell discovered, that by opening the spinal canal in a living animal, and dividing the posterior roots of the nerves, the parts to which they are distributed are deprived of feeling. The limb may be prick. ed or lacerated in any way, without the animal manifesting the least feeling, or indication of suffering, while at the same time the power of motion remains. He also found that when the posterior roots were divided, sensation was destroyed, but motion remained. One of Majendie's experiments, is interesting. Availing himself of the fact, that the introduction of nux vomica into the system, produces violent spasms, tremors, and rigidity of the muscles : he administered it to an animal, after having severed the anterior roots of the spinal nerves. The consequence was, that while all the muscles, whose nerves remained entire, were thrown into a state of violent spasm; those supplied with the nerves, whose roots had been divided, remained unaffected.

8. The spinal cord then serves to connect the brain, which is the common centre of sensation and voluntary motion, with all the sensible parts of the body, and with the muscles, the instruments of motion.) We may view it in this sense, as forming a channel of communication for a bundle of nerves running from the brain to every part of the system to carry messages from the will, and to transmit intelligence back again, as if all the roads and high-ways in the country should terminate in one grand post-road, connecting them with the seat of government.

9. To illustrate, suppose I seize a hot iron in my hand, not knowing it to be heated; the painful impression is im. mediately transmitted along the sensiferous nerves to the spinal cord, and through that to the brain. The brain takes cognizance of it, and a mental determination is immediately formed to drop the iron. The will sends back its command through the anterior column of the spinal cord to the motific nerves, distributed to the muscles, which go to the hand. The muscles instantly obey; the iron drops, and the whole 
process occupies but an instant. Thus we have two channels of nervous influence; the one transmitting intelligence to the mind, the other conveying the purposes of the will to the muscles necessary to carry them into effect.

10. That such is the chief function of the spinal marrow, is proved by the well-known fact, that if it is divided in any part of its course, that portion of the body, as well as the limbs, which are situated below the seat of the injury, will be paralyzed ; that is, all sense and motion will be lost, while the parts above the injury will be unaffected. If the injury occur very high up in the neck instant death will ensue, because the nerves, which go the diaphragm and are necessary to carry on breathing, are separated from their connection with the brain. These leave the spine as high as the third vertebra of the neck.

11. I have stated that it has been proved, that the (principle of motion resides to some extent in the spinal marrow itself.) This is shown by the following experiment. If after the spinal cord be divided in the neck, and then lower down in the back, we irritate any of the muscles which are supplied with nerves from this isolated segment, motion will be produced. If the foot, or the hand be pricked, it will im. mediately contract; and this contraction is produced by the irritation being transmitted to that portion of the spinal marrow, from whence the nerves of the part arise, and whose connection with the brain has been severed, and then an im. pulse is sent back again from this portion to the muscles of the hand or foot which causes them to contract. Still, all voluntary motion, as well as sensation, depend on the brain.

12. If the medulla oblongata is injured, breathing immediately ceases. If the spinal marrow is severed opposite the second bone of the neck, death also speedily follows; because the nerves of respiration are cut off from their connection with the part above. If the spinal cord be divided, as low as the fifth cervical bone, then life will not be immediately destroyed; but the breathing will be difficult; because the dia. 
phragm is paralyzed, and death sooner or later follows from suffocation. (If it be divided about the first dorsal vertebra, then life may be maintained for a considerable time, although the ribs cannot be elevated, as the intercostal muscles are rendered paralytic.) Breathing is, however, kept up by the action of the diaphragm. I have seen a man whose spine was dislocated in this region, live seven or eight weeks. All sensation and motion were lost in the parts below the seat of the injury, but his reason and senses were perfect.

13. As the heart, lungs, larynx, and many of the most important organs of the body are supplied with nervous influence by the eighth pair of nerves, or par vagum, why is it that a division of the spinal marrow causes death? This question is easily answered, by remembering that one of the functions of the par vagum is, to convey to the brain the sense of the want of air, or of respiration, and that this stimulus reacts upon those parts of the spinal cord which give rise to the respiratory nerves of the chest? Now if this communication be cut off, the influence of the brain, or the me. dulla oblongata, cannot be transmitted so as to excite those muscles which are employed in breathing.

14. That this is the true answer to the above question is also shown by dividing the par vagum in the neck. This causes palsy of the lungs, and also of the muscles which open the larynx; in consequence of which, the top of the wind. pipe is immediately closed, and death follows from suffocation. Besides this, it also prevents transmitting to the medulla ob. longata, the sense of the want of respiration, and thus prevents also the reaction of this part upon the spinal marrow.

15. Does the spinal marrow exert any influence upon the circulation of the blood? (It is ascertained that the action of the heart is nearly independent of the spinal marrowl Its nervous influence is derived from the par vagum and the great sympathetic nerve, the former of which has but little connection with the spinal cord. The whole spinal marrow has been removed, and still the heart has continued to act. 
Its action, however in such cases is much weakened. That the heart is, however, in some measure influenced by the spinal innervation, must be admitted.

16. What is called the capillary circulation, or that in the small vessels, is much under the influence of the spinal mar. row. It is found that when any part of it is destroyed, the blood does not, circulate in the small vessels which derive their nerves from the portion destroyed. In these cases, the skin becomes purple, and dry ; perspiration ceases, the cuticle peels off, and the part becomes sensibly colder. The whole nervous system, however, is concerned in the produc. tion of animal heat.

17. Digestion is to a considerable degree under the influ. ence of the spinal cord) (In all cases of diseases of the spine, the appetite is poor, and the digestive powers weak. Colic and dyspepsia are frequent attendants upon such complaints. If the eighth pair of nerves be divided, the stomach is imme. diately paralyzed, and digestion interrupted.) This shows that the stomach depends for nervous influence on the me. dulla oblongata, and that it is derived through the medium of the par vagum.

18. The spinal marrow exerts an important influence over the kidneys, more so perhaps than over any of the abdominal viscera. Some physiologists also think that it presides over the functions of nutrition. What seems to confirm this opinion, is the fact, that in the crustacea, insects, and worms, which have the power of speedily reproducing any part that is cut off, the spinal marrow preponderates over every other portion of the nervous system. Nutrition is known to depend chiefly on the influence of the great sympathetic nerve, but its connections with the spinal marrow are so numerous and intimate, that there can be little doubt, it derives a consider. able portion of its nervous energy from the latter. The fol. lowing cut represents the left side of the brain and spinal marrow, shown by making a section of the cranium and the spinal column, and removing the dura mater. 


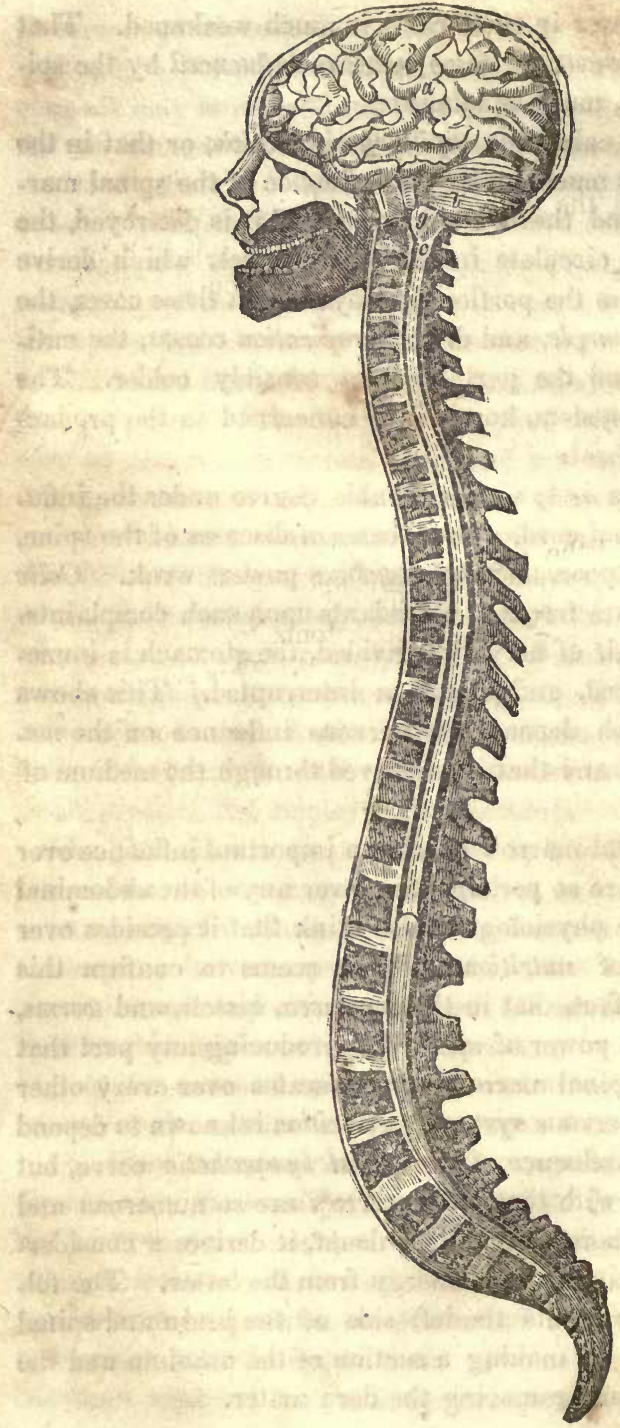


a. The convolutions of the cerebrum.

b. The laminæ of the cerebellum.

e. The pons varolii.

g. The medulla oblongata.

$c . d . f$. The medulla spinalis, or spinal marrow, extending from the first cervical to the first lumbar vertebra, and terminating in the cauda equina. The cerebrum, it will be seen, is the largest portion of the brain, and occupies the whole upper cavity of the skull. It rests anteriorily upon the arches of the orbits; in the centre, upon the middle fossac of the base of the skull, and posteriorily upon the tentorium cerebelli.

Questions.-How do we find the brain developed in the lower animals? Have they great tenacity of life $\$ *$ Will zoophytes live when divided into pieces 7 What is the medulla oblongata? What its func. tion? Describe the spinal cord ?-its membranes? its shape?-its structure? How many pair of nerves arise from it How many from the neck 8 -the back? - the loins ? What is the function of the anterior roots ? - the posterior roots? What is the use of the spinal cord? How is this illustrated? How proved? What follows, if the spinal cord be severed opposite the second bone of the neck? - the fifth ?-the first dorsal? Does the principle of motion reside to any extent in the spinal cord itself? What experiment proves this ? Why does a divi. sion of the par vagum or eighth pair cause death? Does the spinal mar. row exert any influence on the circulation of the blood? - on the capil. lary circulation ? on digestion? What proves this? Has it any influence over the kidneys ? - over nutrition? 


\section{CHAPTER XII.}

\section{THE NERVES AND THEIR FUNCTIONS.}

1. In describing the nerves and their functions, it will be necessary to classify them, or to reduce them to such arrangement, as the present state of our knowledge on the subject will admit. The following comes as near such a classifica. tion as it is possibie to malie:-1/Nerves of Special Sense. 2. Motific Nerves. 3. The Respiratory Nerves. 4. The Regular Nerves, 5. The Ganglionic Nerves.

2. First Order. - The nerves which contribute to the senses of sight, hearing, and smell, constitute the first class, and are called Nerves of Specific Sense, because they are in. capable of communicating any other impressions, than such as belong to the respective senses with which they are connected. For example, the olfactory can only transmit ideas of odours, the optic of colours, the auditory of vibrations, no matter what the stimulants may be which excite them to action. If we send an electric shock to the eye, it receives the impression of light ; to the ear, of sound; and to the nose, an odour is perceived: so also, if we press or strike the ball of the eye, we experience a vivid sensation of light, and the same phenomenon occurs when the eye is pierced by the needle of the surgeon : so also, if we take two pieces of different kinds of metal in the mouth, and placing one over, and the other under the tongue-allow their edges to come together, we perceive at once a peculiar taste, excited by galvanism. Thus do these nerves communicate to the mind that they are affected in the only manner of which they are capable. 


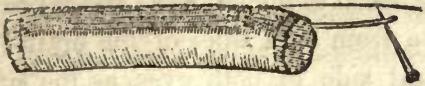

This cut represents a portion of nerve, showing the filaments of which it is composed, and one of them drawn out.

3. First, or olfactory.-These nerves take their name from "olfactus," the smell, as they are essential to this sense. They are the softest nerves in the body, and more closely connected with the hemispheres of the brain than any other) They lie immediately under the anterior lobes of the brain; and as they pass on, they swell into a bulb, from which numerous fibres issue, and pass into the nose through a plate of one of the bones of the skull. This plate is pierced with so many holes for transmitting these twigs of the nerve, that it has the appearance of a seive; and from this circumstance is called the ethmoid bone. The olfactory nerve is spread out upon the lining membrane of the nose, and is merely defended by a thin layer of mucus. It was necessary that these nerves should come to the surface, in order to come in contact with the vapours inhaled by the nostrils. In some animals these nerves are very large, especially in ruminants, but in others they are entirely wanting, as in whales! In fishes, you may see the bulb of the olfactory placed immediately under the cup-like nostril. From the bulb, the nerve runs backward along a canal filled with transparent fluid, enters the skull, and joins the brain.

4. The second, or optic. These are the largest of the cerebral nerves, and can be traced as far back as the medulla oblongata at the base of the brain. They pass along the base of the brain, and just before they enter the orbits they unite with each other) or seem to decussate, or cross each other. In some fishes, these nerves evidently cross without union; but in man, it is now pretty well established, that a semidecussation takes place; thut is, one half of the right optic nerve crosses to the opposite side, and joins a half of the 
left nerve to proceed to the lef sye; so that each eye receives its optic nerve from both sides of the brain; the right sup. plying the right side of both eyes, as the left does its cor responding side of both. After the nerve has entered the orbit, it proceeds forwards to the ball of the eye, and pene, trating the coats of that organ, expands into a very delicate web, or nervous net-work, called the retina, which (serves to receive the image of objects falling upon it.)

5. The auditory nerve. - The last nerve of specific sense, runs along with another, the two together being known as the seventh, of which the auditory forms the soft portion, or portio mollis. It arises from the medulla oblongata, and goes on in contact with the hard portion, or portio dura, to the internal auditory passage, which they enter. Here the soft portion spreads out into a great many small branches, which are distributed over the surface of the internal portions of the ear, and their extremities float in the water contained in the labyrinth, from which they receive vibrations which produce the impressions of sound)

6. Second order. -The motiferous nerves which constitute the second order, consist of three nerves; the third, the sixth, and the ninth, with perhaps a branch of the fifth. These take their origin at the anterior columns, in the same line with each other; but fibrils of sensation afterwards join them, so that they are analogous to the double-rooted nerves of the spinal marrow.

7. The third pair rise from the crura of the brain, and pass forward to a hole in the bottom of the orbit, through which they enter, and supply four of the six muscles which move the eye, and also the muscle which moves the upper eye-lid, thus placing these muscles under the command of the will. Besides this, a small twig of the fifth nerve swells out into a ganglion, and then joins a twig from the third, which go on together, and penetrate the coats of the eye, to which they impart sensibility, and are connected with the functions of the iris. It is worthy of remark, that here the 
general law is kept, viz., that a ganglion is formed in the sensific nerves, before they become associated with the fila. ments of motion.

8. The sixth pair arise near the last, and also enter the orbit there they are entirely expended upon the muscle which turns the eye towards the temple. Where this nerve has been injured or lost its power, the eye is permanently turned in towards the nose; and such a person is said to be cross-eyed

9. The ninth pair arise from the pyramidal bodies, and passing through holes in the occipital bone, proceed forwards towards the angle of the jaw, by the side of the hyoid bone of the tongue, and are distributed upon the muscles between the lower jaw, hyoid bone, and tongue, the motions of which it regulates

10. 'Tinrd Order.-This division embraces what Sir Charles Bell calls the (respiratory nerves) These are not only connected with the function of respiration, but contribute also to the expression of the passions and emotions of the mind. They consist of the fourth; the portio dura; of the seventh, or facial; the eighth, or par vagum; the phrenic; and the external respiratory. As the medulla oblongata, consists of three columns; the nerves of motion arise from the anterior, those of sensation from the posterior; while the respiratory nerves, already mentioned, spring from the middle portion, and all nearly on the same horizontal plane.

11. (The fourth nerve supplies the superior oblique muscle of the eye, which rising from the bottom of the orbit, runs along the roof of that cavity, till it comes close to its brim, where it terminates in a small tendon, which passes through a loop or pulley, then turns back, and is inserted into the posterior part of the ball, so that its contraction turns the eye in towards the nose.) When the will ceases to control the movements of the eye, it comes under the action of the superior oblique muscle. We see this, in acute bodily pain, and at the point of death, when the voluntary muscles 
have lost their power. This turning of the eve inward is supposed to indicate great agony; but it rather shows that all suftering has ceased, and that the powers and sen. sation and motion are lost. If we raise the eye-lid of a person asleep, we shall find the eye turned in the same direc. tion ; also in fainting, and in cases of suspended animation. The fourth nerve is partly then under the influence of the will, and partly independent of it.)

12. The seventh nerve consists of two portions, one of which, the auditory, has already been described. The other portion is called facial, because it is distributed orer the face. Its origin has already been stated, though it receives filaments from each column of the medulla oblongata; so that its function is complicated. It seems, in fact, to combine the character of a regular nerve and one of instinctive motion; it enters the internal auditory passage in conacction with the nerve of hearing, then entering a canal in the tempora bone, it comes out just before the ear, and spreads out orer the face in three principal branches, called pes caserina, 01 goase's foot, from its resemblance to that object.

13. (The ffith nerve is distributed to the same parts on which the facial is ramified on the faco; the one serving for sensation, the other for expression. Thus when the facia nerve is divided, or its functions destroyed by disease, thr side affected loses all power of expression, though sensation remains unaffected; on the contrary, if we divide the ffft pair, sensation is entirely abolished, while expression remaias The facial nerve not only communicates the purposes of thr will to the muscles of the face, but at the same time, it call them into action under the infuence of instinct and sympa thy. On this subject a late writer remarks, "How expres sire is the face of man? How clearly it announces the thoughts and sentiments of the mind! How well depicte are the passions on his countenance! tumultuous rage, abject fear, devoted lore, envy, hatred, grief, and every other eanc tion, in all their shades and diversities, are imprinted thes 
in characters so clear that he that runs may read! How difficult, nay, how impossible is it to hide or falsify the ex. pressions which indicate the internal foelings! "Thus conscious guilt shrinks from detection, innocence declares its confidence, and hope anticipates with bright expectation."

14. (The eighth pair of nerres consist of three distinct partions; the first of which, from its being distributed to the tongue and throat is called glassapharyngeal; the secoond, from its irregular course is called nagars, or the wandering nerve; and the thind, from its origin from the spinal marrow, is called accessory. These different nerres join just as they are about to escape from the skull, which they do in cons. pany with the internal jugular rein, and as soon as they emerge they form connections with the great sympathetic.

15 (The vagans, on learing the skull, sends off branches to the pharynx and esophagus, also to the larynx and the muscles which close the air passage, and the mucous mem. brane covering it. Its trunk runs down the neck included in the same sheath with the carotid artery and jugular vein, and enters the chest under the collar bone) (Here a branch is giren off, which locks round the subclavian artery on one side, and arch of the aorta on the other, and goes up to the larynx, hence it is called recurrent.) It supplies those muscles particularly which open the air passage. The ragans sends down twigs with the sympathetic which surround the the divisions of the wind-pipe, and accompany them in all their ramifications through the lungs. It also sends numer. ous twigs to the heart, stomach, liver, nunereas, spleen, in. testinal tube, and finally with the sympathetic nerve, and forms those great nervous centres or ganglia in the abdomen, which supply all the viscera of that cavity with nervous energy? 16. The phrenic nerve derives its name from its distribution to the diaphragm, which at one tine, was considered as the seat of the soul. IIt passes out of the vertebral canal between the second, third, fourth, and sometimes fifth cervical 
vertebræ; it runs down the neck, and enters the chest on the outer side of the internal jugular vein.

17. The external respiratory nerve is distributed to the intercostal muscles, and those which extend from the ribs to the shoulder, and which are occasionally employed in labo. rious breathing. It is through the instrumentality of the accessory, phrenic, and external respiratory, that the muscles employed in respiration are brought into action, com. bined and directed with the proper degree of force, velocity, and extent, without the necessity of interference of the mind. Though to a certain extent, they may be under the influence of the will, yet it is only in a secondary degree. No one, for example, can long suspend the movements of respiration, for in a short time, instinctive feeling issues its irresistible mandates, which neither requires the aid of erring reason, nor brooks the capricious interference of the will.)

18. The influence of this order of nerves in the expression of the passions, is strikingly depicted in Sir Charles Bell's Treatise on the Nervous System. "In terror," he remarks, "we can readily conceive why a man stands with his eyes intently fixed on the object of his fears, the eye-brows elevated, and the eye-balls largely uncovered; or, why with hesitating and bewildered steps, his eyes are rapidly and wildly in search of something. In this way we only perceive the intense application of his mind to the objects of his apprehension, and its direct influence on the outward organs. But when we observe him farther, there is a spasm in his breast ; he cannot breathe freely ; the chest remains elevated, and his respiration is short and rapid; there is a gasping and convulsive motion of his lips, a tremor on his hollow cheeks, a gasping and catching of his throat; his heart knocks at his ribs, while yet there is no force in the circulation, the lips and cheeks being ashy pale."

19. "To those $I$ address, it is unnecessary to go farther than to indicate that the nerves treated of in these papers are the instruments of expression, from the smile upon the 
infant's cheek to the last agony of life. It is when the strong man is subdued by this mysterious influence of soul on body, and when the passions may be truly said to tear the breast, that we have the most afflicting picture of human frailty, and the most unequivocal proof, that it is the order of functions we have been considering that is thus affected. In the first struggles of the infant to draw breath, in the man recovering from a state of suffocation, and in the agony of passion, when the breast labours from the influence at the heart, the same system of parts is affected, the same nerves, the same muscles, and the symptoms or characters have a strict resemblance."

20. Fourtir Order.-Regular Nerves.-I have already stated that there arelthirty pair of regular nerves which go out from the spine each nerve being composed of two kinds of fibres; those of the anterior column being subsidiary to motion, and those from the posterior to sensation. With these, physiologists now class the fifth nerve. This large nerve divides into three principal branches the first going to the eye, is called opthalmic) (he second to the upper jaw, is called superior maxillary fand the third sent to the lower jaw, is named inferior maxillary. It is the third branch, however, which is truly a compound nerve, as its roots arise both from the anterior and posterior columns. The inferior maxillary branch, is a nerve of both sense and motion; its filaments of motion supply the muscles which shut the jaw, while those of sensation go to the tongue, salivary glands, gums, teeth of the lower jaw, external ear, cheek, chin, and lower lip. (It is this nerve) which gives sensibility to the face, and it is this which is the seat of that painful affection called tic dolouroux, which is sometimes removed by cutting the nerve affected. In the cat, the hare, and other animals with large whiskers, the filaments of this nerve can be traced to the bulbs of the hairs, which accounts for the delicate tact which these animals are endowed with, and by means of which they are enabled to wind their way in the 
dark, through intricate passages, with the greatest facility. (The fifth nerve is associated with the organs of the senses of smell, sight, and hearing; it exercises that of touch, is the immediate instrument of taste, and is affected in some degree by pungent odorous substances, by light, and by sound,

21. Spinal nerves. - The nerves of the spinal cord are all similar in their construction, and in the functions which they perform] [The two sets of filaments of which they are composed, though enclosed in the same sheath, yet remain entirely distinct throughout their entire course.). If to every muscular fibre in the system, and spread out over the entire surface of the body) which possesses, accordingly, a more exquisite sersibility than the deep-seated parts. Thus in amputating a limb, the chief pain is in cutting through the external parts; for the bone may be sawn through, the muscles, tendons, and ligaments cut and la. cerated, and even burnt with a red-hot iron, and still the patient experiences little or no suffering.

22. (The object of endowing the skin with such a high degree of sensibility, is, doubtless, to warn us to avoid, not only what is injurious to the skin itself, but also what might endanger internal parts. It thus serves as a protector to the whole body. The extremes of heat and cold, which might prove injurious, produce their painful impressions mechanical causes rouse by their sharpness, roughness, or hardness; aerid and corrosive chemical agents induce uneasy sensation-all which serve to admonish us to shun the causes producing such effects. IIt is remarkable to notice how every part of the body is endowed with its own kind of sensibility. (The skin feels changes of temperature; the muscles experience only a sense of fatigue ; the eye is sensible only to light; the ear to sound; the nose to odours; the heart to blood; the stomach to food \&c. ; and these sensations are sent along up to the brain by little threads, in close contact with other threads, which bring back the 
commands of the will! Truly may it be said, "man is fearfully and wonderfully made."

23. The spinal nerves are classed according to the portion of the spinal column from which they issue as the neck, back, loins, and pelvis ; forming eight cervical, twelve dorsal, five lumbar, and five sacral nerves; all being connected with the sympathetic. The four lower cervical and first dorsal go to the arm-pit, where they form a complicated plexus, from whence nerves issue to supply the arm and hand. The dorsal nerves supply the integuments of the body, the intercostal muscles, and those of the chest. The lumbar and sacral nerves supply the muscles of the loins and abdomen, together with the lower limbs.

24. Fifth Order.-Ganglionic Nerves.-We have now considered, somewhat minutely, that portion of the nervous system which is called the cerebro-spinal, embracing the brain, the material instrument of thought, the source and channels of voluntary motion, and of instinctive movements and sympathy. The ganglionic nerves parelsometimes called great sympathetic, or the great intercostal ; but sympathy has been shown to be chiefly independent of it, except so far as it receives filaments from the cerebro-spinal nerves; and it is called great, not so much from its size, as from its supposed importance.

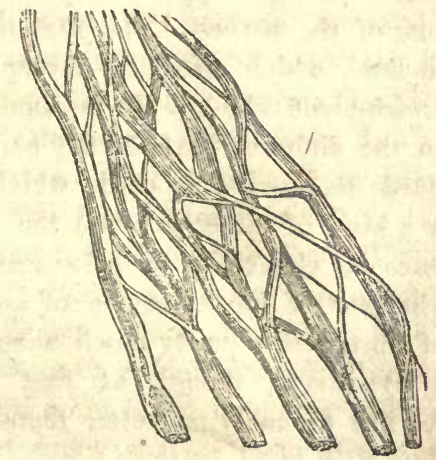

A plexus of nerves. 
25. The ganglionic, or great sympathetic nerve, consists in a series or chain of ganglions, extending from the base of the cranium to the extremity of the sacrum. They are placed on the lateral part of the bodies of the vertebrae, and are united to each other by intermediate nervous cords, and send off continually filaments to all the adjacent organs. With the exception of the neck, there is a ganglion for each intervertebral space, both of the true vertebrae and sacrum. Besides these, there are other ganglia situated around the trunks of some of the large vessels of the abdomen? These ganglia are composed of a mixture of cineritious and medul. lary matter, and are supposed to be the centres of peculiar nervous power.

26. As to the functions of this order of nerves, there is good reason to believe that the peculiar vitality of every organ in the body directly depends on them. Most physiologists believe that they preside over the involuntary func. tions, as secretion, nutrition, absorption, calorification, \&c. Others suppose that the office of the ganglions is to render the organs, which are supplied with nerves from them, independent of the will. As branches from them, accompany the blood-vessels throughout their course, every part of the body must, to a certain extent, be under their influence.

27. There have been three hypotheses prevalent in respect to the functions of the nerves. The first, that the brain secretes a fine fluid, which circulates through the nerves, called animal spirits, and which is the medium of communi. cation between the different parts of the nervous system; the second regards the nerves as cords, which transmit all impressions by a kind of vibration; and the third ascribes nervous influence to electricity or galvanism. But there is no proof whatever of the existence of any such fluid; the doctrine of vibrations is pretty much abandoned; while the electrical hypothesis, though at first view perhaps more plausible, has probably no better foundation to rest upon. 
Questions.-How are the nerves classified? What nerves consti tute the first order? Why called nerves of specific sense? Describe the first or olfactory. Is it large in animals ? - in fishes ?-in whales? -Describe the second, or optic. Do the fibres cross each other kits function? Describe the auditory nerve. What nerves constitute the second order? Where do they arise? Describe the third pair;-their function? Describe the sixth pair ; - their function ?-The ninth pair ; -their function ? What compose the third order of nerves? Describe the fourth nerve;-its function? Describe the seventh nerve;-its function ? $^{2}$ The fifth nerve; -its function $/$ fuistribution, \&c.? Describe the eighth pair of nerves. What are its three branches called? Describe the vagans; - the recurrent; - the phrenic;-the external respiratory? What does Sir Charles Bell say of the influence of this order of nerves? What compose the fourth order of nerves? Why is the fifth nerve classed with the regular nerves? - Where does its first branch go;-its second;-its third? What nerve is affected in tic doloreaux;-its function? Describe the spinal nerves;-their mode of origin;-their distribution? Why is the skin so sensible? Has any part of the body its own sensibility? Illustrate this. How are the spinal nerves classed? What compose the fifth order? What other names for the ganglionic nerves? Describe them. What is the function of the ganglionic nerves? What hypotheses have prevailed in relation to the functions of the nerves ? 


\section{CHAPTER XIII.}

THE FIVE SENSES.-gENSE OF TOUCH.

1. (A sensation is the perception of an impression made on some organ. By our sensations we receive a knowledge of what is passing within or without the body. They are accordingly (divided into internal and external.) (An internal sensation, is one which is produced by causes acting within the system, as hunger and thirst but an external sensation is one that is occasioned by the impression of a body, exter. nal to the part impressed, as sight, hearing \&c.

2. No sensation, we have seen, can be perceived unless it is transmitted to the brain. When ideas, which have been called ' the images of sensible objects, $)$ are reflected upon and compared with each other, we exert thought and judgment ; and when they are recalled, we are said to exert the memory. Thus are the senses avenues to knowledge, though they do not give rise, as some have stated, to our intellect and moral powers.) With every sense an animal discovers a new world; thus creation is to it increased or diminished, accordingly as its senses are more or less numerous. A sensation lasts a certain time after the exciting cause has ceased. Thus if a piece of wood, with one end ignited is whirled round, we see a luminous ring; the sensation produced by the wood in each point of the circle continuing till the wood arrives at that point again; a rocket forms a train.

3. The external senses are five in number; touch, taste, smell, hearing, and vision. These are all situated at the surface of the body, so as to be capable of acting on external bodies. (Most of them are under the control of the will; at least they may be exercised actively or passively and by 
directing the attention, the impression may be rendered more vivid.

4. The sense of touch is the general feeling or sensibility produced by the skin, and which instructs us regarding the general qualities of bodies.) It resides also to some extent in mucous membranes, as in the mouth, throat, \&c., although in a very imperfect degree. For example, we cannot feel the pulse by placing the tongue over it on the wrist, as any one can ascertain by trying the experiment. (The sense of touch is distinguished by some writers from that of feeling, but they are only modifications of the same sense.

5. I have already given some account of the structure of the skin, and stated that it is divided into four layers, viz., the /cuticle, mucous web, papillary body, and true skin and that the cuticle is the thin, transparent pellicle or membrane, which (forms the external incrustment of the body, protecting those papillae, in which reside the sense of touch.) As no blood-vessels or nerves have been traced in it, it is supposed to be an unorganized texture, or an albuminous secretion, poured out by the subjacent vessels, and hardened by the in. fluence of the air. This accounts for its rapid formation, when destroyed by a blister, burn, \&c. When a part of the body is exposed to irritation, the vessels which pour out the lymph, from which the cuticle is derived, have their action increased, and the cuticle either becomes thickened, as in the palms of the hand and soles of the feet, or the effusion is so abundant as to cause a separation between it and the true skin, causing blisters.

6. Now, it is a general law, that pressure promotes ab. sorption; and we see this exemplified daily in cases of tumours, abscesses, bandaging for dropsical effusions, \&c. Had this tissue been subjected to this general law, the friction and pressure to which the cuticle of the hands is ex. posed in manual labour, and of the feet in walking, would, in a short time, have entirely deprived them of protection, instead of rendering their covering more dense and thicker, 
that it may more effectually serve as a shield to the parts it covers. As the cuticle is constantly renewed from its inter. nal surface, it is also constantly peeling off in the form of a fine powder, or thin scales. After scarlet fever, and other diseases, attended with great heat of the skin, it is entirely removed; the old scarf-skin, as it is called, being thrown off in large patches. We find a cuticle in all organized beings, plants, as well as animals, though it differs greatly in structure and appearance. In many reptiles and crustaceous animals it is entirely shed at certain periods, presenting an exact mould of their bodies, their scales, and other external parts, and even their eyes being exactly represented.

7. The mucous web has already been pretty fully described. It is a soft pulpy net-work, and seems to consist chiefly of the shaggy extremities of blood-vessels, interlaced and bound together by delicate filaments of cellular membrane. It is the seat of those minute globules which constitute the colouring matter which vary in their tints in different races. These tints are influenced in a greater or less degree by climate, for we find in tropical countries the colours of both plants and animals are more intense and brilliant than in colder regions, and that exclusion from light produces a pale blanched appearance, while exposure to it has a contrary tendency; but these variations are neither permanent nor do they descend to the offspring.

8. The dermis, or true skin, is the thickest part of the external integuments, and is composed of an infinite number of plates, consisting of filaments inextricably wound together, and abundantly supplied with blood-vessels and nerves. The external surface of the cutis is every where studded by very minute nipples or papillae, and in several parts, as the palms of the hands and the ends of the fingers, they are arranged in symmetrical rows, which form wavering lines, and separated by small crevices that admit of the flexions of the skin and its adaptation to the surfaces of external objects./These papillae are the terminations of nerves and blood-vessels, and 
are the immediate instruments of touch. Although covered by the cuticle and mucous web, yet the removal of these by blisters or otherwise, does not increase the sense, but tends to destroy and disturb it. From this arrangement, sensation is communicated through the hair and nails, as well as the cuticle. In animals, of the cat tribe, which are furnished with whiskers, these serve as organs of touch, as their roots terminate in these nervous papillae.

9. The property of touch belongs to every part of the body, though the hand is considered as its special organ? The great number of bones of which it is composed, make it susceptible of every variety of motion, by which it changes its form, and adapts itself to the inequalities of the surfaces of bodies. What is called the pulp of the fingers, seems composed chiefly of a tissue of blood-vessels and nerves, covered by the cuticle and mucous web, and supported by the nails The delicacy of touch is vastly improved by education and practice. This is shown in the case of the blind, who often can distinguish by touch the different colours, and even their different shades. This will not ap. pear impossible when we consider that difference of colour may depend on the dispositions, arrangement, and number of the little inequalities which roughen the surface of bodies, even of such as appear the most polished, and thus fit them to reflect certain rays of light, while they absorb the others? That the exercise of this sense is a gratification to the young, is apparent from the eagerness with which the child stretches out his little hands to all the objects within his reach, and the pleasure he seems to take in touching them, in all their parts, and running over all their surfaces.

10. I have already mentioned that the external surface of the body is endowed with this special sensibility (not only that it might furnish us with a knowledge of the characters of external objects, and so lead us to avoid dangers which surround us, but also to be a source of positive pleasure) Though in the acuteness of the other senses many animals 
surpass man, yet in the exquisite sensibility of his skin, man stands unrivalled. "The skin of man," says Majendie, $\psi$ is more delicate, fuller of nerves than that of the mammiferæ; its surface is covered only by the epidermis, insensible indeed, but so thin, that it does not intercept sensation, whilst the hairs which cover so thickly the body of quadrupeds, the feathers which clothe that of birds, quite deaden it.) The hand of man, that admirable instrument of his intelligence, of which the structure has appeared to some philosophers, to explain sufficiently his superiority over all living species; the hand of man, naked, and divided into many moveable parts, capable of changing every moment its form, of exactly embracing the surface of bodies, is much fitter for ascertaining their tangible qualities, than the foot of the quadruped, inclosed in a horny substance, or than that of a bird, covered with scales too thick not to blunt all sensation."

11. The hand then, is the chief organ of touch, and in the ends of the fingers it resides in the greatest perfection. 'Thus we see that the (blind are able to read with facility by passing their fingers over the letters, which are raised by a particular kind of type.) In this manner they acquire a knowledge of geography, arithmetic, reading, and the usual branches of education, not often met with even in those who have the use of their eyes as well as their hands.

12. Buffon, the celebrated naturalist, thought so much of the sense of touch, that he believed the cause, why one person has more intellect than another is, his having made better use of his hands from early infancy. Other philosophers, as Majendie states, have ascribed man's superiority over animals, and his intelligence, to the fact that he possesses a hand. But the hand is only the instrument of the mind, the agent of the will; it can only execute ; the mind must plan. Besides, the idiot has sometimes the sense of touch more delicate than the man of genius, or than the most skilful artist; while some of the most ingenious artists have by no means, the most delicate touch. Galen truly says, that man had 
hands given him because he was the wisest creature; but he was not the wisest creature because he had hands.*

13. The following cases prove that hands are not indispensable to genius, and that the human mind can even triumph over the imperfections of the body. A few years since a Miss Biffin was exhibited in London, who was entirely destitute of both upper and lower extremities; and yet she was very intelligent and ingenious. She could hem-stitch with the greatest facility, turning the needle very rapidly in her mouth, and inserting it by means of her teeth. She also painted miniatures faithfully and beautifully, holding the pencil between her head and neck. All her motions in fact were confined to the tongue and the lips, and to the muscles of the neck.

14. In the year 1825 there was a young artist in Paris, who had no hands or arms, and only four toes on each foot; and yet he sketched and painted beautifully with his feet. I have myself seen a young lady, born without arms, who had acquired so much skill in the use of the scissors as to be able, by holding them in her mouth, to cut likenesses, watch-papers, flowers, \&c. She would also draw and write, and execute all kinds of needle work with her mouth. A boy was not long since exhibited in the museum of this city, who performed all these things with his toes. This shows that other parts of the body besides the fingers, are capable of acquiring great delicacy of touch.)

* On this subject Dr. Elliotson remarks, "As philosophers have ascribed the superiority of man's intellect to his hand, and of the elephant's to its trunk, the constructiveness of the beaver to its tail, and the ferocity of the tiger to its teeth and claws, the poor man may be excused who was lately cxecuted at Chelmsford, and left the following directions. "I, Edward Clarke, now in a few hours expecting to die, do sincerely wish, as my last request, that three of my fingers be given to my three children, as a warning to them, as my fingers were the cause of bringing myself to the gallows, and my children to poverty." 
15. In animals, the organ of touch varies. In the ape tribe it is similar to that of man. In some quadrupeds it is seated in the lips, snout, or proboscis, as in the horse, the hog, the mole, the rhinoceros, and the elephant. Indeed, the trunk of the elephant comes very near to the human hand in nicety of touch, and delicacy of perception. The bat is remarkable for sensibility of touch. It has been found that if its eyes were destroyed and its ears and nostrils shut up, it would fly through intricate passages, without striking against the walls, and avoid every object placed in its way. This faculty is supposed to be owing to the great delicacy of touch residing in the membrane of the wings, which feels instantaneously any change produced in the resistance of the air.)

16. In insects, the antenna or feelers, are the organs of touch. These are of a great variety of forms, very flexible; and constantly in motion, when the insect is walking. If the feelers of an insect are cut off, it either remains motionless, or if it attempts to fly, it appears bewildered and lost. It is by means of their feelers that bees are able to work in a hive without light, and build their cells with the greatest regularity; by them also, they communicate to one another their impressions and their wants.)

17. It is supposed that the different modes in which ants touch each other with their feelers, when they happen to meet, constitutes a kind of natural language, understood by the whole tribe. It is evident that they could not co-operate in their labours without some kind of language. When an alarm is given in time of danger, one ant strikes his head against the corselet of every ant which it chances to meet, and these repeat the same act to all that fall in their way, and so the news is quickly spread through the whole society)

18. Sentinels are always placed on the outside of ants' nests to apprize the inhabitants of any danger. When an enemy approaches, these guardians quickly enter the nest and spread the news in the way just stated, and soon the 
whole swarm is in motion. While a larger proportion of the ants rush out to repel the attack, others, who have the office of guarding the eggs and the larvo, or eggs, hasten to remove their charge to places of greater security. These acts all depend on the faculty of touch, so that it is as import. ant to the lower animals as to man.

19. Sight, hearing, and touch, have been called intellectual senses, because they are the means through which we obtain our most yaluable information, the witnesses that fur. nish the evidence of the existence of external things. We can have no doubt as to the evidence they deliver, if they all agree in their report. We find however that if we depend on either alone, we are liable to be deceived. (Sight is liable to many illusions) we may, under the influence of the ima. gination, or of a diseased brain, imagine that we see a thousand strange sights, ghosts, hobgoblins, spectres, and devils; or from similar causes, we may believe that we hear strange and unearthly sounds; but if we attempt to touch the objects which appear to present themselves to our vision, or which discourse such unnatural music, we find that they vanish before us, like the ignis fatuus, or jack-o'lantern, which we may chase "o'er bog, and o'er moor," but we can never lay our hands upon it. I have often watched, with a degree of wonder, the action of a patient labouring under drunken delirium; the unhappy maniac not only sees strange objects about his bed, and flitting before his eyes, but he hears them singing and talking to him; he puts out his hand to grasp them,- - he grasps nothing,- - still he is not unde. ceived, nothing can make him believe that what he sees and hears are only the phantoms of a diseased brain; he persists in endeavouring to seize, to touch the strange objects, and only ceases, when after days and nights of incessant vigilance, his strength exhausted, he either sleeps or dies!

20. Touch has, therefore, been relied on in every age, as the most certain of our senses, and it is well to recollect that the most important fact that ever occurred on the theatre of 
this earth, viz the resurrection of the Saviour is established by the testimony of the three intellectual senses. In the gospel of the evangelist St. John, we read, "But 'Thomas, one of the twelve, called Didymus, was not with them when Jesus came. The other disciples therefore said unto him, we have seen the Lord. But he said unto them, except I shall see in his hands the print of the nails, and put my finger into the print of the nails, and thrust my hand into his side, I will not believe. And after eight days again "his disciples were within, and Thomas with them; then came Jesus, the door being shut, and stood in the midst, and said, peace be unto you. Then saith he to Thomas, reach hither thy finger, and behold my hands; and reach hither thy hand, and thrust it into my side; and be not faithless but believing. And Thomas answered and said unto him, my Lord and my God. Jesus saith unto him, Thomas, because thou hast seen me, tho: hast believed; blessed are they that have not seen, and yet have believed." Thus was the fact of the resurrection established by the evidence of so many of the senses, as to render deception impossible.

21. In some instances the touch itself, is liable to error. For example if we roll a pea, or a bullet, between two fingers crossed, we receive the impression of two distinct objects, though we know there is only one; and if we look at it, at the same time, the illusion is not removed, though we see at once that it is an illusion. 2 The organs here are, however, placed in an unnatural position. Another fallacy occurs with respect to heat. If we place the hand in separate vessels, the one containing warm, and the other very cold water, and after some time withdraw the hands, and immediately plunge them in the mixture of both waters, to the one hand the mixture appears warm, and to the other cold. So in a tropical country, if one person descends a high mountain from the regions of perpetual snow, and meets at the middle, another ascending from the hot valley below, he who is descending will feel oppressed with heat, while the other is 
shivering with cold, and both sensations are produced by the same temperature. Frozen mercury excites the same sensation as red hot iron. A piece of marble will feel colder than a woollen garment, although both be of the same temperature, because the marble is a better conductor of heat than wool. Ten; a deep cellar appears warm to us in winter, and cold in summer, though its termperature is nearly the same all the year round. During the voyages made by Captain Parry to discover the north-west passage, it was found that after having lived for some days in a temperature of 15 or 20 degrees below zero, it felt quite mild and comfortable when the thermometer rose to zero and conversely. The sense, therefore, only, gives us an idea of the relative, not the actual heat of bodies?

22. (The sense of feeling may become blunted to an extraordinary degree) (Chabert, the Fire King, was said to have been in the habit of swallowing forty grains of phosphorus at once; washing his hands in melted lead; and drinking boiling oil, without any apparent injury. There is a great difference in the degree of sensibility of the mucous membrane, in different individuals, some being able without inconvenience, to swallow fluids of a temperature which would be very uncomfortable to others?

23. The tactile power of the skin is not proportionate to its sensibility. Thus the arm-pits, flanks, soles of the feet, and other parts of the body, have slight power of distinguish. ing objects by touch, although they are very sensible. It would be difficult to make a person laugh by tickling the ends of his fingers, and yet we have seen that their sense of touch is more delicate than that of any other portion of the skin. All the surfaces and solids of the body possess a kind of sensibility, peculiar to themselves, and in disease may give sensations, but this a different property from that of touch.

Questions.-What is a sensation? How are they divided? What 
is an internal? What an external sensation? What are ideas? What is the office of the senses? How many external senses are there? Are they under the control of the will? What is touch? Is touch the same as feeling? Of how many layers is the skin composed? What is the cuticle? How formed? Its use? Is it subjected to the same law as the other parts of the body are in relation to pressure? "What would have been the consequence? Describe the mucous web.-The true skin. Where is the sense of touch chiefly situated? Describe the papillæ. What is the pulp of the fingers chiefly composed of? Can the blind distinguish colours by the touch? How is this explained? Why is the external surface endowed with special sensibility? What does Majendie say of the human skin? By what process are the blind enabled to read? What cases show that the possession of a hand is not necessary for the display of intellect and ingenuity? What is the organ of touch in animals ?-in insects ? What senses are liable to illusions? Which is the most certain of the senses? What fact was established by the senses of hearing, sight, and touch? Is the touch ever liable to error $y$ In what cases? May the sense of feeling become blunted? What facts prove it? Are the tactile powers of the skin in proportion to its sensibility? 


\section{CHAPTER XIV.}

\section{SENSE OF TASTE.}

1. The sense of taste is allied to that of smell and touch, as it requires the immediate contact of the body with the organ where the sense resides). (The quality of bodies, which it teaches us, is called sapidity. The superior surface of the tongue is the chief organ of taste; though the general lining of the mouth and the upper purt of the throat partici. pate in the function (The tongue is chiefly composed of muscular fibres, running almost in every direction; consequently it possesses great versatility of motion, and can be moulded into a great variety of shapes. It may be con. sidered as a double organ, as it is formed of two symmetrical halves, whose boundaries are marked by a slight groove in its upper surface; dividing it into right and left. From this groove a membranous partition extends down through its centre, and is attached to the froenum or bridle beneath. The tongue is not only the organ of taste but also of articu. lation, and also aids in mastication and deglutition.

2. The tongue is abundantly supplied with blood-vessels; and its nerves, as we have seen, are supplied from three sources. There has existed great difference of opinion among physiologists, as to which of these three is the special nerve of taste. General opinion now holds the $f$ fith as the proper nerve of taste, as well as of sensibility ; the ninth, as that of voluntary motion; and the eighth, as the means whereby the organ is brought into association with the throat, gullet, larynx, \&c. Dr. Elliotson, however, and some others, think that the glosso-pharyngeal is the nerve of tastel

3. When we examine the surface of the tongue, we find it thickly studded with fine papillae, or villi, giving the organ 
a velvety appearance. There are three varieties of these papillae. The first are situated near the root of the tongue, and belong to the class of mucous follicles, whose office it is to furnish this secretion. These are much larger than the others, and are called lenticular, from being shaped like a lens. It is these, together with the almonds of the throat, or ears, as they are sometimes called, which afford the mucus to lubricate the food in the act of deglutition, and also to keep the tongue moist, and in a condition for the due performance of its function.)

4. The other two sets of papillae are the instruments of taste. The one set is named conical, or filiform, and consists of small nipple-shaped bodies, broader at the base than the top, and scattered over the whole surface of the tongue, giving it its rough or shaggy appearance. The other set of papillae is larger, and consisting of small rounded heads, supported on short stalks, something in the shape of a mush. room, they have been called fungiform. These are but few compared with the former. These sensitive papillae are supplied with numerous blood-vessels as is shown in the next cut. In order for the exercise of taste, it is necessary for the mucous membrane to be in a state of integrity, for if it be removed, we only experience a sensation of pain. The animal papillae, which abound on the sides and tip of the tongue, appear to be the most exquisitely sensible. Certain bodies seem to affect one part of the more than another. Acids, for example, act especially on the lips and teeth ; acrid bodies, like mustard and cayenne pepper, on the pharynx. We read of cases in medical works, where, after the tongue has been removed by disease, or a surgical operation, persons could still speak, spit, chew, swallow, and taste. In one case, the individual could distinguish the bitterness of sal ammonial, and the sweetness of sugar; and Blumenbach mentions a young man, who was born without a tongue, and yet when blindfold, could distinguish between solutions of salt and aloes put upon his palate. 


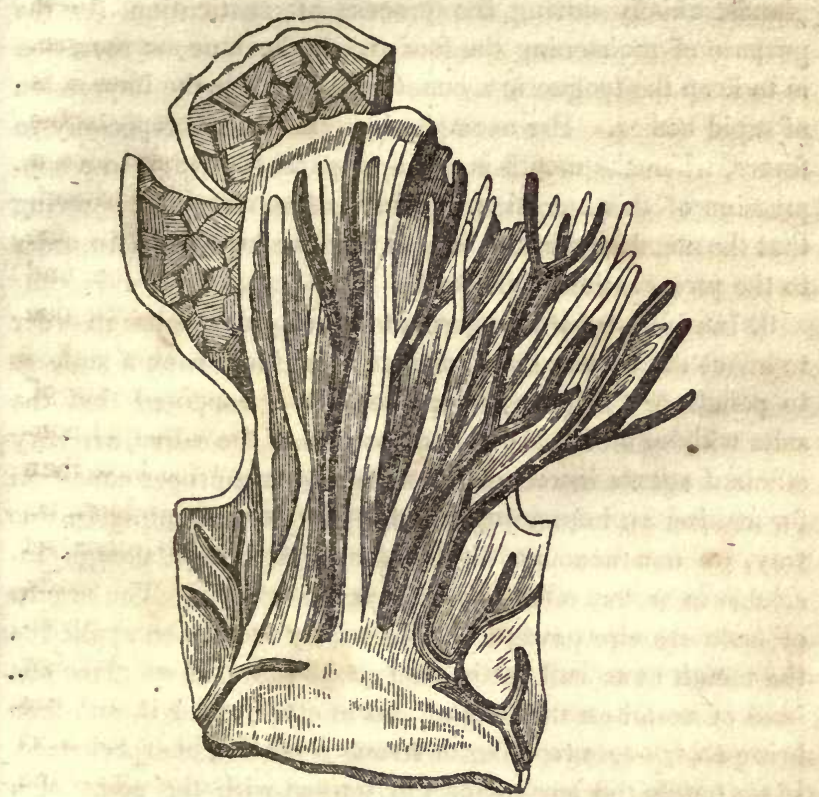

An upright section of one of the papillae of the tongue very greatly magnified, and split open, to show the nerves (engraved white) and the blood-vessels (black.)

5. The process of taste, then, is as follows :-When a fluid is taken into the mouth, these papillae dilate and erect themselves, being endowed with the property of adapting themselves to the active or passive condition of the sense of taste. If a solid portion of food is received, it is first touched by the tip of the tongue and brought into close contact with the papillae; when if it be dry or solid, it is carried to the back of the tongue and moistened with saliva, which thus becoming impregnated with its flavour, and flowing over the sides of the tongue, gives to the papillae a perception of the savoury juices. The saliva, or spittle, it should be recollected, is secreted by the parotid and other salivary 
glands, chiefly during the process of mastication, for the purpose of moistening the food, while the mucous secretion is to keep the tongue in a condition to receive the impression of sapid bodies. For example, in sickness, and especially in fevers, when the mouth is dry and parched, owing to a sup. pression of this secretion, the taste is entirely lost, showing that the membrane of the tongue must be kept moist in order to the preservation of the taste.

6. Insoluble substances are totally insipid, because in order to affect the nerves, the substance must-be in such a state as to penetrate the spongy papillae. (It is supposed that the salts which enter into the composition of the saliva, are very efficient agents in reducing substances to a proper condition for making an impression on the gustatory organ $\downarrow$ In this way, we can account for the fact, that metals, though insoluble in water, often impart a peculiar taste. The organs of taste are also powerfully affected by metals, so applied to the mouth as to call forth electric action. If we place onc kind of metal on the tongue and another under it, and then bring their edges together, a strong sensation is experienced If we touch the surface of the tongue with the point of a wire, connected with the positive pole of a galvanic battery, a sour taste is experienced; while the negative pole excites an alkaline taste. (These phenomena may be owing either to the electric action, disengaging from the saliva an acid in one instance, or an alkali in the other, or the electric excitement may call forth the special sensibility of the gustatory organ, in the same manner as it causes the special sensibility of the other organs.)

7. Savours, like odours, are innumerable, and as they differ so much from each other, it is impossible to classify them in any satisfactory manner. We can readily understand what is meant by the terms sweet, bitter, sour, saline, acril, ) \&c., yet each of them differs in intensity, as well as other shades of character. For example, rectified sugar, brown sugar, maple sugar, beet sugar, molasses, honey, \&c., are all 
sweet, but the taste of each is different. Linneus and Booer. have both made a classification of savours, but they have never been generally adopted by physiologists. Adelon divides them into two kinds, the agreeable and disagreeable. But even this division is not founded in nature ; for we find the old adage true, that "one man's meat is another man's poison." Every person has some peculiarities of taste, dis likes to particular articles of food, or shades of difference in the appreciation of tastes, which may be constitutional, or caused by association. Besides, the taste sometimes becomes unaccountably morbid or depraved. We often see children devouring chalk, brick-dust, ashes, dirt, and slatepencils, when if, at other times, they were required to swallow such articles, as medicine, they would doubtless deem it a peculiar hardship.

8. Savours differ as to the permanence or transientness of impression which they leave upon the organs of taste. (Aromatic and bitter substances particularly leave their taste in the mouth for a long time after they have been swallow. ed the physician, therefore, when he wishes to administer some nauseous drug, forestalls the sense of taste, by directing one of these substances to be held previously in the mouth. There is a common experiment on this subject, which has led to many bets, viz., giving to a person blind. fold, brandy, rum, gin, or any other spirituous liquor in rapid succession, and see whether he can tell one from another. In a short time, the nerve becomes so impregnated with the different substances, that all distinction becomes confounded 'Tasters of wine, tea, \&c., understand this principle ; for w see them take up a small portion and move it over the whole surface of the mouth, so as to extend its action, and then they wait for some time after the impression is made before they taste of other samples, When a person takes a medi cinal draught, he gulps it down as quick as possible, in ordes that it may come in contact with as small a portion as pos sible of the organ of taste. 
9. The taste is greatly under the influence of habit. (Many articles which at first excite disgust, being taken through fashion or necessity, at length become highly grateful. We need only name tobacco, and perhaps ardent spirits. The taste for these substances is altogether artificial, no one being fond of them, when taken for the first time. Such perversion of taste often becomes national. Thus garlic forms a constant ingredient in the dishes of some European countries. The most celebrated sauce of antiquity, was the Roman garum, prepared from the half-putrid intestines of fish. Another of their favourite condiments was assafoetida; and this is still in high repute among many of the orientals. Rotten eggs are highly esteemed by the Siamese, and fish in an advanced state of decomposition is highly relished in the northern and western islands of Scotland. Dried, putrid mutton is habitually eaten in Iceland, and epicures in every country esteem game and venison a greater luxury, if in a putrescent state. To be a fashionable epicure of the present day, requires that the taste should be educated or trained, like a sportsman's setter. It is then prepared to scent out, with infallible certainty, what fashion has taught it to relish as choice luxuries ; but which simple, unadulterated taste, rejects as fit only for the kennel or the carrion crow

10. The gratification which we derive from eating depends chiefly on the state of the stomach. If that is not in a condition to digest food properly, no matter how much we may generally relish any particular article; it will, at such times, invariably excite disrelish or even disgust. \$o also when we sit down with a keen appetite to a meal, as our hunger is appeased, the relish proportionally dimınishes, till at length we reach the point of satiety, and if we persist, nausea and disgust are certain to succeed) Here then, is another wise provision, informing us with infallible certainty when we have taken sufficient food to supply the wants of the system. The ancient Romans availed themselves of a knowledge of this law, and hence were in the habit 
of leaving the table once or twice during a meal, and after having, by means of an emetic, unloaded the stomach, of returning again to the charge.

11. As a general rule, articles that are agreeable to tho taste, are safe and nutritious, though this is not invariably the case. For example, prussic acid has a very agreeable savour, as well as odour, and is accordingly used to impart flavour to dishes and liqueurs, such as noyeau, yet prussic acid is one of the most powerful poisons in nature, Many substances which at first are highly agreeable, in a short time lose their relish; we see that grocers understand this principle, for instead of forbidding a new apprentice from eating sugar, raisins, honey, and molasses, he tells him to eat all he wants, knowing, that in a short time, his appetite will be cloyed, and all temptation removed.

12. Among animals, we find a great difference in the perfection of this sense). (Some enjoy it, doubtless, in as great, if not a greater degree than man, as they are able by it to distinguish plants that are nutritive and good for food, from those which are poisonous and accordingly it is a rare thing for animals to die from eating such vegetables. Many insects feed on the leaves of poisonous plants, and scme animals eat the leaves of the poison ivy without injury. There is an insect which feeds on the leaves of the tobacco, and the southern planter guards against its ravages by a process called worming. The taste also in animals sometimes becomes morbid, as we see it happen among our own race. Mr. Bennet, in his "Wanderings in New South Wales" states, that serious losses happened to the farmers in that country from the sheep acquiring the habit of licking and devouring earth impregnated with saline matter. In a short time, he says, their natural innocent dispositions become changed, and they become carniverous and savage, and devour the lambs. Thus out of a flock of twelve hundred lambs, eight hundred were devoured by the sheep themselves.

13. The sense of taste is most delicate in youth.' It is 15* 
(much impaired by the use of alcoholic drinks, tobacco, and highly seasoned food; so that the spirit-drinker, the tobaccochewer, and the epicure often lose this sense to such a degree that they cannot relish plain dressed food. That man relishes his food best who rarely uses powerful stimulants and narcotics. Majendie says that man would probably excel all the other animals in delicacy of taste, if he did not, at an early period, impair its sensibility by strong drinks, or by the use of spices, and other luxuries.

14. (The taste may be improved by cultivation like any of the other senses. Dr. Kitchener states that some epicures are able to tell from what precise part of the Thames a sal. mon had been caught, when presented at table. Many gourmands pretend to be able to pronounce by sipping a few drops of wine, the country whence it comes, as well as its age; to tell by the taste, whether birds put upon the table are domesticated or wild, \&c. Such acuteness of taste is however, by no means desirable, as we are liable, in the "rough and tumble" of life, to meet with so much that demands obtuseness rather than refinement of feeling. The epicure with his acuteness and delicacy of taste, is liable to continual annoyances and discomforts, while the man of simple and unsophisticated taste will receive gratification and pleasure from the very same objects which excited disgust in the former.

15. If we examine the lower animals, we shall find that in none of them is the tongue precisely like that of man. The resemblance is the nearest in apes; but in them, even, it is much elongated. In animals that chew the cud, or ruminants, we find the tongue covered with a dense cuticle, studded over with numerous pointed papillae, especially towards the root. These projections, together with the waving ridges on their palates, are of great use in collecting and swallowing the tender herbage on which they feed. In the cat tribe, the sharp, horny prickles on the tongue, enables them to take a firm hold. In the lion and tiger these prickles are suffi- 
cient to tear off the skin even of large animals. Ant-eaters are furnished with a very long and slender tongue, covered with a viscid, adhesive secretion, whereby they are able to seize their prey, on thrusting it into an ant-hill.

16. Whales have an enormous tongue, though it has been doubted whether it is endowed with the sense of taste. They have, moreover, projecting downwards from the upper jaw, a kind of pallisade, consisting of several hundred plates of whalebone, the outer edges of which are sharp, the inner fringed with long hair like appendages, the spaces between the plates being little more than half an inch. The length of the plates sometimes exceeds twelve feet. This pallisade, when the mouth is closed, is covered by the enormous fleshy lower lip, but when open, it presents a kind of grating through which the water loaded with meduse and other small animals, flows, Captain Parry states that these medusa or sea.blubber, so abound in the arctic seas, that when the water is still, and the surface smooth, they present a striking resemblance to a thick snow-fall, when the flakes are large and the air calm. The soft, spongy texture which forms the tongue of the whale, is thought to be better adapted for licking the food from the hairy whale-bone roof, and transferring it to the gullet, than to serve as an instrument of taste.

17. The tongue of birds varies much in form and consistence. In some, it is horny, as in the toucan, where it is several inches in length and exceedingly narrow, like a long strip of whale-bone; or in the wood-pecker, to the tip of whose tongue there is fixed a long, sharp, pointed, spear-like body with serrated edges, for piercing and seizing on insects burrowing beneath the bark of trees. Parrots, which belong to the same class, have soft fleshy tongues well adapted to the exercise of taste.

28. In rentiles also, we find great variety of forms and applications of the tongue. In the crocodile it is small and immoveable, so much so, as to lead some naturalists to deny 
its existence. In serpents, it is forked, and susceptible of considerable motion; while in the frog, it is folded back in the state of inactivity; but when the animal is about to seize an insect, it suddenly unfolds and projects it out of the mouth. The tongue of a chameleon is contained within a sheath, and admits of being projected to the extent of six inches, and is besmeared with a glutinous secretion. In the twinkling of an eye it is darted out to catch its food, which consists chiefly of flies. Fishes have the mere rudiments of a tongue, fixed near the throat, which is often furnished with teeth. There is reason to believe that many of the invertebrated animals are endowed with taste, such as bees, wasps, flies, and leeches.

Questions.-To what sense is that of taste allied? What is sapiaity? What is the chief organ of taste? What other parts participate in the function? Describe the structure of the tongue. From what source does the tongue derive its nerves? Which is the nerve of taste? What are papillæ? How many kinds are there on the tongue? What is the office of the mucous papillæ?-Of the conical and fungiform? What is the process of taste? Can insoluble substances be tasted? Why not? What are the use of the salts in the saliva? How do we taste metals? How is the taste excited by galvanism explained? Are there many savours? Name some. Can they be classified Why not? What articles leave a taste in the mouth the longest? What use can be made of this fact? How do tasters manage? Is taste under the influence of habit ? What facts show this? To what is the pleasure of eating owing? How is this shown? Is the taste a sure guide to what is safe and nutritious? Do animals differ as to taste? Do they possess it in as great perfection as man? Does it ever become morbid in them?. When is taste most delicate? How is it impaired? May the taste be improved? 2 Are the advantages or disadvantages the greatest, which attend great delicacy of taste? Have any of the lower animals a tongue like that of man? Describe some peculiarities? What apparatus have whales for eating small sea animals? What is said of the tongue of birds ?of reptiles? of fishes? Do any of the invertebrated animals possess the faculty of taste? 


\section{CHAPTER XV.}

\section{THE SENSE OF SMELI.}

1. The sense of smell takes cognizance of the odorous properties of bodies.) (The seat, or organ, is the mucous membrane, which lines the nasal cavities, and is called the schneiderian, or pituitary membrane.) (It is covered with nervous papillae, similar to, but more delicate than those which cover the organ of taste.) These cavities open anteriorily through the external nostrils, and posteriorly into the fauces or throat, to permit the air to traverse them in its passage to the lungs. (The nasal organ seems to be designed for the purpose of collecting the odorous particles; and it is divided into two similar cavities, by a bony partition, called the vomer, which is extended by means of cartilage to the anterior extremity of the nose. Each nostril contains

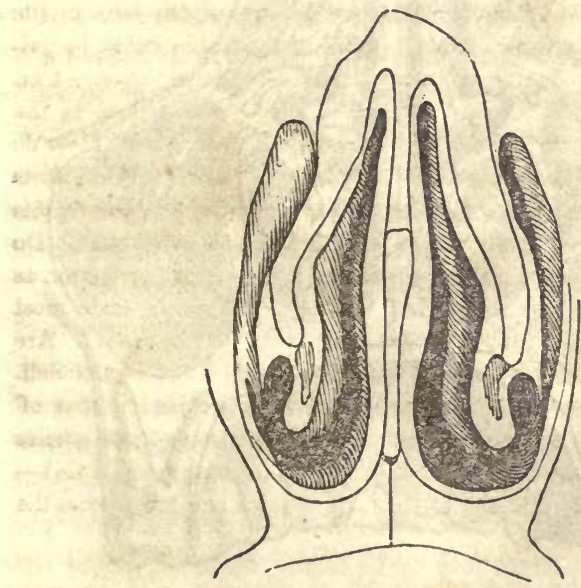

Front view of the nasal fossae. 
two convoluted or turbinated bones, of a light spongy texture, one being situated above the other; and they divide the general cavity of the nostril into three passages?

2. In connection with the nostrils, there are several cavities, as in the frontal and upper jaw-bones, called sinuses. These communicate with the nostrils, and as they extend the surface on which the lining membrane is expanded, they are supposed to contribute to the sense of smell, by affording capacious receptacles for air, loaded with odorous particles. Of the 14 bones which enter into the formation of the face, 11 assist in forming the cavities of the nostrils, as do also three out of the eight bones that form the cranium. Be.

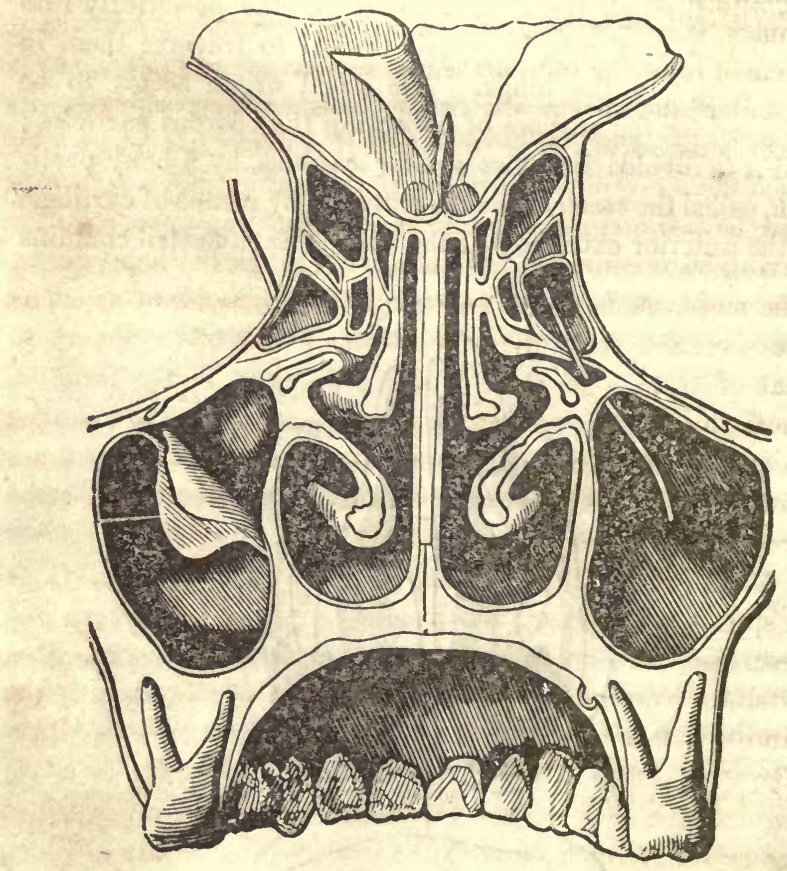

Nasal fossae seen from behind, 
sides the cartilage which forms the septum of the nose, two others of an elastic nature constitute the Wings; landias they admit of motion, several muscles are attached to them, in order to regulate the external orifices in accordance with different conditions of respiration, and also to enable us to exercise the sense of smell with greater effect, when we wish voluntarily to employ that function.

3. The membrane which lines the nasal fossae, resembles the mucous membranes generally, and adheres firmly to the bones and cartilages which it covers.) Externally, this membrane is continuous with the common integuments, and pcs. teriorly with the lining membrane of the throat. It varies somewhat in appearance in different situations. In the sinuses, it is thin, pale, and of a smooth surface; but where it constitutes the immediate seat of smell, it is thicker, more vascular, and of a redder colour than mucous membrane in other situations. It is studded with mucous follicles, which yield the secretion with which it is moistened; though it is also bathed with the tears that spread out upon it, after having been conveyed from the eye through the nasal ducts. The nasal mucus seems as essential to the sense of smell, as the secretion from the mucous membrane of the mouth to that of taste. In those who use tobacco in the form of snuff, this secretion often becomes so scanty or so changed in quality, that the smell is much impaired, and sometimes entirely lost : the voice also is seriously injured by the same practice.

4. The olfactory, or first nerve, is the sense of smell. This is spread out on the thick vascular portion of membrane just described. Twigs from the first and second branches of the fifth, are plentifully ramified over the whole surface of the pituitary membrane, imparting to it common sensibility. The nose is also supplied with branches from the facial to regulate the action of the muscles. Dr. Majendie says, that the organ of smell ought to be described as a sort of sieve, placed in the passage of the air, as it is introduced into the 
chest, and intended to stop every foreign body that may bo mixed with the air, particularly the odours?

5. What is called odour, or smell, resides in nearly all bodies, and is given off by moisture, heat, motion, or friction. Those which do not possess this quality are called inodorous. Those little particles which convey the odour, are scattered through the air, and in breathing drawn into the upper part of the nostrils, where the sense of smell principally resides. If we breathe through the mouth, odours in general will not be perceived, unless very pungent. The fluid which moistens the lining membrane of the nose, is supposed not only to render it more sensitive and delicate, but also to entangle the odorous particles, and in this way detain them longer in contact with the olfactory nerve. The constant evaporation which takes place from the membrane, owing to the passage of the air in respiration, requires that the secretion should be constant as well as copious; otherwise the membrane would soon become dry and parehed.

6. It is very difficult to describe an odour, except to those who have smelled it, or something with which it may be compared. We can say that odours are pleasant or disagreeable; that they are aromatic, or sweet, rancid, or fetid, \&c. ; but we can give no correct idea of the peculiar smell of bodies, such as camphor, musk, garlic, the rose, \&c., without experiencing the sensation which their smell produces.

7. The odorous particles of bodies must be very small to excite any sensation on the animal organs. A grain of muslc will, it is said, scent a room for years, and not lose any of its weight ; Mr. Boyle asserts that the smell of cinnamon, from Ceylon, is perceived at sea at the distance of twentyfive miles from the island.) Scales in which a few grains of musk have been weighed, have been found to retain the smell for twenty years, though during all this time, they must have been constantly giving off odorous particles. Haller kept some papers forty years, which had been perfumed by a single grain of amber, and at the end of that time they did not 
appear to have lost any of their odour. But these particles cannot be as small as those of light, because we see that glass is capable of retaining the former, but suffers the latter to pass through it. The art of the perfumer consists in fixing and preserving odours in the most agreeable and convenient vehicles.

8. Odours differ very much as to the permanence of the impression which they produce. While that of some is very transient, in others the scent remains for hours after the application of the substance. They also differ, as we have seen, as to the extent to which their influence extends. Moisture in the atmosphere is favourable to the diffusion of odours, which would seem to show that vapour is a good conductor. For example, a flower garden is never more grateful to the smell than in the morning, when the dew is evaporating, or after a warm summer shower. So also the plants of a green-house are more fragrant, just after they have been watered. Some flowers give off their odour only at certain times, generally after they are fully expanded, and their parts in the greatest activity.

9. Though the air is the usual vehicle for odours, yet we find that thcy adhere to solid bodies, and can even be conveyed through water. (But though the whole art of perfumery is founded on this fact, it has been strenuously denied that they could be conducted through water, and consequently that fishes could smell. Some physiologists state that fishes have no olfactory organ; that the part commonly considered as such is the organ of taste. This opinion is, however, erroneous. "Not many naturalists of the present day," says Dunglison, "will be hardy enough to deny, that fishes have an organ, or sense of smell. At all events, few anglers, who have used their oil of rhodium, or other attractive bait, will be disposed to give up the results of their experience, without stronger grounds than any that have been assigned by the advocates of that view of the subject."

10. Fishes are furnished with organs of smell, but they 
have no communication with the mouth or gullet. They are insulated cavities, covered with a valvular lid, and lined with a plaited membrane, similar to the under surface of some mushrooms. This serves to extend tho surfice, while it is covered with a viscid mucus. In tho cod-fish, the nerves of smell are spread out in a cavity filled with fluid, and larger than that which contains the brain itself. "That the cod is guided by smell in the selection of food," snys Aitkin, "must be well known to overy ono who has taken it with bait, in circumstances where he could watch the conduct of the fish. If not very hungry, it may frequently bo observed to approach the bait, apparently attracted by the sight, till, at a closer distance, it seerns distinctly to smell at it; and if not satisfiod, turns aside und neglects it." Every person who has been in the habit of fishing much, must have often observed the same fuct, in catching common pond.fish, such is perch, roach, \&d.

11. It was an opinion formerly entertuined, that odours possess nutritive properties, as savoury smells seem to have the effect of allaying hunger, or at lenst of satisfying the appetite in some degree. 'This effect, however, is best ex. plained, by reterring it to the influence of odours on the nervous system, as we soe the nppetite often instantly des. troyed by unwelcome news. In persons whose digestive organs are wenk, the appetite is often destroyed instantane. ously by a nauseous odour. We rend that Democritus lived three days on the vapour of hot brend; and Bacon speaks of a man, who was supported several days by inhaling the odour of a mixture of uromatio and nliaceous herbs. In 1638 , Dr. Wilkins, the Bishop of Chester, published a book, the object of which was, to show that the moon is inhabit. able, and that it is possible for us to find a pussage thither. In this work, ho snys, "If wo must needs feed upon something, why may not smells nourish us ? Pluturch and Pliny, and divers other uncients tell us of a nation in India, that lived only upon plensing odours; and it is the common 
opinion of physicians, that these do strangêly both strengthen and repair the spirits."

12. We read an amusing anecdote in Fuller, who lived at the same time with the bishop, in relation to this supposed nourishing property of odours A poor man being very hungry, staid so long in a cook's shop, who was dishing up the meat, that his stomach was satisfied with only the smell thereof. The choleric cook demanded of him to pay for his breakfast; the poor man denied having had any ; and the controversy was referred to the decision of the next man that should pass by, who chanced to be the most notorious idiot in the whole city; he, on the relation of the matter, determined that the poor man's money should be put between two empty dishes, and that the cook should be recompensed with the jingling of the money," as he was satisfied with the cook's meat.

13. The sense of smell is closely associated with that of taste. It seems indeed as a sentinel standing on guard, to see that no enemy approaches the citadel ; it tells us whether the aliment placed before us, is agreeable or disagreeable; of course whether it will agree or disagree with the stomach. The taste and the smell are hardly ever at loggerheads; it does, however, sometimes happen that a substance that is repugnant to the smell, is agreeable to the taste. In such a case they soon come to an understanding, and the smell chooses, to make the best of it, and drop its repugnance. At any rate, its aversion, some way or other, is soon neutralized. The smell is, however more useful to animals, as a sentinel, than it is to man, whose reason is more than a match for the instinct of the brute creation. In them, indeed, it rarely fails to guide aright. How wonderful is this provision which leads them with unerring certainty to choose the innocent herb from the poisonous plant ; the nutritious vegetable from that which is destitute of nutriment; and to

"Dunglison's Physiology. 
reject instinctively, every thing which would prove noxious or disagreeable. It is not, however, infallible even in the brute creation; for we see the flesh-fly attracted by a certain species of mushroom which admits a cadaverous odour, simi. lar to putrid flesh; in these they deposit their eggs, which, when hatched, perish for want of suitable food to nourish them.

14. A singular custom, which prevails among shepherds in some countries, shows that the sheep is more under the guidance of smell than sight or any of the other senses. "When a lamb has died," says Aitkin, "the shepherd wishes to put to the ewe another lamb that may have lost its dam ; if she refuses to foster the stranger, he is sure to succeed by stripping off the skin of her own offspring, and tying it on the back of the stranger, that she may smell the skin; she then entertains and treats it as her own. In this case she neglects the sense of sight, for nothing can be more uncouth than the object of her affections; neither does she attend to the evidence afforded by hearing; however unlike the bleating of the foster lamb may be to that to which she was first accustomed, her smelling is satisfied, and she is content." The same practice succeeds with the cow.

15. In the elephant, the tapir, and the hog, as well as in oxen, sheep, deer, and antelopes, we find the cavities of the nose very capacious, and the surface of the pituitary mem. brane vastly extended; and accordingly the sense of smell is proportionally acute, In France it is customary to employ the hog to hunt for truffles, a species of edible mushroom which grows at some distance below the surface of the ground. By the sense of smell alone, he is accurately guided to the spot where one is growing, and begins to turn up the earth with his snout, in order to get at it. The vegetable hunter, however, anticipates him, and driving away the animal, digs down, and appropriates it to himself. In this way he secures, in a short time, sufficient for a family din. ner. 
16. The delicacy of this sense in the greyhound is most astonishing. He not only tracks the hare, the fox, or the wolf with unerring certainty, long after their footsteps have been imprinted, but even in a large city, he will trace the progress of his master through thoroughfares and thickly crowded streets, distinguishing his footsteps from those of a thousand passers-by, and amidst the odorous particles emanat. ing from a thousand sources. When Hispaniola was first discovered by the Spaniards, they employed the greyhound in hunting the poor natives, who, unlike the more fortunate Seminoles of Florida, could find no ever-glade, no fastness, no retreat, which could save them from the unerring scent of these animals.

17. The organ of smell is universally found in birds, though varying in size. Rapacious birds and waders, or those that live on fish, have it more largely developed than any others. Humboldt relates that in South America, when the inhabitants wish to take the condor, they kill a horse or cow, and in a short time, the odour of the dead animal attracts those birds in great numbers, and even in places where they were scarcely known to exist. Some of the Roman historians tell us that vultures went from Asia to the field of battle at Pharsalia, a distance of several hundred miles, attracted thither by the smell of the dead. Pliny, the natural historian, affirms that the vulture and the raven have the sense of smell so delicate, that they can foretell the death of a man three days beforehand.

18. Mr. Audubon, however, relates two experiments to show that vultures are indebted to sight rather than smell, in the discovery of their prey. He stuffed a deer's skin with hay, allowed it to become as dry as leather, and placed it in a field; in a few minutes a vulture made for it, attacked it, tore open the stitches, and pulled out the hay. He then put a dead hog into a ditch, and covered it over with care; it soon putrefied and became intolerably offensive, but the vultures, which were sailing about in all directions in search of 
food, never discovered it, although several dogs had been attracted to it by the scent. His next experiment was to stick a young pig, and cover it over with leaves; vultures soon saw the blood, descended to it, and by this means soon discovered the pig, while it was still fresh. The general opinion of physiologists at present is, that birds of prey, have not so acute a sense of smell as has been generally supposed, and that they are guided chiefly by sight.

19. It is stated by whale-fishermen, that in Greenland, when a whale has been captured, although at the time scarcely a single bird may be visible, yet in a short time, immense numbers of gulls and other sea-birds hover about, and hasten to the spot from every point of the compass. Although these birds have the organ of smell, and consequently the sense itself, largely developed, yet such facts may be more satisfactorily explained, than by supposing that they are able to smell the flesh of a dead whale, before putrefac. tion has commenced, at a distance of many miles. A better explanation cannot be given than is contained in the first volume of "MacGillivray's History of British Birds." Speaking of ravens gathering together in immense numbers over a dead carcass, in explanation of the phenomenon he remarks, "A single raven might first perceive the carcass. Ravens have character in their flight as men have in their walk. A poet sauntering by a river, a conchologist or fish. woman looking for shells along the shore, a sportsman searching the fields, a footman going on a message, a lady running bome from a shower, or a gentleman retreating from a mad bull, move each in a different manner, suiting the action to the occasion. Ravens do the same, as well as other birds; so those at the next station, perhaps a mile distant, judging by the flight of their neighbours that they had a prize in view, might naturally follow. In this manner the intelligence might be communicated over a large extent of country, and in a single day a great number might assemble. We know from observation that ravens can perceive an 
object at a great distance, but that they can smell food a quarter of a mile off we have no proof whatever; and as we can account for the phenomenon by their sight, it is unnecessary to have recourse to their other faculties." Every person who has seen the manner in which crows collect together about a dead animal in the country, will be satisfied that the above is a correct explanation of the phenomenon.

20. The olfactory organs of reptiles are but slightly developed. Frogs have two small holes, which serve as the organs of smell. The pituitary membrane of the turtle is of a very dark colour, and the nerve is of considerable size. In serpents, they are more elongated, and in lizards still more so. The animals of this class have no cavities corresponding to the sinuses; of course the sense of smell cannot be very acute.

21. The smell can be greatly improved by education. Humboldt states, that the Peruvian Indians can distinguish in the middle of the night the different races by their smell; whether they are European, negro, or American Indian. By habit, the perfumer acquires the faculty of distinguishing the nicest shades of odours. We see the influence of education, by the difference between a dog that has been trained to the chase, and one that has not. In the blind, the sense of smell is particularly acute. A boy in Edinburgh, who was born blind and deaf, could tell the entra nce of a stranger into the room by the smell alone; and he told one person from another by smelling at him.

22. Dr. Good remarks, that " we occasionally meet among mankind with a sort of sensation altogether wonderful and inexplicable. There are some persons so peculiarly affected by the presence of a particular object, that is neither seen, tasted, smelt, heard, or touched, as not only to be conscious of its presence, but to be in agony till it is removed. The vicinity of a cat not unfrequently produces such an effect; and $I$ have been a witness to the most decisive proofs of this 
in several instances." There can be no doubt, I think, that this peculiarity is referable to delicacy of smell. Dr. Dunglison states, that a gentleman, blind from birth, had an extraordinary antipathy to cats. One day in company, he suddenly leaped up, got upon an elevated seat, and exclaim. ed, that there was a cat in the room, and begged them to remove it. It was in vain that the company assured him that he was mistaken. He persisted in his assertion and in his state of agitation; when, on opening the door of a small closet in the room, it was found that a cat had been accidentally shut up in it.)

Questions.-Define the sense of smell. Where is it seated? Describe the pituitary membrane; - the nose. What cavities are concerned in the sense of smell? What is the object of such an extended surface? How many bones assist in forming the cavities of the nostrils? Why are they supplied with muscles? Does the membrane that line the nostrils resemble the other mucous membrane? How is it moist. ened? Do the tears answer any purpose except washing the eye? What effect has snuff-taking on the sense of smell? What is the nerve of smell? What other nerves send twigs to the nose ;-their function? To what does Majendie compare the organ of smell? What is odour? How given off from bodies? Are odours easily described? What facts show that their particles are very minute? What is the art of perfumery? Do odours differ as to the permanence of the im. pression they produce? What favours the diffusion of odours? Can odours be conveyed through water or other fluids? Have fishes any organ of smell? What facts prove this? What article renders bait attractive to fish? Were odours ever believed to be nutritious? What anecdotes in relation to this? Are the senses of smell and taste associated $y$ What is the use of smell? Are any substances disagreeable to the smell and agreeable to the taste? Is smell more useful to animals than man Is it infallible in them ? What fact proves that it is not? What singular custom prevails among shepherds? What animals have the sense of smell the most acute? How is the smell of the hog employed in France? What is said of this sense in the greyhound? Was it ever employed to hunt savages? When and where? Have birds any organ of smell? What does Humboldt say of the condor? What experiments did Audabon try, to prove that birds of 
prey are guided by sight instead of smell ? What do whale fishermen say of birds in Greenland? How does Mr. MacGilivray explain the gathering together of so many birds over a dead carcase? Have reptiles any olfactory organs? Can this sense be improved by education? What causes the singular antipathy to cats, which we meet with in some persons? 


\section{CHAPTER XVI.}

\section{THE SENSE OF SIGHT.}

1. THIs is the most refined and admirable of all our senses. By it especially we hold converse with the external world; and without it, we should not only be deprived of a large portion of the pleasures we now enjoy, but we should be unable to maintain our existence for any length of time. The wisdom, power, and benevolence of God are chiefly manifested to us through the sense of vision.

2. The eye is the organ of sight, and the most beautiful of all the organs of the senses. So admirable is its struc. ture, so wonderful the provisions which adapt it to the purposes for which it was designed by our Creator, that I shall give as full a description of it as my limits will allow; and in order to an easy and clear comprehension of its structure and function, I shall first describe the coats of the eye, including the retina, or the expansion of the nerve of vision; then the humours of the eye, by the agency of which, the rays of light are concentrated so as to form an image upon the retina; and lastly, explain the laws of vision, the motions of the eye, and the means of protection against injury.

3. The Coats of the Eye.-The coats of the eye are generally reckoned as three in number, viz. the sclerotic, the choroid, and the retina) (besides these, there are the cornea, the iris, and the ciliary processes, which are viewed and described as appendages to these coats.

4. The sclerotic, ${ }^{*}$ or outer coat, is the firm, opaque, fibrous substance which preserves the globular figure of the eye ; and besides defending its internal delicate structure, serves for the attachment of those muscles which move the eye. It invests

* From a Greek word, signifying hard. 
the eye on every side except the front, forming about fourfifths of the external covering, and extending from the entrance of the optic nerve, at its base, to the cornea. This coat has almost the firmness of leather, and possessing but $\mathrm{li}^{++l}$ ? sensibility, it is rarely exposed to inflammation or other

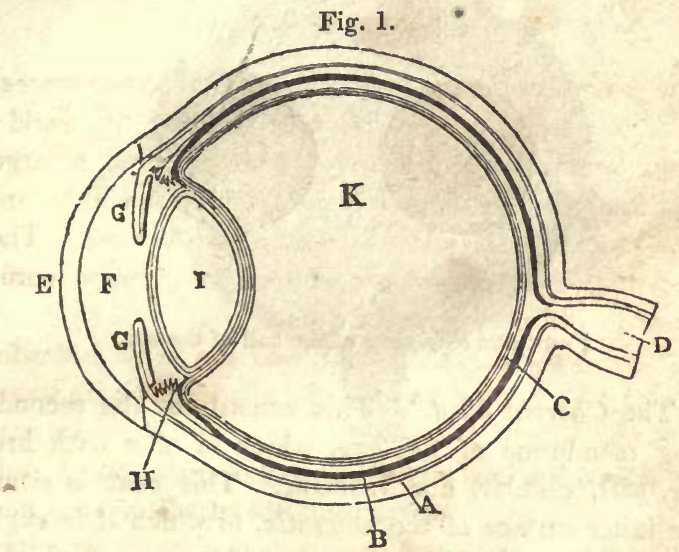

Plan of the eye, seen in section.

A, The Selerotic Coat.

B, The Choroid Coat.

C, The Retina.

D, The Optic Nerve.

E, The Cornea.
F, The Aqueous Humour.

G, The Iris.

H, The Ciliary Processes.

I, The Crystalline Lens.

K, The Vitreous Humour.

diseases! The sclerotic coat is much denser in the eyes of fishes than in the eyes of creatures which live on the surface of the earth. In the whale, it is more than an inch thick, in order, that when he dives some hundreds of fathoms deep, the pressure of the water on the eye may not be greater than its structure can withstand. That this pressure is very great, is shown by the common experiment of corking an empty bottle tight, and then letting it down into the sea by a cord; the cork will always be found forced in, and the bottle full of water; the pressure being equal to the weight of the column of water above it, of which it is the base. Dr. Buck. 
land states, that in one experiment, a copper cylinder, containing atmospheric air, was crushed flat under a pressure of 300 fathoms, and bottles filled with air were crushed in. stantly. This shows the necessity of a strong sclerotic coat in animals that dive far beneath the surface. .

Fig. 2.

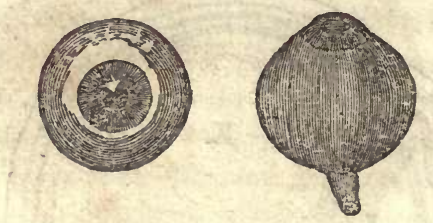

Front and side view of the ball of the eye.

5. The Choroid Coat.* - This constitutes the second investing membrane of the eye, which is of a dark brown colour, soft, cellular, and vascular. This coat is situated on the inner surface of the sclerotic, to which it is slightly attached by means of blood-vessels and nerves, of which indeed it seems to be chiefly composed for, on injecting the eye carefully with coloured wax, it assumes a uniform red colour. (The inner as well as outer surface of this mem. brane is covered by the pigmentum nigrum, or black paint; which seems to absorb the rays of light imrnediately after they have struck the sensible surface of the retina.) (This pigment, sometimes called tapetum $\dagger$ in animals that see best at night, is wanting in albinos, as I have already stated; and it is owing to this cause that the iris and pupil appear of a red colour, and that their vision is so imperfect, that they cannot view objects in a strong light; and indeed can scarcely see enough to go about in the day-time. In animals that prowl by night, this pigment is wanting, or of a

* Choroides, fleecy, like a lamb skin.

+ Tapetum, like cloth, or tapestry. 
bright green, or silvery whiteness, and the dark pigment is peculiar to those animals that see in the brightest light of day.

Fig. 3.

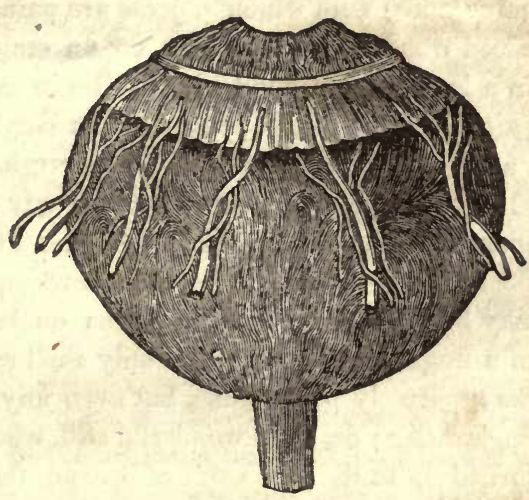

The cye, after cutting away the sclerotic coat and cornea, to show the vessels of the choroid coat; magnified.

6. The Retina.*-This is the third and innermost mem. brane of the eye, and is the expansion of the optic nerve, and the immediate seat of vision. It is a soft, thin, and transparent substance, extending from the optic nerve to the crystalline lens, and lining the choroid coat throughout without adhering firmly to it. The retina may be divided into three layers, viz., serous, nervous, and vascular; the former of which passes on over the surface of the lens, and forms part of its capsule. There is a small portion of the retina, supposed to be near where the optic nerve pierces the sclerotic coat, which is not susceptible of vision, as may be shown by an experiment hereafter mentioned. It was formerly supposed, that the retina was endowed with extreme sensibility; but it is now ascertained that it is almost insensible to every stimulus but that of light. The same is true 
of the optic nerve. The ordinary sensibility of the eye is derived from the branches of the fifth pair of nerves; and we have already seen that several pairs of nerves are sent to its muscles.

7. The minuteness with which objects are painted on the retina is indeed wonderful. Standing on an eminence, the eye takes in a landscape of hundreds of miles in extent ; and all this is painted on the retina, though, as an English writer calculates, a portion of the castle of Edinburgh, 500 feet long and 90 feet high, occupies on the retina only the twelve hundred thousandth part of an inch, when seen at a certain distance. "A whole printed sheet of newspaper," says Arnott, " may be represented on the retina on less surface than that of a finger nail, and yet not only shall every word and letter be separately perceivable, but even any imperfection of a single letter ; or, more wonderful still, when at night an eye is turned up to the blue vault of heaven, there is portrayed on the little concave of the retina, the boundless concave of the sky, with every object in its just proportions. There a moon in beautiful miniature may be sailing among her white-edged clouds, and surrounded by a thousand twinkling stars, so that to an animalcule, supposed to be within and near the pupil, the retina might appear another starry firmament with all its glory. If the images in the human eye be thus minute, what must they be in the little eye of a canary bird, or of another animal smaller still! How wonderful are the works of nature!"

8. The Cornea is the term applied to the anterior transparent portion of the ball. It resembles a watch crystal in shape, and it is received into a groove in the sclerotic coat, in the same manner as a watch-glass is received into its case, as in this cut. It is somewhat thicker than the sclerotic

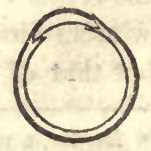


coat, and is composed of six concentric plates; but its blood. vessels are so small, that they exclude the red particles altogether, and admit nothing but serum. Under the first plate, little glands are found, perceptible only by aid of the microscope, which are supposed to secrete an oil which gives the eye its bright, sparkling appearance. In the last stage of life, we find this fluid forming a thin pellicle over the corned. What is called the ciliary ligament, is the groove or circle, where the cornea is inserted in the sclerotic coat,

9. We find the tunics just described in the lower grades of animals, as well as in man, differing of course in form, density, \&c., but always fitted to the circumstances of the animal. Thus in soft, molluscous animals, the defensive coats of the eye are soft also; but then their eyes are placed on ten. tacula, or feclers, so that they can retract them within their shells. In the articulata, as insects, the coverings of the eye are firmer, and of a horny consistence. In the crustacea, such as crabs, lobsters, \&c., the eyes are set in short bony cylinders, and the cornea is often covered merely by a portion of skin, which passes over it. In fishes, we see the cornea flat, on account of the absence of the aqueous humour. In birds, the cornea is conical, corresponding with the quantity of aqueous humour; and it is more prominent in rapacious birds, such as the hawk, eagle, and kite, than in aquatic birds. It is remarkable that the sclerotica in birds consists of three different layers, the middle one of which is bone, and composed of several plates, overlapping each other; designed doubtless to protect their eyes against each other's sharp-pointed bills, which they have to encounter in their attacks. In the higher animals, the coverings of the eye are similar to those of man.

10. The Iris, is a circular membrane, which hangs sus. pended like a curtain in the aqueous humour, and is attached to one of the coats of the eye at its circumference. It derives its name $i r i s$, or rainbow, from the various colours it has in different individuals, such as dark-brown, or black, 
light-grey, olue, and several shades and combinations of these. It is on this alone that the colour of the eye-de. pends. The colour depends indeed on the refraction of the light, as it falls on the fleecy or velvet-like surface of the membrane, and also upon the degree in which the black paint which covers its back is seen through it ; according as the iris is more or less transparent, will the "colour of the eye" be lighter or darker.

11. In many of the lower animals, especially birds, the iris assumes a still greater variety of colours. The round hole in the centre of the iris is called the pupil, and it is the dark pigment of the choroid coat, that we see through this when we look into the eye of another. Aitkin says that this name has been given to it, from the fact that when we look into the eye, we see a small image of our own face, like a very minute child or pupil. In albinos, and in animals that see best in the dark, like owls, the dark pigment is wanting not only on the choroid coat, but also on this membrane, and as these parts are very vascular, the blood is seen imparting a red colour to the eye.

12. The iris has the power of dilating or contracting in order to admit more or less light according as it is needed. (This is effected by muscular fibres.) Of these, there are two kinds. The first set converge from the circumference of the iris to the circular margin of the pupil, and are called the radiated muscles. When these contract they dilate the pupil. The other set is composed of circular fibres which go round the border, and indeed, form the pupil; these are called the orbicular muscle; and when they contract diminish the size of the pupil. Now, when more light enters the eye than is wanted, the excited retina immediately gives warning of the danger, and the nerves which are plentifully distributed to the iris, stimulate the orbicular muscle to contract, and the radiated one to relax, by which means the size of the pupil is instantly lessened. On the contrary, when in the dark or twilight, more light is needed, to transmit a distinct image 
of objects to the brain, the orbicular muscle relaxes, and the radiated one contracts, so as to enlarge the pupil to its full extent. Between these two muscles is a middle layer, composed of a net-work of blood-vessels and nerves.

Fig. 4.
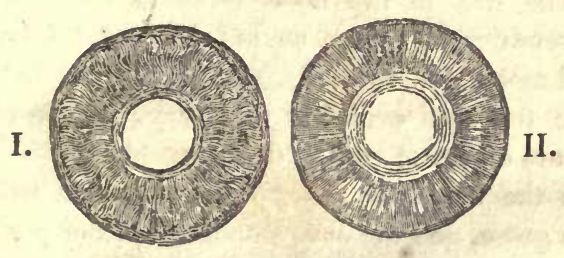

The cut marked I. represents the iris magnified as seen from the front, showing the radiated muscle.

Cut II. is a back view of the same showing the orbicular muscle.

13. The iris then, regulates the quantity of light passing through the pupil. The pupil during sleep is in an intermediate state; in inflammation of the brain it is generally contracted; but when the functions of the brain are interrupted by narcotic poisons, the pressure of effused fluid, a tumour, or any other cause, the pupil is dilated. The bella donna, or deadly night-shade, is employed by surgeons for this purpose, when they wish to couch, or perform other operations on the eye. The contraction of the pupil is readily seen by holding a candle close to the eye of a person, and then withdrawing it slowly ; or by directing a person to look at a very near ob. ject, and then at one more distant. Some persons can dilate and contract the iris at pleasure. I possess this faculty to a very great extent, and was conscious of it before $I$ ac. tually tried the experiment. The motion of the iris is not at all associated with that of the lids, as Walker suggests in his late excellent work on the Philosophy of Sight, the lids remaining the whole time perfectly stationary. I am, when contracting the iris, sensible of an effort similar to that of examining a very near object, and when dilating it, like that 
of looking on one at a distance; but it is not necessary actually to look at any object in either case, nor do I attempt it. If this does not prove that the muscles of the iris are somewhat under the control of the will, then it cannot be proved that any muscles of the body are so.

14. The iris, in the lower animals, not only presents great diversities in colour, as has been stated, but also in form and mobility. In birds, and in the cat tribe, its mo. tions are free and evidently voluntary; but in reptiles, its motions are obscure; and in fishes imperceptible. In ruminants, in the horse, the marmot, in the whale tribe, and in owls, the goose, and the dove among birds, the pupil is elon. gated transversely or sideways. In the horse, a small square curtain hangs down, which intercepts a great portion of the rays coming from above. In the cat tribe, including the lion, the tiger, leopard, the lynx, the jaguar, \&c. the pupil is elongated vertically, as it is also in the crocodile? Now we see a wise design in this arrangement, for in such animals as have to watch their prey, which is generally placed more above them, as on a tree, than at either side, the pupil is elongated vertically, so as to admit of more extended vision in such direction; while in timid animals, like the ox, sheep, and hare, who have to guard against the insidious approach of enemies, while quietly grazing the fields, we find this arrangement reversed, and the pupil admits the greatest number of lateral rays.

15. Ciliary Processes. - These are little folds or fringes of the choroid coat, which, joining the sclerotica near the cornea, (which union is termed the ciliary ligament) turn backwards and inwards, in the form of a circular, plaited fringe, the lit. tle threads of which are called the ciliary processes. They are covered, like the choroid, with the black pigment, and closely embrace the margin of the crystalline lens, forming round it an opaque blackened partition, which absorbs all the side rays of light, which might otherwise have disturbed the clearness of vision. These threads or processes are plaited 
like the folds of a ruffe, of which there are about $\mathbf{7 0}$ in the human eye, all arranged in a radiated manner round the lens, as represented in the following cut

Fig. 5.

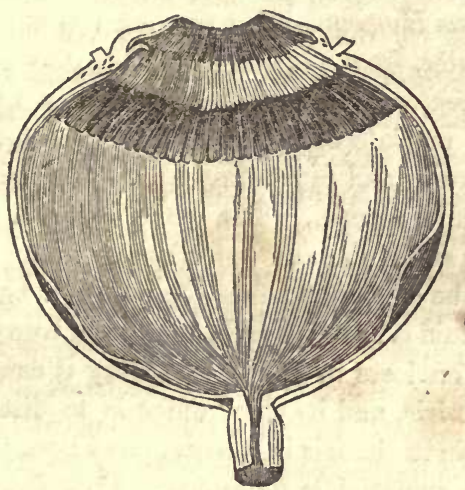

Section of the eye magnified, showing the ciliary processes, the pig. mentum nigrum, the retina, and the choroid coat.

16. The ciliary processes are thus cellular and vascular, and some have thought muscular, in order to give support to the weight of the crystalline and vitreous bodies, to keep them from falling towards the iris, or into the aqueous hu. mour. To accomplish this, we find them placed immmediately in front of the vitreous humour, and closely embrac. ing the circumference of the crystalline lens, and then to strengthen the slender materials of which it is formed, we find it implanted in little furrows on the surface of the vit. reous body, glued as it were to it, and adhering to it very firmly. We know that very substantial fabrics are made by plaiting and matting together very slender and flimsy sub. stances, as straw, chip, and grass to form hats; and it is on this principle, doubtless, that the ciliary processes are im. pacted or plaited together.

17. Humours of the Eve.-The humours of the eye 
have been compared to the glasses of a telescope, and the coats to the tube which keeps them in their places. They are three in number, and though all are perfectly transparent, they differ in density, and in the space which they respec. tively occupy.

18. Aquebus Humour. - The aqueous humour is as clear as the purest water, from whence its name, although its specific gravity is greater; containing, as it does, a little albumen, gelatine, and muriate of soda. It fills the entire space between the cornea and cyrstalline lens. The iris floats in it, suspended like a curtain. The space between the iris and the cornea is called the anterior chamber; and that between the iris and the crystalline lens, the posterior chamber of the eye. This fluid is secreted by a very thin, transparent membrane which encloses it, though some say it exhales from the vessels of the iris, and its chief office is to distend the cornea, and preserve the iris in a moist condition, fit for the discharge of its appropriate functions. This fluid is also in a constant state of secretion and absorption; for when entirely discharged, in extracting the lens, for cataract, we find that in a few hours it will be restored again. In old age, its quantity is lessened, and the eye becomes flatter, needing the aid of convex glasses. Fishes have no aqueous humour at all, as the water, in which they swim, answers the same purpose, as this was designed for, in land animals.

19. Besides this, the aqueous humour probably aids in adjusting the eye to different distances. As the lens lies immediately behind it, it is evident that, when the quantity of fluid is increased, it will press the lens back nearer the retina, while, at the same time, it renders the cornea more convex, and the reverse happens when the quantity is diminished. When the distension is very great, the pressure causes a cloudiness or opacity of the cornea, thereby pro. ducing blindness. This not unfrequently happens with horses that have been fed during the winter on dry food, either placed on a level with the head or above it. In the 
spring, when they are turned out to the green pasture, where their diet is changed from dry to succulent, and where also the head is held near the ground to collect the food, a con. gestion of the aqueous humour is apt to occur, sufficient to produce temporary blindness.

20. The Crystalline Lens. - This is placed immediately behind the aqueous humour, a short distance back of the pupil, and is a double convex lens, perfectly transparent. In shape it closely resembles the common burning glass; its posterior surface is, however, a little more convex than the exterior, and it approaches nearer to a sphere in infancy than in old age. When the crystalline lens is first removed from an eye, it looks like a mass of transparent crystal, without any trace of organization. Near the surface it is much softer than at the centre, which is harder and more compact. It is also softer in the young than in the old. As it consists chiefly of albumen, when exposed to heat, as of boiling water, alcohol or acids, it becomes white, like the white of an egg. If we examine it in this state, we shall find that it consists of an immense number of concentric plates or Lamella. More than two thousand of these have been counted, disposed in the form of layers like the coat of an onion, each layer consisting of an infinite number of very minute filaments, wound round in different directions, from various centres. The arrangement of these fibres differs in various animals, but is uniform in every individual of the same species. In fishes the lens is nearly spherical; in reptiles it is less so, and in birds and mammalia, it is still more flattened. In amphibious animals, as turtles or frogs, or those whose vision is adapted both for air and water, as seals and whales, the lens is more convex than in those which live entirely in the water. When this lens becomes so opaque as to obstruct the passage of the light, either partially or entirely, a person is said to have a cataract. This can only be cured by a surgical operation. 
Fig. 6.

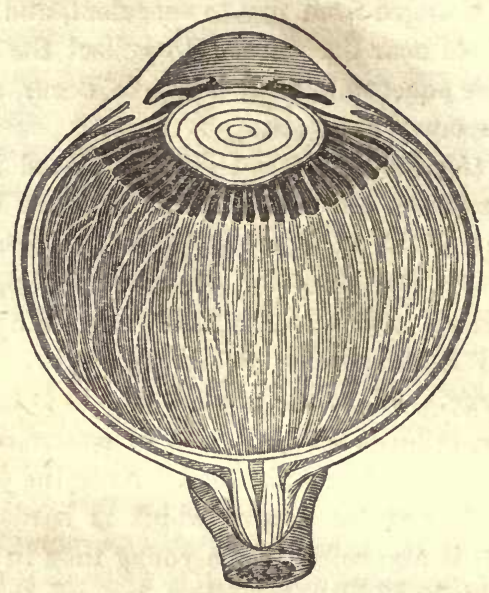

Section of the eye magnified, showing the Crystalline Lens in its proper situation, between the aqueous and vitreous humours.

21. The Vitreous Humour.-The vitreous body or humour is so called from its resemblance to melted glass. It is, like the other humours, perfectly transparent, and occupies the globe of the eye, of which it constitutes at least the posterior two thirds. It is surrounded by the retina in nearly its whole extent, to which, however, it does not adhere. It is composed of a fluid, contained in cells, formed of a membrane called the hyaloid, which communicate with each other, so that if it is punctured, the fluid with which it is filled will escape, though slowly in consequence of the intricacy of the cellular structure. On removing the vitreous humour from the eye, it appears to be of about the consis. tency of the white of an egg; its use being to afford a surface for the extension of the expanded retina, to keep the lens at the requisite distance, and to transmit and refract the rays of light. 
Fig. 7.

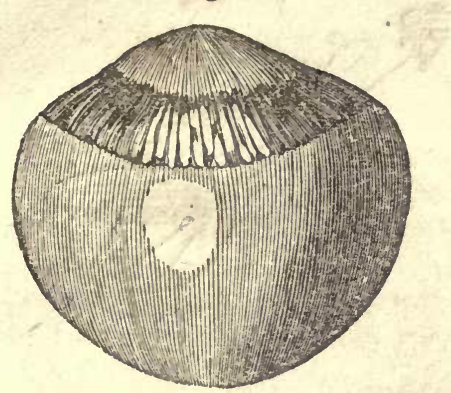

The vitreous humour and crystalline lens magnified, with the stains of the pigmentum nigrum left by the ciliary processes.

22. Laws of Vision. - Light passes through the air, or any medium of the same density, in straight lines; but when it passes from one medium into another, it is refracted, or bent out of a straight course, unless it strikes the new medium in a perpendicular direction, when it passes directly through. Air, water, glass, or any substance through which light passes, is called a medium. When a ray of light passes from a thinner or rarer medium, into one more dense, as from air into water, it is bent towards a line drawn perpendicularly to its surface. The contrary is the case when the reverse happens. This is shown by plunging a straight stick into the water, which will appear crooked. This may be illustrated by the familiar experiment of taking an object, such as a shilling, and fixing it at the bottom of an empty basin, then retiring 'backwards until the brim of the basin hides it; then let water be poured into the vessel, and the coin will again come to light, as in the following cut) (See Fig. 8.)

Thus the ray of light from the coin will proceed in the di. rection $a$, previous to the addition of the water, but when water is poured into the vessel, the ray will be reflected down to the eye, and the shilling will appear to occupy the 
Fig. 8.

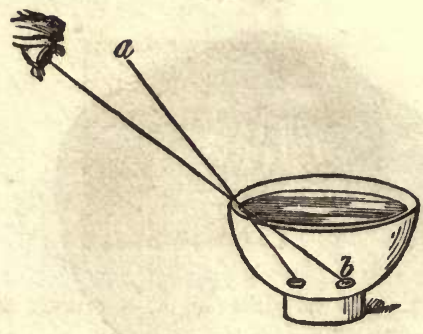

situation $b$. In the same way, when we look into a river, the pebbles appear to be raised in the water, and it looks shallower than it really is. From this circumstance, persons have often been drowned.

23. Lenses. - A lens is usually made of glass, its surface being ground into some of the following shapes:

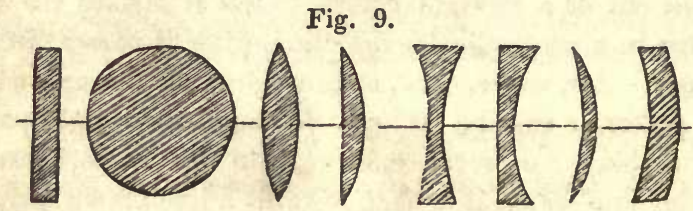

The first of these on the left hand would be called a plain lens; the third, double convex; the fourth, plano-convex; the fifth, double concave; the sixth, plano-concave; the seventh, . concavo-convex, \&c. Now, light in its passage through these glasses, would be refracted in proportion to their greater or less degrees of convexity or concavity; but in passing through a plain lens, like the first, the rays would not be bent out of a straight course. For example, if you place an object at the bottom of a tub of water, and place the eye in a perpendicular direction over it, the object is seen precisely in its true situation; but if you withdraw a short distance, it will appear to be situated where it is not. 
Fig. 10.

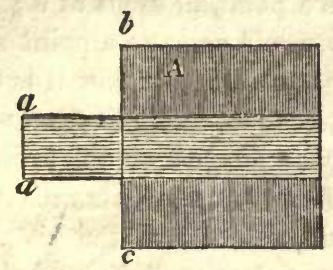

$A$, a solid oblong piece of glass; $a, a$, a stream of light, which strikes the surface of the glass, $b, c$, and which, being perpendicular, suffers it to pass through without refraction.

24. Now let us take a concave lens, and see what effect that will have on the light.

Fig. 11.

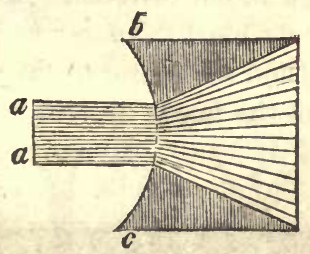

A, a solid oblong piece of glass; $a, a$, a stream of light which strikes the surface of the glass $b, c$, and which being concave, causes the light in its passage through it to diverge.

25. Now try a convex lens, such as the crystalline humour of the eye, and see how that will affect the rays of light.

Fig. 12.

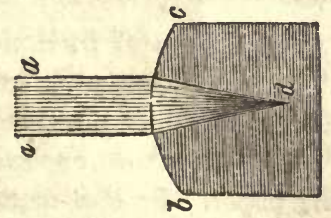

We see that this form of glass causes the rays of light 
$a, a$, to converge to a point, or focus at $d$; and if it was still more convex, they would come to a point still nearer. We are now able fully to understand how it is that the humours, or lenses of the eye collect the light from visible objects, and converge them into an image upon the retina. Whese media, we have seen, are four in number, viz., the cornea, the aqueous humour, the crystalline lens, and the vitreous humour; each possessing a different density, different sphericity, and consequently different refractive powers. ))

26. Now let us examine the principle on which an image is formed. This may be shown by holding a common sunglass opposite a window in a room, and placing a sheet of paper behind it. We immediately see depicted on the paper a perfect image of the window, diminished according to the convexity of the glass, but inverted. The greater the conconvexity, the nearer must the paper be held to the glass to receive the image, and the nearer to the window the glass is held, the larger will the image appear.

Fig. 13

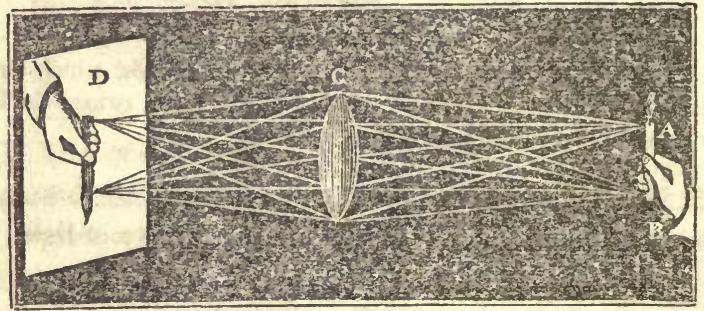

In this cut, rays of light pass from the candle, and the hand $\mathbf{A}, \mathbf{B}$, and falling on the lens at $\mathbf{C}$, are conveyed to the paper $\mathrm{D}$, which is consequently illumined with the object in the same way as in the above experiment, the window was painted on the paper. In like manner precisely, are images painted on the retina, as is shown in the following cut. 
Fig. 14.

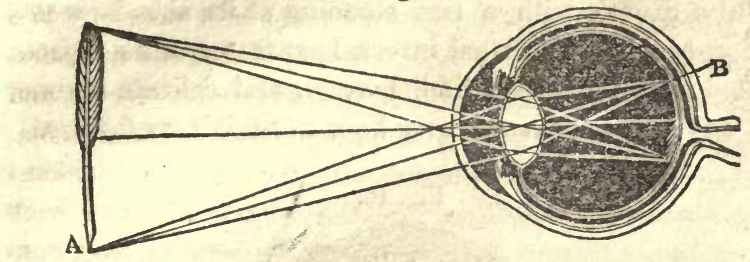

27. Thus the convergence of the rays begins in the aqueous humour is perfected in the crystalline but when they strike the vitreous humour, which is concave on its front surface, and also less dense than the crystalline, they diverge or spread out, and are thrown upon the back part of the eye. The manner in which this is effected may easily be seen by the following illustration.

Fig. 15.

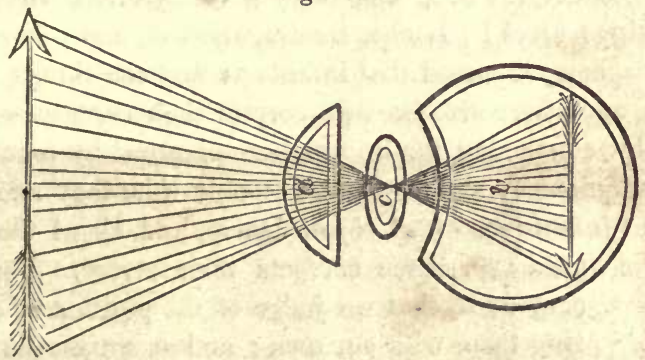

$a$, the aqueous ; $c$, the crystalline ; $v$, the vitreous humour.

In passing through the crystalline, the rays cross each other, so that those rays which pass from the lower part of an object are presented uppermost in the bottom of the eye and the reverse, so that the images of objects are always inverted, or bottom side upwards. Any one can see this by cut. ting out a circular portion of the outer coat, at the back part of the eye of an ox or sheep recently killed, and holding it up at a window; he will then see, on its posterior surface, a perfect but inverted representation of objects whether 
stationary or in mótion. Now, suppose a person was look. ing at a church with a tree standing at its side, he would have in each eye an actual inverted panorama of the objects, painted in a more beautiful, correct, and delicate manner than any effort of art can ever hope to exhibit, as follows.

Fig. 16.

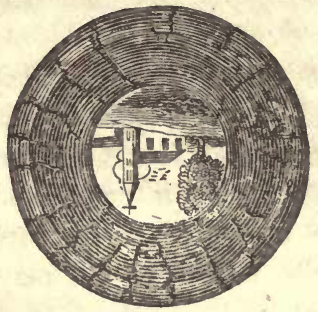

28. But if the images of objects are inverted, why do we see things erect? Locke, Buffon, Diderot, and other great philosophers, supposed that infants at first see things upside down, and afterwards learn to correct their erroneous sensation, by comparing the information obtained by touch with that acquired by sight. And not only this, they maintain. ed that infants see every object double, and all at the same distance, until experience corrects their errors. Berkeley, however, contended, that we judge of the position of objects by comparing them with our own; and as we see ourselves as well as every thing else wrong side up, or inverted, external bodies are in the same relation to us as if they were erect. But in that case, the boy who stoops down and looks at objects between his legs, ought certainly to see them wrong side up ; but though a little confused perhaps at first, he soon sees in that way as well as any other. This diffi. culty is easily explained by what is called the law of visible direction; that is, each point of an object is seen perpendicular to the point of the retina on which its image falls. The surface of the retina being concave, and nearly as pos. 
sible spherical, these lines of visible direction meet and cross at a point within the eye, which is called the centre of visible direction; the lines from the upper part of the image go to the lower part of the object, and those from the lower part of the image proceed to the upper part of the object. Thus an inverted image necessarily produces an erect object, and the external object is the thing to which the mind attends, and not the object on the retina. The error of all these philosophers has consisted in this, that they have imagined a true picture to be formed on the retina, which is regarded by the mind, and therefore seen inverted. But there is no interior eye to see or take cognizance of this image; but the mind accurately refers the impression made on the retina to the object producing it. In short, the mind stands behind the retina and looks at objects as they are through this screen, but it does not see the screen itself, but judges of the position of objects by the direction in which the light comes from them towards the eye; and as Arnott well remarks,- " no more deems an object to be placed low be. cause its image may be low in the eye, than a man in a room into which a sun-beam enters by a hole in the window. shutter, deems the sun low-because its image is on the floor."

29. Again, why, as we have two eyes, does not every object appear double? The reason is, that in the two eyes are corresponding points, so that when a similar impres. sion is made on both, the sensation, or vision, is single. Now, we have the faculty of so directing the axis of the eyes, that the image of an object falls exactly on the same point in each ; but if from any cause there is the least disturbance, then vision becomes double, as often happens to the drunkard. This is easily known by slightly pressing a finger on the ball of either eye, so as to prevent its following the motion of the other. Persons who squint always have double vision, but then they acquire the power of attending to the sensation in one eye at a time. Animals that have 
the eyes placed on opposite sides of the head, possess in a more remarkable degree the faculty of thus attending to one thing at a time.

30. It follows then, that the eye itself does not see; it is only an instrument employed by the brain, or rather the mind, whose servant the brain is. The optic nerve is the channel by which the mind peruses the hand writing of na. ture on the retina, and through which it transfers to that material tablet its decisions and its creations. There is then a portion, or rather an organ of the brain, where vision or the mind's eye is seated; and this portion is sometimes imperfectly constituted or organized, as Gall has proved to be the case, in those who cannot distinguish colours. That such is a true statement of facts, we learn from observing that disease of a given portion of brain produces blindness, whilst the eye remains perfectly healthy. Either this was the case with Milton, or he was afflicted with amaurosis, or palsy of the retina, for he says,

"These eyes, though clear

To outward view, of blemish, or of spot, Bereft of light, their seeing have forgot: Nor to their idle orbs doth sight appear Of sun, or moon, or star throughout the year !"

We also have the power of internal vision when asleep; and those who have lost their eyes perceive spectral illusions, and other similar phenomena, and they can also conjure up the figures and forms of various objects familiar to them before they lost their vision.

31. From the principles now laid down we can understand why rivers appear shallower than they are, and why a stick placed in the water appears crooked, In spearing of fish, or shooting them in the water, every sportsman knows that he must make suitable allowance for this refraction, for the fish is always nearer to him than it appears. Birds that dive for fish seem to understand that there is but small chance of success if they dive obliquely into the water, so like skilful 
opticians, they hover over, and when they see their prey, dart down perpendicularly, in which direction, as we have seen, there is no refraction. There is a curious fish in the East India waters called chactodon, about eight inches long, that appears to understand optics remarkably well. When it sees a fly, sitting on the plants that grow in shallow water, it swims within five or six feet, and then with the dexterity of a practical marksman, ejects from its tubular mouth a single drop of water which never fails to strike the fly into the sea, where it soon becomes its prey. Dunglison states that Hommel, the Dutch governor, put some of these fish into a tub of water, and then pinned a fly on a stick within their reach. He daily saw the fish shoot at the fly, and they never failed to hit their mark.

32. Short-sightedness. - This generally arises from too great convexity of the cornea, or excessive density in the structure of the crystalline lens; either of which will cause the visual rays from near objects, to converge to a focus, before they reach the retina (This is remedied by concave glasses, which, as we have seen, cause the rays to diverge, as is represented in the following cut.

Fig. 17.
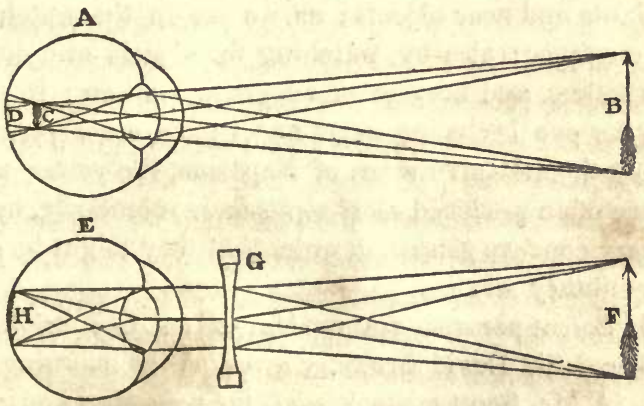

A. a short-sighted eye; B. an arrow which it attempts to perceive, but is prevented by the convergence of the passage of the visual rays to foci, at C., before they reach the retina at D. E. the same eye. 
similarly situated, showing how by the intervention of a concave lens, G., the rays are di-verged, and the image of the arrow, F., accurately converged to the retina at $\mathbf{A}$.

33. Long-sightedness is the opposite defect to this, and is owing to a flattening of the cornea, and a relaxation in the structure of the crystalline lens, by which its power of refraction is lessened. In this case, the rays of light are carried beyond the retina, and therefore do not form a distinct image on it. Old persons usually are subject to this defect; the only remedy known is convex glasses.) Where persons have been short-sighted in youth, as the eye grows flatter by age, they at length are able to see well, without glasses of any kind. This change in the shape of the eye is often denoted by a tendency to hold a book at a greater distance when reading. Glasses do for the eye that portion of the labour of bending the rays of light, which it is not able to do for itself. By adapting glasses to the successive changes which age produces in the shape of the eye, the sight may be pro. longed very often to the close of life. After the operation of extracting the crystalline lens for cataract, or depressing it by couching, very convex glasses are needed to remedy the deficiency.

34. The sight is often injured by long-protracted attention to minute and near objects; as we see in the watch-maker and engraver; also by watching for objects at a distance; as in sailors, and keepers of telegraph stations; in the one case the eye becoming near, and in the other far-sighted. During the arbitrary reign of Napoleon, the young men of France often produced short-sightedness voluntarily, by wearing very concave glasses, in order that they might be exempt from military service.

35. Some persons are unable to tell one colour from another. Sir David Brewster gives us the following exam. ples. A Mr. Scott mistook pink for pale blue, and red for green. His father, uncle, sister, and two sons, all mistook these colours in the same way. A shoemaker named White, 
could only see two colours, black and white, and he could never distinguish the cherries on a tree from the leaves. A tailor at Plymouth could only see yellow and blue. On one occasion he repaired a black silk garment with crimson, and on another, he patched the elbow of a blue coat with a piece of red cloth. M. Nicoll tells us of an officer in the British navy, who purchased a blue uniform coat and waistcoat, with red breeches to match. The cause of this defect is believed to be a malformation, or deficiency of that portion of the brain which takes cognizance of colours.

36. The lowest order of animals have no organs of vision, or if so, they have never been detected. Many in. sects have two kinds of eyes, one kind on each side of the head, and the other on the top, in a row, or in the form of a triangle. The spider has generally eight of these eyes on the top of the head. What are called the compound eyes are placed on the side of the head, and in the wasp and dragon-fly they cover a large part of it. These eyes are formed of a large number of separate cones or cylinders, closely packed together, each being a distinct eye, and hexagonal, or six-sided in shape, like the cells of a honey-comb. The ant has about 50 ; the beetle 3,000 ; the silk-worm moth upwards of 6,000 ; the dragon-fy 12,000 ; and some insects as many as 20,000 .

37. It is now ascertained, that each eye forming these compound eyes of insects, consist of a distinct tube, furnished with every thing necessary for complete vision. The object of this wonderful arrangement seems to be to compensate for want of motion, by the number of eyes, as the insect thus supplied, has an eye pointed towards the object in whatever direction it may appear, and may therefore be truly called circumspect. If we examine the wasp and dragon-fly, we shall find these compound eyes to cover a large portion of each side of the head. By examining with the microscope, we find each of these conical tubes covered with a cornea, and containing a crystalline lens, and aqueous and vitreous 
humour, an iris, a choroid coat, and a retina; the pigment running back around the lens, separating each cylindrical compartment. They have no eye-lids, eye-lashes, or tears ; but these are compensated for by the great hardness and insensibility of the cornea.

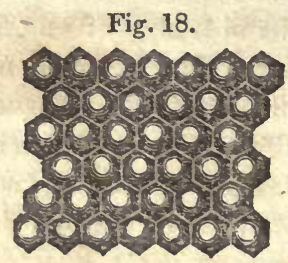

Eye of the yellow beetle magnified, composed of 8,820 hexagonal cylinders, the interior of each tube being round.

Fig: 19.

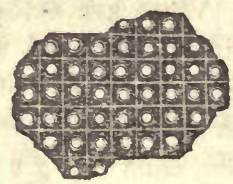

Eye of the phalaena or butterfly, magnified, consisting of 11,300 square sections. The eye of the mordella is similar, containing 25,088 prisms.

38. Motions of the Eye.-We have seen that the eye is a perfect optical instrument, infinitely surpassing the boasted specimens of human skill; but without the power of motion, of adapting it to the varied objects which surround us, we should derive but a very small proportion of that gratification - and pleasure, of which it is now the source. We shall perceive the great advantages we enjoy from this benevolent provision, if we contemplate the movements of a telescope; how difficult it is to direct it to any object, so as to obtain a view of it, and what complicated and cumbrous machinery are required to effect it. But all the various motions of the eye are produced by six little muscles!) 
39. Four of the, muscles of the eye are called straight or recti muscles; the other two are named the oblique muscles. The first four arise from the back part of the orbit, and are inserted by broad thin tendons into the four sides of the globes near the junction of the cornea with the sclerotic coat. The white pearly appearance of the eye is caused by these tendons. The oblique muscles arise from the front and inner side of the orbit, and pass to the eye-ball at right angles from the straight muscles, one passing over its upper surface, and the other upon its under surface, and both are inserted into its outer side, one a little above its horizontal axis, the other a little below it. The superior oblique muscle is, how. ever, worthy of more particular notice, as no part of the body exhibits clearer marks of design and contrivance. It arises as I have said, from the bottom of the orbit, it proceeds forwards and becomes tendinous, and when it reaches near the margin of the orbit, it passes through a little cartilaginous pulley, by which the direction of its action is changed, precisely as we see done by a pulley among the ropes of a ship ; after passing through this little loop, which is dense, smooth, and elastic, and furnished with a lubricating fluid to diminish friction, the tendon runs obliquely backwards and towards the internal angle to be inserted into the ball. When this muscle acts, the eye is rolled directly inwards. Thus the muscle pulls in a direction contrary to its own action, as when a man raises himself by a rope thrown over a beam. The other, or inferior oblique muscle, rolls the eye outwards towards the temple. When they both act together, the eye is steadily carried forwards. The recti muscles move the eye in four directions, upwards, downwards, to the right, and to the left, each movement being affected by its appropriate muscle. When the four act together, the eye is drawn back towards the bottom of the orbit. 


\section{Fig. 20}

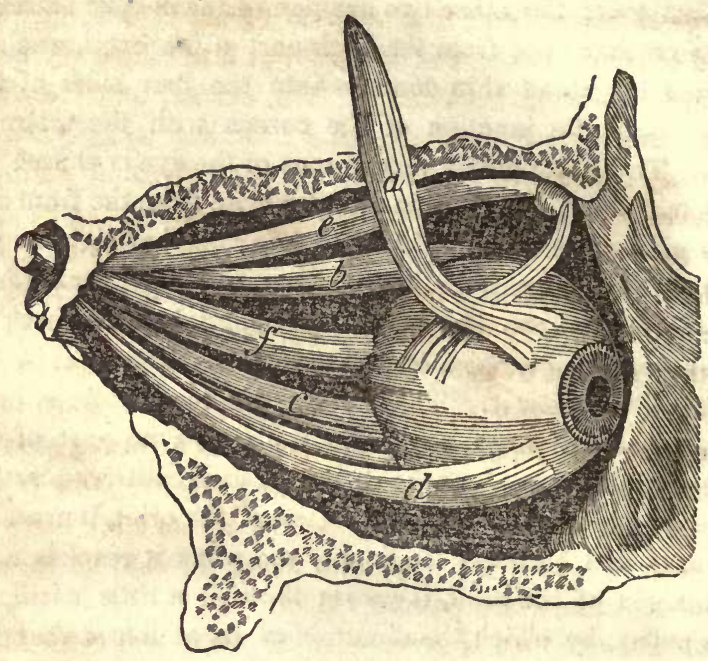

Side view of the muscles of the eye in their natural positions. a. $b$. c. $d$. the four straight muscles. $a$. is turned up to prevent the others from being bidden. $e$. the superior oblique muscle. $f$. the optic nerve. The other oblique muscle is not shown, but it lies on the other side of the ball, and comes round, and is inserted near the superior oblique; so that they pull opposite ways, like two men sawing timber. By the com. bined action of all these muscles, an infinite variety of motions of the eye can be produced.

40. In order to facilitate the motions of the eye it is lodged securely on a soft bed of fat. This is contained in very large cells at the bottom of the orbits, and is more fluid than fat in general, and is less affected than any other part of the body by those causes, which produce general emaciation. The eye-ball may therefore be said to move in a fluid medium, fully adequate to give every necessary sup. port, and at the same time affording the least possible resistance.

41. Defences and Appendages of the Eye.-These are 
the orbit, the eyebrows, the eyelashes, the eyelids, and the lachrymal apparatus.) (The orbit is a four-sided vault, composed of seven bones, and shaped like a pỳramid or cone, the apex pointing backwards. The eyeball and the orbit seem exactly made for each other; the one being globular, the other rounded to receive it. At the bottom of the orbit are holes for the passage of the blood-vessels and nerves. Now this cavity is not scooped out of the skull, as a boy would make a hole in a block of wood, but the seven bones, which enter into its composition, are so curiously dove-tailed together as just to leave this space for the reception of the eye and its appendages. What mechanic could place seven irregular, jagged bones together so as to form a smooth, polished cavity, for such a delicate organ as the eye to roll in! So securely is the eye protected by its bony house or encasement, that it is a very rare thing for it to be injured, except by some sharp pointed object.

42. The eye then is surrounded on every side with bone, except the front; now, what have we here to serve as a means of defence? It would not have answered our pur. pose to have had it entirely shut up in a box of bones, or even to have left a little hole just to peep through. As we cannot draw our heads into a shell when danger threatens, like a snail or turtle, we are furnished with a couple of moveable curtains or eyelids, placed before the eyes, which we can let down or raise up just when we please. If the eyes are "the windows of the soul," then I would call the lids a pair of inimitable window shutters, for they exclude the light whenever its presence would be disagreeable to us.

43. The eyelids are composed of a thin skin, externally; internally of cellular membrane,-its cells filled with a soft semi-transparent fluid; while their inner surface, in contact with the eye, is lined with a delicate mucous membrane, continuous with the skin, called conjunctiva? Besides these there are beneath the skin, two sets of muscular fibres; one called orbicular, running round the lid horizontally, whose 
contraction serves to close the eye ; the other lying beneath, are the fibres of the levator muscle, which serves to : aise the lid, or open the eyed These two muscles are well e rhibited in the following cut:

Fig. 21.

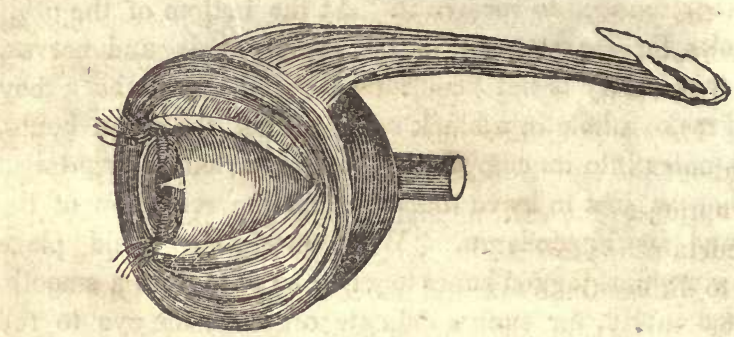

Muscles of the eyelids, the elevator passing back into the orbit; the sphincter, or orbicular muscle surrounding the eye.

44. Around the margin of each lid, there is a delicate elastic cartilage placed, which serves to preserve the shape of the lid; and into this, as is shown in the cut, the fibres of the elevator muscle, are inserted. In contact and around each cartilage, on its anterior surface, at the root of the eyelashes, is situated a row of little bags or follicles, which secrete an oily fluid, to keep the parts soft and pliant, and prevent the lids from sticking together. It is this mattcr which we often find in the morning, collected on the margin of the lids, or in the-internal angle of the eye.

45. Now, mark this difference; the levator muscle, which rises from the bottom of the orbit, is entirely under the control of the will; the orbicular muscle is not. See the ad. vantage of this. If we had always to issue a command of the will to shut the eyes, before going to sleep, I imagine there are a good many in this lazy world who would forget to shut their eyes, and so go to sleep with them wide open. To what dangers would they be exposed, and what injuries might they not sustain in consequence! But watch a 
sleepy person. No sooner does he begin to grow drowsy, than his eyes begin to close ; in other words, "they grow heavy." If he wishes to keep awake he makes a desperate effort to open his lids; and in the drunkard, whose involuntary muscles overpower the voluntary ones, it is quite ludicrous to watch the expression of countenance, and see how quick the disobedient, rebel lids close, upon the oft-repeated efforts to keep them open.

46. The opening and closure of the lids ordinarily occupies about the eighth part of a second, so that there is no interruption to the continuance of vision. Besides serving as a curtain to protect the eye, the lids serve, by their motions to diffuse the tears and mucous secretions, thus keeping the surface of the cornea moist, and wiping off any foreign matter, as dust, that may be lodged on it. The eyelids when closed, do not entirely prevent the transmission of light; for when we have been refieshed by sleep, the stimulus of the light falling upon the lids, is sufficient to arouse sen. sibility and awake us.

47. It is a curious fact, that while the upper eye-lid falls, the lower eye-lid is moved towards the nose, and thus aids in collecting all offensive particles in the corner of the eye. This can readily be shown by marking the edges of the lids with a black spot; when the lids are opened and closed, the spot on the upper eye-lid will rise and fall perpendicularly, while that on the lower one will play horizontally like a weaver's shuttle. When any thing gets into the eye, there is this continual play of the lids maintained, till the offending particles have been driven into the inner corner of the eye, when relief is at once obtained. When the object is very small, or not sufficiently irritating to excite these muscles of the lids to action, it is common to place an eyestone, which is a smooth piece of sulphate of lime in the eye. This not only excites an abundant secretion of tears, but also causes the necessary motions of the lids, by which the object is soon washed into the angle of the eye. 
48. Many animals have what may be called a third eye. lid, called the nicitating membrane. This slides from one angle of the eye to the opposite side, under the lids, whether open or shut. Its use is to clear away all matter which might be irritating to the eye. Birds that see best by night, such as owls, defend their eyes against the light of the sun, by drawing this curtain over them.

49. The eye-lashes, or cilia, also aid in the protection of the eye. They ward off insects, protect the eye from particles floating in the air, and also break the intensity of light. Indeed, when moist, as they often are with perspiration, the little drops serve to decompose the rays of light, causing the appearance of a luminous zone around the flame of a candle. The eye-brows are composed of loose cellular substance, covered with skin, from which spring short bristly hairs projecting outwards. Like all hairs, they penetrate little follicles, and become besmeared with an oily secretion, which preserves their glossiness, so that the drops of sweat which may accumulate on the brow are prevented from trickling over the eye-lids, where they might interfere with vision.

50. Lachrymal Apparatus. The tears are secreted by the lachrymal gland, which is a small spongy body of a flatten. ed form, seated in the hollow of the bone, in the upper and outer part of the orbit, just beneath the outer end of the bone. These serve as fountains, as well as laboratories or distilleries, separating, as they do, a pure water from the red blood, and discharging it by means of seven or eight little tubes, upon the inner surface of the upper eye-lid, from whence it is spread along with the mucus from the con. junctiva over the eye, by the movements of the lids. But what becomes of the tears? (In the inner corner of the eye are two very minutc apertures, one in each lid, which are the orifices of two canals, which communicate with a pipe, by which the superfluous moisture is drained off into the nostrils. This process is constantly going on without notice But when there is much irritation, then the natural chan 
nels are insufficient for their escape, and the tears roll over the cheek.

Fig. 22.

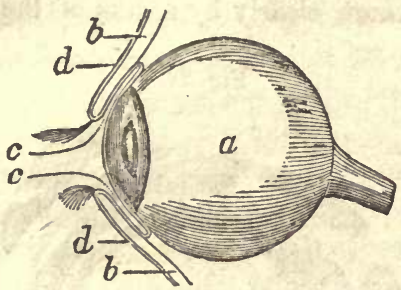

$a$, the eye-ball, and $b, b$, are the upper and lower sides. Now in order to prevent dust and other bodies from working their way between the Dall and the lid, through passages at $c, c$, into the socket of the eye, where they would excite great inconvenience and pain, we find the common skin of the eye-lids $d, d$, after covering their edges, turn in a little way between the lid and the ball, and then turn back and are reflected over the surface of the cornea ; where, to prevent the obstruc. tion of vision, it becomes perfectly transparent.

Fig. 23.

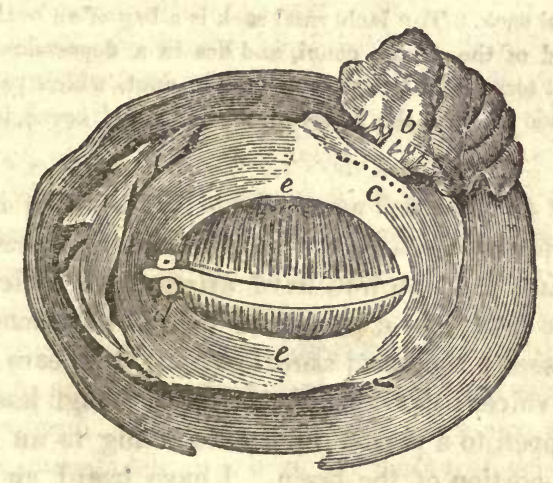

The eye-lids separated, and viewed from behind; $a$, the lachrymal gland; $b$, the ducts from the lachrymal gland; $c$, the mouths of these ducts; $d$, the puncta lachrymalia; $e$, the meibomian glands, which secrete the oily fluid. 
51. There is a striking proof of design in the manner in which the opaque, lining membrane of the eye-lids becomes transparent, as it is reflected over the cornea. But we can illustrate this more clearly by means of the following dia. gram.

Fig. 24.

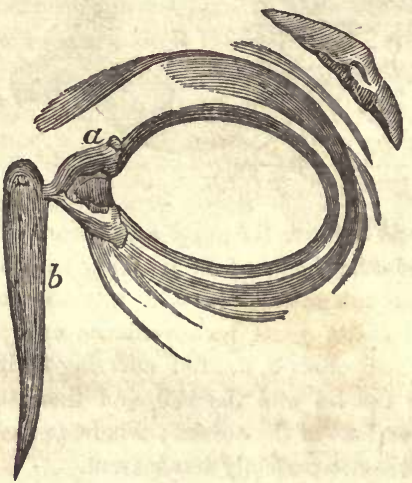

The eye-lids viewed from before; $a, a$, the lachrymal canals; $b$, the larchrymal sack. The lachrymal sack is a bag of an oval shape, fixed to the end of the double canal, and lies in a depression of the nasal bones. It terminates in a tube called the duct, which passes through a hole made for it, in the bones of the nose, and opens into the nostril.

52. It is now well ascertained that a belief in supernatural appearances, and stories in relation to seeing ghosts, hobgoblins, and spectres, have arisen from optical illusion.) We have seen how a person in delirium tremens, imagines that he sees a thousand unreal objects, and hears a thousand strange voices; the same phenomenon, though less in degree, may happen to a person in health, owing to an excitement in some portion of the brain. I have heard an aged relative, who believed in witchcraft, tell of frequently having seen the ghost of some deceased friend, and once of having fired at a deer three times, in the twilight, while he was cropping the tender grain just springing out of a newly 
sown field, without frightening the animal; and when at length he suddenly disappeared, no tracks or traces of him could be discovered on the soft mould. Nothing could convince the old gentleman that his sight had deceived him, that these objects had only existed in his brain.

53. One source of deception lies in the fact that, indirect as well as direct vision is intermittent, as any one may learn by attempting to read simall print by moonshine, or in twilight, or by looking at a single star for some time, when it will be found to vanish often and reappear. In an obscure light we find that a painful effort is required to distinguish objects; and after all they appear and disappear, because the impression they make upon the retina is not sufficiently vivid to be continuous. We can easily imagine therefore, that in the dusk, to a person who is ignorant of this fact, the sudden disappearance and reappearance of objects must seem very extraordinary.

54. Dr. Paley remarks that, "were there no example in the world of contrivance except that of the eye, it would be, alone, sufficient to support the conclusions which we draw from it, as to the necessity of an intelligent Creator." When we look at a telescope, and see how it consists of a tube composed of various pieces, containing several glasses or lenses placed at different distances in order to refract the rays of light, and bring them to a focus; how, within it, there is a partition of metal, through which is a round hole in the centre for the purpose of lessening the surface of the lens on which the rays of light strike; and when, in addition to all this, we see the inside painted black, to absorb the oblique and scattering rays that would otherwise render objects confused and indistinct; when we see all these things, we immediately say, here are marks of design, here is evidence of wise and skilful contrivance! and yet the telescope is but a close imitation of the human eye, which had God for its designer. When, also, we look at the camera obscura and see a tight, dark box, with a lens fitted in. 
to it, through which the light, passing, falls upon a screen behind, forming an inverted image of the object represented, we say at once here is design! But this instrument also is copied from the human eye!

Qucstions.-What is said of the sense of sight? What are the coats of the eye? Describe the scelerotic?-the choroid? What is the pigmentum nigrum? Is it ever absent ? Describe the retina? Illustrate the minuteness with which objects are painted on it? Describe the cornea? - the ciliary ligament? What is said of these tunics in the lower order of animals? What is the iris ? How does it contract and dilate? Are the muscles ever under the control of the will ? What is said of the iris among the lower animals? Describe the ciliary processes? What are the humours of the eye? Describe the aqueous? the crystalline?-the vitreous? Explain some of the laws of vision? What is a lens? How many, and what kinds of lenses are there? What effect on light has a concave? a convex? a plain lens? Illustrate this by the humours of the eye. Are images erect on the retina? Where do the rays cross? How do you explain why we do not see objects inverted? Why do we not sce objects double? Why do rivers appear shallower than they are? To what is short-sightedness owing? How may it be corrected? What is long-sightedness? What is the remedy? Are there persons who cannot distinguish colours? To what is this owing? What is said of compound cyes? How many muscles are there to move the eye ? Describe them; the recti; the oblique. What are the defences of the eye? Describe the orbit; the eyelids; the muscles of the lids. Are they voluntary muscles? How are objects carried into the angle of the eye ? What is the use of eyelashes? - of eyebrows? How are the tears secreted? How carried out of the eye? What has led to a belief in supcrnatural appearances ? 


\section{CHAPTER XVII.}

THE SENSE OF HEARING.

1. Throvgr the sense of hearing, we obtain a know. ledge of the peculiar vibrations of sonorous bodies, which constitute sounds. The organ of hearing is very complicacated, like that of sight, and the precise office of the different parts is not yet fully known; it is, however generally divided into the outer, the middle, and the inner part, and the auditory nerve.

2. The External Ear.-The outer part of the organ of hearing consists of what is called the external ear, and the cavity which leads to the ear-drum; and is composed chiefly of cartilage, covered with the skin, and supplied with bloodvessels and nerves. Its use is to collect sound, or rather the vibrations of the air, and transmit them through the tube that leads to the ear-drum. For this purpose it is admirably contrived; its surface being smooth and folded into grooves, which, assisted by a raised border and several concave spaces, conduct whatever sounds fall upon it, with the greatest certainty, directly to the drum of the ear. The external ear is furnished with muscles, and savages are said to have the power of raising or bringing forwards their ears, like a horse, to catch sounds as they come from different direc. tions; but the habits of civilized life destroy this faculty. The following cut represents the external ear, and the muscles by which it is moved. (See Fig. 1.).

3. Various names are assigned to the different portions of the external ear, such as helix to the outer border, scapha, the large boat-like depression, \&cc.; but passing these by, as of little importance, we remark that the external ear is confined to the class mammalia, nor does it always exist among them, for the mole, the water-shrew, and other diving animals, 
Fig. 1.

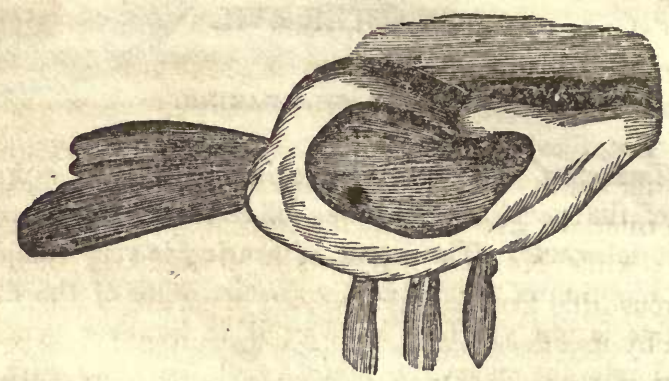

External Ear and Muscles.

seals and whales, are destitute of it. Indeed, as water is a much better conductor of sound than air, there would seem to be little occasion for the external ear in them; but they suffer in consequence, when they attempt to live with their heads out of water. Owing to this obtuseness of hearing in the whale, he is easily approached by the whaler, and before he hears the oars of his enemy, the harpoon is fixed into his unwieldy carcass. In like manner, the walrus and the seal remain unconscious of the footsteps of their foe, till it is too late to retreat. In land animals that are timid, as the hare and rabbit, the ear is very large, so that they may be apprized of the approach of their enemy in time to flee to a place of safety.

4. The Tube of the External Ear.-This is the passage, called by anatomists meatus auditorius externus, which extends from the outer ear to the tympanum or drum, which is stretched across its inner end. 'This passage is about ten lines, or nearly an inch in length; and pursues a somewhat winding course inwards, a little forwards and downwards; its external portion being composed of cartilage, and its in. ternal of bone. The width, as well as tension of this tube, are effected by the motions of the jaw, as any one can learn 
by placing his little finger in his ear, and then opening and closing the mouth. This is, no doubt, one reason why a person stands with his mouth open when he is listening attentively. This tube being constantly open, is liable to the entrance of foreign bodies, such as dust, insects, and the like. But, like the eye, it is not left without means of defence, for on its inside, there are numerous fine bristles, which interlace and prevent the entrance of any thing but sound; while between the roots of these hairs, there are numerous little glands, which secrete a nauseous bitter wax, which by its offensiveness, either deters insects from entering, or if they do, entangles them, and thus prevents any further advance. This wax often becomes hard, and ob. structs the tube, causing more or less deafness. This form of deafness is easily cured, although it may have existed even for years. When the ear is dry, from a deficiency of wax, the hearing also becomes imperfect, as also when it is thin and purulent.)

Fig. 2.

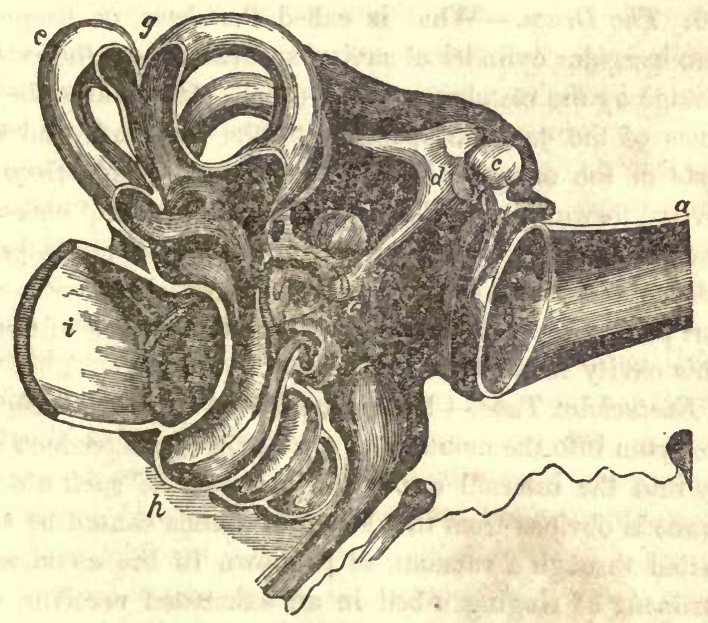

General sectional view of the structure of the ear; $a$, the meatus 
auditorius externus; $b$, the tympanum; $c$, the malleus; $d$, the incus; $e$, the os orbiculare; $f$, the stapes; $g$, the semicircular canals; $h$, the cochlea ; $i$, the meatus auditorius internus; $k$, the eustachian tube.

5. Membrane of the Drum, stretched across the inner end of the auditory tube, is a membrane, called by anatomists the membrane of the tympanum, (membrana tympani,) or drum of the ear. It is somewhat oval in shape, but hollowed out, or depressed at the centre, where, as we shall presently see, it is fastened to the end of a small bone. This membrane is tense like a drum-head, thin, and transparent. Its use is to convey the vibrations of the atmosphere to the expansion of the optic nerve in the internal ear. It does not seem entire. ly essential to the function of hearing, as the hearing sometimes remains after it is destroyed. When it is ruptured, a person can force the air out of his ear ; but while it remains entire, it is impossible for insects or other bodies to get into the drum, as is generally believed. The drum is capable of being rendered more or less tense, and thus of moderating the intensity of vibrations transmitted to it.

6. The Drum. - What is called the drum, or tympanum, is an irregular cylindrical cavity, separated from the external passage by the membrane of the drum. It contains the little bones of the ear, the openings to the labyrinth and other parts of the organ. Anteriorly a passage leads from this cavity, forwards and downwards to the throat, called the Eustachian tube. Posteriorly there are several openings into osseous cells, called the mastoid cells, which are situated in that projecting process of bone immediately back of the ear. This cavity then is filled with air.

7 Eustachian Tube. - I have stated that this tube leads from the drum into the mouth, and serves for the introduction of air into the internal ear. The necessity of such a contrivance is obvious from the fact, that sounds cannot be trans. mitted through a vacuum, as is shown in the common ex. periment of ringing a bell in an exhausted receiver, when no sound is made. So in a drum, there is an air-hole, else 
the sound would be flat, and the head liable to be ruptured. When this tube is obstructed by the swelling of its lining membrane from cold, or the accumulation of secretion in the passage, deafness is the consequence. This passage is about an inch and a half in length, and widens from the ear to the throat like a trumpet. When deafness occurs from complete closure of this tube, hearing may be restored by perforating the membrane of the drum. We may ascertain with a good degree of certainty whether deafness arises from this cause, by placing a watch between the teeth, if its motions are audible, we may conclude that the essential organ of hearing is unaffected,

8. Bones of the Ear. - These are four in number, and are so connected with each other in the drum, that they serve to transmit vibrations of the membrane of the tympanum to the internal ear. From their shape, they are called the mallet, the anvil, the orbicular, and the stirrup bones, and are exhibited in nearly the natural size in the following cut.

Mallens, Incus, and Orbiculare, Stapes.

Fig. 3.

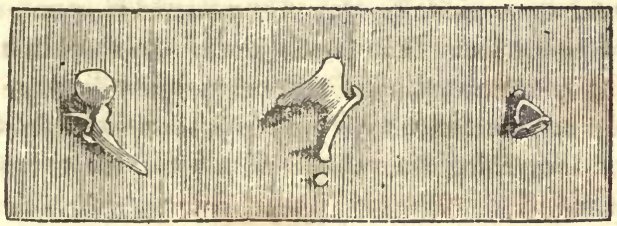

Bones of the ear.

'These bones are very hard and brittle, have no cartilage on their articular surfaces like other bones; neither are they furnished with ligaments or synovia, but their dry and polished surfaces are accurately fitted to each other in the form of a bent lever ; and in this way, being connected and held together by the little muscles, by which they are moved and attached to each other, the intensity of vibration which they receive from the membrane of the drum is not blunted. 
The handle of the mallet is attached to the membrane of the drum, and its other extremity rests on the anvil, which is connected with the orbicular bone, the smallest in the body, and not much larger than a grain of sand. This is interposed between the round bone and the stapes, whose base rests upon the membrane of the oval fenestra. Now the contraction of the muscles which connect these bones, puts the drum-head on the stretch, and thus adapts it for the ready transmission of sound.

9. Mastoid Cells. - These are seated in the hard portion of the temporal bone, and are also filled with air. The ear is thus surrounded with an atmosphere of its own. In the elephant, the two tables of the skull are separated from each other by a bony cellular structure to the extent of upwards of a foot, and these cells are filled with air which communicate with the drum of the ear. We find in the cat tribe, in dogs, and in gnawing animals, that there is a hollow sphere of very hard bone attached to the drum, shaped something like a conch, and well adapted for reflecting the vibrations of sound, and rendering them more intense, like the sound. ing board of a piano-forte. A similar hard conch is found in the whale tribe. The two tables of the skull in birds are also widely separated, thus rendering them lighter, and as the cells communicate with the drum, doubtless for the purpose of increasing the volume of air for the reception of vibration.

10. Petrous Portion.-The internal ear is situated in a portion of the temporal bone, called petrous, from petra, a rock, because of its solid structure. The object of this is evident from the fact, that hard elastic substances transmit vibrations of sound far better than matter of a softer texture. This portion of the temporal possesses indeed almost an ivory hardness, being the densest structure in the animal body, next to the enamel of the teeth; and in this solid body the labyrinth of the ear is situated. Now in whales, the skeleton is formed of loose spongy bones, with a considerable 
quantity of oil, collected in their cells. To compensate for this soft structure, whales are furnished with a sounding board, or the dense conch, above mentioned. In fishes, we often find several of these little bony concretions, of a smooth and polished appearance, and hard and brittle as porcelain. These are often seen in cutting up boiled fish, when placed upon the table, but few are aware of the uses they serve in perfecting the organ of hearing.

11. In order, however, to understand the precise function of these bones, it will be necessary to examine a little more into their situation and connection. In the following plan, they are represented, greatly magnified, but each bone in its natural position.

Fig. 4.

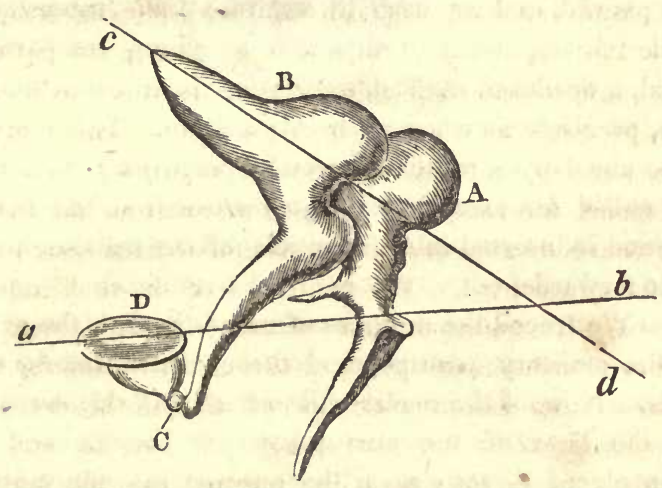

A, the malleus, or mallet, with its long handle running down, to touch with its delicate extremity the membrane of the drum. $B$, is the incus, or anvil, nicely fitted to the mallet, and showing $\mathbf{C}$, the orbicular bone placed between its termination, and $\mathrm{D}$, the stirrup. The line $a, b$, represents the centre of motion of the malleus, and $c, d$, the centre of motion of the incus. Now this chain of bones acts -on the principle of a long lever, as a small motion at one end of a long pole serve to move it through a wide space at the other. As Sir Charles Bell explains it, the head of the malleus is so articulated with the body of the incus, that the centre of motion of the incus is a line drawn through the centre of its body, and consequently the extremity of the long process, to 
which the orbicular and stirrup bones are attached, moves through 2 greater space than that which receives the impulse of the head of the malleus. Thus a very small degree of motion, communicated by the head of the malleus to the body of the incus, is greatly increased in the extremity of the long process of the incus ; and consequently this mechanism assists greatly in giving strength to the vibrations transmitted to the internal ear.

12. Now in distinguishing low sounds, the drum head is supposed to be put upon the stretch, chiefly by the aid of one little muscle, called tensor tympani, which is attached to the malleus, and the centre of the membrane, so that when it acts, it pulls the long handle of that bone, and draws the tym. panum inwards. Thus being made tense, it is prepared for the reception of low sounds. When sounds are so acute as to be painful, and we wish to diminish their intensity, this muscle relaxes, and the tympanum becoming comparatively flaccid, a deadened muffled impression is transmitted to the brain, precisely as when we muffle a drum. This relaxation is also aided by a muscle expressly prepared for that pur. pose, called laxator tympani, which arises from the temporal bone and is inserted into the handle of the malleus, so as to pull it forwards.

13. We traced the progress of sound through the external ear, the auditory passage, and the chain of bones, to the stapes. Now, if the reader will look at plate II., he will see that the base of the stirrup-bone is smooth and flat; this is placed directly upon the passage into the labyrinth, called foramen ovale, as a seal is placed on an impression, or a valve upon a hole. The cavities we have described are filled with air, those now to be mentioned are filled with wa. ter. The labyrinth then, which has been called the audience chamber of the ear, consists of three parts, viz., the vestibule or lobby, which may be compared to the porch of a building; three semi-circular canals shaped like three hoops tied together at one point, and their opposite points widely separated; and lastly, the cochlea, which closely resembler 
a snail shell, consisting of two spiral canals, which wind round a central pillar twice and a half, and also separated by a spiral partition.)

Fig. 9.

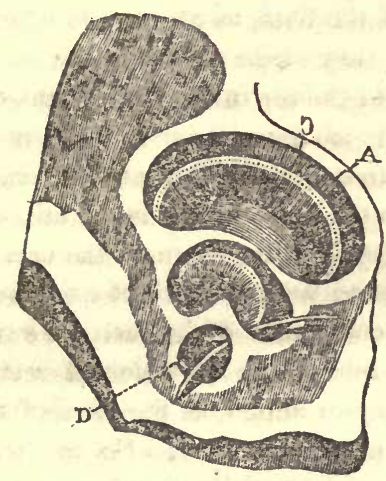

Section of the Cochlea.

14. The stapes then rests upon the membrane which is placed across the opening into the labyrinth. When the tympanum, or drum-head, is impressed by the vibrations of the air, the vibration is communicated to the little bones, and through them to the membrane of the labyrinth, which causes corresponding tremors in the fluid which fills its winding canals, and the spiral passages of the cochlea; upon which the auditory nerve is spread out like a fine pulpy web, in the same manner as the retina is spread out upon the choroid coat of the eye, or the olfactory nerve upon the mucous membrane of the nose, and thus is sound conveyed by the nerve to the brain.

15. The object of these spiral passages returning into themselves is, doubtless, to furnish an extensive surface, within a small space, for the expansion of the auditory nerve, and also that the undulations of the fluid which fills them after passing from the oval fenestra along the winding 
passages, and up the spiral staircase of the cochlea, might come down to the round fenestra, whose elastic membrane would transmit the vibration in the opposite direction. When the sounds, therefore, have done their office, in order that the hearing might not be rendered confused by a prolonged vibration of the fluid, as an echo is repeated between two mountains, as they strike the above named membrane, they are given off to the air in the tympanum, and there the vibrations end; for we have seen that it is probably the bones in the tympanum chiefly, and not the air, which transmits impressions to the fluids of the labyrinth, and that they receive their impulse from the drum of the ear.

16. Sound. - Sound has no distinct existence, but is the result of certain conditions of bodies. We see how, by throwing a pebble into a lake of water at rest, the undula. tions spread in every direction, in the form of a circle, until the impulse is lost in the distance. So in air, frequent vi. brations produce sound; and hearing has been defined to be that function by which we obtain a knowledge of the vibra. tory motions of bodies. These motions produce waves or undulations in the air, which are propagated in every direction, as the circular waves are produced in the lake, by throwing in the pebble.

17. Air is the common vehicle of sound, though all elastic bodies are capable of conveying. it. Water conveys sound better than air, and some solid bodies better than either. If two stones are struck together under water, a person whose head is under the surface may hear the sound at a great dis. tance. A blow struck with a hammer by a workman in a diving bell, far below the surface of the water, is heard dis. tinctly many fathoms above. So also if the ear be applied to the end of a long stick of timber a slight scratch made at the other extremity will be distinctly heard. The report of a cannon is heard to a much greater distance over the frozen surface of snow ; and, under such circumstances, firing has been heard from one to two hundred miles. Savages are 
acquainted with this fact, for they apply their ears to the ground to hear the approaching footsteps of their enemy or their prey. An easy way to tell whether a tea-kettle boils, is to touch it with a stick, and place the other end to the ear. On this principle, I suppose, watchmen strike the curb stone with their clubs, as the sound is communicated much farther than it was formerly by means of their rattle. So also a musical box, when held in the hand is scarcely heard, but when placed on a bureau or sounding board, it "dis. courseth most eloquent music." The stethoscope now used by physicians to assist in determining the nature of many diseases is derived from a knowledge of this principle. It is merely a cylinder of wood, about an inch in diameter, one end of which is placed on the surface of the body over the diseased part, and the other applied to the ear; sound is thus carried along the tube, and most important aid is derived to the skilful physician, in ascertaining the nature and seat of all discases of the heart and lungs.

18. The transmission of sound is affected materially by the condition of the atmosphere, with respect to temperature, moisture, \&c. During the night, when the air is still, and of uniform density and temperature, sounds are heard to a great distance; but when it is loaded with vapors, as in a fall of snow or rain, sounds are more limited, and rendered confused and indistinct.

19. The density of the air has a great effect upon the transmission of sound. In a dry, cold atmosphere, at the level of the sea, sounds are transmitted to vast distances, while on high mountains, such as the Andes, or even Mont Blanc, the report of a pistol is not louder than that of an Indian cracker. The wind, also, has a great influence in aiding or retarding the transmission of sound. Sound is also reflected like light, and indeed is subject to the same laws, for the angle of reflection is always equal to the angle of incidence. Reflected sound is termed an echo. The rolling of thunder is supposed to depend partly on the sound 
being reflected from cloud to cloud, and through strata of air of different densities, though it also arises from a dis. charge of electricity, through a wide extent of air. In this case, as the sound from the point nearest the hearer reaches his ear first, and some moments elapse before that from the more distant arrives, there must consequently be a continued peal. Some of our large public houses and manufactories are fitted with pipes for conveying intelligence to distant apartments, attention being attracted by ringing a bell.

20 . It has been doubted whether sound can be propagated from one medium to another, as from air to water It is now known, however, that if a musket is discharged over a person who is under water, he will hear the report. The question has also arisen, whether sound can be propagated from water to the air again. This is easily proved by strik. ing two stones together under water, although we are told that persons in a diving-bell under water, could not hear a musket discharged immediately over it. But here the sound had to be communicated from the air to the water, and from the water to the air again. Sound travels at the rate of eleven hundred and forty-two feet in a second, or a mile in four seconds. As light travels much faster, we see the flash of a gun before we hear the report. This will enable us to tell in a thunder storm how far we are from a thunder-cloud; as we have only to allow eleven hundred feet for each second, between the time when the flash is seen and the report heard, and one beat of the pulse for a second. In this way, too, the distance of a ship of war at sea is often ascertained by those on board of the vessel she is in pursuit of. Solids and fluids convey sound not only more perfectly, but also more rapidly than air. It is found that the velocity of sound in water, is about four thousand nine hundred feet in a second, being between four and five times more rapid than it is through air. Sound passes through tin at the rate of eight thousand one hundred and seventy-five feet, and through iron, glass and wood, eighteen thousand five hundred and 
thirty feet in a second. 'This explains why, when a gun is fired at a distance over the surface of a frozen laks, we hear two reports after we see the flash; first a sharp and loud one, transmitted by the solid ice, and then a weaker and duller one, through the air. Franklin, however, found by his experiments, that, after travelling about a mile through the water, sound lost some of its intensity, which indeed might be expected. Musical tones are said to be acute when the intervals between the vibrations are short, and grave when they are long. Thus a flute called an octave produces a shriller sound than the common flute; a fiddle than a bass viol. The strings, too, of a violin, which are designed for high or acute notes, are smaller than the others, that their vibrations may be more rapid; while those which make the grave tones are large, and wound round sometimes with fine wire, to increase the weight, and make them vibrate more slowly. It is the quality and variety of the sounds which, in musical tones, gives the hearer so much pleasure.

21. In the lower order of animals, hearing is performed by means of an apparatus, much more simple than in man. Some of them have merely a membranous sac, supplied with nervous threads. This is even the case in fishes, which require neither tympanum nor bones, nor any of the accessory parts found in land animals, as the undulations of water strike with greater force upon the organ of hearing than those of air. The apparatus of hearing in the frog is very singular, and designed so as to enable the animal to hear both in air and water.

22. Animals with long ears are able to move them by muscles for that purpose, and turn them to the point whence the sound proceeds. This may be seen in the horse, which turns his ear always in the direction of the sound. In stage horses, we often see the leaders turn their ears forward, while those behind turn theirs backward. Some men also have the power of moving their ears]

23. Like all our other senses, that of hearing is capable 
of much improvement by cultivation. The Indian in the forest, accustomed to listen to the approach of his enemies, or of his prey, acquires such acuteness of this sense, as to hear sounds which would be inaudible to those who live amid the din of civilized life. The blind also excel in the acuteness of hearing, and for this reason especially, acquire great skill in performing on musical instruments. Shakspeare thus describes a person destitute of musical taste.

"The man that hath no music in his soul,

Nor is not moved with concord of sweet sounds,

Is fit for treasons, stratagems, and spoils;

The motions of his spirit are dull as night,

And his affections dark as Erebus;

Let no such man be trusted."

Questions.-What are sounds? Describe the external ear; - the tube of the external ear; - the membrana tympani ;-the drum, or tym. panum; - the eustachian tube. How many little bones of the ear are there? Their names and office? How are low sounds perceived? What is the use of the spiral passages? How is sound conveyed? Is it conveyed by solids; - by water? What is the stethoscope? Can sound be propagated from one medium to another? At what rate does it travel? How can we tell the distance of sound? What effect has the density of air on sound? How is the lengthened peal of thunder explained? How is hearing performed in the lower order of animals? Can hearing be improved by cultivation ? 


\section{CHAPTER XVIII.}

\section{RESPIRATION.}

1. Bx Respiration, is meant the process of taking air into the lungs and throwing it out again.) (Inspiration is the act of drawing the air in); (expiration, that of forcing it out. Respiration is essential to all animal existence. It is in the lungs that the last change is produced in the assimilation of the food, by which it is converted into that vital fluid, which carries life, and strength, and nourishment to every fibre in the animal system.

2. The parts concerned in respiration may be arranged into three divisions, viz., 1 , the bones which form the respiratory cavity; 2 , the muscles by which these bones are moved,

Fig. 1.

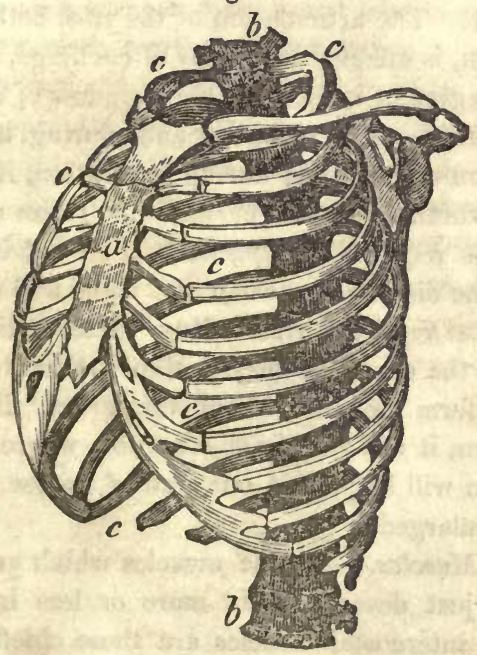

Thorax, or chest ; $a$, the sternum; $b, b$, the spine; $c, c$, the ribs, 
and the size of the cavity regulated; 3 , the respiratory organs contained within the cavity)

3. The bones which enter into the composition of the chest, are the sternum, or breast-bone; twelve dorsal vertebrae, and twenty four ribs. By examining the preceding plate, Fig, 1., the sternum will be seen to terminate at its lower part in a triangular piece of cartilage, which lies directly over the stomach, and may be felt externally; the seven uppermost, or true ribs, will be seen to extend the whole distance from the spine to the sternum, strips of elastic cartilage being interposed between the breast-bone and their anterior extremities, while the five lower, or false ribs, are merely attached to each other by slips of cartilage; the two lower, indeed, float loosely, without any attachment to the others, except by means of muscles.

4. I have already stated that the ribs are attached to the spine at an acute angle, so that they cannot be moved out of their ordinary position, without enlarging the dimensions of the chest. The articulation of the ribs, both at the spine and sternum, is effected by means of cartilage, thus allowing sufficient degree of motion for the purposes of respiration in a healthy state. The chest expands during inspiration for the reception of air ; and during expiration, it contracts to expel air, which is no longer useful. There are, therefore, two motions required, an upward and an outward; the first increases the distance between the spine and sternum; the last, that between the ribs. Now these motions are both effected by the ribs, and they are so articulated, that they cannot perform the one without the other. By looking at the cut, then, it will readily be seen how where the ribs rise, the sternum will be pushed out, and of course the cavity of the chest enlarged.

5. The Muscles.-All the muscles which are attached to the bones just described, aid more or less in respiration, though the intercostal muscles are those chiefly concerned, These run from one rib to another, filling up the spaces be. 
tween them. These muscles, though thin, consist of a double layer of fibres, the external and the internal, which pass in inverse directions, one layer from above downwards, the other from behind forwards, from edge to edge of the ribs, crossing each other. Now, the first rib being fixed, the second moveable, but less so than the third, the third less than the fourth, and so on through the whole series; the contraction of the intercostals must consequently elevate the whole series, as the upper ribs serve as fixed points for the action of the muscles.)

6. The chief muscle, however, of respiration, is the diaphragm. By the aid of this, the capacity of the chest is enlarged downwards, as we have seen it to have been upwards and outwards by that of the ribs. The diaphragm, or midriff, is a circular muscle, placed transversely across the trunk, nearly at its centre, dividing the cavity of the thorax from that of the abdomen. It is attached to the inside of the breast-bone and the cartilages of the false ribs, and is fleshy all around its border, but tendinous towards its centre; the surface towards the abdomen is concave, and that towards the chest convex. Even when it is not in action, its upper surface forms an arch, the convexity of which is towards the thorax, and reaches as high as the fourth rib. The central, or tendinous portion of the diaphragm, is attached to the pericardium supporting the heart; and is nearly, or quite immoveable, in order to afford a fixed point for the action of the muscular fibres, which constitute its sides. Owing to this arrangement, its motions do not interfere with those of the heart. 
Fig. 2.

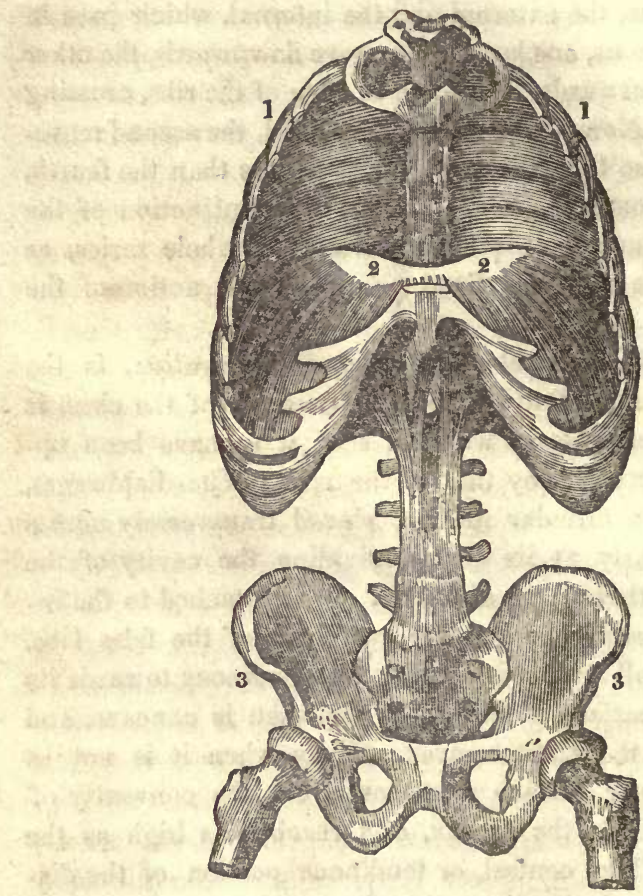

View of the diaphragm ; 1, cavity of the thorax ; 2, diaphragm sep. arating the cavity of the thorax from that of the abdomen; 3 , cavity of the pelvis.

7. During the act of inspiration, the diaphragm contracts; the muscular fibres shorten themselves, and the muscle de. scends, passing from the fourth rib to below the seventh, losing the arched form, as represented in the cut. At the same time, the muscles of the abdomen are protruded forwards, and the viscera in its cavity pushed downwards. The degree in which the capacity of the chest is enlarged by these movements is very satisfactorily shown in the follow ing cut. 
Fig. 3.

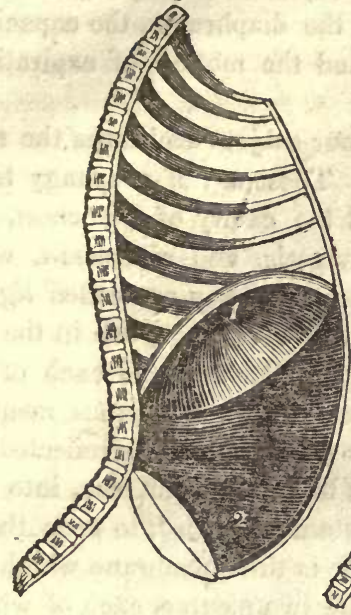

Fig. 4.

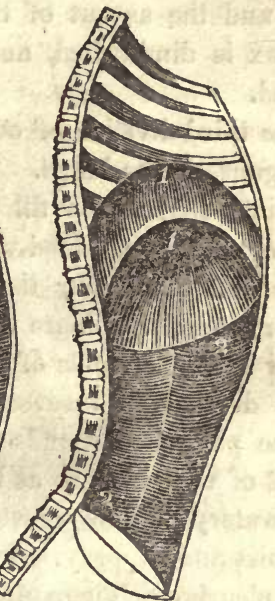

Fig. III, diaphragm in its state of greatest descent in inspiration; 2 , muscles of the abdomen, showing the extent of their protrusion in the action of inspiration. Fig IV, diaphragm in the state of its greatest ascent in expiration; 2, muscles of the abdomen in action foreing the viscera and diaphragm upwards.

8. We have now seen how the capacity of the chest is enlarged by inspiration, how is its capacity diminished by expiration? The descent of the ribs is occasioned by the elasticity of the cartilages and ligaments which join them to the sternum and the spine. Indeed the natural condition of the chest is that which obtains after a full expiration; and therefore we may consider the bones which form the walls of the chest, and the muscles which cover those bones, as anrtagonizing or opposite forces. (The ribs, then, have a natural tendency to fall, owing to their peculiar structure, as well as their position; while their expansion is effected by the specific action of their muscles.) Besides this, when the diaphragm relaxes, the abdominal muscles contract and push the abdominal viscera, and the diaphragm also, up to. 
wards the cavity of the chest ; and thus by the descent of the ribs and the ascent of the diapluragm, the capacity of the thorax is diminished, and the motion of expiration is completed.

9. The third division of our subject embraces the respiratory organs, or the lungs. These are of a spongy texture and conical shape, and fill the cavity of the chest, being composed chiefly of blood-vessels, and air-vessels, with a small portion of cellular tissue.) They are called (lights in the lower animals. There are two lungs, one in the right, the other in the left side of the thorax; and each of these lungs is divided into several lobes. A serous membrane called the pleura surrounds the lungs, and is reflected upon the walls of the chest, so as to form a shut sac, into which a thin watery fluid is constantly exhaled, to keep the surfaces moist and slippery.) It is this membrane which is the seat of pleurisy. There are two pleurae, each of which is confined to its own side of the chest, lining its cavity, and covering the lung. (Behind the breast.bone, they form a partition, called mediastinum; between the sides of which, the heart and pericardium are situated. The pleurae serve to attach the lungs by their roots to their respective cavi. ties, and to facilitate their movements, by means of the fluid exhaled from their surfaces. Each lung is attached to the spine by its roots, where blood.vessels, nerves, lymphatics, and a branch of the windpipe enter it. (See Fig. 5.)

10. Thus we perceive that the chest is divided into three compartments, one on each side, containing a lung; (the middle one, the heart.) Between these there is no communication; so that if a fluid is thrown into one of them, it does not find its way into the others. As the heart lies chiefly on the left side, the lung of that side is smaller than the one on the right, and divided into only two lobes, while the other is divided into three. The lungs are the lightest texture in the human body, owing to the air which they contain, ano their aspect varies with the age. In infancy they are of a 


\section{Fig. 5.}

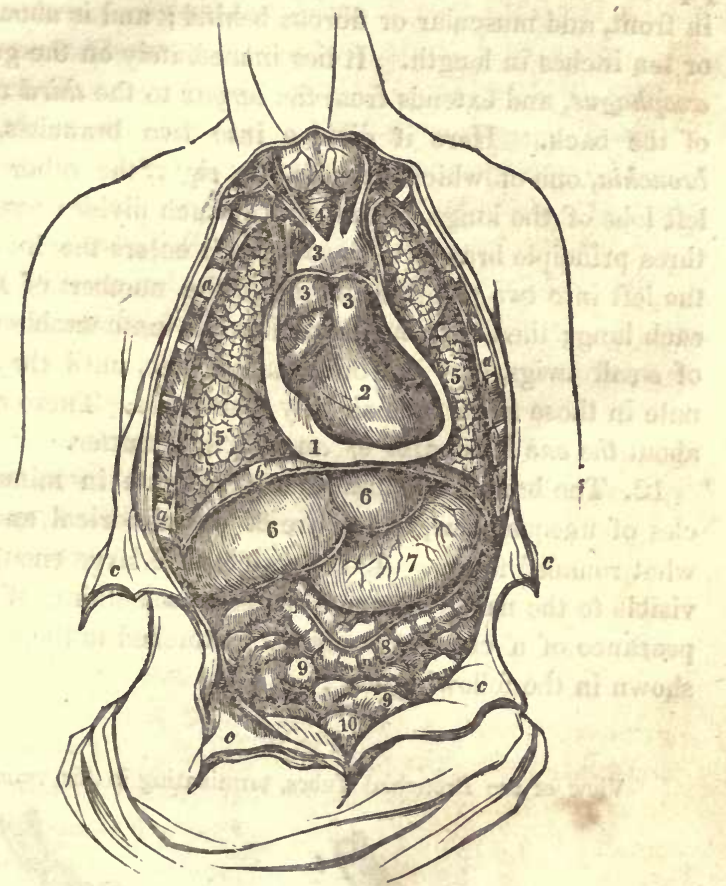

$a$, the cut edges of the ribs, forming the lateral boundaries of the cavity of the thorax; $b$, the diaphragm, forming the inferior boundary of the thorax, and the division between the thorax and the abdomen; $c$, the cut edges of the abdominal muscles, turned aside, exposing the general cavity of the abdomen.

Fig. 1, the cut edge of the pericardium turned aside; 2 , the heart ; 3 , the great vessels in immediate connexion with the heart; 4 , the trachea, or wind-pipe; 5 , the lungs; 6 , the liver; 7 , the stomach ; 8 , the large intestine; 9 , the small intestines; 10 , the urinany bladder.

pale red, in youth of a darker colour, and in old age of a livid blue.

11. The air enters the lungs through the trachea or wind. 
pipe. (This is a tube, made up of little rings, cartilaginous in front, and muscular or fibrous behind; and is about eight or ten inches in length. It lies immediately on the gullet or asophagus, and extends from the larynx to the third vertebra of the back. Here it divides into two branches, called bronchia, one of which goes to the right, the other to the left lobe of the lungs. The right branch divides again into three principle branches, as soon as it enters the lung; and the left into two; corresponding to the number of lobes in each lung; then they subdivide into an innumerable number of small twigs, like the branch of a tree, until they terminate in those small cells already mentioned. These cells are about the one hundredth of an inch in diameter. $)$

12. The bronchial tubes then, terminate in minute vesicles of unequal size, which are of a cylindrical and somewhat rounded figure. These vesicles are large enough to be visible to the naked eye, and present something of the appearance of a cluster of currants attached to their stem, as shown in the following cut :

Fig. 6.

View of the Bronchial Tubes, terminating in Air vesicles.

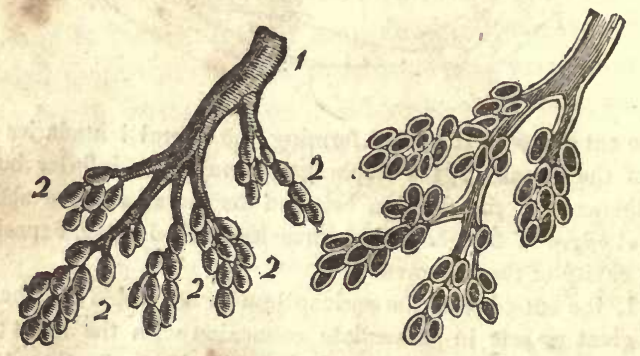

External view.-1. Bronchial tube. |

The Bronchial tube and Air 2. Air vesicles. vesicles laid open.

It should be borne in mind that the office of respiration is to bring the blood in contact with the air, and, accordingly, the lungs are so constructed as to allow the largest possible 
quantity of deteriorated blood, to enjoy the fullest intercourse with the largest possible quantity of vital air; and all the mechanism of bones and muscles which I have described, are only subservient to th $\mathrm{s}$ end. Now it has been calcula. ted by Hales, that each air cell is the one hundredth part of an inch in diameter, and that the amount of surface furnished by them, collectively, is Equal to twenty thousand square inches. Other physiologists have calculated the surface to be over fifteen hundred cubic feet, and Munroe states that it is thirty times the surface of the human body,

Fig. 7.

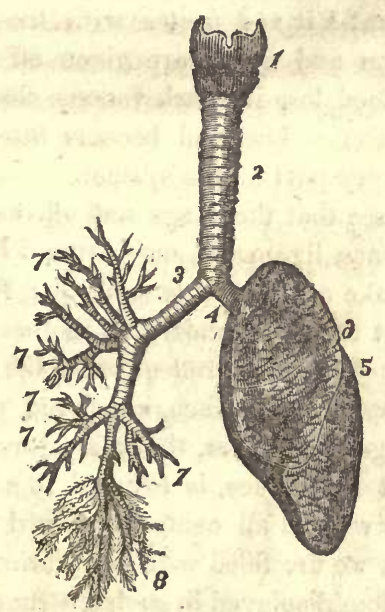

1. The larynx; 2. The trachea; 3. Right bronchia; 4. Left bronchia; 5. Left lung divided into three lobes; 7. Large bronchial tubes; 8. Small bronchial tubes ending in air cells or vesicles.

13. Such is the structure of the vessel which conveys the air to the blood; let us examine how the blood gets to the air. This is effected by means of the pulmonary artery, which springs from the right ventricle of the heart, divides 
into two branches, one for each lung, and again subdivides, and ramifies through the organ in a manner precisely similar to the bronchial tubes.) Every bronchus, or branch of the trachea, thus has a corresponding blood-vessel, which tracks it throughout its entire course until it reaches the air vesicles, upon the surface of which the minute vessels expand and ramify, forming a net-work so beautiful, that the anatomist who first observed it, called it the rete mirabile, or the wonderful net-work. Thus the air is on one side, and the blood on the other, of an immense surface of membrane, finer than the most delicate lace or gauze; and as such membranes are permeable to air and other gases, the oxygen of the air penetrates it and unites with the blood, while a portion of carbon and water are given off by exhalation. Thus does the blood lose its dark venous character, and as. sume a florid, arterial hue, and become fitted to carry life and vigour to every part of the system.

14. Thus we see that the lungs and all their complicated machinery of bones, ligaments, muscles and cartilages, were formed for the sake of these little air-cells; for it is through their agency that the blood undergoes the necessary changes and alterations. When we reflect upon the relative extent of the actual respiratory surface, compared with the dimensions of the lungs themselves, that a stratum of blood several hundred feet in surface, is exposed to a stratum of air still more extensive, and all compressed within the compass of a few inches, we are filled with admiration and astonish. ment at the wisdom displayed in such a structure, and search in vain, among all the contrivances of human skill and genius, for a counterpart!

15. We are now prepared to trace the successive acts of respiration, accomplished through the agency of the me. chanism just described. About one second and a half after expiration, the muscles of inspiration begin to act, the intercostals contract, and, by elevating the ribs, increase the dis. tance between the spine and sternum. As the ribs rise, the 
diaphragm descends, and thus the cavity of the chest is en. larged in every direction. This expansion, like that of a bellows, causes a vacuum, and as the lungs are passive, the air consequently rushes in through the mouth and nostrils to fill it, and this influx of air continues until the density of the internal, is equal to that of the external air, when the act of inspiration is at an end. Again, the intercostal muscles relax, and the ribs, by their elasticity, are restored to their natural position, while, at the same moment, the diaphragm relaxes, and allows the abdominal muscles to contract and thrust it up into the chest. Thus the lungs being pressed upon in every direction, below by the diaphragm, before by the sternum and ribs, and behind by the spine and ribs, the air within them is pressed out Such is the beau. tiful and complicated mechanism of respiration.

Fig. 8.

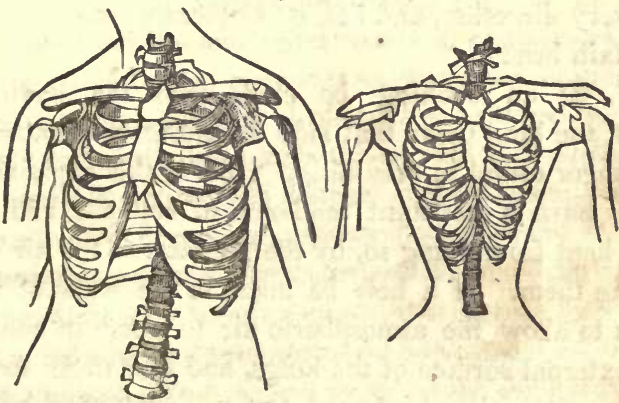

The cut upon the left represents the natural shape of the chest, and that upon the right, the contracted state of it, owing to tight lacing.

16. Now we can easily understand how tight-lacing alters the shape and diminishes the capacity of the chest. By looking at the cut, we see that the figure of the chest is that of an irregular cone, with a convex projection on each side, and flattened before and behind. By compressing it, how. ever, by corsets, it is changed into a cylinder, its lower part being forced in, so that its transverse diameter is diminished 
nearly, or quite, one half. Now, in this state of things, it is very clear that the ribs cannot be raised upwards and outwards, as they are in natural and free respiration, and, consequently, the capacity of the chest cannot be enlarged in these directions How, then, is life supported? Clearly by the play of the diaphragm alone, which, by its descent, enlarges the cavity of the chest in its long diameter. But even the action of this muscle is cramped by this unnatural practice; for, as the compressing apparatus extends down over the loins behind, and in front over all the soft parts, or the organs below the chest, it acts like a solid wall, preventing, by its resistance, the protrusion of these organs, and thus restrains the diaphragm above, in its attempt to descend; so that in fact, the beautiful mechanism, contrived by a Supreme architect, for performing a function indispensable to life, health, beauty and enjoyment, - is confined, in every direction, and life, consequently, sapped at its very fountain head!

17. If an opening be made into the cavity of the chest, the lung upon that side immediately collapses, and is no longer useful in breathing. How is this explained? The lungs have a constant tendency to collapse, and they are only kept from doing so, by the pressure of the air contained within them. If a hole be made in the walls of the chest, so as to allow the atmospheric air to come in contact with the external surface of the lungs, and thus make the pressure on the external and internal surface equal, they immediately collapse and shrink to that size which is natural to them, and which they assume when removed from the chest. This operation, of opening the cavity of the chest, has been pro. posed as a remedy for consumption; as the lung in a state of rest would be more likely to heal than when in constant motion.

18. The atmosphere is an invisible elastic fluid, surrounding the earth to the height of about forty miles. Water is seven hundred times heavier than air; (and yet a column of 
air a foot in diameter, and extending to the top of the atmosphere, would be equal in weight to a column of water of the same diameter thirty-two feet high, or to a column of mercury twenty-eight inches high. The pressure of the atmosphere then, upon the body of a common sized man, is equal to between thirty and forty thousand pounds. Atmospheric air is composed of oxygen, azote and carbonic acid, in the proportion of ( 20 parts of oxygen, 78 of azote, and 2 of carbonic acid.)

19. Oxygen is an invisible air, or gas, and enters into the composition of air, water, and all animal and vegetable substances. It is the supporter of combustion, and no animal can live without it. What are called acids and oxyds in chemistry, are oxygen combined with other substances, as sulphur, salt, nitre, \&c. (Azote can neither support combus . tion nor respiration, at least in man; though it is an element in all animal matter, and in some vegetables.) In these cases it is obtained, both from food and the air.

20. It is now fully ascertained, that while the chemical composition of the blood is essentially changed, its weight always remains the same; as the carbon discharged is precisely equal to the united weight of the oxygen and azote absorbed, and the same change is effected by the respiration of all animals, whatever be their rank in the scale of organization. It is worthy of remark, that plants and animals produce directly opposite changes in the chemical constitu. tion of the air. The carbonic acid given off by animals is composed of oxygen and carbon; this is decomposed by vegetables, which absorb the carbon and give off the oxygen to the air, which in its turn is absorbed by animals, and car. bonic acid given off: so these two great departments of organized structure furnish food for each other/ renovating the air, and preserving it in a state of coustant purity. The immense quantity of oxyen given off by vegetables, may be inferred from the following experiment. About fifty leaves were enclosed in a jar of air ; the surface of the whole being 
about 300 square inches; by adding some carbonic acid to the jar, in a short time 26 cubic inches of oxygen were evolved. What then must be the amount given of by an entire tree, especially in cities, where carbonic acid abounds ; hence how important it is that cities should be thickly plant. ed with trees, not only for the sake of ornament, but much more for that of utility.

21. The quantity of oxygen consumed by a man in a minute, is about 30 cubic inches. He breathes 20 times in a minute; and every time he breathes, takes into his lungs 15 cubic inches of atmospheric air, which contains three cubic inches of oxygen, so that one half of that which is inspired disappears in every act of respiration. This will amount to about 2,000 cubic inches in an hour, and/45,000 cubic inches in 24 hours.) Thus one man will consume, in 24 hours, all the oxygen contained in a space of 312 square feet ; or in 12 hours, in 156 square feet. And still our churches, and schoolrooms, and dwelling-houses, are constructed with no view to a renovation of the air we breathe !

22. Dr. Southwood Smith has lately performed a series of very interesting experiments, from which he deduces the following general results :- " 1 . The volume of air ordinarily present in the lungs is about 12 pints. 2. The volume of air received by the lungs at an ordinary inspiration is one pint. 3. The volume of air expelled from the lungs at an ordinary expiration, is a little less than one pint. 4. Of the volume of air received by the lungs at one inspiration, only one-fourth part is decomposed at one action of the heart, and this is so decomposed in the five-sixth parts of one second of time. 5. The blood circulates through the system, and returns to the heart in 160 seconds of time, which is exactly the time in which the whole volume of air in the lungs is de. composed. These circuits are performed every eight minutes; 540 circuits are performed every 24 hours. 6 . The whole volume of air decomposed in 24 hours is 221,882 cubic inches, exactly $\mathbf{5 4 0}$ times the volume of the contents of the lungs. 
7. The quantity of blood that flows to the lungs to be acted upon by the air at one action of the heart is two ounces, and this is acted on in less than one second of time. 8. The quantity of blood in the whole body of the human adult is 24 pounds avoirdupois, or 20 pints. 9. In 24 hours 57 hogsheads of air flow to the lungs. 10. In the same time, 24 hogsheads of blood are presented in the lungs to this quan. tity of air. 11. In the mutual action that takes piace between these quantities of air and blood, the air loses 328 ounces of oxygen, and the blood 10 ounces of carbon."

23. The blood, as it goes the round of the system, leav. ing a little bony matter here, a little muscular there; supplying the nails, and the hair, and the skin, and every thing, with the particles which, in the wear and tear of the machine, they have lost; loses by degrees its bright arterial colour, and by the time it comes round again to the lungs, it is no longer fit to perform its duty; it has been robbed of all its principles most essential to life, and it must be renewed and prepared afresh, before it can be of any further use. This is done in the lungs : and this process is what physiologists call the vital part of respiration.

24. All animals have not lungs. (Insects absorb the air from the surface of the body so also do many of the family of zoophytes. (Some have feathery tufts, like a plume of feathers, which they keep in constant motion 3 while the common earth-worm, or (angle-worm, has a single row of holes along its back, about one hundred and twenty in num. ber, which open each of them into a small respiratory bag, situated between the skin and the intestine. The leech or blood-sucker, and the lamprey eel, have the same kind of apparatus for breathing.

25. Un fishes, the gills, which are their lungs, are made up of an infinite number of little fibres, or filaments, set close together, like the teeth of a fine comb, or the barbs of a feather; and these are covered with innumerable small processes, crowded together like the nap of velvet, and over 
these are spread myriads of blood-vessels, like a fine network. The air which is contained in the water, is drawn in with it by the mouth, and forced, by the muscles of the throat, through the opening leading to the gills, the filaments of which are expanded and separated by the same process, so that they receive the full action of the fluid as it passes by them. When a fish is taken out of water, the reason he cannot breathe is, that these filaments collapse, and adhere together in a mass, and the air cannot separate them.

26. The seal, porpoise, dolphin and whale, belong to the class mammalia, and therefore have to rise to the surface of the water to get air to breathe. It is this necessity which exposes the whale to the harpoon of the fisherman; for such are his strength and swiftness, that, could he live entirely under water, he might defy the utmost ingenuity of man to capture him.

Fig. 9.

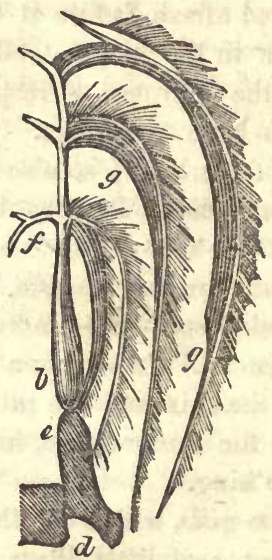

The above cut shows the mode of respiration in fishes. The gills are seen bent over in the form of a feather: $d$ is the auricle of the heart; $e$, the ventricle; $f$, the bronchial artery; $g, g$, the gills. The 
heart of a fish throws the blood only to the gily and net to the rest of the body as in other animals. This is the reason why the gillsard red, while the other parts of a fish are white. Respiration on fishes is; therefore, performed by taking water into the unoutl. and forcing it through the gills; in this manner the air contained in the wrater is brought in contact with the thin coats of the blood-vessels, through which the oxygen is absorbed.

Questions.--What is meant by respiration?-by inspiration?-by expiration? How are the parts concerned in respiration arranged? What bones are concerned? Describe the position of the ribs. What muscles are chiefly concerned in respiration? Describe the intercostals, - the diaphragm. How does the diaphragm act in inspiration? In expiration? What causes the deecant of the ribs in expiration? Describe the structure of the lungs. What (called in the lower animals? What are the pleure? - the mediastinum How many compartments is the chest divided into I In which is the hcart? What is the trachea? What does it end in? How large are the air cells? What is the office of respiration? What amount of surface do the air cells present? How does the blood get in contact with the air? Describe the process of respiration. How does tight lacing injure the health ? What happens if a hole is made into the cavity of the chest? What is the weight of the atmosphere equal to? Of what gases is it com. posed? What effect do vegetables have on air? What is oxygen ?azote? What is the effect of respiration on air? How much oxygen is consumed by a man in twenty-four hours? How do insects breathe? -the earth-worm?-fishes ?-birds?-the whale? \&c. 


\section{CHAPTER XIX.}

\section{THE CIRCULATION OF THE BLOOD.}

1. That the blood is constantly circulating throughout the human body, was unknown till (Harvey)made the discovery, two hundred years ago. Before this time, air was supposed to circulate through the arteries, or air tubes; hence their name. The reason why this great truth was not found out sooner, was, that (on examining dead bodies, the arteries were always found empty of blood; owing to the contractile force with which they are endowed.)

2. The circulation is called one of the vital functions, (because it is essential to life) Its suspension for a short time throughout the body is certainly fatal. Hence we find that diseases of the heart and great vessels are apt to terminate in sudden death, while in other diseases the approach of death is gradual.

3. Life, in all the organs, is maintained by the presence of arterial blood? Without it they could not be nourished, nor could they perform their appropriate functions. The moment any part of the body is deprived of blood, from that time it ceases to grow ; it withers and decays, and soon becomes a mass of dead matter. If the arteries which supply any of the limbs with blood are tied, the limb soon grows black, and mortifies. In the same way, if we stop the circulation of sap in a tree by girding or dividing the vessels which convey this fluid to the branches, the tree immediately dies. Blades of grass and corn are often destroyed by worms severing the same vessels with their teeth; and peach and other fruit trees, are generally short lived from the same cause.

4. Some animals are destitute of a circulation, such as insects, worms, \&c. Air and food are essential to the existence 
of life, but the food cannot be changed into blood before the air has acted on it by one of its principles, oxygen. Now, if these two principles are not introduced into the system in the same place, but in separate organs, it is evident they cannot be employed in nutrition till they are brought together; which is done in the lungs; the blood is there fitted to carry nourishment and life to every part of the system. Every animal then, that has a local respiration, must also have a circulation.

5. The organs of the circulation are the heart, arteries, the veins, and the capillary vessels. The arteries and veins, or the arterial and venous systems as they are called, have been compared to two trees, the one scarlet and the other purple, whose trunks are united at the heart, and whose branches are connected at their extremities, thus forming a regular circle. The blood is then forced out of the heart by the contraction of that organ, into the arteries, by which it is distributed throughout the body; from whence it is returned by the veins. Between the ends of the arteries and the commencement of the veins, are the small hair-like vessels called capillaries.

6. (The heart is a hollow organ of a muscular and fibrous structure, and somewhat conical in shape. It is placed in the fore part of the cavity of the chest, inclined to the left side. It rests on the midriff or diaphragm, which is the muscle that separates the chest from the abdomen; and it is supported also at its base which is uppermost, by means of the large blood-vessels connected with it.) (The heart is surrounded by a strong membranous bag, called the pericar. dium, by which it is, in a measure, protected. This bag is the seat of dropsy of the heart, and is generally found to contain more or less water after death.)

7. In the human species, and throughout the class mammalia) the heart is a double organ; consisting in fact of two single hearts, each of which gives motion to a different kind of blood. One of these, the right heart, receives the dark 
venous blood which is returned from all parts of the body, and sends it through the-lungs, from whence it returns to the left side of the heart changed to bright arterial blood, and is distributed by the aorta, or great artery, through the system. The right heart then may be called the venous or pulmonary heart, the left, the arterial heart. Both, however, are so united together, as to form in appearance but one heart.

Fig. 1.

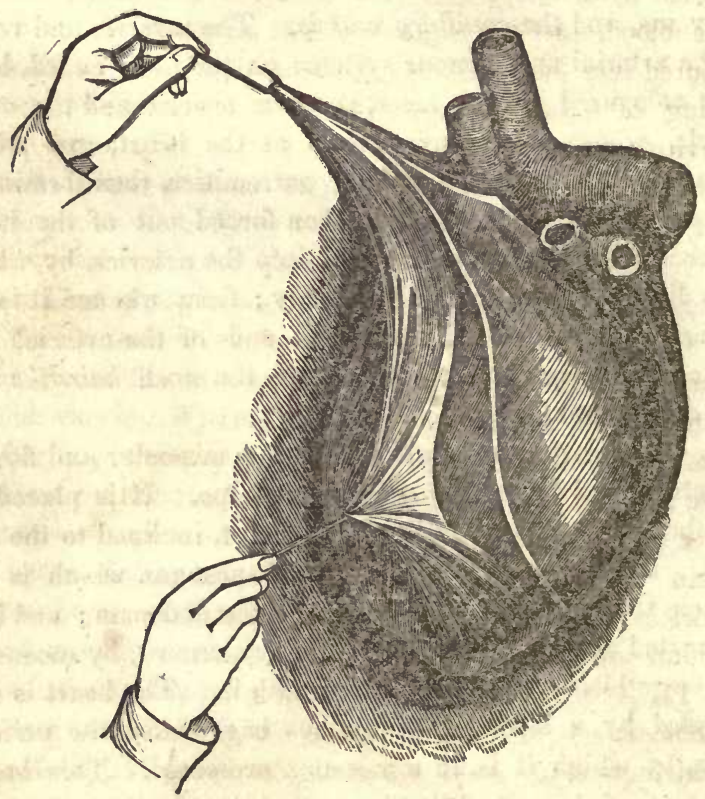

View of the heart inclosed in its bag, or pericardium, which is a serous membrane. It is here laid open and turned back.

2. Each of these hearts has two separate cavities; one to receive the blood, and the other to pump it out. The cavi. ties which serve as receptacles, are called auricles, those 
which, by contracting, force it out, are called ventricles. The walls of the heart are composed of strong muscular or fleshy fibres, crossing and interlacing one another, and those of the ventricles are much thicker than those of the auricles.

9. The cavities in the right side of the heart are triangular in shape, and those of the left, oval. Each cavity will hold about two ounces of blood.) Between each of these two cavities or chambers, there is a passage, which is closed with a valve; so that when the ventricles contract, the blood, instead of passing through into the auricle, is poured into the arteries, (This valve is formed by the doubling of a thin, transparent membrane, which lines the cavities, and extends both through the veins and arteries. The valve in the right side of the heart is called tricuspid, and that in the left, bicuspid or mitral)

10. There are also valves placed at the orifice of the great arteries of the heart, the pulmonary and aorta, as they are given off from the right and left ventricles. (They differ somewhat from the former, by being of a half-moon or semilunar shape, and formed by folds of the lining membrane of the arteries. These are called sigmoid valves; and their use is to prevent the blood from flowing back from the arteries into the ventricles.) Where the vena cava, or the great vein which returns all the blood, empties into the right auricle of the heart, there is another valve, called the Eustachian valve. (See Fig. 2.)

11. The arteries are the vessels into which the blood is immediately propelled by the action of the heart, and which distribute it to all the parts of the body) The pulmonary artery or the artery of the right side of the heart, circulates dark-coloured or venous blood through the lungs, where by exposure to the air, it becomes a bright scarlet. This is returned into the left auricle, which forces it into the left ven. tricle, whence it is sent through the aorta to every part of the system. 
Fig. 2.

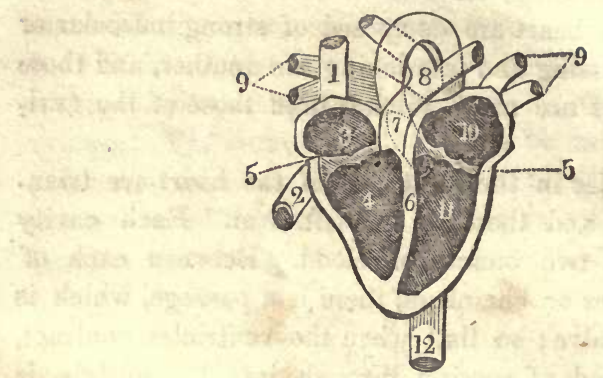

View of the heart with its several chambers exposed and the vessels in connection with them. 1. The superior vena cava. 2. The inferior vena cava. 3. The chamber called the auricle. 4. The right ventricle. 5. The line marking the passage between the two chambers, and the points of attachment of one margin of the valve. 6. The septum between the two ventricles. 7. The pulmonary artery, arising from the right ventricle, and dividing at 8 into right and left, for the corresponding lungs. 9. The four pulmonary veins, bringing the blood from the lungs into 10 , the left auricle. 11. The left ventricle. 12. The aorta, arising from the left ventricle, and passing down behind the heart, to distribute blood to every part of the system. Thus the blood moves in a double circle, one from the heart to the body, and from the body back to the heart, called the systemic circle; the other, from the heart to the lung, and from the lung back to the heart, called the pulmonic circle.

12. The arteries are very strong and elastic, of a yellowish white colour, and have three coats, the outer one of which is called cellular, the middle, the fibrous coat, and the internal, serous. It is very important that arteries should be elastic and capable of stretching, because, if they were not, every time a limb was broken, the artery would be ruptured, and the person bleed to death. (See Fig. 3.)

13. The veins which return the blood to the heart constitute two systems like the arteries; the one brings all the dark-coloured blood from the head, trunk and limbs, and in. ternal organs, to the right side of the heart, into which it opens by the two great trunks, called the upper and lower 
Fig. 3.

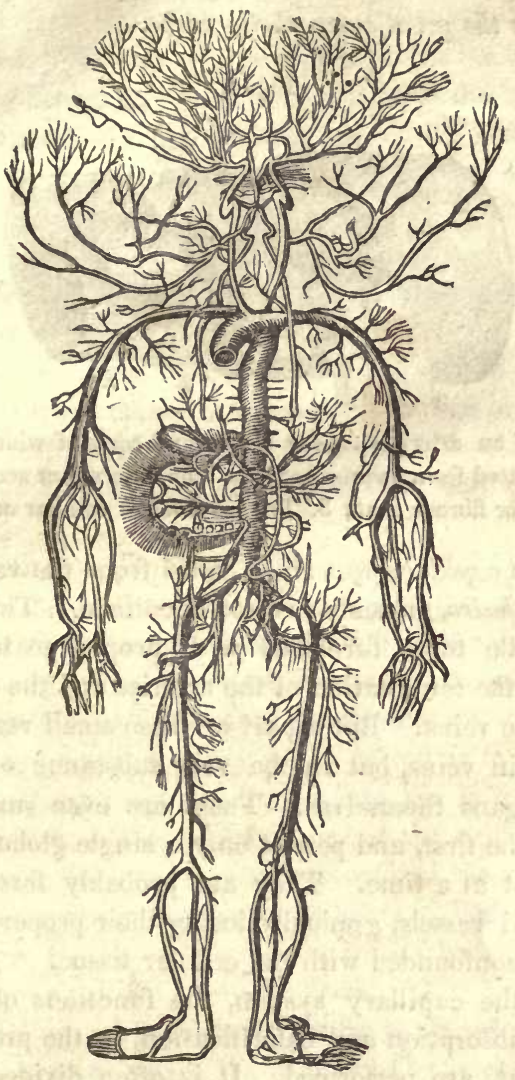

The Arterial system.

vena cava. The other conveys the scarlet-coloured or arterial blood, from the lungs to the left auricle, into which it issues by four large trunks, called pulmonary veins, The veins are strong and flexible, but not elastic like arteries. They are furnished with little valves placed at short distances from each other, so as to prevent the blood from flow. 
ing back again. Like the arteries, they are supplied with nerves from the great sympathetic nerve.

Fig. 4.

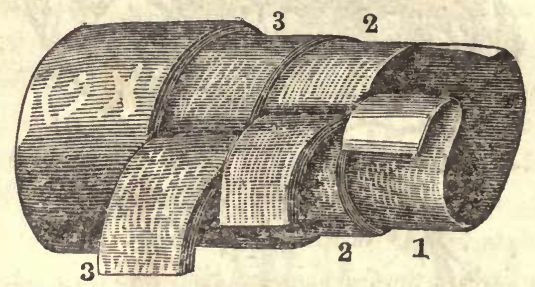

Portion of an artery, showing the several coats of which it is composed, separated from each other. 1. The internal or serous cont; 2. The middle or fibrous coat; 3 . The external or eellular coat.

14. The capillary system, so called from the vessels being small, like hairs, presents two modifications. (The first consists of little tubes, furnished with proper coats or walls, which are the termination of the arteries and the commencement of the veins. But a part of these small vessels do not terminate in veins, but in the very substance of the flesh, and the organs themselves. These are even smaller chan. nels than the first, and permit only a single globule of blood to pass out at a time. They are probably formed by the fine arterial vessels, gradually losing their proper coats, and becoming confounded with the cellular tissue

15. In the capillary system, the functions of secretion, nutrition, absorption and calorification, or the production of animal heat, are performed. It is often divided into two sections, the general and the pulmonary. The first has already been described. The other exists only in the lungs, and connects the pulmonary arteries and veins. In this the blood is changed from venous to arterial.

16. The account which has been given of the circulation applies to the human species, mammalia and birds. (Reptiles have but one heart, containing one ventricle and one or two 
auricles, which receive arterial blood from the lungs, and venous blood from the body, and in its cavity both are mixed together. The main artery going from the heart, divides into two branches, one of which goes to the lungs, the other is distributed throughout the body. In some of the other classes of animals, such as worm there is no heart, and the circulation consists in the passage of the blood from the surface, where are seated the organs of respiration, to all parts of the animal and back again, which is performed exclusively by vessels (Fishes have a single heart, designed only to circulate venous blood, which it conveys to the gills, or lungs; and from thence it is carried to every part of the body, by an artery which rises from the gills themselves? Shell-fish have also a single heart, but this only circulates arterial blood.

17. The following facts were brought forward by Harvey to prove the circulation of the blood. (If the chest of a cold-blooded animal be opened, the heart will be seen dilating and contracting) The valves are so situated throughout the circulating system, as to promote the circulation. Between the auricles and ventricles they are so placed as to allow the blood to pass freely from the former into the latter, and to prevent its return. The valves placed at the orifice of the arteries, permits the blood to enter them from the ventricles, but prevents it getting back into the heart. The valves in the veins allow the blood to go towards the heart, but prevent it from going in the other direction.

18. In bleeding, a bandage or ligature is placed round the arm, above the point where the arm is to be opened. The blood, in its return toward the heart, is interrupted, but the artery which carries the blood to it is not compressed, be. cause it lies deeper. Sometimes, however, the ligature is so tight that the blood will not flow till it has been loosened. If the vein be opened below the ligature it will bleed freely, but no blood is obtained if it be opened above.

19. When a limb is amputated by a surgeon, he only ties 
the arteries. The reason is, that as these convey the blood from the heart, the patient would soon bleed to death unless some means were adopted to prevent it. But, although the veins are as large as the arteries, yet, as they carry the blood back to the heart, they do not bleed, although they are not tied.

Fig. 5.

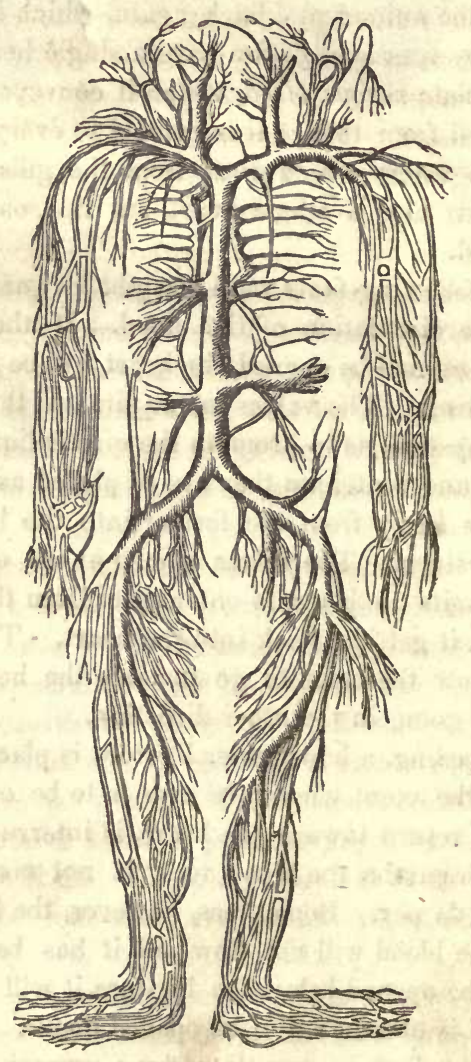

The Venous System. 
20. The blood can also be seen to move in the small capillaries by means of a microscope. The fine web of a frog's foot is generally used for this purpose. Microscopical observations, however, should be received with great allowance, for no two observers have ever found the same appearances. One makes out the globules of the blood to be round, another square, and another tubular. Some physiologists, it is to be feared, find just what they wish to find. Owing to the refraction of light, the microscope is little to be depended on in examining the minute structure of bodies.

21. The motion of the blood is chiefly owing to the action of the heart. This contracts with great force, and in the following manner.) The auricles both contract at the same instant, forcing the blood which is received from the lungs, and the general circulation, into the ventricles; these then contract at the same moment; the right one sending the blood through the lungs, the left one through the aorta. This alternate action is constant, as long as life continues. The reason why the auricles act together, and the ventricles the same, is probably owing to the fact, that both have a common septum or dividing wall, so that one cannot contract without the other.

22. The ventricles contract more suddenly and powerfully than the auricles, and they are three times as long in dilating or expanding, as contracting. When the ventricles contract, the apex or point of the heart rises up and strikes against the left wall of the chest, between the sixth and seventh ribs, and this can be felt by placing the hand on the left side. The left ventricle has much thicker and stronger walls than the right, because it has a greater distance to throw the blood; but the right ventricle will hold more than the left, because the venous system is more capacious than the arterial.

23. (The velocity of the blood in the arterial system grows slower in proportion to its distance from the heart, while that in the veins is accelerated the nearer it approaches the 
heart. The reason why the blood moves slower in the arteries as it recedes from the heart, is owing, probably, to friction, and the increased capacity of the vessels, for the arterial system is compared to a cone, whose apex is at the heart. The course of blood in the arteries is intermittent, or by jets; not that it does not flow all the time, but its flow is more or less rapid, according as the ventricles are contracting or dilating.

24. (The force with which the blood is thrown from the heart is variously estimated. Hales computed that the left ventricle of a horse exerted a force equal to 113 pounds, and that of a man at 51 pounds. Some think that the contraction must overcome the whole pressure of the air upon the body, which is equal to forty thousand pounds. As we cannot, however, correctly estimate the influence of breathing and other causes, we cannot, with any degree of certainty, tell what degree of power is exerted by the heart. Dr. Arnott thinks, however, that the heart acts with a force of about six pounds on every square inch, and as the left cham. ber of the heart has about ten square inclies, the whole force exerted is sixty pounds.)

25. The Blood. - The blood is not necessarily red, it may be white, as in the fish; transparent, as in the insect; yellowish, as in the reptile; and indeed there is no animal in which the blood is red in all the parts of its body.

26. In a short time after blood is taken from the body it separates into two portions, by a process called coagulation, viz 1. a watery portion called serum, and a solid portion called coagulum or clot; the white substance which forms the upper part of the clot is called fibrin, and the red mass under it, the red parlicles. The fibrin is the material from which all the solids of the body are formed) (See Fig. 6.)

27. The red particles owe their colour, it is supposed, to the presence of iron; though some say it depends on an animal substance of a gelatinous nature. These are usually described as being minute globules, but the latest microsco. 
Fig. 6.

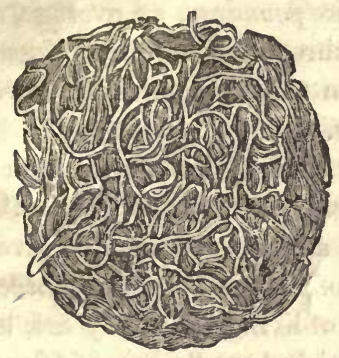

A portion of fibrin, showing its fibrous structure and the net-liks arrangement of its fibres.

pic observations show that they are flattened cakes, having rounded and slightly thickened margins, as shown in the following cut :

Fig. 7.
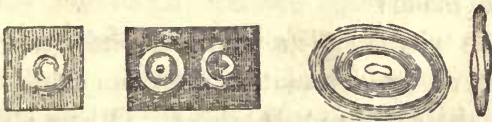

1. A particle of human blood as it appears when transparent and floating. 2. The same, seen as illuminated. 3. The same, one half illuminated. 4. A partiele of frog's blood floating. 5. The same, seen edge-wavs. All these objects are magnified five hundred diameters.

28. (The blood constitutes about one fifth part of the weight of the whole body); so that the whole quantity of blood in the body of an adult may be estimated at between thirty and forty pounds. (A complete revolution of the blood takes place every three minutes, and there are about five hundred and fifty revolutions every twenty-four hours The contractions of the ventricles, or the pulse, is about seventy-five times in a minute, in a grown person, and one lundred and forty in an infant; in old age about sixty. 
Now as two ounces of blood are thrown out of the heart at each beat, thirty-five pounds on an average, must pass through the heart every three minutes; seven hundred pounds every hour; and sixteen thousand pounds, or eight tons, every twenty-four hours.

29. Dr. Barry states, that the quicker the blood circulates the sooner will the machine wear out. Now, suppose that the pulse of a temperate man be seventy in a minute, and by the use of ardent spirits he forces it up to eighty. five, then instead of living seventy years, his number of pulsations will be finished at the age of fifty-six ; thus cutting short his life fourteen years.

30. The heart beats morc than one hundred thousand times in twenty-four hours, and sometimes continues to beat thus for one hundred years. What other machine so complicated, could last as long? And still it is made of nothing but flesh. How strange that it should act so long, without growing weary! Truly is it said, that " $\mathrm{man}$ is fearfully and wonderfully made!"

31. Some physiologists consider the heart the only moving power of the circulation: Others think that the arteries aid by their contractile power. Others still believe that the capillary vessels have a kind of absorbing and propelling force, independent of the heart and arteries, while a last class ascribe the circulation to a self-moving power in the blood itself. All these theories may have some truth in them, but they err in being too exclusive.

32. That the heart is the chief moving power of the blood is generally admitted. If the heart of a frog be ta. ken from the body and placed in warm water, it will concontinue to contract and dilate with great force for a considerable time. This would seem to prove that its action does not depend on the contact of air and blood. In serpents the heart retains this power a long time after death; and it has been known to contract at least four days after life appeared extinct. The heart of a sturgeon was cut out 
and laid on the ground, and after it ceased to beat it was blown up and ordered to be dried. It was then hung up when it began to move again and continued to beat, though more slowly, for ten hours ; and it continued to contract till it became so dry as to rustle with the motion. If the heart of any animal be taken from the body immediately after death and carefully washed, it will continue to act for some time; showing that this alternation of action is natural to its irritable fibre, and results directly from its structure.

33. The arteries have not an equal power of contraction, with the heart, though they are generally found more or less contracted after death. The pulse, which may be felt by placing the fingers on the side of the wrist, takes place at the very instant the heart contracts, and is not probably owing to the contraction or dilitation of the artery, but chiefly to the jet of blood, which is sent along the tube. When arteries are changed into bone, the pulse is still felt. No pulse exists in animals destitute of a heart.

34. That the arteries are not only elastic, but contract so as to assist the heart in circulating the blood, is evident from the following facts. If an artery be laid bare, and two lig. atures applied so as to cut off all communication, and then a small opening made between the ligatures, the blood will spirt out with considerable force, and the artery become much contracted. When a person or animal is bleeding to death, the arteries always contract in proportion to the loss of blood; after death they relax again. Arteries too will contract by the application of stimulants or irritating sub. stances.

35. Besides these facts to prove that arteries contract, We may mention the following. We read of cases of pal. sy, where in the paralytic limb no pulse could be felt, al. though the heart beat as strongly as ever. We read of oth. er cases where the arteries continued to beat after the pulsations of the heart ceased. In diseases of the heart, we sometimes have a weak pulse, although the heart beats very 
strongly. And in apoplexy the pulse is often strong, when the heart acts feebly. Burns relates cases where the pulse at the wrist did not correspond with the contractions of the heart : and it cannot be denied that in some animals a circulation exists, although they have no heart. Although fish. es have a heart, their blood is moved through the body by vessels. After the heart is taken out of the body, the blood is still seen to flow in the small vessels.

36. I have stated that arteries contract by an irritating substance being applied to them. Hartshorn, or ammonia, will make an artery shrink so as to lose one eighth of its circumference. A partial enlargement of an artery takes place in a living animal by exposing it, and rubbing it between the finger and thumb, but in general no pulsation will be seen in an artery thus exposed.

37. The capillary vessels have an action independent of the heart. Whin the blood has reached the ends of the arteries, or the capillary vessels, the force of the heart and arteries is probably nearly, if not quite exhausted. Dr. Arnott says that the blood is driven into them, by a force equal to four pounds to the square inch. There is no doubt that the action of the heart is sufficient to force the blood through the arteries into the veins; for when the heart acts feebly the surface of the body is pale and cold. But the blood is known to move in a backward or retrograde direction. When a leech is applied to the skin, the blood flows to the spot from all quarters. In blushing, the capillaries of the cheek dilate instantly and admit more blood; under the influence of fear they contract, and the face becomes pale; tears will gush from the eye in a moment and suddenly disappear; now all these things could not happen if these vessels did not act independent of the heart.

38. It is probably capillary action which moves the fluids in all animals that have no heart. Persons have lain in a swoon apparently dead for days together and then revived. In these cases life was preserved in the capillary circulation. 
I have seen a case of this kind, where a young lady of this city, was kept a fortnight after she was supposed to have died; her looks being so natural that her parents were unwilling to bury her, for fear she would come to life. Although she lay in a room without a fire in the winter season, yet her body retained its natural warmth for several days, her cheeks their florid colour, and her limbs their usual flexibility. These singular phenomena were perhaps owing to a continuance of the capillary circulation.

40. The capillary vessels are the last part of the body that continues to act. After the breathing and the action of the heart have ceased, they still continue to act like innumera. ble little pumps, drawing the blood out of the arteries and substance of the organs, and forcing it into the veins. As nutrition and secretion are performed by that portion of the capillary system which acts independently of the heart and arteries, the continuance of action in this system accounts for the growth of the beard and the hair, which takes place after death. It is owing to the same reason, that the arteries are always found empty after death.

41. Physiologists are not agreed as to the cause of the motion of blood in the veins.) The veins have thinner coats than the arteries and are destitute of elasticity. As they are wanting in elasticity, if they had no irritability, they could not act upon the blood contained in then, and accordingly could exert no active force in circulating the blood. But it is found by experiments that the veins are not mere passive tubes ; they possess a certain degree of contractile power, as is shown in the shrinking of the veins on the back of the hands in cold weather; besides, if a vein be punctured between two ligatures, the blood will spirt out. (The veins then assist the circulation by a sli ht degree of contractile power.

42. Again : when the heart dilates, the blood is sucked up in the veins precisely as it is in a pump. This is denied by some, who sny. that if the end of a svringe be placed in a 
tube of eel-skin, or any thing which is not elastic, and you attempt to pump the water out of it, supposing it to be filled, the sides will be brought together, and the tube closed, so that the water cannot escape. This, however, will not hap. pen, if, as in the veins, the fluid is forced in at the other end.

43. The expansion of the chest in breathing, also aids in circulating the blood in the veins. When the chest is dilated, both air and blood rush into it. This may be seen by watching the jugular veins in the neck, which empty them. selves during inspiration. Dr. Barry placed one end of a tube in the jugular vein, and the other in a coloured fluid. During inspiration, the fluid was sucked from the vessel into the vein; during expiration, it remained stationary. It should be remembered, that during one act of respiration, the heart beats five or six times.

44. One other cause remains to circulate the blood in the veins, and that is, the action of the muscles. When the muscles contract, they press upon the veins in contact with, or near them, and so force the blood along their cavities. This can be seen in bleeding from the arm; if a person grasps a stick, the blood flows much more freely than when the muscles are relaxed. It is in this way, that exercise proves so beneficial to health, by promoting the circulation of the blood through the system; and we account in this way also, for the fact that sedentary habits so often lay the foundation for incurable diseases.

45. (The heart is not so dependent on the brain for its ac. tion as many other organs.) Monsters, born without heads, sometimes live for several days. Snakes have lived six months without a head; and any animal may live for some time in the same condition, if the blood-vessels of the neck are tied. If the breathing be kept up by artificial respiration, life may be continued for a long time. I have myself kept a child alive two hours, that had its neck broken, by keeping up artificial breathing; persons have been saved in the same way, who had taken large doses of laudanum.) 
46. In fainting, the heart ceases to act.) It may be owing to various causes, acting on the nervous system, or on the blood-vessels. Mental emotion, loss of blood, or any thing that renders the blood-vessels about the heart less full or tense than usual, will cause a person to faint. This state is soonest relieved by (lying down, probably because the action of the heart is sufficient to force the blood along horizontal tubes, but not to raise it in a perpendicular position. Where blood has been lost in sufficient quantity to endanger life, it has been supplied from the veins of another person, by a pro. cess called transfusion.

Questions.-When was the circulation of the blood discovered? and by whom? Why not discovered before? Why is the circulation called a vital function? How is life maintained? Have all animals a circulation Describe the structure of the heart. What is the pericardium? In what animals is the heart double? Describe the cavities of the heart-the valves. What is their use ? What are arteries? How many coats have they? Describe the venous system. Have the veins valves What is the capillary system? Describe the circulation in reptiles-worms-fishes. What facts did Harvey bring forward to prove the circulation of the blood? What is the motion of the blood chicfly owing to ? Are the veniricles thicker than the auricles? Why? What is said of the velocity of the blood? Of the force of the heart? Describe the composition of the blood? What proportion of the body does it constitute? How long is the blood in performing a revolution? What is the last part of the body that continues to act? Why are the arteries found empty after death? What circulates the blood in the veins? What aids in this process? Does the heart depend on the brain for its action? What facts connected with this sub. ject? What occurs in fainting? What position is most favorable in recovering from fainting ? 


\section{CHAPTER XX.}

NUTRITIVE FUNCTIONS.-DIGESTION.

1. Digestion, absorption, secretion, and nutrition constitute what are called the nutritive functions.) Digestion is that process by which the food is brought into a state in which it may be taken up by the lacteal vessels and carried into the blood. The digestive apparatus consists of the mouth and its appendages; the pharynx; esophagus; the stomach and intestines); the whole tract making what is called the alimentary cdnal. Besides these, there are the salivary glands; the liver; the pancreas, or sweet-bread of animals; all of which aid in the process of digestion.

2. The parts which compose the mouth, are (the lips, cheeks, palate, tongue, teeth, and salivary glands, There are six salivary glands, which secrete saliva, viz.: the parotid; sub-maxillary; and the sub-lingual. The parotid gland is situated on the cheek before the ear ; the sub-maxillary immediately beneath the lower jaw; and the sub-lingual under the tongue. They all pour forth a fluid, during mastication, into the mouth to moisten the food, and prepare it for the change it is to undergo in the stomach. A swelling of the parotid gland is called the mumps.

3. In a grown person, there are thirty-two teeth; four incisor, or cutting teeth, two canine or dog teeth, ten molar or grinders in each jaw. The first set of teeth begin to come, when the child is about six months old, and by the time it is two years and a half old, it has twenty; about the seventh year, they all become loose and fall out, and their place is supplied by another set. The teeth are the hardest part of the body; their internal parts resemble bone; the external consist of a very hard and highly polished substance, called enamel, which is very durable. 


\section{Fig. 1.}

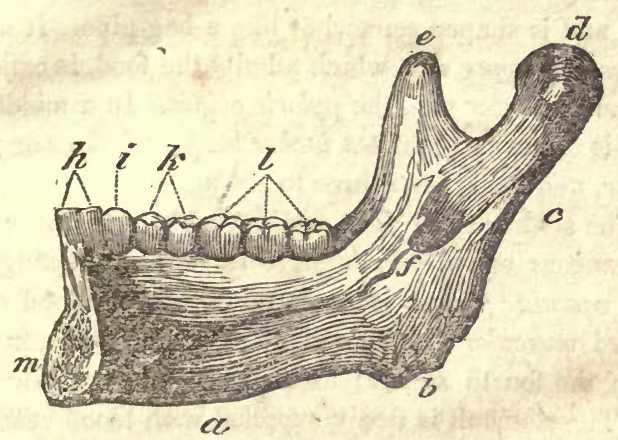

Half of the lower jaw; $a$, the base; $b$, the angle; $c$, the ramus; $d$, the condyle; $e$, the coronaid process; $h$, the two incisors or cutting teeth; $i$, one canine or $\operatorname{dog}$ tooth; $k$, two small molar; $l$, three large molar or grinding teeth.

4. The jaws perform an important part, in fitting the food for the stomach. The lower jaw only has motion; being moved by means of strong muscles, which rise from the temples and upper jaw ; and it not only moves directly upwards and downwards, but sideways, so as to grind the food between the teeth, as grain is ground between two mill-stones.

5. The tongue is likewise very useful in the process of mastication, as it removes the food from one part of the mouth to another, so as to bring every portion between the teeth; and then it forms it into a suitable shape for swallowing. The tongue is made up by different muscles, and is supplied by nerves, chiefly from the eleventh pair.

6. The esophagus or meat-pipe, lies directly behind the wind-pipe, and is about one inch in diameter. It connects what is called the pharynx, with the stomach. All these organs are lined by a soft, velvet-like membrane, termed mucous membrane, because it is always covered in health, with a riscid fluid, called mucus. 
7. The stomach is the largest organ of digestion. It lies immediately under the false ribs, on the left side, below the midriff, and is shaped somewhat like a bag-pipe. It has two openings, the upper one, which admits the food, is called car. diac, and the lower one, the pyloric orifice. In a middle sized man, this organ is about ten inches long, and three or four in diameter, and holds from three to six pints.

8. The stomach has four distinct coats; the inner one is called mucous or villous; being thin, soft, and spongy; the second vascular; as it is made up chiefly of blood vessels; the third muscular; composed of muscular fibres, and very strong; the fourth serous; as it secretes a serous or watery fluid. The stomach is freely supplied with blood vessels and nerves; the latter being furnished partly from the spinal marrow, and partly from the brain.

Fig. 2.

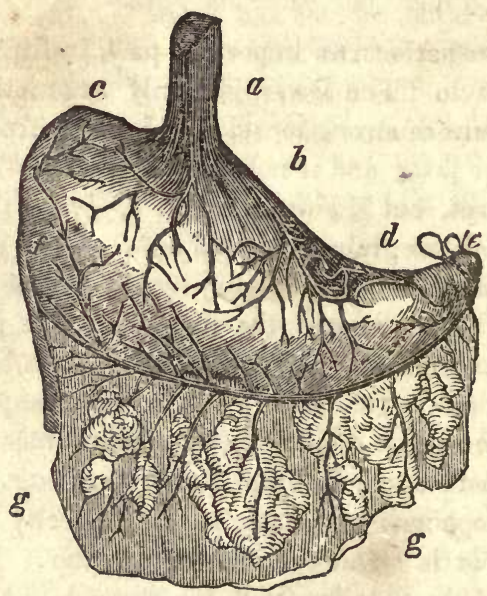

The human stomach : $a$, the esophagus or gullet; $b$, the cardiac portion; $c$, the left extremity ; $d$, the small extremity ; $e$, the pylorus tied; $g g$, the omentum or caul, which is attached to the outside of the stomach, and falls over the intestines like a curtain. 
9. The intestines in man, are from five to six times the length of the body; and are divided into large and small intestines; the latter making about four fifths of the whole. The small intestines are divided into duodenum, jejunum, and ileon. The duodenum is so called because it is about twelve finger's.breadth in length; the jejunum from its generally being found empty; the ducts or canals from the liver and pancreas enter the duodenum near the middle, and it is abundantly supplied with lacteals. The different portions of the large intestine are called coecum, colon, and rectum.

10. The liver is the largest gland in the body; and it lies directly under the ribs, on the right side, and reaching below them. In a grown person, it is about ten inches in diam. eter, and weighs not far from four pounds. It secretes the bile, which is poured out into a bag called gall-bladder, connected with it ; from thence it is carried into the duodenum. The liver is found in all the vertebrated animals and in the mollusca; in birds, reptiles and fishes, its size is greater in proportion to that of the body than in the human species. It is attached to the diaphragm, which lies above it, by a fold of the peritoneum, called the suspensory ligament of the liver.

11. The pancreas is a gland about five inches in length, of a whitish colour, lying immediately behind the stomach. It is supplied, like the stomach, with numerous blood-vessels and nerves. It secretes a fluid, called the pancreatic fluid, which is white, viscid, inodorous, slightly saline, and con. tains a large proportion of albumen. This gland is found in all the mammalia, in birds, and in amphibious animals, or such as live both in air and water, like the frog; but it is much larger in animals that live on vegetables, than in those that feed on flesh. Hence, the fluid which it secretes, is supposed to aid in difficult digestion. (See Fig. 3.) 
Fig. 3.

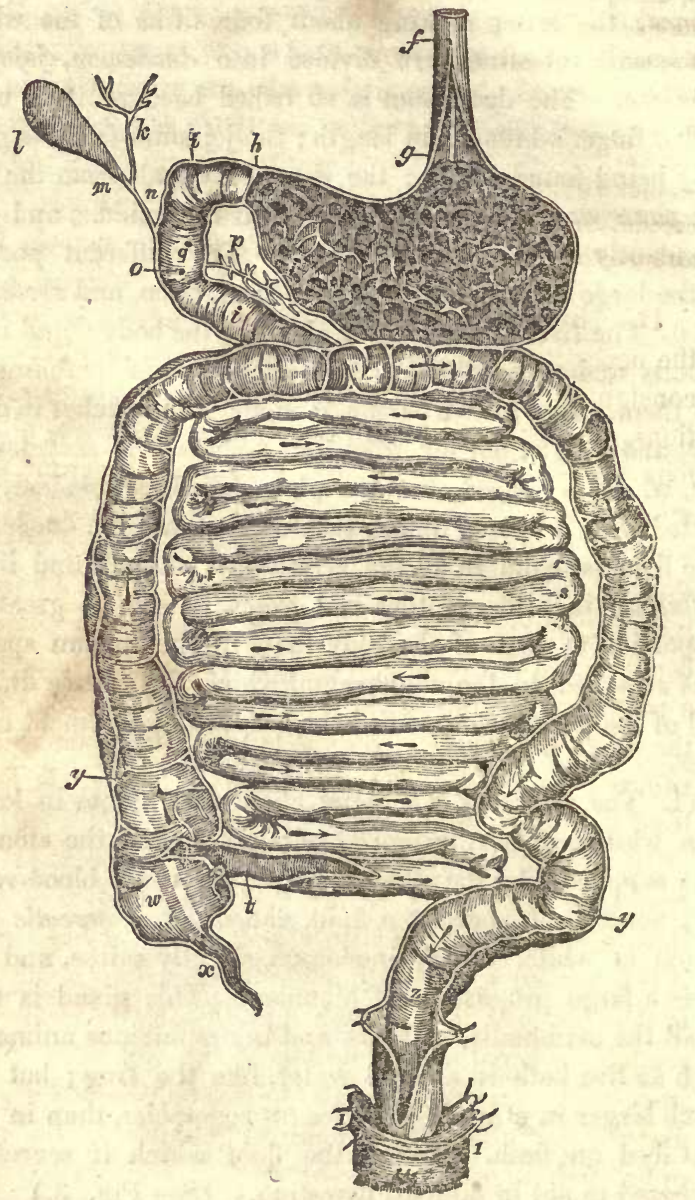

The above cut represents the whole tract of the intestinal canal, not exactly in its natural position, but spread out so as to show the relative proportions ; $f$, the æsophagus ; $g$, cardia ; $h$, pylorus ; $i, i$, the duodenum, about twelvo fingers' breadth in length; $k$, hepatic duct; $l$, gall blad- 
der; $m$, cystic duct; $n$, ductus communis, formed by the union of both; $o$, the opening of this duct into the duodenum; $p$, pancreatic duct; $q$, its opening into the duodenum; $r$, jejunum; $s$, ilium; these constitute the small intestines, and are about twenty-six feet in length, or five times the length of the body; $t$, termination of ilium in the coecum; $u$, superior fold of valve of colon; $v$, inferior do.; $w$, coecum ; $x$, ver. miform process; $y, y$, colon; $z$, rectum. The coecum, colon, and rectum, form the large intestines, and are about six feet in length; the coecum being about 4 inches long, and the same in diameter. The arrows show the direction which the food takes in digestion.

12. Hunger and thirst are sensations designed to teach us the necessity of supplying those losses which the system is constantly undergoing by the different secretions and excretions, amounting to several pounds in the course of twentyfour hours. The blood first feels the loss, and then the solids, whose particles are continually taken up by the ab. sorbents, and carried into the blood, and thus ejected from the system; and were not these losses supplied by the timely introduction of food, the body would rapidly emaciate, till death closed the scene. Hunger is supposed to be owing to a peculiar affection of the nerves of the stomach; for when the nerve which goes from the brain to the stomach (the parvagum, is divided, the sensation of hunger is lost, or at least the appetite for food is destroyed.

13. While the food is undergoing the process of masticatıon, that is, of being divided and ground down by the teet it is thoroughly mixed with a quantity of saliva, amounting it is supposed to between eight and ten ounces. The food is thus brought into a condition to be easily swallowed, and readily dissolved by the action of the stomach. It is very important, therefore, that the food should be slowly chewed, and reduced to as fine a state as possible in the mouth, in order that digestion may be easy. Too great rapidity in eating, probably lays the foundation of many cases of indigestion.

14. After the food has been sufficiently masticated, it is carried down the esophagus into the stomach, first by the 
contraction of the muscles of the pharynx, and then by a successive contraction of the circular fibres of the gullet it. self, from above downwards. That the morsel is not carried down merely by its own weight, is proved by the fact, that a man can swallow with his head downwards.

15. In the stomach, the food is converted into a soft, grey, pulpy mass, called chyme. This process has been called chymosis. It is produced by the motions of the stomach, together with the agency of the secretions, which are thrown out by the gastric vessels. These motions have been called vermicular or worm.like; and undulatory, or like wave suc. ceeding wave. The crawling of a worm furnishes a very good illustration of the successive contractions of the muscular fibres of the stomach, commencing, as they do, at the æsophagus, and proceeding onwards to the pylorus, and so back again. These motions of course bring every portion of the contents of the stomach in contact with all parts of its surface; and so they become intimately mixed with the gastric fluid.

16. The food is thus carried round the interior of the sto. mach, from one extremity to the other; and from one to three minutes are employed in each revolution. In the mean time, both orifices are closed; so that the contents cannot escape. During this process, the gastric fluid is secreted in large quantities, and becomes mixed with the food as it passes round. In a short time, the taste, smell, and other sensible properties of the food, are entirely changed. This is produced by the agency of the gastric juice, which subverts the chemical affinities of the food; and with its elements forms new combinations.

17. (The gastric fluid is a clear, transparent fluid, produced by arterial exhalation; acid to the taste, slightly saline, and free from odour.) It possesses the singular property of co. agulating albumen; resists the putrefaction of animal matter; and dissolves nearly every kind of alimentary substance. Its acid properties are owing to the muriatic and acetic acids 
which it contains. The gastric fluid is found to contain more acid, in proportion as the food is more difficult of digestion. It is only secreted, when food is present in the stomach.

18. The aliment then is converted into chyme, chiefly by the gastric fluid; aided, however, by the motions of the stomach. This is proved by the fact, that this fluid will dissolve alimentary substances out of the stomach: the chyme which is prepared by artificial digestion, presenting the same sensible properties as that which is found in the stomach. Such is the power of the gastric fluid, that it will dissolve bones, not only in the stomach, but out of it. It curdles milk; and for this purpose the rennet, or stomach of the calf, is used by farmers in making cheese. But every thing which is coagulated in the stomach, is dissolved again, in its conversion into chyme.

19. But digestion is a vital and not a chemical process. Though aliment may be reduced to a substance resembling chyme, by the action of gastric fluid out of the body; yet it is destitute of all those peculiar properties which assimilate it to the nature of a living animal. The food may doubtless be brought to a fluid state by a chemical process, and even alimentary principles may in the same way be changed into each other, as starch into sugar and gum; but there is still another power, which may be called vitalizing or organization, by which alimentary substances are brought into such a condition as adapts them for an intimate union with the living body. Such a power is beyond the reach of chemical action.

20. The time which is required to change food into chyme, varies according to the nature of the food. Animal food is digested sooner than vegetable. The average time required, is about three hours and a half. A good deal depends, also, on the degree of mastication it has undergone. If swallowed in large masses its solution must go on slowly.

21. As fast as the aliment is changed into chyme, it pass. 
es out of the stomach into the duodenum, and it generally stays in the stomach until it has undergone this change. Indigestible substances have thus been vomited up, more than a week after they were swallowed. All fluids which are swallowed, are supposed to be taken up by absorption.

22. If the par-vagum, or nerve which goes from the brain to the stomach, be divided, digestion is impaired or suspend. ed. The same happens under the influence of mental emotions, such as grief, anger, \&c. Some physiologists have thought that this nerve presides over the secretion of the gastric juice; others, that it stimulates the muscular motions of the stomach; while a third class consider it to be the seat of sensation in the stomach, giving rise to hunger and thirst. But it is not yet fully settled what particular influence this nerve exerts over digestion.

-23. The chyme, on passing from the stomach, is received into the duodenum. This, like the stomach, has a serous, muscular, and mucous coat, and has a mucous, as well as serous, secretion. In this portion of intestine, the chyme in its passage meets with the pancreatic and the biliary fluids; the irritating properties of the acid chyme, cause these fluids to be poured out in great abundance, as well as the other secretions; and these are thoroughly mixed with the chyme by the contraction of the intestine. It now becomes of a yellowish, instead of a gray colour; its acid properties disappear, and large quantities of albumen are developed. This is supposed, by some, to be derived from the pancreatic fluid, which contains a large proportion of it.

24. As it becomes intimately mixed with the biliary and pancreatic secretions, the substance called chyle is produced. Though some say it is not to be found in the duodenum-but only the elements out of which it is formed. But albumen, which is the basis of chyle, exists abundantly in the duode num; and so also do particles of fibrin. By the microscope, globules also may be detected in the chyme, similar to those which are found in the chyle. 
25. It would seem, then, that the great business of digestion is to change the food into albuminous matter, which forms the basis of the chyle as well as the blood; and it is certain that no albumen is formed in the stomach; though the change which the food there undergoes, is an approach to the nature of albumen. As the bile is alkaline, it doubtless combines with, and routralizes the acid properties of the chyme, which would precipitate the mucus of the bile, and leave it in a state of coagulation.

26. Chyle then is the fluid, which is taken up by the absorbent vessels, called lacteals, whether it exists ready formed in the chyme, or is manufactured out of it, by the action of these vessels themselves. It is usually of a milk white colour, but varies in appearance in different animals; and according to the nature of the food. In animals that feed on flesh, it is opaque; in such as live on vegetables, it is trans. parent ; in birds and fishes, thin, serous, and clear like water. It is saltish, and somewhat sweet to the taste; heavier than water but less so than blood. It coagulates on standing, like blood, and separates into three portions; a fluid, a coagulum, and a fatty substance. The fluid portion is chiefly of albumen and coagulates like the serum of the blood by heat, acids, and alcohol; the coagulum consists of fibrin, and a coloring matter, which is white.

27. Whatever the food may consist of, physiologists are now pretty well agreed, that the chyle will always be composed of fibrin, albumen, a fat matter, muriate of soda, and phosphate of lime, though in variable proportions. Food that contains much azote, such as that of animals, it is sup. posed will form chyle, which contains a greater portion of fibrin than that of vegetables, as azote is one of the chief ele. ments of fibrin. Dr. Marcet states that chyle produced from vegetable aliments contains three times as much carbon as that formed out of animal substances. It is certain that chyle from animal food is milky; and that from vegetables traasparent. As both however are composed of the same 
essential elements, we may be assured, that man can live on either animal or vegetable diet, as it may be most convenient. As the most important part of digestion seems to be completed in the small intestines, we shall not follow the process any farther.

28. A few years since, a man in the United States army received a gun-shot wound, which made a hole in his sto. mach ; and which left an opening into the cavity of that organ, so that the whole process of digestion could be seen, as it was going on. Dr. Beaumont, a physician in the army, availed himself of this singular case, and performed many curious experiments which occupied him for several years. The following are the most important inferences, which he drew from his experiments.

29. "Animal and farinaceous aliments are more easy of digestion than vegetables. Digestion is faqilitated by minuteness of division and tenderness of fibre; hence the importance of thoroughly chewing the food. The ultimate principles of aliment are always the same, from whatever kind of food they may be obtained, whether vegetable or animal. The quantity of food generally take into the sto. mach, is greater than the system requires. Splid food is easier of digestion than fluid. Stimulating condments, such as spices, are hurtful to a healthy stomach.

30. The continued use of ardent spirits al ways produces diseases of the stomach. Hunger is the effect of the distension of the vessels, which secrete the gast ic juice. The temperature of the stomach is 100 degrees of Fahrenheit. The gastric juice dissolves the food, and alters its properties. It also coagulates, or renders solid, albumen, and afterwards dissolves it.

31. The gastric juice is a clear and transparent fluid; a little saltish, and somewhat sour to the taste. When pure, it suffers no change by keeping. Gentle exercise assists the digestion of the food. Water, ardent spirits, and most other fluids are not affected by the gastric juice, put disappear from the stomach soon after they are received" 
Questions.-What constitute the nutritive functions? What the digestive apparatus? What the mouth? How many salivary glands are there? How many teeth are there in an adult? How divided? When do they begin to appear? When are they shed? What is the outside of the tooth called? How is the tongue useful in mastication? Describe the esophagus - the stomach-the intestines-the liver-the pancreas-hunger and thirst. Describe the process of digestion. What is the gastric juice? Chyme? Chyle? What is rennet-what used for? Is digestion a chemical process? How long does it generally take to convert food into chyme? What influence has the par vagum nerve on digestion? Where do the pancreatic and biliary fluids enter the intestines ? their use? Is the nature of chyle changed by the kind of food? Of what is it always composed? What are the principle results of Beaumont's experiments in relation to digestion? 


\section{CHAPTER XXI .}

\section{SECRETION.}

1. Secretion is one of the most obscure and mysterious functions in the animal economy. To secrete means to separate; / but most of the fluids formed by this process, did not previously exist in the blood, but only the elements out of which they are made. It is purely a vital and not a mechan. ical process, like straining through a seive, to which some have compared it : and the vessels by which it is accom. plished may well be called the architects and chemists of the system; for out of the same material, the blood, they con. struct a variety of wonderful fabrics, and chemical com. pounds.

2. We see the same wonderful power possessed also by vegetables-for, out of the same materials, the olive prepares its oil ; the cocoa-nut its milk; the cane its sugar; the poppy its narcotic juice; the henbane its poison; the oak its green pulpy leaves, its light pith, and its dense woody fibre all composed of the same, few simple elements, only arranged in different order and proportions.

3. In like manner, we find the vessels in animal bodies, capable of forming all the various textures and substances which make up the frame; the cellular tissue; the membranes; the ligaments ; the cartilages ; the bones ; the marrow; the muscles, with their tendons; the lubricating fluid of the joints; the pulp of the brain ; the transparent jelly of the eye ; in short, all the textures of the various organs of which the body is composed; and still all are made out of the same blood; and consist of the same ultimate elementsd

4. The most simple form of secretion, however, seems to be, the mere separation of some principle, which previously existed in the blood, as serum is deposited in most of the cavities, by a kind of exhalation. Some other principles also 
exist in the, blood, which are found in the secretions, as $f$ brin, a fatty substance; and some of the elements of the bile. Some physiologists believe, that many of the secretions do exist ready formed in the blood, but cannot be detected by analysis. In proof of this, two ounces of bile have been injected into the veins of a dog, but the blood of the animal, which was analyzed a few moments after, exhibited not a trace of bile.

5. That secretion is a vital process and not a chemical one, is evident from the fact, (that it is so much under the influence of the nervous system. For example, sorrow and grief change the qualities of the bile: a fit of anger sometimes causes an excessive flow of it : it will also change the nature of milk to such a degree, as to produce colic, vomiting, and even convulsions in the infant that swallows it Grief will also suspend the secretion of the gastric fluid, and thus destroy the appetite; while fear causes a cold sweat to break out, all over the surface of the body. If the nerves going to any organ are divided, the function of secretion will be suspended. It is doubtless owing in a great degree to the changeful states of the nervous system, that the secretions vary so much in quality as well as quantity at different periods.

6. Though we are able to understand but little of the true nature of secretion, we know that there are three kinds of se. cretory organs, vif., exhalent vessels; follicles; and glands.) The exhalents are believed to be the termination of the arteries, or capillaries? and they are of two kinds, internal and external; the former terminating on all the surfaces within the body; and the latter on the outside. (Their use is to soften and lubricate these parts)

7. The fluid, which is thrown out by the serous membrane which surrounds the brain, the lungs, and the contents of the abdomen, as well as into the cavities of the joints, is very similar to the water of the blood, and its use is, to keep the parts in a moist state, and enable the organs to move ea. 
sily on each other. (Fat is also a secretion, which is thrown out in a fluid state, from the cellular tissue, into little cells ) and it is mostly found immediately under the skin, between that and the flesh. Its use seems to be, to lubricate the so. lids and facilitate their movements; to form a cushion around the body, and protect it from external injuries as well as the extremes of heat and cold.

8. During sickness, when we take little or no food into the stomach, nife is supported by the absorption of the fat, which is taken up by little vessels and again poured into the blood, to nourish the body; also in animals which lie in their burrows, in a half torpid state during the winter, their nourishment is derived from the same source.

9. Marrow which fills all the cavities of the long bones, is very much like fat, and this also is a secretion from a thin, delicate membrane, that lines the cavities of the bones.) These are the principal internal exhalations, or secretions.

10. The external secretions are two in number;//the first and most important from the skin is called, when insensible, perspiration; and when it is visible, is called sweat; the second is from the lungs, and can be seen in the form of a va. pour in a frosty morning 'The fluid which escapes from the skin, is chiefly water, containing a little acid and some salts, with a small quantity of animal matter.

11. The skin is covered with an innumerable number of pores, so small indeed, as to be invisible to the naked eye, through which the insensible perspiration is constantly pouring, (amounting in weight to more than one half of all the food and drink taken into the stomach, and much exceeding that lost by all the other excretions?

12. From a vast number of experiments performed by different persons, it appears that the largest amount of insensible perspiration amounts to five pounds in twenty-four hours, and the smallest to thirty-two ounces. Now, when we con. sider that the skin, serves as one of the chief outlets, by which the old and useless particles are got rid of, out of the 
blood, and that checked perspiration is one of the most powerful causes of disease and death, we shall see how important it is to keep the pores of the skin free, by frequent washing and bathing at all seasons of the year.)

13. When the surface also is chilled by cold, and reaction does not follow, the blood-vessels become contracted all over the skin, and the blood retreats to the inner parts of the body; the 29 ounces of waste and noxious matter, which ought to be discharged, are kept in the system, and sickness is the consequence. Accordingly, we find that it is a good remedy, in most cases of disease, to excite a perspiration and keep it up for some time.

14. The uses of transpiration by the skin, are, (not only to carry out of the body the noxious properties of the blood, but also to render the skin soft and pliable, the sense of touch delicate, and also to cool the body when exposed to great heat)

15. The exhalation from the lungs closely resembles that from the skin. It was once supposed to be formed in the lungs, by the union of hydrogen from the blood, and oxygen from the air, thus forming water; but it is the opinion of most physiologists at present, that it is either the watery part of the mucus secreted by the mucous coat of the lungs and air passages, or that it is given off directly from the blood)

16. (The Follicles, are small sacks or bags, found in the skin, and the mucous membranes.) 'The pores which we see on the skin are only the outlets of these follicles. Their use is to secrete an oily matter to mix with the perspiration, and help to keep the skin soft and moist; when these outlets are closed, sometimes there appear small black specks on the skin, sometimes called worms, but they are nothing more than hardened mucus. Every hair has a follicle at its root, and the wax which collects in the ears, is secreted by follicles.

17. The chief agents of secretion in the body, are the glands, which are bodies of various size, generally of a 
rounded form; and the fluids they secrete, are very different from each other, and also from the blood which furnishes the same materials to all. For instance, the liver secrites the yellow, ropy fluid, called bile; the kidneys, secrete urine; the lachrymal gland, which is placed immediately over the eye in the orbit, secretes the tears; and the spittle or saliva is poured out from the salivary glands.

18. Glands are formed of a large number of arteries, veins, nerves, and lymphatics, disposed in a peculiar manner, and connected together by a tissue of cellular membrane) When in a cavity, they are covered on their external surface by a coat, derived from the membrane that lines the cavity, and they are also provided with a canal, called excretory duct, which is lined with mucous membrane. There are seven kinds of glandular secretions.

19. The secreted fluids have been divided (into serous or watery, albuminous mucous, oily, and the mixed such as sa. liva, bile, tears, \&c. They have also been divided into recrementitious and the excrementitious, or those which are des. tined to be absorbed and returned into the mass of the blood, and which are deposited in cavities that have no external opening; and the second, those which are designed, after their formation, to be expelled from the system.

20. When any substance is taken up by the absorbents, and carried into the blood, which cannot be converted to any useful purpose in the system, it is immediately discharged by means of the secretions Not many years ago, a man was carried into a London hospital, who was picked up drunk in the streets. He lived but a short time, and on examining his brain, nearly a half a gill of fluid strongly impregnated with gin, was found in the ventricles. This was secreted.

21. Unless the secretions all go on, we cannot enjoy good health. If that from the skin is stopped, fever, or some internal inflammation is the consequence. If the bile ceases to flow, we cannot properly digest our food; and so if any of the others are interrupted, some serious disease will be the 
result. The use of ardent spirits deranges all the secretions, and this is one reason why they shorten life so much.

Questions.-What is Secretion? Is it a vital process? Have vegetables the same property of secretion? Illustrate this. What is the use of this function? What is the most simple form of secretion? How is it proved that secretion is a vital process? How many kinds of se. cretory organs are there $f$ What are exhalents ?-their use? What is fat? How is life supported in sickness? What is marrow? What are the external secretions? How much does the insensible perspiration amount to in 24 hours? What important inference do we derive from this in relation to health? What is use of transpiration by the skin? What is the exhalation from the lungs owing to ? What are follicles? What are the chief agents of secretion? What are glands composed of ? -their structure? How are the secreted fluids divided? What becomes of useless substances carried by absorption into the blood? Can health be maintained if the secretions be checked ? 


\section{CHAPTER XXII.}

\section{ABSORPTION.}

1. Absorption is another function of the animal body, immediately connected with nutrition.] By it is meant that process by which food and drinks, designed for the nourish. ment and growth of the body, are taken up and carried into the blood; and also those particles and materials that have been already deposited, and have become either useless or injurious, are conveyed into the general mass of the circulating fluids, and thus removed from the system. The first is effected by the lacteal vessels; the second by the lymphatics.

2. The absorbent system, so called, consists of fhe lymphatic vessels, the lymphatic glands, and the thoracic duct) The lymphatic vessels arise, not only from all the mucous surfaces, but also from the whole surface of the body the intimate tissue of every structure; and from all cavities, such as the chest, abdomen, the joints, the pericardium, and even the ventricles of the brain. (They are exceedingly small at their origin, but by uniting, form larger and larger trunks as they proceed, which is generally in the course of the veins, till they finally discharge their contents, either into the thoracic duct, or some of the large veins near the heart. Throughout their whole extent, they are provided with numerous valves, which, when they are distended with lymph, causes them to resemble a string of beads.)

3. Every part of the body is supposed to be furnished with absorbent vessels, with the exception of the nails, the hair, the cuticle, and the enamel of the teeth. And even in these, it is not impossible that they may exist; only they are too small to be detected.

4. (The lymphatics of the small intestines, called lacteals, ) are the agents of digestive absorption. (They arise from the 
surface of the mucous coat, pass between the serous and muscular coats, and proceed to the small glends or ganglions of the mesentery As they emerge from these, they increase rapidly in size, till they finally unite in a large trunk, which passes up along the spine, and at last empties its contents into the left subclavian vein near the heart. Many physiologists are of opinion that the lacteals not only terminate in the thoracic duct, but also in numerous veins in the ab. domen.

5. The chyle, which is the fluid taken up by the lacteals, does not exist ready formed in the chyme, but 'is/formed or manufactured out of the nutrient principles contained in it, by a specific action of the lacteal vessels themselves In like manner, the sap which is contained in vegetables, does not previously exist ready made in the materials which are absorbed from the ground, but is formed by the peculiar action of the roots. No chyle has ever been found in the intestines.

6. As the chyle passes on towards the heart, it undergoes important changes. It loses some of its albuminous qualities; while its fatty matter, its fibrin, and cruor, considerably increase) Its tendency to coagulate, also becomes greater as it approaches the venous system, and it becomes clearer and more transparent. What is the precise nature of the change which the chyle undergoes in passing through the glands is unknown.

7. Absorption not only takes place from the small intestines, but from the whole tract of the intestinal canal, including the mouth and æsophagus. But those vessels which absorb chyle, are chiefly found in the small intestines. It is highly probable that alimentary substances may be directly absorbed from the intestines, without undergoing any pre. vious change or assimilation, like alcohol or water ; but that in their passage through the absorbent system, they undergo a species of digestion, and become in a good degree fitted for the replenishment of the blood. To this, however, alco. 
hol is an exception, as it frequently, if not always, passes into the blood unchanged.

8. Various medicinal substances are absorbed, and enter the circulation, nearly or wholly unchanged. Colouring matter, such as madder, is taken up and carried into the blood, and even tinges the bones. Oderiferous particles, such as of garlic, camphor, asparagus, \&c., are also readily absorbed, and in this way the blood derives its saline properties. It is pretty well established, that articles not of an alimentary nature, which are absorbed, are chiefly taken up by the veins, while the lacteals absorb chyle more readily than any other substances.

9. Absorption takes place from the external surface or skin. This is proved by many facts. Thirst may be quenched by applying moist cloths to the skin, or by bathing. The body increases in weight by the use of the bath ; and it has been found that the hand, immersed to the wrist in warm water, will absorb from 90 to 100 grains of fluid in the space of one hour. The saliva has become bitter by the absorption of sea water; and it is stated that patients have been supported by baths of milk or broth.

10. Medicinal substances are often absorbed by the skin. Mercury, Spanish fly, morphine, and many other articles are frequently introduced into the system through the skin. Metallic quicksilver has been found in the bones of persons who had been subjected to mecurial frictions; and it has also been obtained by distilling the blood of rabbits, dogs, and cats, which had been rubbed with this mineral. Gases are also absorbed by the skin.

11. As every part of the body is subject to constant renovation and change, absorption must be (continually going on among the particles and substance of which each organ is composed.) This is called interstitial absorption. It is this which counterbalances the action of the nutrient ves. sels, and preserves the form and size of every part of the body. When it is too active, the body emaciatest when it 
is deficient, plethora is the result. In the later periods of life it is more active than nutrition, and the body dwindles in size; in youth the reverse is the case.

12. Foreign bodies, introduced into the substance of organs, are also absorbed. Wens and tumours of considerable size, often disappear from the same cause. Instances are known where the absorbent vessels have set to work and removed the whole bone of a limb; and but lately a case occurred in Boston, in which every particle of bone in the arm was thus taken up and carried away, after a fracture had occurred. How admirable is that arrangement by which the vessels of absorption and secretion so act as to balance each other; and how soon would a loss of this balance produce derangement, disease, and even death.

13. Another form of absorption is called respiratory, which we have already considered under the subject of respiration. We understand by it (merely the introduction of oxygen into the blood, through the pulmonary cells) Substances, however, in a state of vapour, or fine dust, are also readily imbibed when drawn into the lungs; such as metallic vapours, oderiferous particles, marsh and other effluvia. It is in this way, probably, that contagious diseases are caught.

14. It is by means of what physiologists call recrementitial absorption, (that fluids are removed from the system which are secreted upon surfaces that have no external outlet $/$ as in the cavity of the chest, abdomen, brain, \&c. These fluids are various : such as the serous fluids; the synovia of the joints; the fat; the marrow, and the humours of the eye. It is this which prevents dropsies in these various cavities; and also removes them when already existing. This form of absorption is also proved by the fact, that fo. reign substances, placed in contact with these surfaces, in a short time disappear.

15. Another variety of absorption has been called excrementitial; as it relates to the fluids which have been excreted 
These are liable to be absorbed; at least the more fluid parts of them, by which they are again carried into the mass of the circulating fluids, and such parts selected as are fit for the uses of the animal economy, such is the case with the fluids exhaled by the skin; the mucous membranes; the saliva; the bile; the gastric and pancreatic fluids; the milk, \&c. Thus, has it been remarked, does nature choose to subject the materials of decomposition to a careful revision, before rejecting them finally from the body.

16. All these varieties of absorption are constantly going on from the moment of birth to that of dissolution, and all the fluids which are absorbed, are changed in their charac. ter, and fitted to repair the wastes of the system. Thus, by absorption in the lungs, oxygen is converted into one of the elements of the blood; in the intestines, chyme is changed into chyle; in the tissues of the organs, solid particles are converted into fluid lymph; and from the cavities secreted and excreted fluids are again taken up and thrown into the circulation, to be once more revised and elaborated.

17. Frogs, and several other amphibious animals, are furnished with large receptacles for the lymph, situated immediately under the skin, which exhibit distinct and regular pulsations like those of the heart. The use of these lympha. tic hearts is evidently to propel the lymph along the lympha. tic vessels. The frog has four of these organs; the two posterior being situated behind the joint of the hip ; and the two anterior ones on each side of the third vertebra. These organs have also been discovered in the toad, salamander, and lizard.)

Questions.-What is meant by absorption? What composes the absorbent system? Where do the lymphatic vessels arise? Describe their structure. Are they found in every part of the body 7 What are the agents of digestive absorption? Describe the lacteals. What is chyle? Does it exist ready formed in chyme? What changes does it undergo in its passage to the heart? Where are the chyliferous 
vessels chiefly found? Are alimentary substances absorbed without be. ing previously changed into chyle g 4 Is alcohol digested arre medicinal substances absorbed $\boldsymbol{V}$ How is this proved ? Does absorption take place from the skin? What is interstitial absorption? What is emaciation owing to?-plethora? Are foreign bodies absorbed when introduced into the substance of organs 3 /Are the bones ever absorbed ? What is respiratory absorption? What is recrementitial absorption? What excrementitial? Are these processes always going on ? What peculiarity is there in the lymphatic system of frogs? 


\section{CHAPTER XXIII.}

\section{NUTRITION.}

1. Nutririon may be considered as (the completion of the functions of digestion.) It is that process by which the waste of the organs is repaired, and by which their development and growth are maintained. Respiration, digestion, circulation, absorption, and secretion, are but separate links in the chain of nutrition; which would be instantly destroyed by the absence of any one of them.

2. In the construction of a machine, or an instrument, designed to last for many years, the mechanist seeks for the most durable materials.) In making a watch, for instance, he forms the wheels of brass, the spring and barrel-chain of steel, and for the pivot, which is subject to incessant friction, he employs the hardest of all materials-the diamond. The necessity for this arises from the fact, thaf such instruments do not contain, within themselves, the power of repairing their own losses)

3. But far different is the case with the animal machine. (In order to qualify it for exercising the functions of life, it must be so constructed as to render it capable of continual alterations, displacements and adjustments; and these subject to continual variation, according to the stage of growth, and also to the different circumstances in which it may be placed Instead, therefore, of a few elementary bodies, or their simpler combinations, nature has employed such compounds as admit of greater change, and a more variable proportion of ingredients, and greater diversity in the mode of combination. It is nutrition that moulds these plastic materials, and forms these ever-changing compounds; and so preserves the animal machine, amid all the varying changes of condition to which it is subject. 
4. No one can doubt that the system is continually un. dergoing changes. (This is proved by the losses to which it is subjected; by the necessity of frequent supplies of ali. ment; by the rapid wasting of flesh on the withdrawal of food; and by the emaciation caused by sickness and old age. It is also shewn by an experiment, which has often been made, viz. of giving modder to animals mixed with their food; which in a short time tinges their bones of a red colour. If the madder be withdrawn, the red colour in a few days disappears from the bones; evidently from the effects of absorption)

5. Every part of the body is subject to this constant change of matter. While one set of vessels, the lympha. tics, are taking to pieces and carrying away the various parts of which the machine is composed, another set, viz., the capillaries, are constantly at work, repairing the loss, ) depositing bone, muscle, cartilage, nerve, tendon, fat, mem. brane, ligament, hair, nails, \&zc. where each is wanted, and this with such regularity and order, as to preserve the shape, size, and appearance of every organ, so that, though after an interval of a few years there may not remain in the body a single particle of which, at the former period, it was made up; still, the individual preserves the same form and features; his personal identity is never lost.

6. (Those animals, which are the most complicated in their structure, and are distinguished by the greatest variety of vital manifestations, )are subject to the most rapid changes of matter. Such animals require more frequent, and more abundant supplies of food, and in proportion as they are exposed to a greater number of external impressions, so will be the rapidity in this change of matter. The frog, for in. stance, has been dug from the earth many feet below its sur. face; and even taken from cavities in solid limestone, where he had been shut up probably for centuries, and still exhibit. ed signs of life when exposed to the open air. As he was so situated as to lose nothing, by secretion or evaporation, of 
course he required nothing to supply any loss, hut how the vital principle was preserved for such a length of time, is a mystery not easy to be explained.

7. (The blood contains all the materials of nutrition.) The process by which the food is changed into blood has been al. ready explained. As it goes the round of circulation, the nutrient capillary vessels select and secrete those parts which are similar to the nature of the structure, and the other portions pass on; so that every tissue takes up and converts to its own use the very principles which it requires for its growth; or in other words, as the vital current approaches each organ, the particles appropriate to it, feel its attractive force; obey it ; quit the stream; mingle with the substance of its tissue, and are changed into its own true and proper nature.

8. (Before the body has attained its full growth, the function of nutrition is very active; a large amount of food is taken, being not only sufficient to supply the place of what is lost by the action of the absorbents, but also to contribute to the growth of the body. In middle age, nutrition and ab. sorption are more equal ; but ( $n$ old age the absorbents are more active than the nutrient vessels); (the size consequently diminishes; the parts grow weaker; the bones more brittle; the body bends forward; and every function exhibits marks of decay and dissolution?

9. A few years ago, a man by the name of Calvin Edson, of Vermont, commonly called the living skeleton, exhibited himself through the country for money. From having been a large man, he had wasted away by degrees, so that instead of his usual weight, he weighed but sixty pounds. He had been gradually losing flesh for eighteen years; and he attributed it to having taken cold from sleeping on the ground. This emaciation was owing to the absorbent vessels being more active than those of nutrition; whatever may have been the cause of the loss of balance. 
10. On the other hand, when the nutrient vessels are the most active, the person grows fleshy and corpulent, as in the case of Daniel Lambert, who weighed seven hundred and thirty-nine pounds at the age of forty ; or in that of a London butcher, who weighed eight hundred pounds. There are several cases on record, where men weighed eight hundred pounds.

11. The degree of nutrition, depends much on the quantity and quality of the food.) A person who confines himself chiefly to animal diet, and drinks freely of ale and other malt liquors, will usually grow fat; but this does not indicate strength but weakness. It shows that there is not only a weakness of the absorbents, which are not ab'e to take up and remove the $f a l$; but also a muscular debility, and a want of force in the circulation. Motion is impeded; the heart is loaded and oppressed; the breathing is laborious; the blood accumulates in the brain, and the person is every mo. ment exposed to apoplexy.) In all such cases, a sparing diet of vegetables, with proper exercise, will prove an effectual remedy. By sweating, horse-riding, and a Now diet, jockeys have not unfrequently reduced themselves 15 or 20 pounds, in a week or ten days.

12. Large accumulations of fat, it is said, sometimes take place, as the sudden effect of the influence of the atmosphere. Thus, in the short space of twenty-four hours, it is stated by writers on natural history, that a mist will occasionally fatten thrushes, robins, \&.., to such a degree, than they can hard. ly get out of the way of the sportsman's gun. This however is not fat, but the appearance is owing to a fulness of the vessels, from a suspension of evaporation.

13. The hump of the camel appears(to form a sort of reserve, by which, the Arabs say, he is nourished, during his long journeys.) In a period of plenty, the rapid secretion of fat converts it into a pyramid, equalling a fourth of the animal's entire bulk; but a journey through the desert gradual. ly lowers it, so that it becomes scarcely visible. The camel 
then gives out, and can travel no further till the store is re. plenished by rest and food.*

14. (Tumours, wens, and other morbid growths are the consequence of an error in nutrition.) The nutritious vessels deposite fat where it is not wanted, and occasionally bony mat. ter, where fibrin should be left or something else. In this way only can we account for the bony concretions and scales which are sometimes met with about the heart and blood-vessels ; for the chalky deposits about the joints, in cases of gout and rheumatism, and even for horny projec. tions, which have in a few cases been known to sprout out from the head. A few years ago, there were exhibited in London, several individuals called the porcupine family, who were all covered with dark colored horny excrescences; which they shed annually in the autumn or winter. These curious organic peculiarities, resembled the quills of the porcupine, and were two or three inches in length. But these are only exceptions to the usual regularity of nature's operations, and ought, instead of lessening, to increase our admiration at the admirable symmetry and uniformity that prevail, through every department of organized being.

15. (The activity of muscular nutrition, depends much on exercise.) The arm of a blacksmith, or a stone-cutter, for instance, is generally large and brawny, because their mus. cles are almost in constant use. The same is true of the muscles of the leg, in rope-dancers and tumblers, also in great walkers. Let any one examine the muscles of the $\mathrm{Ra}$. vel Family, so celebrated for strength and agility in all gym. nastic exercises, and he will find them not only unusually developed, but also hard and firm. If a person meet with an accident so that he is unable to walk, although his appetite remains, his muscles dwindle away for want of exercise. If then, a person who leads a sedentary life be corpulent, the excess is not to be considered sound muscle or flesh, but fat, which, I have before stated, is a sign of weakness.

* Burkhardt's travels. 
Questions.-What is nutrition? What is sought for in constructing a machine? Why the necessity for this? How is it in the animal machine? Is the system constantly undergoing changes? How is this shown? What vessels repair the losses of the system ? What animals are subject to the most rapid changes of matter? What contains the materials of nutrition? When is nutrition most active ?-when least so? What is the consequence? What does the degree of nutrition depend on? Does fatness indicate strength ${ }^{-6}$ Why not? What use does the hump of the camel serve? What are tumours and wens owing to? What causes muscular nutrition? 


\section{CHAPTER XXIV.}

ANIMAL HEAT.

1. Calorification, is a function of animal bodies, not yet thoroughly understood.) We see certain phenomena, but the causes are hidden from our view. It is very doubtful whether we shall ever be able to penetrate the veil which conceals the wonderful operations of vital chemistry; and perhaps it would lead to no useful result if we could; should we ever attain to the knowledge of all the natural laws of life, we shall then be assured that it is only in consequence of their violation that man pays, by suffering, sickness and premature death, the penalty of their transgression.

2. What causes the temperature of the body to be maintained at an average of ninety-eight degrees, and this, too, under all climates, and at all seasons ? In the first place, respiration is much concerned in the production of animal heat.) It was once indeed believed, that the chief office of respiration was to cool the blood; and that the heart was the great furnace of the system, where all the heat was produced.

3. When it was discovered that both in combustion and respiration, carbonic acid was produced, and oxygen absorbed, it was at once surmised, that breathing must be a kind of combustion by which all the heat of the body is generated.) But it was objected to this, fthat if the heat was all pro. duced in the lungs, why were not the lungs hotter than the other parts of the body, as those parts of a stove in contact with the fuel, are hotter than those at a distance.

4. This objection to Mr. Black's hypothesis, led Mr. Crawford to propose the following solution. Although ani$\mathrm{mal}$ heat is produced in the lungs by the process of respiration, yet as arterial blood has a greater capacity for caloric 
than venous, that is, requires more caloric to preserve it at the same temperature, the heat becomes latent in saturating this increased capacity of arterial blood; and is gradually given off in every part of the body, as the blood assumes the venous character. / But unfortunately for this theory, it has been ascertained that there is no difference, and that arterial and venous blood have an equal capacity for heat.

5. But however it may be explained, no one can doubt, that calorification is closely connected with respiration. If the latter is increased by any cause, the heat of the body is also increased. When it is impeded, as in asthma, fainting, breathing deleterious gases, and suffocation the animal heat is sensibly diminished.) Those animals whose respiratory apparatus is the most perfect and the best developed, have the highest temperature, as we see in birds, whose bodies are several degrees warmer than the human species.

6. On the contrary, if we look at the cold-blooded animals, we shall find that a large proportion of them live in water, where the supply of oxygen is but scanty, and that their respiration is very imperfect); while in animals that lie torpid during the winter, and are quite cold, respiration is almost if not quite suspended. According to Majendie, respiration produces (four-fifths of the heat in herbivorous animals; (three-fourths in carniverous, and the same in birds.)

7. It is found by experiment, that arterial blood is warmer than venous. (The blood is found to acquire one degree of heat in passing through the lungs, and as the whole mass of the blood passes through the lungs twenty times an hour, it follows, that the system receives from respiration twenty degrees of heat in an hour, or two hundred and forty degrees every twelve hours Respiration, then, is one of the chief sources of animal heat.

8. Another theory in relation to animal heat is, that it is produced by, or depends on, nervous influence.) This is 
supported by a few experiments of Mr. Brodie, (who kept up artificial respiration in animals after cutting off their heads. He found that, notwithstanding, the usual changes took place in the blood, and in the air introduced into the lungs, yet the temperature fell even faster than in another animal killed at the same time, in which respiration was not kept upd This experiment, however, is not conclusive, as an animal may be cooled by forcing too much air into the lungs; and if less be introduced the heat may be preserved for some time.

9. Another theory is, that animal heat is generated in the capillary system. (This is supported by the fact, that some parts of the body are often hotter than others, as in inflammation; that it is always proportioned to the energetic action of any organ, as the head becomes hotter by hard study; and a glass of spirits excites a feeling of warmth in the stomach.)

10. It may be laid down as an axiom, or admitted truth, that all movements among the particles of bodies which cause a change of state, are attended with change of temperature) This is the case in combustion, which is a union of oxygen with the inflammable body, and the production of carbonic acid ; and so also when two liquids are mixed together, which chemically unite, heat is always evolved. Now, in all the processes of nutrition, secretion, digestion, respiration, \&c., such changes are constantly going on. In respiration, a part of the blood is thrown off in a gaseous form, while a quantity of oxygen unites with the remaining portion. This process, according to all the known laws of caloric, must be attended with an elevation of temperature. And this proves to be the fact.

11. By the function of nutrition, fluids are changed into solids; and by absorption, solids are changed into fluids; by secretion, new chemical compounds are formed out of a few simple elements contained in the blood; and by digestion, a 
new fluid, chyle, is formed out of the solids, which constitute the food. By all these processes, animal heat must necessa. rily be generated.

12. But in order to the production of animal heat, by the action of the capillary vessels, two conditions are necessary. One is, the presence of arterial blood; the other, the action of the nervous system) (That arterial blood is necessary, is shown by the operation of tying the vessels which supply a limb with blood.) The consequence always is, that the temperature immediately falls, and such limbs have to be wrapped in cotton, and other means used to preserve a comfortable degree of warmth. That nervous influence is also productive of animal heat, is shown by dividing, in like manner, the nerves which go to any part.) The temperature of a paralytic limb is always lower than that of the sound one.

13. It may be concluded then, that respiration, circulation, and nervous influence) all co-operate in producing animal heat, or that they are conditions essential to this phenomenon. We here also perceive a circle of actions; or a chain, composed of many links, no one of which can be spared. Each one contributes to a result essential to organic existence, and one of the most curious and wonderful which the mind can contemplate.

14. If these principles be correct, we should expect to find the greatest heat in those animals whose structure is the most complex; whose organic or vital actions are the most intense; and whose changes are the most rapid. Now all these conditions belong to the warm-blooded animals especially, and particularly to (birds,) whose - temperature exceeds, by several degrees, that of man. In them, as I have already stated, (respiration is more perfect, and the circulation more rapid,

15. Upon the same principles, it would also follow, that animal heat would be the highest in those portions of the body (where the organic actions are most active) And such 
is actually the case. If a thermometer be placed over the chest, the stomach, or the liver) it will indicate a higher temperature by some degrees than exists in the extremities, because it is near the seat of respiration, digestion, and the largest secretory organ in the body. The temperature of different parts of the animal body ranges from 91 to 100 degrees ; and in fever to 112 , which is marked "fever heat" on the thermometer.

16. Those animals that belong to the class mammalia, and which live in water, such as the whale, the dolphin, and the porpoise have a temperature as high as that of man Captain Scoresby found the temperature of a whale, in the Arctic Ocean, to be 104 degrees; while that of the polar bear and wolf were no greater. Warm-blooded animals are generally covered with hair or feathers, to protect them from the cold; cold-blooded animals need no protection, as they can live in a temperature as low as the freezing point of water. Seals, bears and walruses in the Northern Ocean, are protected by a coating of hair; the whale is protected by the great thickness of its skin and the stratum of fat im. mediately beneath it. Dr. Edwards states that frogs, which can live in water at 32 degrees, will die in a short time in water at 105 degrees.

17. But this does not seem to be the case in all coldblooded animals. In some of the warm springs in Brazil, which have a temperature of 88 , many small fishes are found; and also in a hot spring at the Manillas, which raises the thermometer to 158 degrees; and Humboldt, in his travels, tells us that in the province of Quito, in South America, he saw fishes thrown up from the bottom of a vol. cano, along with water and heated vapour, which raised the thermometer to 210 , or only two degrees short of the boiling point. Lord Bute saw beetles in the boiling springs of Albano, which died when plunged into cold water; and Dr. Elliotson states that a gentleman of his acquaintance boiled some honeycomb two years old, and after extracting all the 
honey, threw the refuse into a stable, which was soon filled with bees.

18. Warm-blooded animals have the faculty of preserv. ing the same degree of heat in nearly every variety of climate. During Captain Parry's voyage to the Arctic seas, in quest of the northwest passage, the crews of his vessels were often exposed to a temperature of fifty degrees below zero, or one hundred and fifty degrees below that of their own bodies, and still they were able to resist it, and escape being frost bitten. "When the temperature was thirty-two degrees below zero, they found that of an Arctic fox one hundred and six degrees, which shows what a strong coun. teracting energy there is in animals, against the effects of cold.

19. The human body can also resist great heat as well as cold. In summer we are often exposed, when in the sun, to a temperature many degrees above that of the body, but the heat of the body is not elevated. Chantry, the sculptor, often entered his furnace when heated for drying his moulds, when the thermometer in it stood at three hundred and twenty; and his workmen did the same when the temperature was three hundred and forty degrees. Dunglison states that Chabert entered an oven with impunity, the heat of which was from four hundred to six hundred degrees. In all these cases, where even water was boiled, and meat cooked to a crisp, the heat of the body was raised but a few degrees.

20. In these cases the heat of the body is kept down to near the natural standard, by exhalation, or sweating. This carries off the heat in a state of vapour as fast as it is produced. For the same reason, water cannot be heated above two hundred and twelve degrees, as it then escapes in the form of vapour. By evaporation, also, bottles of wine are cooled in summer, by wrapping them round with wet cloths. In India, it is said, that ice is produced in a simi. lar manner. If an animal be saturated with moisture, and 
placed in a hot oven, it soon dies, because the exhalation from the body is prevented. It is for this reason, also, that we feel the heat more in damp weather than in dry, although the temperature be lower. Such weather is called sultry, close, muggy, \&c., because the saturation of the air by moisture, prevents the escape of heat by evaporation from our bodies.

21. In infancy, the faculty of generating animal heat is much less than in adult age. This is the chief cause why so many perish during the first years of life, and particularly in winter, during the first few days. At this period, the temperature of infants is only about ninety-three degrees, and in some instances not more than eighty, and is rapidly diminished by slight exposures. This shows the great importance of guarding against the effect of cold, by proper clothing, and a regulated temperature of houses. Man has no natural protection against the influence of cold, but reason was given him as a substitute. How few appear to employ this faculty, in guarding against atmospheric vicissitudes by a proper adaptation of the dress; and in consequence, how many, instead of consulting their health, comfort, and usefulness, fall victims to negligence or fashion!

Questions.-What is calorification? What are the causes of animal heat? Why was it surmised that respiration was concerned in this process ? What objections to this? What was Crawford's hypothesis? What occurs when respiration is impeded? What occurs in coldblooded animals? How much heat, according to Magendie, is produced by respiration in herbiverous animals ?-in carniverous ?-in birds? Is arterial blood warmer than venous o How much heat does the blood acquire in passing through the lungs? How many degrees does the system acquire from this source in 24 hours ? 8 What is Brodie's theory with respect to animal heat? What facts in favour of it? What is said of animal heat being generated in the capillary system? What axiom in relation to a change in the particles of bodies has a bearing on this subject? What conditions are necessary to the production of animal heat by the action of the capillaries? How is this proved? 
What functions co-operate in the production of animal heat? In what animals is heat the greatest? Why? In what parts of the body is it the highest? Why? What is the temperature of the mammalia that live in water? What effect does a change of temperature have on cold-blooded animals ? Can warm-blooded animals preserve the same temperature in every climate ? H How is this effected? What effect will checking evaporation have? Is the faculty of generating heat less in infancy g. What inference do we draw from this fact?

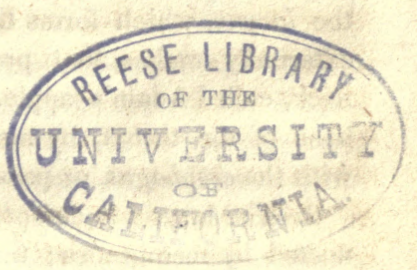




\section{CHAPTER XXV.}

THE VOICE.

1. The voice is a sound produced in the larynx, or wind. pipe, by the passage of air, either to or from the lungs. It is generally caused in the act of respiration, and/its seat is the larynx, which forms the very top of the wind-pipe, and externally makes that prominence at the fore-part of the neck, called Adam's apple. It is connected above with the bone of the throat, by means of small muscles, and behind with the esophagus, or passage to the stomach.

2. (The larynx is composed of four cartilages, closely connected by membranes; these are called the thyroid, the cricoid, and the two arytenoid cartilages. The thyroid cartilage is shaped somewhat like a shield, and hence its name It forms the front and lateral part of the larynx, being broader in front than behind, and made up of two parts which join in the front of the neck at an acute angle thus making the prominence spoken of above. (It has two projections above, and two below; the former connect it with the bone of the tongue, and are called the upper horns; by the latter which are called the lower horns, it is united with the cricoid cartilage, by means of ligaments.)

3. The cricoid cartilage is so called from its resemblance to a ring. (It lies immediately below the thyroid cartilage, being broad at its sides, narrow in front, and connected with the thyroid cartilage behind by a still broader surface? (In front it is not connected with the thyroid cartilage; but the space is occupied by the lining membrane of the larynx, covered with the common integumerts.

4. (The arytenoid cartilages are much smaller than the others, and are situated at the back part of the larynx, in connection with the cricoid cartilage.) (They have small mus- 
cles attached to them, by which they are moved sideways, and it is by these motions that the opening in the larynx, called the glottis, is enlarged or contracted. Two fibrous ligaments connect these cartilages with the thyroid; these two are called vocal chords, as they are supposed to be particularly concerned in the production of voice. They pass from the artenoid cartilages to the angle formed by the two side pieces of the thyroid, and are about half an inch in length. The opening between them is called glottis, rima. glottidis, or chink of the glottis.

5. The epiglottis is the little moveable cartilage; which lies over the top of the wind-pipe, at the root of the tongue, and has been compared to a trap-doon It prevents the food from passing into the wind-pipe when we swallow. From its elasticity, its position is usually perpendicular, except in the very act of swallowing, when the tongue is carried back. wards, so as to bring it exactly over the opening; this prevents the passage of foreign bodies into the lungs.

6. The larynx is abundantly supplied with nerves which are given off from the eighth pair. (The thyroid gland is a body consisting of two lobes, lying one on each side, and somewhat below the larynx) (the use of which is unknown; it is the seat of the disease called goitre, or (swelled neck so common in Switzerland, and some other countries.

7. Such is the description of the organs immediately con. cerned in the voice; (the whole vocal apparatus, however, comprises the muscles concerned in breathing, the moutb, and nasal cavities, as well as the parts above mentioned. It is essential to the production of voice that the air should pass from the lungs through the larynx for if an opening be made in the wind-pipe, so that the air escapes, the voice is lost. I lately witnessed this in a man who undertook to destroy his life by cutting his throat. He succeeded in cutting the wind-pipe completely off, but as no large blood vessels were divided, he got well. This man could not utter a 
syllable, not even in a whisper, until the wind-pipe healed up; his voice was then restored to its former condition.

8. Volition is necessary to the production of vcice. If the nerves going to the larynx are cut, the voice will be lost.) Palsy of the muscles of the larynx, also causes dumbness; and fear effects the voice by paralyzing muscular effort. The epiglottis is found not to be concerned in the production of the voice, as it may be removed without affecting it; its sole office being to guard the wind-pipe against the introduction of foreign substances.

9. It has been proved by experiments, that fnearly all the larynx except the chorde vocales, or vocal chords, may be removed without destroying the voice.) These are the small ligaments that pass from the arytenoid cartilages to the thyroid cartilages, and are usually called the inferior ligaments, or the lower vocal chords.

10. It is now ascertained that these chords perform the principal part in the production of the voice. In what way this is done, is not precisely known; but, we may suppose that the air in passing from the lungs in expiration, is forced out of small cavities, as the air-cells and minute branches of the wind-pipe, into the main channel; it it is thence sent through a narrow passage, on each side of which is a vibratory chord; the vibrations of which, by the action of the air produces voice or sound.

11. It has been said that if this theory of the voice be correct, there ought to be sound produced by forcing air through the wind-pipe of a dead animal. But this takes for granted what is not true, namely, that the voice is the result of a purely mechanical process; instead of which, it is a vital function, performed by living agents, and therefore under the control of voluntary action.

12. In producing sound, there can be no doubt that numerous voluntary muscles are put in action, bringing the arytenoid cartilages in contact with each other, thus putting upon the stretch the lower vocal chords which are attached 
to them. It is therefore by no means strange that vocal sound cannot be made by forcing air through the larynx of a dead animal.

13. It has often been disputed whether the larynx was a wind or stringed instrument. Most physiologists at the present time, regard it as a wind instrument of the reed kind, such as the clarionet, hautboy, \&c., and they differ chiefly in explaining the various modifications of the tone and quality of the voice). There is, however, great reason to believe that it partakes of the character of both.

14. (The strength of the voice depends on the extent of the vibrations, of course on the size of the larynx, and partly also on the force with which the air is sent from the lungs. Thus the voice of men is much stronger than that of wo. men and children; and that of a well person stronger than that of a feeble individual. The change of voice at the period of manhood, is owing to the increase in size of the larynx.)

15. The tone of the voice can be almost infinitely varied: indeed, nothing can exceed the human organ of voice in variety and execution. We may perhaps safely calculate the number of changes that can be produced in the organ, at least tombe equal to the number of muscles employed, together with all the combinations of which they are capable. Now, the muscles immediately concerned in the function of voice are (seven pair. Besides these, however, there are fifteen other pair, which are connected with the larynx, and have more or less to do in regulating the motions of the cartilages, keeping them steady or moving them in different directions)

16. Now, if there were only seven pair of muscles concerned, the different movements which theil varied action would produce, will amount to more than sixteen thousand. Taking the whole number of muscles into account, the different combinations will be more than (one thousand million.) But besides these, there are the midriff, or diaphragm, the $a b$. 
What does the whole vocal apparatus comprise? What is essential to the production of voice? What effect has cutting the nerves which go to the larynx? What part of the larynx can be removed without effecting the voice? What are chiefly concerned in the production of voice? Is the larynx a wind or stringed instrument? What does the strength of the voice depend on? What is a change of voice owing to ? What is said of the tone of the voice? How many muscles are concerned? How many combinations can they produce? How are acute sounds produced? How grave ones? What is ventriloquism? What is natural voice? What acquired? Why are deaf children dumb ? Why are idiots? What is whistling ?-whispering ?- sighing, \&c.? What is said of singing? 


\section{CHAPTER XXVI.}

\section{LOCOMOTION AND ITS ORGANS.}

1. MaN is distinguished from the vegetable world, not only by his possessing a nervous system, organs of sense, and voice, but also by the power of locomotion or moving from place to place. (This power connects him with the external world, enlarges his sphere of action and increases his means of acquiring knowledge. It implies that he has a will, and that these motive organs are under the influence of volition; else he would be the sport of chance and wander about without a motive.)

2. Many of the functions of the body are not under the control of the will; such are digestion, absorption, circulation, respiration, and secretion, which go on as well when we are asleep as when awake. They are possessed, at least some of them, by vegetables as well as animals, and are therefore called organic functions.

3. The agents of locomotion are the bones and muscles; but they would be useless for motion were they not supplied with nerves of voluntary motion, and thus brought under the influence of the will. The bones are tied together by means of strong fibrous ligaments or cords, allowing the joints great freedom and extent of motion, as we see in the shoulder and hip joints.

4. We then have the bones, which act as levers; the muscles are the moving power, and the brain and nerves are the vital agents, which set the machinery in motion. (Muscles alone have the power of contraction, and it is one of the most remarkable properties of life. Were it not for this, the food could not be digested, the blood could not bo 
circulated, and the iris could not guard the eye against the admission of too much light, which would speedily destroy the vision.

5. The shape of muscles is various, (some are round, some flat, and the fibres of which they are composed, are con. nected by means of cellular membrane. Some are perniform, or made of bundles of fibres, diverging from a central line, like the feathers of a quill) Muscles compose a large part of the bulk of the body; and when they contract, the fibres shorten and become harder, as may easily be perceived by placing one hand on the middle of the arm and bending the elbow, or on the temple and closing firmly the lower jaw.

6. The force with which a muscle contracts, (depends on the physical condition of the muscle and the energy of the brain. When the fibres of the muscle are large and firm, they will contract with more force than when they are small, soft, and delicate. We see some persons, who labour under great mental excitement, perform astonishing feats of strength, although, perhaps, they may not have muscles of the ordinary size.

7. The knee-pan has often been split in two by the contraction of the muscles of the leg; a horse has been known to break its under jaw by biting a piece of iron. Men have been known to lift eight and nine hundred pounds weight; to break ropes two inches in circumference, and to bend a round piece of iron, a yard long, and three inches in circum. ference, to a right angle, by striking it across the left arm, between the shoulder and the wrist, with the right hand.*

8. The force of muscular contraction is greatly increased (by exercise.) The strength of an active man labouring to the greatest possible advantage, is estimated/to be sufficient to raise ten pounds, ten feet in a second, for ten hours in a day); or to raise one hundred pounds, one foot in a second, 
or thirty-six thousand feet in a day ; or three millions, six hundred thousand pounds, or four hundred and thirty-two thousand gallons, one foot in a day. The weakest men in health can generally lift about one hundred and twenty-five pounds, and the strongest of ordinary men four hundred pounds. The daily work of a horse is equal to that of five or six men.

9. There is much difference in the velocity of muscular contraction, as it is regulated entirely by the will. The swiftest race-horse on record was capable of going a mile in a minute; yet this is trifling compared with the velocity of birds, or even of many small insects. (It has been ascer. tained that a pigeon-hawk can fly one hundred miles in an hour; the eider-duck ninety miles an hour, and the common crow, twenty-five miles an hour. The swallow flies ninetytwo miles an hour, and the swift is said to fly two hundred and fifty miles in the same space of time

10. A falcon belonging to Henry IV. of France, escaped from Fontainbleau, and in twenty-four hours after was in Malta, a distance of one thousand three hundred and fifty miles, making a velocity of fifty-seven miles an hour, supposing him to have been on the wing all the time; but as such birds do not fly by night, his flight was probably at the rate of seventy-five miles per hour. This will give us some idea of the wonderful velocity of the contractions of the muscles of the wings of birds of rapid flight.

11. But this rapidity of motion is much under the influ. ence of habit. How awkward are the first attempts at writing, drawing, dancing, or playing on musical instruments, and with what ease and grace are they performed after a little practice. The same is true with regard to public speaking, or any thing which requires voluntary mo. tion.

12. (It is a law of the human system, that relaxation must follow contraction, for rest, exercise; and although the du. ration of action of the voluntary muscles is in a great de. 
gree under the control of the will, yet it cannot be continued long. This duration will be shorter in proportion as the contraction is violent or moderate. (All muscles do not act at the same time, for as some are contracting, such as the flexors, or those that bend the limbs, the extensors, or those that straighten them, are relaxed

13 It is by the constant action of the muscles that the body is kept in an erect position. If a person gets asleep while sitting or standing up, the head falls forwards, and if he did not wake, the body would fall likewise. The same happens when a person is deprived of sense, by a fit of apoplexy or palsy, or by the intemperate use of ardent spirits.

14. We see that it requires a long time for children to learn to walk securely. The reason is, that the base of support for the body is small, being only the space between the feet and that on which the feet rest. The larger the base, the easier it is to maintain an erect position; so that persons with small feet do not stand as firmly as those with large ones. This accounts for the difficulty of standing on our toes, or of walking on a rope. It is practice and instinct which teaches children where to place their feet in order to be most secure when erect; their muscles also are still weak, for want of exercise.

15. Walking consists in a succession of steps. We first balance the body on one foot, then bending the opposite foot on the leg, and the leg on the thigh, we bend the thigh on the pelvis, and so shorten the limb. In this way the leg is brought forward, and the foot is then brought to the ground resting first on the heel; the body is then partially rotated on the head of the thigh bone, and the other leg is raised, bent, and carried forward in the same manner, and the foot placed in advance of the other. The legs thus act as levers to propel the body along, and the longer the levers the more rapid will space be measured over.)

16. The utility of walking (excels that of all other modes 
of progression. While the able pedestrian is independent of stage coaches and hired horses, he alone fully enjoys the scenes through which he passes, and is free to dispose of his time as he pleases. To counteract these advantages, greater fatigue is doubtless attendant on walking; but this fatigue is really the result of previous inactivity ; for daily exercise, gradually increased by rendering walking more easy and agreeable, and inducing its more frequent practice, diminishes fatigue in such a degree, that very great distances may be accomplished with pleasure, instead of painful exertion.

17. The power of walking great distances, without fatigue is unfortunately in this country a rare accomplishment. A good walker will do six miles an hour, for one hour, on a good road. If in good training, he may do twelve miles in two hours. Eighteen miles in three hours have been achieved, though rarely. At the rate of five miles an hour, pedestrians of the first class will do forty miles in eight hours sand perhaps fifty in ten. Captain Barclay walked 180 miles without resting; and also 1000 miles in 1000 successive hours.

18. In the act of leaping, the whole body is raised from the ground, and for a short time suspended in the air. It is performed by bending the head upon the body, the body on the thighs, these on the legs, and the legs on the feet. The feet do not stand firmly on the ground, as in walking, but the heel is raised, or perhaps slightly touches the ground. The muscles are all in a state of flexion) They are sudden. ly contracted at the same instant; the consequence is, that the feet are raised from the ground and carried forward, and the body with them, until it is brought to the earth by the force of gravitation.) (The distance passed over, is in proportion to the power and suddenness with which the muscles contract.)

19. 'The muscles which form the calf of the leg, act with the greatest powe in leaping, as they have to raise the whole 
body. Their/great strength is shown by raising the body upon the toes, together with a large additional weight; and this power is not only owing to their great size, but also to the manner in which they are inserted into the heel, thus having the advantage of the long arm of a lever.

20. The muscular powers exhibited by many small ani. mals ahd insects is astonishing. Small animals can leap much farther than large ones, according to their size. The flea and the locust leap two hundred times their own length, as if a man should leap twelve hundred feet high. Others leap three hundred times their length, and if man was as strong in proportion, he ought to leap more than a quarter of a mile. We read of an English mechanic, who made a golden chain as long as the finger, with a lock and key, which was dragged by a flea, and of another flea dragging a silver cannon on wheels, that was twenty-four times its own weight. This cannon was charged with powder and fired without the flea seeming to be alarmed. A cockroach, or an ant is six times as strong, for its size, as a horse; and, if an elephant were as strong in proportion, he would be able to tear up rocks and level mountains.

21. Hopping is merely leaping on one foot. As but half the muscular power is exerted, a man ought to be able to leap twice as far as he can hop. Running consists of a succession of low leaps, performed by each leg alternately. It differs from walking, in the body being thrown forward at each step, and the hind foot being raised before the fore foot touches the ground. A person cannot stop running instant$l y$, as he can walking, because his velocity is so great as to carry him forward a certain distance, whether he uses his muscles or not, and thus occasions him to fall.

22. The practice of running may be carried to a great cegree of perfection. A quarter of a mile in a minute is good running; and a mile in four minutes, at four starts, is excellent. A mile was perhaps never run in four minutes; but it has been done in four minutes and a half. A mile in 
five minutes is called very good running; two miles in ten minutes is but rarely accomplished. Ten miles an hour is done by all the best runners. Forty miles, in four hours and three quarters has been done by one individual. Some Indians, it is said, will run at this rate for several hours, but it is very doubtful.

23. Swimming is very much like leaping; at least the same muscles are brought into action in the lower limbs) While the hands are brought to a point before the head, the legs are drawn úp and suddenly extended, as in leaping. By the resistance of the water, the body is projected forwards. The hands are now carried, with a circular motion, the palms being turned outwards, till they reach the sides of the body, and thus the impulse through the water is kept up by a constant succession of these movements. A boat is propelled on the same principle. Indeed the body may be coin. pared to the boat itself, and the hands and feet to the oars. A good swimmer ought to make three miles an hour.

24. The human body is very nearly of the same specific gravity as water; (that is, it is of the same weight as a body of water of the same bulk). Dr. Franklin says if a person avoids struggling and plunging, he may lie on his back with his mouth and face out of water, without difficulty, even if he cannot swim. As swimming therefore, is a highly useful art, and an agreeable and healthy exercise, it should be made a necessary part of the education of boys.

25. The importance of gymnastic exercises will only be questioned by those who are not aware that the health and vigour of all the bodily organs depend on the proportioned exercise of each. (Such exercises ensure the development of all the locomotive organs; and they prevent or correct all the deformities to which those organs are liable. They are the best calculated to produce strength and activity, and to bestow invariable health. At the same time they confer beauty of form, and contribute to impart an elegant air and graceful manners. 


\section{CHÁPTER XXVII.}

\section{THE TEETH.}

1. (1s the teeth are the only bones in the human frame whicts are exposed to the immediate action of foreign bodies, they merit distinct and special consideration in this treatise on the (ieneral Physiology of man) (The most remarkable fact in their history is, that unlike the other bones, the teeth which make their appearance in infancy, are removed at the age of seven or thereabouts, and another set come forward to supply their places.)

2. The Girst set called temporary teeth, are just twenty in number, ten in each jaw. The two front teeth above and below, are known as central incisors, because they serve to cut the food. The teeth adjoining these are denominated lateral incisors, next to which come the canine or dog teeth, of which those in the upper jaw are called eye teeth. Back of these at either extremity of each dental arch are two larger teeth known as grinders from the fact that they operate like mill-stones, in reducing the food to very minute particles in preparation for quick and easy digestion)

3. The second or permanent set has twelve additional teeth, six above and six below, making thirty-two in all. The two next back of each eye tooth, are styled bicuspids, because they terminate in two points; and the four extreme grinders are sometimes called wisdom teeth, because they do not generally appear until the individual arrives at mature age. Thus, there are twelve grinders or molar teeth in the second set instead of eight as in the first set; and there are eight bicuspids which are not found among the temporary teeth at all.)

4. Each tooth consists of two distinct parts, called the crowon and root) (the former being that portion which pro. 
jects from the gum into the cavity of the mouth, and the latter that which is buried in the socket.) The incisors, eye teeth and bicuspids have one root each, the upper grinders three and the lower grinders two. The roots of the wisdom teeth are commonly compressed into one mass having little or no divergency, and in rare instances the bicuspids have two distinct fangs, while the upper molars have been known to have four or five distinct roots.

5. Every human tooth is composed of two distinctly organised substances, namely the enamel covering the crown, and the osseous or bony portion which constitutes the reremainder of the tooth. The osseous part is scarcely distinguishable from other bony structures excepting from its greater density. The enamel on the contrary, is remarkable for its extreme hardness resulting from its chrystaline structure. It consists of needle-formed crystals, one extremity of which rests upon the bone beneath, while the other is presented to the food.

6. The teeth are found by chemical analysis to consist of nearly the same elementary substances as the other bones; namely, phosphorus, lime, magnesia, soda, carbon, oxygen, chlorine, gelatine and water) (As the teeth are a part of the living system, they are supplied with nerves, blood vessels and absorbents, not only by a central cavity extending from the point of each root to the middle of the crown, but by a membranous sheath enveloping the root called the periosteum, as is true of the other bones.)

7. (The teeth are firmly attached to the jaw or maxillary bone, by means of sockets called alveoli.) (In case of extraction the alveoli yield to moderate pressure and suffer the teeth to escape without any injury to the adjacent parts) and as soon as the teeth are removed the investigating bone is sufficient to produce immodiate absorbtion.

8. The first set of teeth begin to make their appearance through the gums, between the sixth and eighth month, and before the infant arrives at the thirtieth month all the teeth 
have assumed their natural position. (The second dentition commences about the seventh year, and is commonly perfected before the fourteenth

9. When the teeth are so nuth crowded as to disturb their regular arrangement; or when they press so hard upon each other as to destroy the enamel, one or more should be removed without delay. If this precaution should be neglected, an unsightly mal-arrangement, or inevitable destruction of several of the teeth, will be the melancholy result. The removal of a sound tooth causes very little pain com. pared with the agony attending those which are suffered to become diseased.

10. It is impossible, under ordinary circumstances, to preserve the teeth for many years without keeping them very clean. Food lodges between them at every meal, and undergoes decomposition if not removed. A substance, called tartar, or salivary calculus, which is deposited from the saliva, adheres to the teeth, becomes very hard, and finally assumes a dark colour, if not constantly washed away with a brush and water. If food be suffered to putrefy in spaces between the teeth the process of mortification is extended to the teeth themselves; and if tartar collect in solid masses, the teeth become loose in their sockets and are thus utterly lost.

11. In order to keep the teeth and gums perfectly clean and healthy, it is necessary to wash them with a stiff brush and water several times in a day. No person of ordinary neatness would consent to eat with knives, forks and spoons, unless they were cleansed after every meal. The teeth are more liable to accumulate filth than any of these domestic utensils, and therefore need at least equally frequent washing. In the morning, after each meal, and before retiring to rest, are not too many times to purify the teeth with a brush and water, and once in each week with good tooth powder.

12. The Dentifrice or Tooth Powder, which I would re. commend in preference to all others which $I$ have ever seen, 
is composed of the following ingredients, well pulverised in a mortar, and intimately mixed together :

Loaf sugar, half an ounce,

Cinnamon, half an ounce,

Gum Kino, quarter of an ounce,

Peruvian bark, three ounces,

Prepared chalk, six ounces,

Armenian Bole, five and a half ounces; making one pound avoirdupoise.

13. In addition to the above described dentifrice, every person should be provided with a good tooth brush, which should be laid aside as useless whenever it loses its stiffness and elasticity. A piece of gloss-silk, well waxed, should be employed to cleanse the open spaces between the teeth, inasmuch as these are not easily cleansed with the brush alone. If tooth-picks are used at all, they should be made of wood or quill, since those formed of any of the metals, particularly of steel or iron, are quite too hard, and therefore destructive to the teeth and gums.

14. If brushing the teeth and using the other methods of keeping them in order as above described, should fail of effecting the desired purpose, the assistance of the dentist should be put in requisition. With his scaling instruments, he can effectually remove every vestige of tartar, together with any other impurities lodged upon the teeth. Above all, abstain from the use of all kinds of powders and washes which render the teeth white by chemical action. These contain acid in one form or another, and are therefore de. structive to the teeth.

15. Persons desirous of preserving their teeth in a sound and healthy state for many years, should consult their general health in all their habits of life, especially in relation to food and drinks. Neither solid nor fluid aliment should be taken into the mouth at either very high or very low temperature, because sudden transitions from heat to cold, or from cold to heat, are liable to crack the enamel of the teeth 
by unequal expansion and contraction, as is readily ascertained by the assistance of the microscope. Teeth thus injured, almost always decay in consequence of the exposure of the bony substance of the tooth to the action of corrosive fluids.)

16. There are three prevalent general causes of the destruction of human teeth, besides occasional accident : viz. accumulation of tartar, ulceration of the fangs, and dental gangrene. Ulcers of the fangs extend to the alveoli or sockets, which are also destroyed, together with the investing gum. The well informed dentist can best prescribe and apply the proper remedies for all these forms of dental dis. ease. 


\section{CHAPTER XXVIII.}

\section{SLEEP AND DEATH.}

1. SLEer is the periodical and temporary suspension of those functions that connect us with the external world. Man is so constituted, that the functions of sensibility, vol. untary motion, and the intellectual faculties cannot be in. dulged for any length of time without fatigue. The nervous energy, which seems essential to their exercise, becomes exhausted; the muscles can no longer contract; the external senses cannot receive impressions; the brain, and consequently the mind, becomes torpid; and a person sinks into a state of torpor and inaction, called sleep.

2. (The approach of sleep is announced by an internal sensation, termed drowsiness, which gradually increases in strength, till at length it becomes irresistible. Great languor of the muscles and heaviness of the eyes are experienced; the sight yields first ; next the smell ; then the hearing ; and lastly, the sense of touch; while at the same time, all the internal sensations, such as hunger and thirst, are no longer felt. The will ceases to control the functions that are under its influence, till finally all power of volition is wholly lost. Respiration is still carried on, but chiefly by means of the diaphragm, which is an involuntary muscle; it is, however, somewhat slower, as well as the circulation, than in the waking condition.

3. During perfect sleep, the functions of the brain are entirely suspended. In such a state, dreams do not happen; for as the brain is in a state of complete inaction, the intelsectual operations are consequently dormant. When the brain is not in a state of complete repose, objects and images may float confusedly through the mind) which are often the result of external impressions imperfectly perceived, as they excite but an imperfect reaction in the brain. 
4. The organic or nutritial functions continue during sleep, but with diminished energy. The circulation and respiration are not only slower, but digestion is retarded, and secretion, nutrition, and calorification, are less active than when awake. The temperature of the body is also lowered during sleep, which may perhaps be owing to the facts above mentioned.

5. The duration of sleep is influenced by a variety of circumstances.) (The average time of regular, periodical sleep, in adults, is from five to eight hours. Infants require twice as much sleep as grown persons. The-quantity of sleep required, depends very much upon habit. It is said of Pichegru, one of Buonaparte's generals, that, for a whole year, he had not more than one hour of sleep in twenty-four hours. Buonaparte himself, when on active duty, seldom slept more than three hours in twenty-four; often but one hour. Men of active minds, who are engaged in a series of interesting employments, sleep much less than the lazy and the listless. The intellectual and moral faculties seem to require a longer period of repose than the functions of voluntary motion.

6. Though (the night is the proper season for sleep, owing to the absence of light, diminished warmth, its comparative stillness, as well as the exhaustion caused by the labours of the day, yet some animals, which pursue their prey by night, sleep during the day, as the cat, fox, wolf, otter, owl, and bat. Hybernating animals sleep for several months during the winter, such as the bear, hedge-hog, marmot, \&c. Some birds, also, such as bats and swallows, sleep during the win. ter, or hybernate. During this state their temperature is di. minished, their secretions nearly checked, their excretions suppressed, their respiration slow, and scarcely perceptible, their circulation very languid, and sensibility to external im. pressions entirely suspended. The arterial blood of hybernating animals, differs but little from venous blood.

7. Dreams are now considered by physiologists to be 
bwing to an irregular action of the brain, in which the con. trolling power of the will is lost, and the memory and the imagination bear unlimited sway.) Indeed all the faculties of the mind may be in exercise. The mind reasons, judges, wills, and experiences all the various emotions. We seem to hear, see, walk, talk, and perform the usual offices of life. Sometimes the voluntary muscles are thrown into action, and the dreamer moves, speaks, groans, cries, or sings; but the moment consciousness is roused, he is awake. Dreams, therefore, have well been said to be "a portion of animal life, escaping from the torpor in which the rest of it lies buried."

8. Before the functions of the brain were understood, dreams were regarded as supernatural, and even now are considered in this light by the ignorant and superstitious. Mr. Baxter, as well as Bishop Newton divided them int two kinds, good and evil, (because they believed that good and evil spirits were concerned in their production, according as one or the other obtained the ascendancy, It is supposed that animals dream, especially the dog; are they subject to supernatural influence?

9. It is a singular circumstance in relation to our dreams, that we mistake our ideas for actual perceptions, and suppose that the train of images that passes through our minds, represents scenes which really exist) (This is doubtless owing to the fact that, during sleep, the senses do not admit external impressions, and of course we are unable to compare the ideas that arise in our minds with sensible impressions, and thus perceive the difference between them Our only con. sciousness consists in the images and ideas actually present in the mind; and it is therefore unavoidable that we should believe that our ideas represent objects actually existing.

10. There is a kind of dreaming, in some cases of imperfect sleep, (where the will retains its power over the muscles of voluntary motion, while the external senses remain buried 
in partial or complete repose. This is called somnambulism or sleep-walking.

11. Many remarkable cases of somnambulism have been lately publishéd, as the effects of animal magnetism; but in many of these, it is to be feared, credulity existed on one side, and imposition was practised on the other. That som. nambulism, or a state nearly similar, is brought about by the practices of magnetizers in persons of acute sensibility, and highly excitable nervous temperament, would seem scarcely to admit of a doubt. Still, all such cases should be regarded with great circumspection, and every means employed to detect imposition and fraud.

12. (Somnambulism seems to differ from the waking state, only in consciousness being absent. The person appears to enjoy the full exercise of all his faculties; he can converse, walk, sing, compose verses, and perform various operations ; and yet in the waking state he has no recollection of what has occurred. In this respect somnambulism differs from dreaming, and resembles a morbid state; indeed, it is a state of disease analagous to trance, catalepsy, or epilepsy.

13. A state, the reverse of somnambulism, is called incubus, or nightmare. In this affection, a person feels a sense of weight and suffocation, as if there was a heavy load on his stomach or chest, and imagines that some frightful object is seated there. This is owing to some oppression of the digestive, circulatory, and respiratory organs, most usually occasioned by a late, hearty supper of indigestible food. (Frightful dreams denote ill health) and are often caused by a derangement of some important organ, as of the heart, stomach, or liver, exciting the brain to sympathetic action. To dream immediately on going to sleep, is always a mark of disease.

14. There is still another state which bears a close resemblance to somnambulism, and this is termed revery, absence of mind, or brown study. In this, the attention is so com. 
pletely riveted to some particular subject, that the person is entirely insensible to the presence of surrounding objects.

15. One great object of education is to give the will power over the attention. The mind that cannot command this faculty, is in a deplorable condition for all the higher purposes of reflection and knowledge for which it is intended. Without it, perception exercises itself in vain ; the memory can lay up no store of ideas; the judgment draw forth no comparisons; the imagination must become blighted and barren; and in proportion as a person has no command over his attention, in that degree must he be an idiot.

16. It is the will of Providence that all organized beings must perish. For a while, life maintains a successful conflict with the chemical laws of matter; but at length its resistance becomes weaker and weaker, till, sooner or later, those functions cease which have enabled us to withstand the destructive influences by which we are surrounded.

17. (The duration of life varies, not only in the animal but in the vegetable kingdom.) (As a general rule, where the growth is slow, the period of decrease is proportionably slow; and where it is rapid, decay as rapidly supervenes) The gourd that sprang up in a night, perished also in a night.

18. (There are two kinds of death, natural and accidental.) Natural death, or that of old age, is caused by a gradual decay and wearing out of all the organs)(accidental death, or such as is occasioned by accident, cuts off existence prematurely. The natural period of life differs in different individuals, (being influenced by a variety of circumstances; such as the original constitution; habits of life; and the health of the locality where a person is situated)

19. The natural period of life, has not materially differed since the time of the flood "The days of our years," says the Psalmist, "are threescore and ten; and if by reason of strength they be fourscore years, yet is their strength labowr and sorrow, for it is soon cut off and we fly away." This 
description is as applicable now, as it was four thousand years ago.

20. Those who die from old age are few; being, in the city of New York, but one in thirty-four. In New En. gland, generally, the proportion is rather greater. (The mean duration of life in New York is but twenty-five years; while the average rate of mortality, (according to population, is one in thirty-five. The diseases to which man is subject, from the earliest to the latest period of his existence, are numerous, and many of them of a fatal character. Syden. ham estimates that two thirds of mankind die of acute dis. eases; and that of the remaining, one third, or two ninths of the whole, die of consumption, leaving only one ninth to perish from other chronic maladies, and from pure old age.

20. As age approaches, the functions are all performed with less energy. The teeth fall out, and their sockets are absorbed; respiration is not as readily accomplished; the valves of the heart, and the coats of many of the arteries becorne changed into bone, thus obstructing the circulation, and often causing an intermittent pulse; nutrition lan. guishes; the senses are blunted; animal heat diminishes, so that warmer clothing is demanded; the muscular system loses its power, and the body bends forward ; the limbs totter, the mental as well as corporeal faculties often fail; and the individual is reduced to second childhood, so well described by Shakspeare.

"Last scene of all,

That ends this strange, eventful history,

Is second childishness, and mere oblivion;

Sans teeth, Sans eyes, Sans taste, Sans everything."

As the other functions cease their office, sensibility gradual. ly becomes extinct, and life almost imperceptibly takes its flight. 



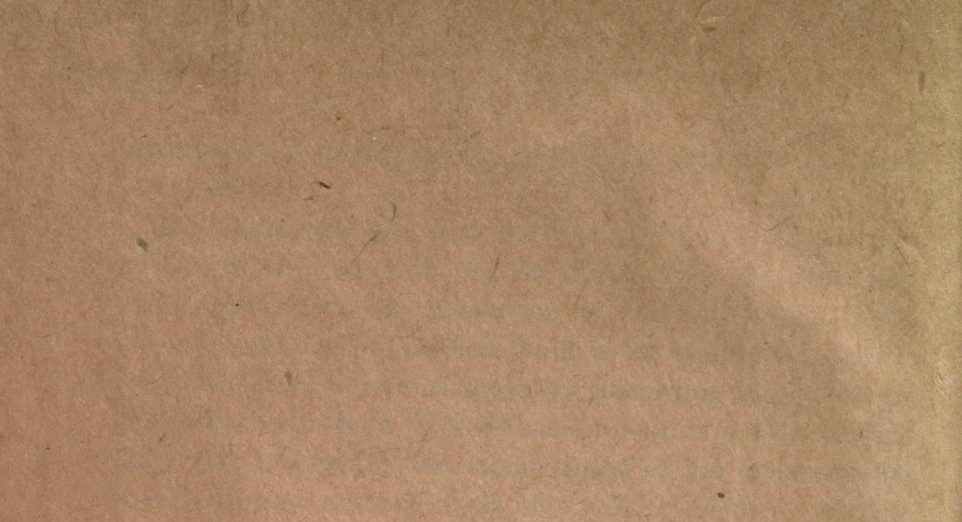

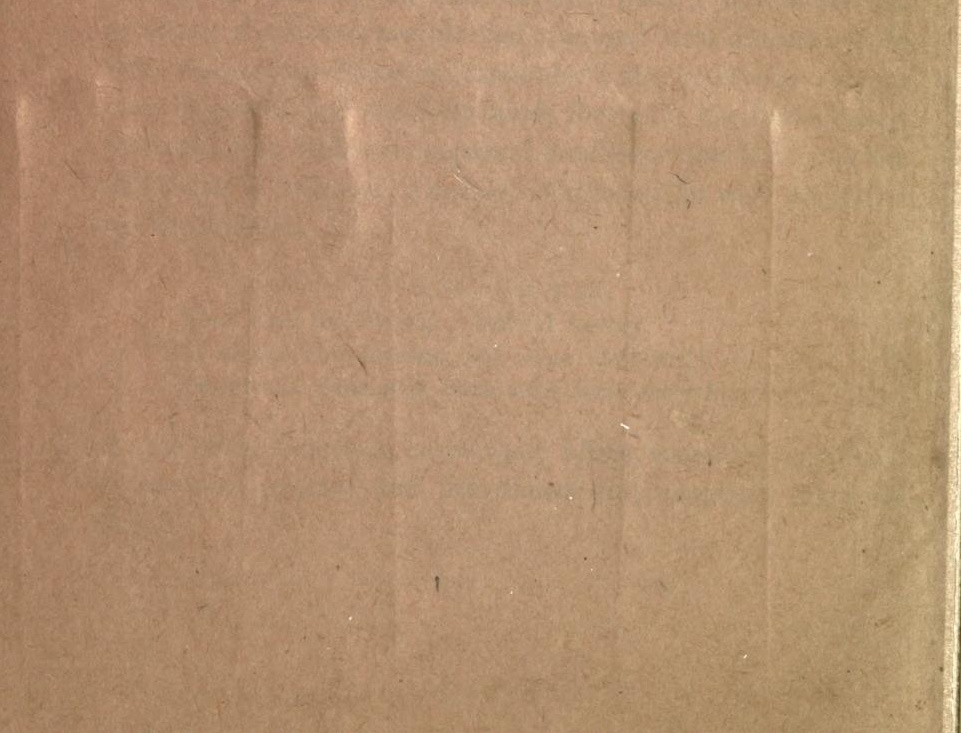





\section{RETURN $\mathrm{TO}=$ \\ CIRCULATION DEPARTMENT 198 Main Stacks}

\begin{tabular}{l|l|l}
\hline $\begin{array}{c}\text { LOAN PERIOD I } \\
\text { HOME USE }\end{array}$ & 2 & 3 \\
\hline 4 & 5 & 6 \\
\hline
\end{tabular}

ALL BOOKS MAY BE RECALLED AFTER 7 DAYS.

Renewls and Recharges may be made 4 days prior to the due date. Books may be Renewed by calling 642-3405.

\section{DUE AS STAMPED BELOW}

\begin{tabular}{l|c|l}
\hline & REC'D BIOS & \\
\hline & WAY 18'00-7 00 P & \\
SENTON & & \\
\hline JAN 05 L & & \\
\hline U.C. BERKELE & & \\
\hline
\end{tabular}

SENT ONTLL

JAN $05^{\text {nnn }}$

U. C. BERKELEY

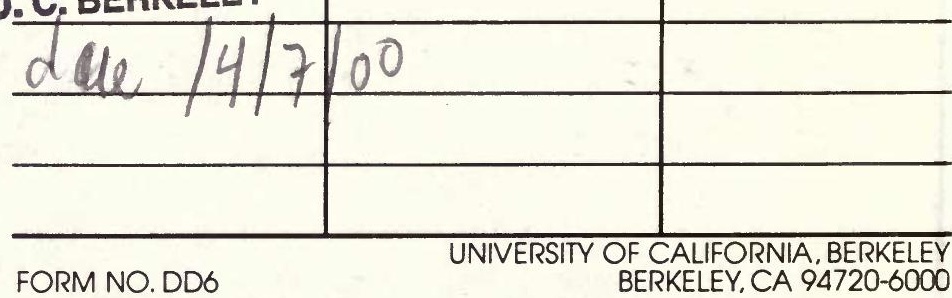




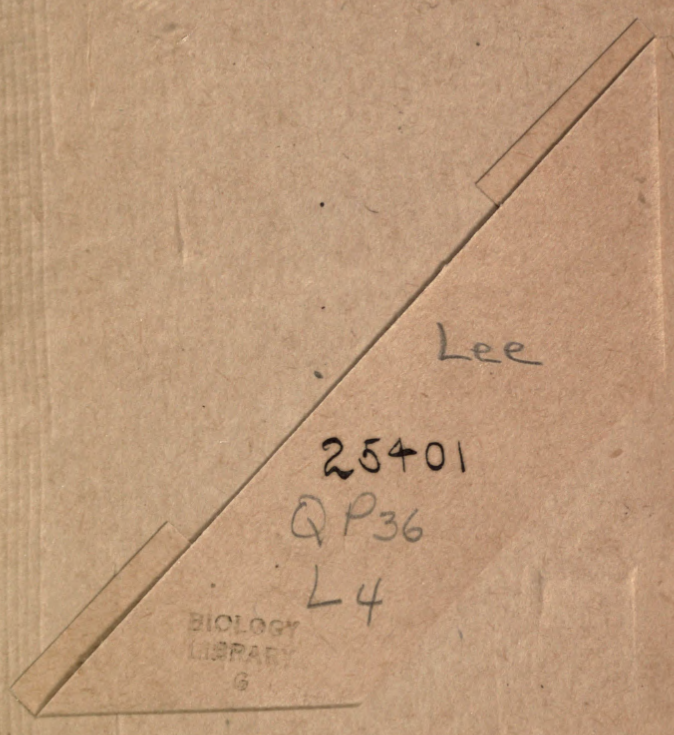


